FAMILY PLANNING DECISION-MAKING AT GRASS ROOTS LEVEL: CASE STUDIES IN WEST JAVA, INDONESIA

by

\title{
Rina Herartri
}

\author{
A thesis \\ submitted to the Victoria University of Wellington \\ in fulfilment of the \\ requirements for the degree of \\ Doctor of Philosophy \\ in Development Studies
}

Victoria University of Wellington

2005 


\begin{abstract}
This thesis examines the process of family planning decision-making with a view to understanding women's empowerment within the context of the Indonesian population policies and family planning programme. The objective of the family planning programme, established in 1970, is to create 'small, happy and prosperous families' through community participation. This goal has been strengthened by the passage of Law No. 10 of 1992 concerning “Population Development and the Development of Prosperous Families”. From 2000, in line with the 1994 International Conference on Population and Development Programme of Action, women's empowerment has become one of the major concerns of the family planning programme as stipulated in its new vision and mission statements.
\end{abstract}

Data for this thesis are provided by fieldwork conducted in two villages in West Java province, Indonesia, from December 2002 until May 2003. A qualitative research design, with a phenomenological approach, has shaped the conduct of this study. The case studies in the two villages revealed that the philosophy of 'small and prosperous family' has permeated down to the village. This idea has influenced the village couples' decisions regarding family size. Smaller families with better-educated children are believed to lead to increased family prosperity.

Generally, decisions to do with family planning and childbearing are made by women because men regard them as women's business. The contraceptive preferences show that women bear the major responsibility in the use of family planning methods. Thus women in these villages were empowered, but only partially. The women's role in terms of decisionmaking still exists within the framework of the interests of their husbands. Nevertheless, women's empowerment in family planning, through access to information and contraceptive services, has emerged from the case studies as a key factor that has enabled village women to make informed choices to control their family size. Women's control of fertility has been a major contributor to the success in reducing fertility and increasing family prosperity. 


\section{Acknowledgements}

I would like to thank the New Zealand Government for providing me with a scholarship to undertake a PhD programme. I am grateful to my employer, the National Family Planning Coordinating Board, for giving the permission to pursue this programme.

I wish to extend my deep gratitude to my supervisors Dr. Nancy J. Pollock and Dr. Jan Rigby for their unstinting advice, commitment and patience in supervising my work. Without their continuous support and encouragement I would not have been able to complete this thesis.

My thanks are due to Dr. Philip Morrison, Professor Vijay Naidu, Ms. Sara Kindon and all academic staff at the School of Earth Sciences for providing support and assistance. I also wish to thank Professor Yaacob Harun and Dr. Arvind Zodgekar who provided invaluable assistance during my fieldwork preparation. Many thanks go to Jill Ruthven, Julie deBoer, Morna Matangi-Want, Marita Basabas, Shannon White and fellow students for their support and assistance during the period of my study. I am indebted to all.

In Jakarta, my appreciation goes to the NFPCB officials, especially Dr. Djoko Sulistyo, and my colleagues and friends for assisting me in completing my study. Special thanks go to all of my sahabat. In West Java, I would like to thank everybody who assisted me to carry out the fieldwork. I am thankful to the staff members of the NFPCB provincial office, and Sumedang and Subang district offices. My sincere thanks are due to the people of the two villages of my study areas, not only for allowing me to undertake the fieldwork but also for accepting me as a member of their village.

My deepest gratitude goes to my parents, sisters and brothers. Without their endless love, support and encouragement I would not have been able to advance this far. I dedicate this thesis to them. 


\section{Table of Contents}

Abstract $\quad$ i

Acknowledgments ii

Table of contents $\quad$ iii

List of figures vii

List of tables viii

List of appendices $\quad$ ix

\section{Chapter 1 Introduction}

1.1. Population policies and family planning program in Indonesia 1

1.2. Theoretical framework 3

1.3. Purpose of the thesis 8

1.4. Structure of the thesis 9

Chapter 2 Methodological approach and research design

$\begin{array}{ll}\text { 7.1. Introduction } & 12\end{array}$

7.2. Epistemological framework 12

7.3. $\quad$ Research design 13

$\begin{array}{lll}\text { 7.4. The researcher's role } & 15\end{array}$

7.5. Data collection strategy 16

$\begin{array}{ll}\text { 7.5.1. Selection of study areas } & 17\end{array}$

$\begin{array}{ll}\text { 7.5.2. Selection of informants } & 18\end{array}$

$\begin{array}{ll}\text { 7.5.3. Timing of fieldwork } & 21\end{array}$

$\begin{array}{ll}\text { 7.5.4. Language } & 21\end{array}$

7.5.5. Data collection methods 22

7.5.5.1. In-depth interviews 23

$\begin{array}{ll}\text { 7.5.5.2. Observations } & 26\end{array}$

$\begin{array}{ll}\text { 7.5.5.3. Focus group discussions } & 28\end{array}$

$\begin{array}{ll}\text { 7.5.5.4. Field notes } & 29\end{array}$

7.5.5.5. Review of documents and records $\quad 29$

7.6. Data analysis 30

7.7. Limitations of the study 31

Chapter 3 Population and family planning in development context:

A literature review

3.1. Introduction 33

3.2. Population debates 33

3.3. Population policy as a part of development strategy 37

$\begin{array}{ll}\text { 3.3.1. Development concepts and approaches } & 37\end{array}$

3.3.1.1. Modernization 39

3.3.1.2. Dependency and the world system school 40

3.3.1.3. Neo-liberalism 42

3.3.1.4. Alternative development 43

3.3.2. Family planning program as the principal instrument of 
population policy $\quad 45$

3.3.2.1. Population policy $\quad 45$

3.3.2.2. Family planning programmes 46

3.3.3. Family planning programmes and fertility decline 50

3.3.4. The roles of international donors 54

3.4. Women, development and family planning 55

3.5. Gender relations within Indonesian households 59

3.5.1. Gender roles and relations 59

3.5.2. The process of internalisations of gender roles and relations $\quad 60$

3.5.3. Marriage and divorce 62

3.5.4. Gender relations and reproductive decision-making 63

3.6. Summary 64

\section{Chapter 4 Participatory development and empowerment}

4.1. Introduction 66

4.2. Concepts and principles of participatory development 67

4.3. Participation as empowerment 70

4.3.1. Constraints on participation 71

4.4. Women's empowerment 72

4.5. Approaches to participatory development 75

4.5.1. Participatory Rural Appraisal (PRA) 76

4.6. Fertility decision-making: empowerment in family planning 78

4.6.1. Models for fertility decision 78

4.6.2. Value of children $\quad 80$

4.6.3. Levels of decision-making 81

4.6.3.1. Community level $\quad 81$

4.6.3.2. Household level 82

4.7. The roles of change agent in family planning program 83

4.8. Summary and implications $\quad 84$

4.8.1. International level $\quad 85$

4.8.2. National level 86

4.8.3. Community level 86

Chapter 5 Population and family planning as part of development strategy in Indonesia

5.1. Introduction 88

5.2. The Indonesian population dynamics 89

5.2.1. Population size and growth 89

5.2.2. Population distribution and migration 94

5.3. Development strategy 95

5.4. Integration of population issues in development planning 99

$\begin{array}{ll}\text { 5.5. Population and family planning policies } & 101\end{array}$

$\begin{array}{lll}\text { 5.6. Discussion } & 102\end{array}$ 
Chapter 6 The Indonesian family planning programme

$\begin{array}{ll}\text { 6.1. Introduction } & 104\end{array}$

6.2. Historical review 105

$\begin{array}{lll}\text { 6.3. Philosophical underpinnings } & 107\end{array}$

6.4. Family planning program approaches 110

6.6.1. Urban-rural approaches 110

6.6.2. The clinic-based approach 111

6.6.3. The community-based approach 112

6.5. Policies and structure 116

6.5.1. Policies 116

6.5.2. Program structure 119

6.5.2.1. Village level 121

6.5.2.1.1. PPKBD 121

6.5.2.1.2. Family planning field workers 123

6.5.2.2. Sub-district level 124

6.6. Planning and decision-making process 125

6.6.1. Village level 125

6.6.2. Sub-district level 126

6.6.3. Central, provincial and district levels 127

6.7. Programmes and strategies 128

6.7.1. Program and activities 128

6.7.1.1. Family planning and reproductive health 129

6.7.1.2. Adolescent reproductive health 130

6.7.1.3. Family empowerment programmes 131

6.7.1.4. Advocacy, information, education and communication 132

6.7.1.5. Strengthening the family planning institutions and networks 134

6.7.1.6. Data and information on population and families 135 6.7.1.6.1. The activities record 135

6.7.1.6.2. Family enumeration 136

6.7.2. Strategies 139

6.7.2.1. Securing Muslim religious leaders' support 140

6.7.2.2. Integration with other development programmes $\quad 144$

6.7.2.3. Promotion of 'Self Reliant Family Planning' 146

6.7.3. Funding 147

6.8. Summary and discussion 150

Chapter 7 Decision-making at community level: Two villages in West Java

$\begin{array}{lll}\text { 7.1. Introduction } & 154\end{array}$

7.2. Background characteristics of the study areas 154

7.2.1. West Java province 154

7.2.2. The Sundanese 156

8.2.2.1. Language 157

8.2.2.2. Religion 158

8.2.2.3. Social relations 159

8.2.2.4. Occupation 161 
8.2.2.5. Marriage

8.2.2.6. Sexual division of labour 162

8.2.2.7. Value of children 163

7.2.3. Village A, Sumedang 164

7.2.4. Village B, Subang 167

7.3. Implementation of the family planning programme at the village level 170

7.3.1. Village administrative structure 171

7.3.2. Village family planning organisations (PPKBD) 175

7.3.3. Family planning activities $\quad 185$

8.3.3.1. Family planning and reproductive health services $\quad 187$

8.3.3.2. Information, education and communication 191

8.3.3.3. Family empowerment programmes 194

8.3.3.4. Activities recording and family enumeration 196

7.3.4. Planning and decision-making processes for the family planning programme at the village level 198

8.3.4.1. Annual plan 198

8.3.4.2. Monthly and weekly planning 200

7.4. Family planning decision-making at family level 201

7.4.1. Access to information 202

7.4.2. Local knowledge 208

8.4.2.1. Local sharing 208

8.4.2.2. Gender relations 210

8.4.2.3. Value of children 213

7.4.3. Preferences 215

8.4.3.1. Number of children 215

8.4.3.2. Sex preferences 218

8.4.3.3. Age of childbearing 218

7.4.4. Capability to control fertility as an important step in
women’s empowerment

$\begin{array}{lll}\text { 7.5. Discussion } & 221\end{array}$

7.6. Household level 222

7.7. Community level 225

\section{Chapter 8 Conclusions and recommendations}

8.1. Conclusions 230

8.2. Recommendations 235

$\begin{array}{ll}\text { References } & 238\end{array}$ 


\section{List of Figures}

Figure 2.1. The study areas in West Java 19

Figure 5.1 Population of Indonesia, 1961-2000 89

Figure 5.2 Total Fertility Rate, 1971-2002/3 91

Figure 5.3 Indonesian Population Pyramid, $2000 \quad 93$

Figure 6.1 Trends in Contraceptive Use, 1987 - 2002/3 115

Figure 6.2 Trends in Contraceptive Use 1987-2002/3 among Currently Married Women Age 15-49 by Urban-Rural Residence 116

Figure 6.3 The Family Planning Programme Structure (prior to Law No. 22/1999 $\begin{array}{ll}\text { regarding Local Government ) } & 120\end{array}$

Figure 6.4 An example of a family map 138

Figure 7.1 Organisational Structure of Village Family Planning Organisation $\begin{array}{ll}\text { (PPKBD) in Village A } & 178\end{array}$

Figure 7.2. Organisational Structure of Village Family Planning Organisation

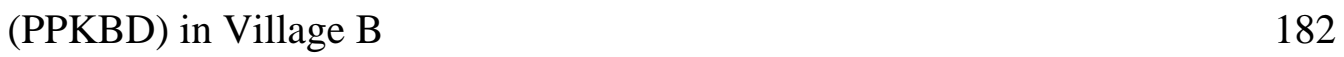

Figure 8.1 The process of family planning decision-making 235 


\section{List of Tables}

Table 4.1 Typology of participation

Table 7.1 Percentage of current users by contraceptive method in Village A and B, 2002 


\section{List of Appendices}

Appendix 1 Interview schedule (for household level, PPKBD chairperson, and focus group discussion with adolescents) 263

Appendix 2 Information sheet and consent form for the informants 271

Appendix 3 Prosperous family indicators 273 


\section{Chapter 1}

\section{Introduction}

This thesis aims to examine decision-making within the context of the Indonesian population policies and family planning programme as an attempt to clarify women's empowerment in family planning. This aim will be achieved by analysing the structure of the government family planning programme as it complements local implementation as revealed in the case studies. A qualitative research design, with a phenomenological approach, have shaped the conduct of this study as it helps the process of understanding family planning decision-making at household and community levels.

\subsection{Population policies and the family planning programme in Indonesia}

The Indonesian family planning programme has achieved a noteworthy reduction in fertility rates. For this achievement, the programme has received numerous awards and has become as a model for the developing world (Smyth, 1991; State Ministry for Population/NFPCB, 1995; Warwick, 1986). The programme, initiated in 1970, has been considered successful in encouraging the acceptance of the idea of fertility control through family planning. With around 50,000 family planning users in 1970, the programme had rown to almost 30 million users in 1997 or more than 50 percent of the currently married women, and it had reached 60.3 percent in 2002/3. The extensive use of family planning methods has led to a sharp decline in the fertility rate, from 5.6 births per woman in 1970 to 2.78 in 1997 and to 2.6 by 2002/3 (CBS et al., 1998, 2003; State Ministry for Population/NFPCB, 1995). Success in bringing down the fertility level, occurring within a relatively low level of economic development, has been attributed to the strength of the government family planning programme (Freedman, Khoo \& Supraptilah, 1981; Molyneaux \& Gertler, 1999; Warwick, 1986).

The Indonesian family planning programme was pioneered by private organisations in the1950s, which provided birth control services despite opposition from the government at that time (State Ministry for Population, 1995). With around 97 million people in 1961, 
Indonesia ranked as the fifth most populous country in the world after the People's Republic of China, the USSR, India, and the USA. In addition to the large population size, the Indonesian population was characterised by rapid growth, with a rate of more than 2 percent annually (Nitisastro, 1970). This led Western donors to encourage the adoption of a population control policy as part of the development strategy (State Ministry for Population/NFPCB, 1995). Subsequently, population control policy has become part of Indonesia's development strategy, with the family planning programme as the principal instrument, because rapid population growth was seen as a burden for economic development The concept of family planning, however, has been adjusted to local circumstances because of religious and cultural sensitivities and has been set within the context of increasing family prosperity through reducing family size.

The family planning programme has been implemented through the government bureaucracy at all administrative levels. By means of these networks, the idea of 'smallfamily norm' as a means to increase family prosperity (discussed in Chapter 6), was filtered through to the communities. This campaign was carried out simultaneously with the extension of contraceptive services to the grass-roots level.

Currently, the family planning programme has a presence in virtually every village in Indonesia. The programme has developed a network of paid fieldworkers and volunteers that formed the village family planning organisations to provide the services to these communities. The organisations, also known as PPKBD (discussed in detail in Chapter 6), initially functioned only as distributors of contraceptives, but over time their responsibilities have increased as they have become 'managers' of the villages' family planning programmes (Hamijoyo \& Chauls, 1993a).

Essentially, the Indonesian family planning programme promotes local autonomy in planning and implementation. Working through paid officials at district level, the programme also acknowledges the role of village heads and PPKBD as family planning programme managers at village level (Hamijoyo \& Chauls, 1993a). However, the programme's design, targets, and budgets are established at the national level. Such a 
system leaves little room for the local level to adjust the pre-planned programme to suit their needs. Local communities, especially women, do not have much opportunity to articulate their needs and interests.

A new policy on decentralisation, initiated in 1999, came into force in January 2001 (Rasyid, 2003). This policy specified that government programmes, including the family planning programme, would be devolved to district governments by the end of 2003. Under this policy, local governments are given a greater authority in decision-making. It is hoped that with a simplified bureaucracy and more control, local governments will be more responsive to accommodating the communities' needs and aspirations. Involvement of the community in decision-making is also expected to be enhanced. At grass-roots level, the community, through PPKBD, is expected to be more involved in planning and designing local specific population control programmes. However, this cannot be assessed here since this thesis focuses on policies and their implications up to mid 2003.

\subsection{Theoretical framework}

The theoretical framework of this study is based on a phenomenological approach. This approach reproduces people's ideas and decisions and it allows an understanding of how couples make decisions regarding family planning. As explained by Schutz (1962, cited in Bernard, 2002, p.23), “...the only way to understand social reality is through the meanings that people give to that reality”. In accordance with the phenomenological approach, this research uses a qualitative research design which according to Taylor and Bogdan (1998, p.7) enables the researcher "...to see the world as subjects see it”. The qualitative research design encourages individuals, couples and PPKBD personnel to participate in the research by expressing their thoughts and views. May (2002) points out that qualitative approach enables the voices of the participants to be heard. To obtain a better understanding of community level decision-making, this research employed a case study approach, which explains how a phenomenon exists within a particular case. The case studies are drawn from two villages in West Java. A combination of a "thick description” (see Geertz, 1973) and a comparison of the two cases is used to provide a detailed account of decision-making 
processes and to highlight the uniqueness of each village (for details of methodology see Chapter 2). All of these approaches allow clarification of the grass-roots approach to development that has emerged to counter external prescription on development policies.

Concern about the consequences of population growth on economic development has generated a debate for decades, starting with Malthus’s “Essay on the Principle of Population” in 1798. Two main contrasting views have emerged and remain in recent debate; either rapid population growth is a burden for development, or development is the primary means to bring about lower fertility (Cassen, 1994; Kelley, 2001; Merrick, 2002). The first view, described as 'traditionalist', identified the negative impacts of population growth on economic development, i.e. diminishing capital accumulation and the rate of savings due to increased expenditure on areas such as health and education (Kelley, 2001). During the Symposium on Population Change and Economic Development in Bellagio, Italy in 1998, economists formed stronger conclusions about the negative effects of rapid population growth (Birdsall, 2001). The second view, on the other hand, argues that poverty could be the cause of high fertility. Poverty forces families to have many children as cheap household labour and for parents' old age security. Therefore, this view proposes social and economic development as a principal means to lower fertility. Provisions of employment opportunities along with health and education services are suggested as the primary instruments (Cassen, 1994; Merrick, 2001).

This thesis addresses both of these views. As documented in the Programme of Action of the 1994 International Conference on Population and Development in Cairo (in Chapter 3: Interrelationships between Population, Sustained Economic Growth and Sustainable Development), “...persistent widespread poverty and serious social and gender inequities have significant influences on, and are in turn influenced by, demographic factors such as population growth, structure and distribution” (UN, 1994).

An alternative perspective, the 'population revisionist', which emerged in the 1980s (Kelley, 2001) downgraded the impacts of population growth on economic development. This revisionism argues that the long-term impact of demographic changes on economic development will be adjusted by feedback within social, economic and political systems. 
Effective markets, governments and institutions will moderate any initial negative impacts. Although this view has been challenged by many economists, the revisionist methodology, which assesses demographic impacts over long time periods, offers a broader perspective to studying the linkages between population growth and economic development. This methodology takes into account direct and indirect feedbacks and effects, and admits a wide range of impacts, both positive and negative (Kelley, 2001).

The current view re-emphasises the potential benefits of a slower population growth, but with a recognition that they depend on the timing and intensity of demographic change, the economic and social status of women, and the economic policies (Merrick, 2002). Merrick (2002, p.45) asserts that fertility reduction alone will not necessarily reduce poverty in developing countries, rather “.... slower rate of population growth, combined with sound and equitable economic development and the reduction of gender inequality, appears increasingly likely to achieve that goal”. This thesis takes on this view, that a family planning programme should be placed within a framework of broad socio-economic development, in contrast with a narrow view of reducing fertility to achieve economic growth. The Indonesian family planning policy, as a response to the ICPD recommendation, has embraced this philosophy by moving from demographic objectives to a greater emphasis on reducing family size as a means to increase family welfare. As proposed by the Bellagio Symposium, “...economic growth is not an end in itself but a means to the larger objective of improved well-being” (Birdsall \& Sinding, 2001, p.20). This concept is salient in analysing the Indonesian family planning programme, as the ultimate goal of the programme is to increase family prosperity.

Since the 1970s, international conferences on population organised by the United Nations have played important roles in disseminating international perspectives on population policies. Dominated by Western countries that have embraced neo-Malthusian and modernization views, these conferences have endorsed population control as an important instrument of development strategy. Recommendations from these conferences have become the framework of Western donors' assistance to developing countries, hence encouraging the adoption of population control policy through the establishment of family 
planning programmes (Luke \& Watkins, 2002). In 1965, only 21 countries in the world employed family planning programmes to reduce fertility and to slow down population growth rates. By 1998, virtually every nation in the world had some form of family planning programme (Seltzer, 2002; United Nations, 1999). Through these processes, international perspectives on population control influenced national governments and eventually reached the grass roots level. In addition, international NGOs are also playing a key role in influencing consensus at all levels; international, state, and grassroots (Luke \& Watkins, 2002).

It merits attention that gender inequities are also closely linked with demographic changes. Feminist activists contend that multilateral agencies and national governments treat women in an instrumental manner with respect to population programmes. Indeed, women world-wide have been identified as primarily responsible for limiting fertility and have become the primary targets for family planning programmes (Buvinic et al., 1983; Moser, 1993; Sen \& Grown, 1987; Smyth, 1991; Young, 1993). This gender bias has been addressed by the proposal to empower women by securing their reproductive rights. The 1994 ICPD Programme of Action supports this view by stating that improving the status of women enhances their decision-making in reproduction. It also declares that empowerment of women and improvement of their status should be ends in themselves (UN, 1994).

Development practitioners maintain that many community development programmes in the past have failed because they did not develop a participative programme structure able to respond to bottom-up initiatives (e.g. Burkey, 1993; Chambers, 1993, 1997). Chambers (1993) proposed a 'new professionalism', which reversed the former values, roles, and power relations between the communities and the professionals. This reversal marked not only the emergence of a new form of professionalism, but also a new development paradigm. Chambers' ideas $(1993,1997)$ include learning and planning with the people, decentralisation of power, and empowerment of the local community as key features of successful community development programmes. This paradigm is useful in analysing the decision-making and planning used by the Indonesian family planning programme, especially at the local level. 
The concept of community participation requires development programmes to allow the community to make its own decisions. Scholars (e.g. Arnstein, 1969; Chambers, 1995; Oakley \& Marsden, 1984) argue that the concept of 'participation’ includes people’s involvement in decision-making processes, in implementing programmes, and in evaluating such programmes. They also suggest that participation is an empowering process, which enables local people to do their own analysis and to make their own decisions. In family planning, empowerment implies that all individuals and couples should be able to make their own decisions regarding the number, spacing, and timing of their children, as recommended by the 1994 ICPD. This is achievable through access to information as well as to safe, effective, affordable and acceptable methods of family planning (UN, 1994). However, at the final point, it is up to the individuals to make the decisions.

A couple's reproductive decision-making process is influenced by their perceptions and attitudes to family wellbeing for the future (e.g. Hollerbach, 1983; Hull, 1983). These authors also maintain that fertility choices are complex and may be influenced by relatives or extra-familial sources, such as neighbours, community leaders, professionals, and state authorities. In addition, a couple's decision-making is affected by the government programmes, which not only make modern contraceptives available, but also actively encourage the acceptance of fertility limitation (Easterlin, 1978; Freedman, 1979; Lesthaeghe, 1980; Watkins, 1987). This not only legitimates the idea of fertility control but also creates a social climate that facilitates family planning decision-making (McNicoll, 1975; Watkins, 1987). Using diffusion theory, Rogers (1973) and Retherford and Palmore (1983) argue that government-sponsored programmes can also facilitate rapid diffusion of family planning at the village level by increasing knowledge and access to a communitybased distribution system. Through such processes, the 'small-family norm' has gradually become accepted as one way to increase family prosperity.

Assessment of the perceptions about the value of children is another important approach to fertility decisions (discussed in Chapter 4). This approach analyses individuals' perceptions about the value of children in terms of economic, social, and emotional 
satisfaction and costs. As such, it can be used to explain how and why socio-economic change affects fertility and children's contribution to the family (Fawcett, 1983). Thus, this approach is useful in assessing the impacts of modernization and economic development on fertility. However, studies reveal that such interactions are complex, especially with regard to social and psychological satisfaction (Fawcett, 1983).

\subsection{Purpose of the thesis}

The overall aim of this thesis is to understand women's empowerment through clarifying how they make decisions regarding family size. This understanding will be achieved by close examination of the contexts of Indonesian population policies and family planning programme. In view of that, this thesis attempts to:

1. Understand women's role in the family planning programme by analysing decisionmaking regarding childbearing and the use of family planning methods at household level. Key factors that influence decision-making process will be identified. This information will also highlight the communities’ perceptions of linkages between family size and family welfare.

2. Identify opportunities to improve the bottom-up planning system, and thus community participation in the family planning programme. Analysis of the involvement of PPKBD in planning and decision-making is important to clarify how these volunteers carry out their tasks compared with the expectations of the programme.

3. Exemplify how the communities' concept of family size as a means to achieve family prosperity for the future will contribute to the process of population dynamics and development efforts in Indonesia. Implementation of such sustainable development theories will illuminate how communities’ contributions can increase overall capability and autonomy in family planning decisions. This will enhance the synergy between population, development and environment.

\subsection{Structure of the thesis}


This introductory chapter began with a summary of the aims and methodology of the study. Then a brief review of population policies and the family planning programme in Indonesia was presented. This was followed by an outline of the theoretical framework used in examining decision-making within the Indonesian family planning programme. Data for this thesis are provided by fieldwork conducted from December 2002 until May 2003. Finally the purpose of the thesis was described.

Chapter 2 describes the methodological approach and research design employed in this study. This chapter establishes a qualitative basis, starting with a description of the epistemological framework which informs the methodological strategy of the study, i.e. phenomenological and qualitative approaches based on case studies. Two case studies at two villages in West Java provide the primary data. This is followed by a discussion of data collection methods which include in-depth interviews, observations, focus group discussions, and review of documents. My role as the researcher is also clarified, as in a qualitative study the researcher is the primary instrument for data collection and analysis. Finally, the limitations of the study are discussed.

Chapter 3 presents a literature review in order to provide a framework for analysing the Indonesian context of population and family planning policies. The chapter begins with a debate on the linkages between population and development, particularly the impacts of rapid population growth on economic development. Then it presents a summary of major development concepts and approaches that inform the development strategies of national governments. This chapter also highlights the roles of international donors in shaping population policies, and how they became an important part of development planning in many developing countries. In line with the objectives of this thesis, a discussion of the adverse impacts of development programmes on women, including family planning programmes, is presented. This is followed by background information on gender relations within Indonesian households to provide a framework for analysing women's empowerment in the study areas. 
Chapter 4 presents a discussion of participatory development and decision-making. It summarizes the concepts of participatory development as a means toward empowerment, which emphasises the involvement of a community in the planning and decision-making of development programmes. This is followed by a discussion on reproductive decisionmaking as it relates to empowerment in family planning. Some major fertility decisionmaking theories are summarized, including the factors that influence a couple's decisionmaking. This chapter also discusses the relationship between participatory development and women's empowerment as this contributes to family planning decision-making. The role of PPKBD as 'change agents' in the family planning programme at grass-roots level is also discussed.

Chapter 5 discusses the mechanisms of how population control policy and family planning have become part of development strategy in Indonesia. It provides background information on the population situation in Indonesia. A discussion about the incorporation of population control through family planning into development plans since 1969 is presented. This chapter also underscores the influences of the international population agenda on the Indonesian development strategy.

The Indonesian family planning programme is comprehensively explored in Chapter 6. Beginning with a historical review and statement of the philosophical underpinnings of the programme, it demonstrates that the family planning concept is set within the context of increasing family prosperity. This chapter also gives a detailed account of the programme's policies, structures and strategies which enabled the idea of small family as a means to increase family welfare to be disseminated to the grass-roots level. The importance of securing Islamic religious leaders support to the programme, as the Indonesian population is predominantly Muslim, is also discussed. These accounts illustrate that the decisionmaking process in the Indonesian family planning programme combines top-down and bottom-up approaches.

Chapter 7 focuses on the case studies, i.e. two villages in West Java. Background information on the characteristics of the study areas includes social and cultural aspects 
of the Sundanese, the ethnic group which constitute the majority of the West Java population. The findings from in-depth interviews and observations are discussed in detail. The process of implementation of the family planning programme in these two villages illustrates how the programme operates at village level. Perceptions of PPKBD personnel are highlighted in order to draw attention to their important role. The findings from indepth interviews with individuals and couples are presented through direct quotes in order to reflect the informants' views. Findings from the two villages are compared to identify key factors influencing the acceptance of family planning, and thus the decisions regarding childbearing and the use of family planning methods.

Finally, Chapter 8 concludes with a summary of the key factors that influence family planning decision-making. Some recommendations are proposed to improve women's empowerment and community participation in family planning in the future. 


\section{Chapter 2}

\section{Methodological Approach and Research Design}

\subsection{Introduction}

This chapter explains the rationale underlying the use of phenomenological and qualitative approaches to both fieldwork and analysis for this research. Most studies about family planning in Indonesia are quantitative based on survey methods. Within such research, qualitative data are collected only to complement the findings of the survey. While these surveys can provide data quantifying, for example, fertility and mortality rates or the use of contraceptives, they cannot explain the processes or factors affecting reproductive decisions in different social settings. Through a qualitative research design, this study aims to gain a better understanding of the family planning decision-making processes in an Indonesian setting.

I conducted fieldwork in two West Java villages in early 2003, the results of which are presented in Chapter 7. Data collection methods for the fieldwork included in-depth interviews, observations, focus group discussions, and a review of documents. My role as the researcher is also clarified in this chapter, as in a qualitative study the researcher can greatly influence the process of data collection, analysis and interpretation (e.g., Denzin \& Lincoln, 1998; Lofland \& Lofland, 1995; Merriam, 2002; Taylor \& Bogdan, 1998). The processes of data analysis are also described. This chapter concludes with a discussion about the limitations of the study.

\subsection{Epistemological framework}

Bernard (2000, p.8) defines epistemology as “the study of how we know things". In a research process, it informs and determines the methodological strategy (McKendrick, 1999). According to Taylor and Bogdan (1998), the social sciences use the term methodology to refer to how research is conducted. The methodology we choose is influenced by our assumptions, interests, and purposes. 
Two major theoretical paradigms used in social science research cover the positivist and phenomenological or interpretive approaches (Taylor and Bogdan, 1998). The positivist approach focuses on finding the facts or causes of social phenomena apart from the subjective states of individuals. On the other hand, the phenomenological approach concentrates on understanding and interpreting the social phenomena from the participant's own perspective.

In light of the objectives of this study, a phenomenological approach was chosen. This approach has allowed me to come as close as possible to understanding the process of family planning decision-making at different levels, i.e. the structure of the family planning programme in Indonesia as it complements delivery at the grass-roots level.

\subsection{Research design}

The philosophical foundation of phenomenology, as developed by Schutz (1962, cited in Bernard, 2002, p.23), reflects that "the only way to understand social reality is through the meanings that people give to that reality”. Taylor and Bogdan (1998) highlight several strong points of the phenomenological approach which I have used to achieve the objectives of this study. The approach enables a researcher to understand human behaviour from the participant's own frame of reference, and to examine the motives and beliefs as expressed in people’s actions.

The phenomenological approach facilitates the development of research strategies which are aimed at clarifying the decision-making processes at various levels. In addition, it enables identification of the villagers' perceptions about the role of the village family planning organisation (PPKBD) in order to clarify its contribution to the decision-making process. It also facilitates an inquiry into the motives and feelings of volunteer workers.

In accordance with the nature of the phenomenological approach, this research uses a qualitative research design. Taylor and Bogdan (1998, p.7) suggest the use of qualitative methods as these methods yield descriptive data which enable the researcher "..to see the 
world as subjects see it”. Denzin and Lincoln (1998, p.3) explain that qualitative research aims to “...study things in their natural settings...to make sense of, or interpret, phenomena in terms of the meanings people bring to them”. Furthermore, they maintain that the qualitative approach “...seeks answers to questions that stress how social experience is created and given meaning” (p.8).

A case study approach was chosen to facilitate the investigation of how couples and village family planning organisations make decisions regarding family planning. As a research strategy, Schramm (1971, cited in Yin 1994, p.12) explains that "the essence of a case study is that it tries to illuminate a decision or set of decisions: why they were taken, how they were implemented, and with what result”. The case is the basic unit of analysis, and cases include individuals, groups, communities, institutions, programmes, events or a larger phenomenon (Huberman \& Miles, 1998; Merriam, 1988; Yin, 1994).

Two villages in West Java province, Indonesia, were selected as part of the case study to provide comparative data. Yin (1994, p.14) categorizes this as a 'multiple case study', while Stake (2000, p.437) uses the term 'collective case study', that is an instrumental case study extended to several cases. The objective of an instrumental case study is to examine a particular case to provide insights into an issue or to draw a generalization. Merriam (1988) also points out that a case study generates a rich and holistic account of a phenomenon which offers insights and illuminates meanings for its readers. However, given the nature of qualitative research, this study cannot represent all villages in West Java, and does not aim for a generalization. As stated by Merriam (2002), the intention of qualitative research is not to generalize findings, but to understand them in depth.

The focus of a case study in phenomenological research is to describe one case in sufficient detail so that good comparisons can be made (Stake, 2000). According to Stake, comparative description is the opposite of what Clifford Geertz (1973) calls "thick description”. This study, nonetheless, combines both approaches. Thick description enables the reader to obtain insights about each case through a detailed account of the informants' views, while comparison highlights the uniqueness of each case. 
The qualitative research design also encouraged individuals, couples and personnel of the village family planning organisation to participate by expressing their own perspectives. Chambers (1997, p.123) emphasises that participatory approaches are the best means to explore people's realities as they “...enable the expression and sharing of their diverse and complex realities, give insights into their values, needs and priorities...”.

\subsection{The researcher's role}

In a qualitative study, the researcher functions as the primary instrument for data collection and a filter for analysis (e.g., Lofland \& Lofland, 1995; Merriam, 2002). Hence it is important for qualitative researchers to set aside, or "bracket" their own perspectives (Taylor \& Bogdan, 1998, p.7; Merriam, 2002, p.7). Likewise, Denzin \& Lincoln (1998, p.4) assert that “... [qualitative] research findings represent the researcher’s images, understandings, and interpretations of the phenomenon under study”. Therefore, it is important that qualitative researchers identify their personal values, assumptions and biases at the outset of the study (Miller, 1992 cited in Creswell, 1994, p.163).

My working background played a crucial role throughout the research process. As an Indonesian, I have been working with the National Family Planning Coordinating Board at the central office in Jakarta since 1987. With my educational background in community nutrition, I have been involved in the Integrated Health and Family Planning Project for most of my career. Nevertheless, joint work with the other units in the office made me familiar with the wider dimensions of the programme. I have also been involved in some of the research conducted by the Research and Development division. This background experience provided a firm foundation for embarking on research for this thesis.

My affiliation with the National Family Planning Coordinating Board certainly has implications for the research. My perceptions of the family planning programme have been shaped by my work experiences and may bring certain biases to this research. Although efforts were made to minimize the biases during data collection, they may have influenced the way I have interpreted and analysed the data. On the other hand, my work experiences 
have helped me to gain a better understanding of the phenomenon that I have been studying. They also clarify the implementation of the Indonesian family planning programme and its activities in the field.

Involvement with both operational and research programmes, and also reviewing the literature while preparing my research proposal in New Zealand, motivated me to examine the decision-making process. As stipulated by the ICPD document, the ability of individuals and couples to make decisions regarding childbearing is an important element of empowerment. Moreover, in light of the new government policy on decentralisation, community participation at grass-roots levels should be enhanced through greater involvement in planning and decision-making processes. The village family planning organisation will play a more important role in the development of population control programmes specific to local communities. The results of this in-depth study of the two villages will make a useful contribution to understanding the dynamics of communities at grass-roots level.

\subsection{Data collection strategy}

...there is no clear window into the inner life of an individual. Any gaze is always filtered through the lenses of language, gender, social class, race, and ethnicity. There are no objective observations, only observations socially situated in the worlds of the observer and the observed. Subjects, or individuals, are seldom able to give full explanations of their actions or intentions; all they can offer are accounts, or stories, about what they did and why. No single method can grasp the subtle variations in ongoing human experience. (Denzin \& Lincoln, 1998, p.24)

The above statement reflects the need for a wide range of methods to be able to understand a phenomenon in a particular social setting. In this section, the data collection strategy of this study is explained.

\subsubsection{Selection of study areas}


As mentioned above, my fieldwork was conducted in two villages within the province of West Java, Indonesia in 2003. I chose West Java because of my familiarity with its culture. My mother is from this province, and I had worked with the West Java provincial health office for three years during the mid 1980s, so I could embark on the fieldwork without spending much time learning the local culture first. In a phenomenological approach, an understanding of local culture is important to achieve the research objective. West Java was also one of the pioneers in the implementation of the family planning programme (see Chapter 6).

The districts of Sumedang and Subang were selected because, although adjacent, they are quite distinct in culture and language. Located in the central mountainous area, people in Sumedang are regarded as 'pure’ Sundanese. However, people in most parts of Subang, particularly in the north coastal area, are influenced by the Javanese, the ethnic group which occupies Central and East Java (discussed in detail in Chapter 7). This distinction has provided insights into the socio-cultural dimensions of family planning decisionmaking.

As one of the focuses of my study is to clarify the role of the community in the programme, I decided to choose a village where the village family planning organisation (PPKBD) is classified as 'advanced' 1 . I expected I could learn more from them than from those with lower classifications. As suggested by Stake (2000, p.446), for a case study it is useful to select cases that offer 'opportunity to learn'. Previous research (e.g., Arsyad et al., 1996; BKKBN \& FKM-UI, 1999) revealed that in villages with an organisation still classified as 'basic' or 'intermediate', much of the work was done by the family planning fieldworkers. In selecting the villages, I visited each district family planning office to obtain their list of villages with an 'advanced' organisation. I also asked for information on villages where I could work together with the organisation. To comply with my ethical

1 The village family planning organisations (PPKBD) are classified into three categories: 'basic', 'intermediate', and 'advanced', based on the guidelines from the national office (see Chapter 6). 
agreement with the informants, I will refer to the villages as village A (in Sumedang) and village B (in Subang).

\subsubsection{Selection of informants}

The informants were selected using a purposive sampling method. As stated by Creswell (1994, p.148), “..the idea of qualitative research is to purposefully select informants that will best answer the research question”. This sampling strategy, where researchers rely on their judgment to find informants that suit their purposes, is also known as 'judgment sampling' (Bernard, 2000, p.176) or ‘criterion-based sampling' (Merriam, 1988, p.48). Further, Bernard (2000) maintains that purposive samples can also be used in the selection of a few cases for intensive study and can be applied to any units of analysis. Most purposive samples are relatively small, although it can apply to larger samples (Bernard, 2000).

Based on the objectives of this research, my informants in the two study areas are drawn from:

1) Household level:

- Married women, aged 15-49 years old

- Married men, with wife aged 15-49 years old

- Couples of childbearing age (wife aged 15-49 years old)

2) Community level:

- The chairperson of the village family planning organisation (PPKBD)

- The family planning fieldworker

- The village midwife 
Figure 2.1:

The Study Areas in West Java Province
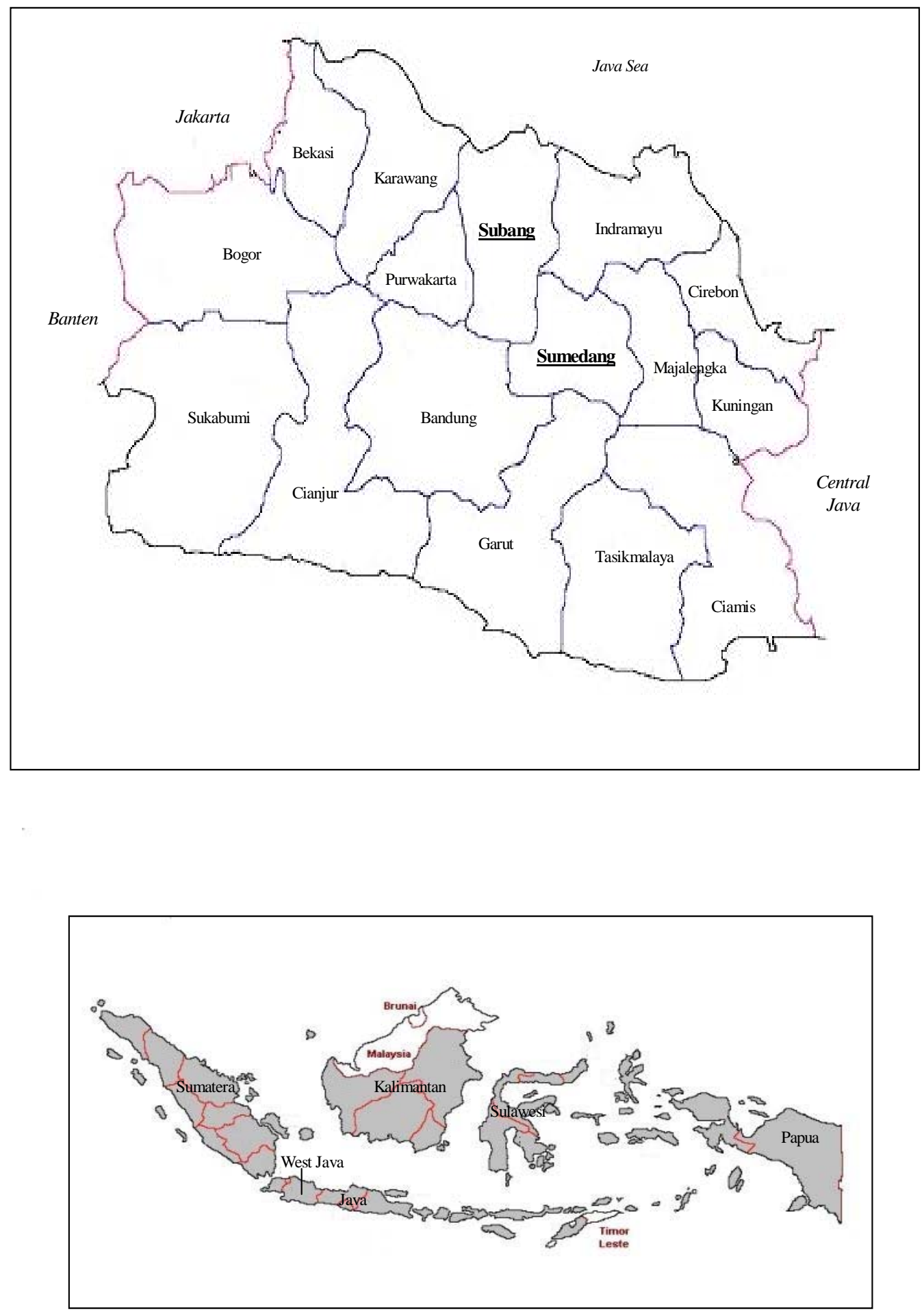
- Village officials (village head or the other officials)

3) Focus group discussions:

- Adolescents aged 13-18 years old, both female and male

4) Family planning officials at sub-district and district levels.

I used the list of families (see Chapter 6 for family enumeration) in each village to select the participants; women, men and couples with different socio-economic characteristics (e.g., age, education, occupation, number of children) and family planning practices (using or not using contraceptives, and the type of contraceptives used). However, in both villages it was difficult to find informants who had never used any modern methods of contraception. These were mostly older women.

In village A, I interviewed 12 wives, 3 husbands and 3 couples, while in village B, I interviewed 10 wives, 4 husbands and 4 couples. I conducted separate focus group discussions with female and male adolescents in both villages to avoid uneasiness. The participants in village A were 6 female and 6 male adolescents, while in village B there were 6 females and 7 males.

Initially, I did not include village officials as my informants because I anticipated they might give 'positive' answers to my questions. As part of the government bureaucracy, it is their responsibility to ensure that all development programmes are successfully implemented in their villages (see Chapter 7). I planned to discuss with the village family planning organisation and other informants the role of village leaders, including village officials. However, in order to obtain better insights into the implementation of the programme in these villages and compare it with the programme structure as outlined by the national office, I eventually decided to include them in the interview schedule.

\subsubsection{Timing of fieldwork}


I carried out my fieldwork from December 2002 until May 2003. The first month was used for preparation, which included finishing the translation of the interview schedules and consent form from English into the Indonesian language (Bahasa Indonesia) and seeking formal permission from the family planning office in West Java as well as the Ministry of Internal Affairs. Permission to conduct field research is required from the local governments at each level.

Upon receiving permission, fieldwork commenced. In each district, a staff member from the family planning office accompanied me to the research sites. As a common practice, they introduced me to the heads of the sub-district and the village governments and informed them that I would begin my fieldwork.

I stayed one month in each village, i.e. January 2003 in village A and March 2003 in village $B$. The intervening month was spent synthesizing the results from village A and preparing for my stay in village B. The last two months were used to review the whole fieldwork process. I visited village A again to obtain some reports for the year 2002 which had not been finished when I carried out my fieldwork there in January 2003. I also collected and reviewed documents and records from various sources.

\subsubsection{Language}

In village A, my familiarity with the local language eased the observations and interviews. As my mother is Sundanese, we speak the language at home. We use the term Sundanese for both the language and the native people of West Java. I also used the language when I worked with the West Java provincial health office during the mid 1980s. However, during interviews I decided to pose the questions in Bahasa Indonesia since the Sundanese language possesses the difficulty of speech levels (discussed in Chapter 7). I was afraid that I might make mistakes which might offend the informants. Luckily, most of the informants could speak Bahasa Indonesia, though they rarely use it in daily 
conversations. So, during interviews they sometimes spoke in Sundanese and I spoke in Indonesian, but we could understand each other.

In village $\mathrm{B}$, the local language is Cirebonese, which is similar to Javanese (the language used in Central and East Java provinces). This language is used in some districts along the north shores of West Java and along the border with Central Java. I know some Javanese language from my Javanese father and from colleagues at the office. This knowledge helped me to better understand the local language. As in village A, people with secondary education mostly could speak Bahasa Indonesia fluently, but others used only the local language. In some interviews, the volunteer who accompanied me helped to translate the questions into the local language, and the informants responded in a mixture of Indonesian and local language.

\subsubsection{Data collection methods}

Qualitative research involves collecting a variety of empirical materials through observations, analysing texts and documents, interviews, and recording and transcribing (Denzin \& Lincoln, 1998; Silverman 1993). The in-depth interview has been regarded as ‘the gold standard of qualitative research’ (Silverman, 2000). For a case study, Patton (1980) and Yin (1994) suggest that the data be collected through interviews and observations, archival records, and also impressions and statements of others about the case.

Based on the above perspectives, data for this study were collected by conducting:

a. in-depth interviews

b. observations

C. focus group discussions

d. a review of documents from the villages, the family planning office, and other sources.

\subsubsection{In-depth interviews}


I conducted in-depth interview with each informant since this type of interview can provide a greater breadth of data than the other types and it facilitates the understanding of the behaviour of the informants (Fontana \& Frey, 2000). According to Taylor and Bogdan (1998, p.88) in-depth interview is "repeated face-to-face encounters between the researcher and informants directed toward understanding informants' perspectives on their lives, experiences, or situations as expressed in their own words". In line with the case study approach, I used semi-structured interviewing which is based on the use of an interview guide (see Appendix 1). Patton (1980, p.200) maintains that an interview guide, defined as "a list of questions or issues that are to be explored in the course of an interview", provides the interviewer with opportunities to build a conversation while remaining focused on a particular subject area. Thus, the use of an interview guide, which enables a researcher to obtain reliable and comparable qualitative data, is suitable for a case study. It also facilitates broad comparisons between cases (Bernard, 2000).

I designed the interview schedules while I was preparing my research proposal in New Zealand. The guides allowed flexibility for the informants to respond according to their own perspectives. I first developed the guides in English, and before starting the fieldwork I translated them into Bahasa Indonesia. I had my colleagues review them to ensure that I used the correct terminologies. I also pre-tested these guides on people in Jakarta with two objectives: first, to see whether the informants understood the questions, and secondly, for practicing the interview.

Fontana and Frey (2000) point out that the decision on how to present ourselves to the informants is very important since it has a great influence on the success of the study. In these two villages, I introduced myself both as a staff member of the National Family Planning Coordinating Board and as a university student doing independent research. To avoid bias, before each interview I always stressed that this research was not for the family planning office nor the local government, but as a part of my study. I also told them that I just wanted them to share their experiences, knowledge and opinions for the purpose of my study. 
Before each interview, I explained the broad purposes of the study and assured them that any information collected would be treated with confidentiality. I had prepared a consent form (see Appendix 2) and I asked the informant's agreement to participate in this research and to be interviewed. These processes were in compliance with the requirement of the Victoria University Human Ethics Committee. To conform with my ethical agreement with the informants, I will attribute direct quotations through the use of pseudonyms.

During the interviews, I posed the questions in Bahasa Indonesia, while most of the informants responded in a combination of Bahasa Indonesia and their local languages. They understood Bahasa Indonesia but could not speak it fluently. I tape-recorded the interviews with the consent of each informant. I also jotted down key responses as back-up notes.

In both villages, a local volunteer helped me as a guide and as an interpreter as well. The presence of the local volunteers reassured the informants that I had obtained permission from the village to conduct this research. To avoid bias, I had to convince the volunteers that this study was not an assessment of the village's performance, rather it was only for my independent study. Since these volunteers sometimes also served as interpreters, I requested them not to influence the informants' attitudes and not to give comment on the informants' responses. I stressed that it was important for me to understand the informants' own perceptions of and attitudes to family planning. My understanding of the local language helped me to ensure this.

Interviews for household level were carried out at the informants' homes. The focus of the interview was how they made decisions regarding childbearing and family size. Each interview usually took about one hour, but for some informants I used both sides of a 90minute cassette. In both villages, I came across two types of informants: those who were talkative and chatty, and those who were less verbal. Therefore, I had to adjust my interview style accordingly. For the first group, the style was conversational and flexible. The sequence of questions and the flow of conversations were determined by their responses. For the latter, the interviews tended to be question and answer sessions. In some 
cases, other members of the family or neighbours were present during the interview. In such cases, I tried to ensure that the informants' responses were not influenced by these people. However, there is a possibility that their presence affected the informants' responses.

In order to obtain comprehensive information on the implementation of the family planning programmes in these villages, I conducted interviews with the family planning fieldworkers, the midwives and other programme facilitators. I interviewed them on several occasions while observing their activities. In village A, it turned out that the family planning fieldworker is also the village midwife. She is one of the family planning fieldworkers trained as midwife with scholarships provided by the National Family Planning Coordinating Board in the 1990s.

I interviewed the chairperson of the village family planning organisation of the two villages on several occasions, either at their homes or while carrying out their activities. The focus of the interview included how they became involved in the family planning programme and their perceptions of their role in the programme. Although I had prepared an interview guide, my interviews with them were more like informal discussions. I used both a tape-recorder and notes for these interviews.

Interviews with village officials were also held to clarify their perceptions and roles in the programme. In village A, I interviewed the village headman, while in village B I had a discussion with the village secretary since the village headman had taken office only a couple of months before my fieldwork began.

Family planning officials at sub-district and district levels were interviewed to clarify how the programme structure works at each level. This information gives a broader picture of the implementation of the programme at grass-roots level. 
All the interviews were transcribed in Bahasa Indonesia. For direct quotes in this thesis, I translated the responses into English. Some expressions are difficult to translate literally, but I have tried to express the meaning as closely as possible.

\subsubsection{Observations}

The focus of the observations included the implementation of the programme in the field, with particular attention to the role of the village family planning organisation, the socio-economic conditions of the villagers, day-to-day family life, and socio-economic activities in the village.

I attended and participated in some activities that took place in the villages during the fieldwork, such as the village weekly meeting and the monthly integrated family planning and health services. Particular attention was given to the village family planning organisation's role, especially its involvement in planning and decision-making. I tried to observe as many of their activities as possible. I asked the chairperson's permission to join them in all their activities during the month of my stay. During interviews and throughout the fieldwork, I also tried to observe family life, interactions between husband and wife, and housing conditions.

Bernard (2000) explains that participant observation involves three different roles: complete participant, participant observer, and complete observer. Based on this classification, in this study I was a participating observer, which according to Bernard (2000, p.321) “...can be insiders who observe and record some aspects of life around them, or they can be outsiders who participate in some aspects of life around them and record what they can”. Although usually participant observation can take more than a year, it can

also be done in just a few weeks if the researcher has sufficient personal experience to draw on or is a member of the culture being studied (Bernard, 2000). My familiarity with both the local culture and the family planning programme enabled me to do the observation without spending much time learning them first. 
Bernard (2000, p.324-6) also identifies some advantages of participant observation as a research method, which include: 1) it makes it possible to collect different kinds of data; 2) it reduces the problem of reactivity, i.e. people changing their behaviour when they know they are being studied; 3) it helps formulate sensible questions in the native language; 4) it gives an intuitive understanding of what's going on and allows the researcher to speak with confidence about the meaning of the data. However, it was difficult to avoid reactivity. For example, the monthly meeting of the village organisation in village A which used to be informal became a formal meeting involving all the volunteers in their 'uniforms'. They knew that I would take a photograph and they wanted to be seen at their best.

During the fieldwork, I participated in some activities in the villages but I was seen as an outsider because I was not involved in the outcomes. I was observing what was happening and taking notes. Sometimes the people involved in the activities explained what they were doing in answer to my questions.

Since it was clear from the beginning that the purpose of my presence in these villages was to conduct a study, I can be categorised as what Lofland and Lofland (1995, p.72-3) call a 'known investigator'. According to these authors, this type of researcher has some advantages with regard to access to data as compared to 'unknown investigator', i.e. able to move about, observe, or question in a relatively unrestricted way, but drawing on previous knowledge and experiences.

The personnel of the village family planning organisation in both villages were happy to receive me. For them, being selected as a project or research location is an appreciation of their work. I intended to stay in the chairperson's house, so I could closely observed their routine activities. Unfortunately, three days before I arrived in village A, the chairperson's mother passed away. In accordance with the tradition, she conducted a 'pengajian' (Qur'an recital) every night until the seventh night, which was attended by families and neighbours, so it was impossible for me to stay in her house. The village headman then suggested that I stay in a village official's house. In village B, the chairperson asked me to stay in her brother's house. She did not want me to stay in her house because according to her, "My 
house is too small and not suitable for you. I feel embarrassed if I let you stay here”, but she invited me to come anytime I needed to see her.

\subsubsection{Focus Group Discussions}

I conducted focus group discussions to explore adolescents' knowledge and perceptions about family planning and reproductive health. One of the advantages of focus groups is that interactions among participants can stimulate discussion. As Stewart and Shamdasani (1990, p.16) state, "[The] synergistic effect of the group setting may result in the production of data or ideas that might not have been uncovered in individual interviews". In addition, participants will feel more comfortable discussing sensitive issues in a group rather than in individual interview situations.

The participants of the focus groups were unmarried adolescents between 13 and 18 years old, both female and male. I conducted two group discussions in each village; each session consisted of 6 to 7 participants of the same sex. Bernard (2000) asserts that smaller groups are better for in-depth discussions about sensitive issues, and the popular size is 7 to 8 people. Due to the sensitivity of the issue, I had separate sessions for female and male participants to avoid discomfort. Bernard (2000) also suggests that participants in a focus group should be more or less homogeneous and, in general, should not know each other since "familiarity tends to inhibit disclosure” (Krueger, 1994, cited in Bernard, 2000, p.210). The latter, however, was impossible since in these villages almost everybody knows one another.

A list of questions for the focus group discussions was also prepared before starting the fieldwork (see Appendix 3). As in interviews, the use of the same discussion guide for both villages enabled broad comparisons to be made between the villages. However, the guide still allowed flexibility for probing any topic emerging during the discussions. The discussions were tape-recorded and transcribed in Bahasa Indonesia. Each session usually took about one hour and a half. As most of the participants were currently attending high school, they spoke Bahasa Indonesia fluently. 


\subsubsection{Field Notes}

I kept jotted notes during each interview, not only to record the responses but also insights and reflections from the interviews which were useful in data analysis. I took notes about the environment of each interview, e.g. presence of other family members or neighbours. These notes helped me to overcome problems and to improve my interviewing technique. I also kept a diary during the fieldwork. I tried to make notes of events, informal interviews or conversations, and also my feelings and impressions throughout the fieldwork. These notes became part of my data to be included during the analysis.

\subsubsection{Review of documents and records}

In a case study, documents can provide other specific details to corroborate information from other sources (Yin, 1994). These documents are useful in providing additional information for data analysis.

Many documents and records have been reviewed during the preparation of this dissertation. These include records of the implementation of the Indonesian family planning programme at various levels, statistical reports, previous studies that related to this study, and relevant documents in the field: village documents and reports from fieldworkers and midwives, as well as theoretical materials.

\subsection{Data Analysis}

Bernard (2000, p.419) states that qualitative analysis is “...the search for patterns in data and for ideas that help explain why those patterns are there in the first place”. Further, he contends that data analysis starts before data collection begins and it continues throughout the research effort. There is no closure in the process. 
However, Huberman and Miles (1998) caution that cross-case analysis is not simple since each case can be very different from the other. They may not readily be compared unless we focus on their common characteristics. This approach, however, might lead to the cases being analysed at high levels of inference, aggregation and generalization. Therefore, Noblit and Hare (1983, cited in Huberman \& Miles, 1998, p.194) stress the importance of preserving uniqueness while also making comparisons.

In this study, the analysis was mainly based on the transcripts of interviews and discussions, and also field notes. I transcribed the tape-recorded interviews and discussions in verbatim form. Some expressions were transcribed in the original language to capture and reflect the informants' views and insights in their own words. This transcribing process took around three months. From the transcripts, I looked for emergent themes, i.e. processes of decision-making and the key factors that influenced the decisions, both of individual informants or across informants' responses. Then I selected statements or phrases from the informants that supported each of these themes for direct quotation in this thesis. These statements became the data for analysis.

As the final process of data analysis, Huberman and Miles (1998) maintain that the researcher should be able to interpret, that is draw meaning, from the data. For multiplecase data analysis, Huberman and Miles (1998) outline several strategies, i.e. case-oriented, variable-oriented, and interactive synthesis or mixed strategies. This study uses mixed strategies, which are more appropriate for the phenomenological approach, as they allow the researcher to look closely into each case and at the same time draw themes that cut across cases.

\subsection{Limitations of the study}

This research discusses data from only two villages among the more than 60,000 villages of the Indonesian archipelago. In line with the nature of qualitative study, it cannot represent the province nor even the sub-district. The findings of this study apply only to the particular cases involved. Comparisons of the two cases can only illuminate the uniqueness 
of each case and this makes generalizations inappropriate. As Huberman and Miles (1998, p.195) emphasize, "case-oriented analysis is good at finding specific, concrete, historically grounded patterns common to small sets of cases, but its findings remain particularistic”.

As discussed above, in a qualitative study the researcher functions as the primary instrument for data collection and analysis. For in-depth interviews, Fontana and Frey (1998) maintain that the researcher can greatly influence the interpretation of the interviews and selects the part of the data to be reported. The language factor became an additional concern for this dissertation as I struggled to find appropriate expressions in English. My choice of words in translating informants' expressions might not have fully captured or reflected their views.

Reports of observations are also susceptible to bias from the researcher's subjective interpretations of situations (Adler \& Adler, 1998). My work experience and my basic knowledge of the family planning programme might have influenced my interpretations of the events and objects that I observed. However, the use of multiple data collection methods, which can add rigour to a research by building triangulation process into data collection, could minimize this bias (Adler \& Adler, 1998; Denzin \& Lincoln, 1998; Huberman \& Miles, 1998).

My interpretations of the findings of this study were also affected by the process of my study in New Zealand. Paradigms and theories used in this study, which were mainly drawn from Western literatures, may not be completely applicable or appropriate for use in Indonesian settings. Nevertheless, drawing on my previous knowledge of the phenomenon under study combined with multiple data collection methods, this study provides relevant information for understanding the decision-making processes in the study areas which can be useful for other research in the future. 


\section{Chapter 3}

\section{Population and Family Planning in Development Context}

\subsection{Introduction}

International perspectives on population have encouraged governments in developing countries to incorporate population control programmes as part of development strategy. This chapter explores the international perspectives of family planning and development that provide a background for analysing the Indonesian context presented in Chapter 5. This chapter begins with a discussion of the debates on the consequences of rapid population growth and the links between population and development. Then a number of major development concepts and approaches that inform the development strategies of national governments are presented. These approaches will shape the population policy adopted by a country as part of its development strategy. The chapter explains how population control policy and family planning programmes have become an instrumental part of development plan in many developing countries. Major theories in fertility transitions will also be summarized as a framework for analysing the relationships between development and fertility decline, which justify the implementation of family planning programmes.

The following section focuses on different views on women and development and their implications on women's positions in population policies and family planning programmes. Then, a review of gender relations within Indonesian households provides a framework for analysing women's empowerment in family planning in the study areas. Finally, this chapter discusses about the relationship between population growth and development.

\subsection{Population debates}

Debate about population and development has been going on for several centuries. The main concern has been about the consequences of population size and growth on economic 
development. Essentially, two main theories have emerged, which still form the root of contemporary discussions.

With his "Essay on the Principle of Population" in 1798, Malthus expressed the need to limit population growth (Appleman, 1976). His concern was that population would outstrip food supply. This pessimistic view sparked off a universal assumption that population growth would impede economic development. Malthus' idea has been broadened by neo-Malthusians, initiated by Hardin's work “The Tragedy of the Commons” in 1968 and Ehrlich's “Population Bomb” (1968). Unlike Malthusians who opposed any form of birth control other than abstinence, the neo Malthusians include artificial birth control as an acceptable means of limiting population growth, and recognise that factors other than population growth contribute to poverty (Ehrlich, 1968; Hardin, 1968; Menard and Moen, 1987).

An alternative view stressing the need for political and economic reform was postulated by Marx and Engels in 1947. They believed that under a fair and just social organisation, population growth could be accommodated while maintaining a high standard of living (Menard and Moen, 1987). The neo-Marxist view has broadened the Marxist perspective with the recognition that there are technological and environmental constraints on population growth. One proponent of this view, Simon (1981, 1992), contends that there is no evidence that a large population creates poverty and underdevelopment. He suggests that population growth helps economic development by increasing business opportunities and efficiency in the use of technology. Interrelations between population growth and technology have been explored previously by Boserup (1981). She concludes that technological change in agriculture will have a positive effect upon population growth through increasing food supply.

Two main contrasting views have emerged and remain in recent population debates: either rapid population growth is a burden for development or development is the primary means to bring about lower fertility (Cassen, 1994, p. Kelley, 2001; Merrick, 2002). The first view, described as 'traditionalist', identifies the negative impacts of population growth 
on economic development, i.e. diminishing capital accumulation and the rate of savings both at household and national levels due to increased expenditure on areas such as health and education (Kelley, 2001). Economists participating in the Symposium on Population Change and Economic Development in Bellagio, Italy in 1998 came up with stronger conclusions about the negative effects of rapid population growth on economic development (Birdsall, 2001). The second view, on the other hand, argues that poverty can be the cause of high fertility. Poverty forces families to have many children as cheap household labour and for parents' old age security. Therefore, this view proposes social and economic development as a principal means to lower fertility. Provisions of employment opportunities along with health and education services are regarded as the primary instruments (Cassen, 1994; Merrick, 2001).

Controversies over differing views of the link between population and economic development have been evident throughout the international conferences sponsored by the United Nations, dating from the 1974 World Population Conference in Bucharest. It was the first international conference which addressed the relationship between population growth and development as well as considering population policies and action programmes.

Different views emerged between developed and developing countries. Developed countries contended that rapid population growth was a serious impediment to development and thus efforts to limit fertility have been promoted in developing nations (Cassen, 1994; Finkle \& Crane, 1975). On the other hand, developing countries saw population problems not as the cause of underdevelopment but rather as a consequence of imbalances in the international economic system. These countries thus proposed "a new and more equitable international economic order" to accelerate socio-economic development in developing countries. They opposed the idea of family planning and maintained that "development is the best contraceptive" (Cassen, 1994; Finkle and Crane, 1975). Despite the debate, the 1974 conference recommended a consensus that trends in population growth were an integral part of economic and social development (Seltzer, 2002). 
In contradiction, at the 1984 International Conference on Population in Mexico City, it was developing countries who took the line that rapid population growth had adverse consequences on development. They also endorsed the principle that governments should help to make family planning services universally available. Influenced by Simon's work (1981), the United States delegate, on the other hand, stated that population growth is a neutral or positive factor, provided the desirable economic system is in place. Therefore, they promoted free markets as a means for accelerating economic growth, which in turn would reduce fertility (Cassen, 1994; Finkle and Crane, 1985).

The following conference, the 1994 International Conference on Population and Development (ICPD) in Cairo, addressed both of the issues. The chapter on the interrelationships between population, sustained economic growth and sustainable development (chapter 3) emphasises that population size, growth and distribution are closely linked to prospects for economic and social development, and that actions in one reinforce actions in the other. It also states "Eradicating poverty will contribute to slowing population growth and to achieving early population stabilization” (UN, 1994; UNFPA, 2004). The ICPD's agenda for addressing the interdependence of population and poverty is also seen by the United Nations as an essential condition for meeting most of the Millennium Development Goals for eradicating poverty and improving people's well-being (UNFPA, 2004).

The debate over the relationship between population growth and development continued to encompass concerns about degradation of the environment and natural resources. For example, in 1987, the World Commission on Environment and Development stated that the critical issue in achieving sustainable development is the balance between population sizes, the rate of population growth and available resources (WCED, 1987). The 1992 UN Conference on the Environment and Development in Rio de Janeiro and the 2002 World Summit on Sustainable Development in Johannesburg suggested the need to integrate demographic issues into the design of development plans (UNCED, 1992; United Nations, 2002). 
As a consequence of these discussions, several gender perspectives have emerged, not only those of the feminists. These perspectives criticize population policies as aiming at national goals such as slower population growth, environmental protection, or economic development while neglecting the needs of women as individuals and as a group. Some critics argue that such policies focus only on the reproductive role of women. Women activists and feminist scholars propose that meeting women's needs should be central to population policy (e.g. Buvinic et al., 1983; Moser, 1993; Sen and Grown, 1987; Smyth, 1991; Young, 1993). The 1994 ICPD addresses this issue by declaring that the empowerment of women and the improvement of their status should be ends in themselves. This thesis develops this integrated approach when examining Indonesia as a case study.

\subsection{Population policy as a part of development strategy}

The following section discusses some major development approaches and their implications on population policy. This is followed by a discussion of how family planning programmes have become the principal instrument of population policy, and of the role of international donors in the programme implementation.

\subsubsection{Development concepts and approaches}

The concept of development is complex and it is informed by multidisciplinary intellectual traditions from both Western and Third World countries. A number of different viewpoints have emerged, including sociological, economic, political and demographic.

Escobar (1995) argues that discussions about development were generated by the ‘discovery’ of mass poverty in Asia, Africa, and Latin America after World War II. Thus, the concept of development was reduced to 'economic growth' as implied in the United Nations Charter in 1947. The 'era of development' began when Harry S. Truman took office as President of the United States in 1949 (Esteva, 1992). He coined the term 'underdeveloped', which according to the Latin America development scholars is a euphemism for backwardness or poverty. In his inaugural address he declared that: 
We must embark on a bold new programme for making the benefits of our scientific advances and industrial progress available for the improvement and growth of underdeveloped areas.

The old imperialism - exploitation for foreign profit - has no place in our plans. What we envisage is a programme of development based on the concepts of democratic fair dealing. (Truman, 1949, quoted in Esteva, 1992, p.6)

This concept has led Western scholars to design approaches for underdeveloped countries, such as Rostow's classic work, "The Take-Off into Self-Sustained Growth" (1964, cited in So, 1990, p.29). He proposes five major stages of economic development: 1) traditional society; 2) precondition for take-off; 3) take-off; 4) the drive to maturity; and 5) high mass-consumption society. These stages are recommended as patterns for developing countries, including Indonesia (discussed in Chapter 5), to move toward development. Population growth becomes a major concern in reaching the take-off stage. Rostow suggests that productive investment should reach at least $10 \%$ of the national income, otherwise economic growth cannot overtake the rate of population growth. This view has led US policy makers to offer aid, in the forms of capital, technology, and expertise, to help Third World countries to modernize.

The concept of 'social development' began to be integrated into the concept of development by the United Nations in the Proposal for Actions of the First UN Development Decade (1960-70), which stipulates that:

The problem of the underdeveloped countries is not just growth, but development... Development is growth plus change. Change, in turn, is social and cultural as well as economic, and qualitative as well as quantitative... The key concept must be improved quality of people’s life. (United Nations, 1962, quoted in Esteva, 1992, p.13)

However, throughout the First UN Development Decade, development continued to be perceived as economic growth. As a response to the narrow economic definitions of development, Todaro (1985, p.86) defines development in broader terms, that is, as “a 
multidimensional process involving major changes in social structures, popular attitudes, and national institutions, as well as the acceleration of economic growth, the reduction of inequality, and the eradication of absolute poverty”. This definition led him to identify the basic components of development: 1) increasing the availability and widening the distribution of basic life-sustaining goods; 2) raising levels of living to generate individual and national self-esteem; and 3) increasing people's freedom by expanding their economic and social choices. He does not mention demographic concerns specifically in his concept of development.

Freedom as the basic component of development is further emphasised by Sen (1999). He maintains that "Development has to be more concerned with enhancing the lives we lead and the freedom we enjoy" (Sen, 1999, p.14). Therefore, development can be seen as a process of expanding the freedoms that people enjoy and removing the sources of 'unfreedom', such as poverty, poor economic opportunities, and neglect of public facilities. In this welfare approach to economic development, expansion of freedom is viewed as both the 'primary end' and the 'principal means' (Sen, 1999).

The above concepts of development inform the paradigms in development theories. The following section reviews four major paradigms that are useful in analysing the link between development and population policies: modernization, dependency, neoliberalism, and alternative development.

\subsubsection{The Modernization School}

The Modernization School emerged in the late 1950s with the rise of the United States as a superpower and the birth of many new nation-states previously colonized by European countries (Preston, 1996; So, 1990). It represents a multidisciplinary effort to examine the prospects for Third World development (So, 1990). It combines a sociological approach, as in Levy's argument, with economic ideas such as Rostow's stages of economic growth, and political ideas such as Coleman's differentiation-equality-capacity model (So, 1990). Industrialization and urbanization were seen as the inevitable and necessary routes to 
modernization, along with education, social mobilization, and more complex and diverse occupational structures (Escobar, 1995; Huntington 1996).

The emphasis on economic growth as the central part of development has prompted developed countries and international population agencies to promote population control policy in the Third World nations to accelerate their economic growth.

Criticisms of the modernization school have focused on its adherence to dichotomising the concepts of development into 'traditional' versus 'modern' (Blomstrom \& Hettne, 1984; Preston, 1996; Rigg, 1997; So, 1990). Further, they argue:

a. The modernization perspective is ethnocentric. Concepts such as "modern" and "traditional” are ideological labels used to justify Western superiority. Dichotomous characterizations of the development issue based on class, ethnic and religious affiliations have been a common feature of Western social thought.

b. The assumption of unidirectional development, where Third World countries should move in the direction of Western countries, overlooks alternative paths and rates of development for Third World countries.

c. The modernization school focuses only on internal traits such as traditional values and lack of productive investment, and neglect of the issue of foreign domination such as unequal trade patterns and the control by multinational corporations over Third World economies.

\subsubsection{The Dependency School and the World System School}

The Dependency School evolved in Latin America in the 1960s as a response to the failure of the development programmes devised by the United Nations. Gunder Frank's work brought about a new approach, namely the dependency of underdevelopment (Blomstrom \& Hettne, 1984; Drakakis-Smith, 1990; So, 1990).

Unlike the modernization school which represents the Western perspective, the dependency school views development from a Third World perspective. According to 
Blomstrom and Hettne (1984, p.1), the dependency school represents "the voices from the periphery” that challenge the dominance of Western development theory. To explain the relationship between Western and Third World countries within the dependency perspective, Frank formulated a “metropolis-satellite”, also known as “core-periphery”, model. This model also provides an explanation of how the mechanisms of underdevelopment work (So, 1990).

The dependency theorists argue that unequal exchanges in the world economic system and core-periphery exploitation promoted the diffusion of underdevelopment rather than development in the Third World. In order to reverse this situation, the dependency school stressed industrialization by import substitution, trade barriers and control of multinational corporations, and regional integration (Blomstrom \& Hettne, 1984; Drakakis-Smith, 1990; Preston, 1996).

Most of the critics of the dependency school deal with its focus on the external factors, such as core-periphery exploitation, to explain underdevelopment. Critics claim that the dependency school exaggerated the power of external forces on the course of Third World countries' development irrespective of local resistance. Furthermore, they argue that the school had failed to construct its own theory of development (So, 1990). Blomstrom and Hettne (1984) reject the critics and maintain that one of the school's main concerns is how external and internal factors interact.

As an answer to the dependency school's limitations, Wallerstein (1979, cited in So, 1990, p.180) has developed a new world-system perspective. He proposes a trimodal system consisting of core, semi-periphery, and periphery, as an alternative to the bimodal system of the dependency school. Semi-peripheral states function to prevent political polarization in the world system while collecting surplus from periphery for transmission to the core (So, 1990).

Mechanisms that the maintain dependency of the 'periphery' nations on the 'core' countries have expanded to the field of population control, as it is considered as an 
important factor for economic growth. Western countries have specified the shape of population control policy and family planning programmes for developing nations.

\subsubsection{Neoliberalism}

Neoliberalist views of development emerged in the 1980s as the Keynesian growth and welfare schemes of post World War II were unsuccessful. These theories revolved around the neo-classical model of the market as a self-regulating system which maximizes the benefits of all participants (Preston, 1996). These approaches have been influential world wide through their link with the International Monetary Fund (IMF) and the World Bank's structural adjustment policies. World Bank and IMF loans have become conditional upon the adoption of structural adjustment which involves deregulation, privatisation of stateowned enterprises, measures to promote export production, devaluation of national currencies to cheapen exports, and trade liberalization (Dasgupta, 1998).

Dasgupta (1998) contends that the structural adjustment package that is being implemented now is different from the original concept. The package was originally introduced as a short-term remedy for economic crises. Now, once initiated, a country will be associated with the World Bank or IMF for a long term, with one loan following another as a continuous exercise. He also maintains that adjustment was not expected to be the sole concern of the Third World countries. The Western countries were expected to play their role by liberalising trade, increasing aid, importing more from Third World countries, saving energy, and increasing capital flows to the Third World countries.

The implementation of this approach in the Third World countries has adverse effects on the people's welfare. The World Bank later introduced 'Adjustment with a Human Face', but this approach, which stresses the responsibilities of the 'community' and 'family' (principally women) in providing welfare services, does not answer the problems (Nelson \& Wright, 1995).

\subsubsection{Alternative development}


The failure of development theories to explain the persistence of problems like poverty, hunger, and unemployment in the Third World countries, and also the 'economic miracle' in some Asian countries has led development practitioners to challenge the very notion of development. There has been increasing discussion regarding the meaning and practice of development, and hence the construction of alternative visions of development during the 1980s and 1990s.

Although the approaches that are grouped under alternative development have many differences, they share common traits, including:

a. Treatment of people as 'subjects' of development

b. Application of endogenous theories and methods

c. Participation as opposed to top-down

d. Concerned with the means and ends of development

e. Limitation of the State's role, non government organisations play an important role

f. Reduction of the role of market and promote self-reliance

g. Decentralisation, transferring decision-making to the local people

h. Emphasis on the empowering process

(Chambers, 1997, p.11; Oakley \& Marsden, 1984, p.10; Rigg, 2001, p.43; White et al., 1994, p.269).

Oakley and Marsden (1984, p.10) assert that the philosophy of alternative development is "people-based development from below". The issue of participation becomes central and is primarily associated with the rural poor. Within this line of thinking, participation is seen not only as an end in itself but also a fundamental pre-condition for and a tool of any successful development strategy. Hettne (1990) proposes 'another development' as an alternative to the existing development approaches. This concept entails empowerment and promotion of endogenous problem solving. It also encourages the decentralisation of decision-making processes from the urban centres to the rural villages. Nevertheless, he acknowledges that such processes are difficult to apply to Third World countries since they require structural transformations. 
With specific reference to the development process in Southeast Asian countries, Rigg (1997) points out arguments for the discussion of alternative development in the region. Some observers argue that the so-called 'Asian Miracle’ has not been a mere adoption of Western approaches by the East, since it was informed largely by culture and history rather than by economic principles. This view, and the negative impacts of modernization, has led some scholars to examine indigenous Southeast Asian development concepts. However, Rigg (1997) challenges Hettne’s calls for 'another development' and questions the basic idea of this concept, which believes that anything local must be better and more appropriate than that which is exogenous. He maintains that there is nothing purely 'endogenous' or 'exogenous’ in development discourse, since the development process has mostly been modified to suit local conditions, and the internal and external elements are merged.

Participatory research became prominent during this era as an attempt to develop an endogenous research methodology for Third World countries. Participatory development grew out of this research methodology. It promotes a new, popular, bottom-up and endogenous vision of development free from Eurocentrism (Burkey, 1993; Chambers, 1997).

\subsubsection{Family planning programmes as the principal instrument of population policy}

\subsubsection{Population policy}

After World War II, the population problem was no longer perceived to be a Malthusian race between population and food, but it became a multifaceted, interdisciplinary, complex structure of social, economic, biological, and environmental factors (Nortman, 1975). 
The debates over the relationship between population and development have generated three schools of thought:

1) The nationalists argue that population growth stimulates development, hence population control is not necessary since population growth is both a cause and a symptom of economic and social development.

2) Proponents of the neo-Malthusian view believe that population control must be part of any development strategy, otherwise that strategy will not be sustainable.

3) Proponents of Marxist and neo-Marxist views argue that population growth has nothing to do with development at all, since development is determined by the national and international social and economic systems (Weeks, 1999, p.448).

The neo-Malthusian view has become the major development policy in most areas of the world. This premise suggests that economic growth could not occur in developing countries without first reducing fertility. Consequently, governments in those countries have been encouraged to employ family planning programmes to slow down the population growth. Although in 1960s many developing countries in Asia demonstrated remarkable economic development despite their rapid population growth, population control programmes have been accepted as a part of development strategy in those countries (McIntosh and Finkle, 1995).

The above premise has also been embraced as part of the agreements and resolutions of the world conferences organised by the United Nations and shared by international institutions dealing with population and development. The inextricable links between population and development have been discussed since the 1984 International Conference on Population in Mexico City (WCED, 1987; World Bank, 1994; Weeks, 1999; UNFPA, 2001).

The 1994 International Conference on Population and Development (ICPD) in Cairo recognised the interconnections between slowing population growth, reducing poverty, achieving economic progress, and protecting the environment (UN, 1994). However, as McIntosh and Finkle (1995) observe, the aggressive feminist voice has shifted the focus of 
ICPD discussions from the issue of controlling population growth as a means of enhancing economic development to the issue of women's rights, status, and empowerment. Women's empowerment, enabling them to control their own fertility, is considered to be one of the preconditions of a falling fertility rate. The ICPD also broadened the concept of family planning to include reproductive and sexual health, which comprises the reduction of maternal mortality, the prevention and treatment of sexually transmitted diseases, including HIV/AIDS, and the prevention and treatment of unsafe abortions.

All the world population conferences organised by the United Nations reflect the global view, influenced by neo Malthusian thinking, that high population growth is a potential hindrance to a country's ability to develop economically. Thus, the action plans generated from the conferences always include a strategy for limiting population growth, although not all of the delegates agree with that premise (Weeks, 1999).

\subsubsection{Family planning programmes}

International population policy derived from the global conferences has played a key role in encouraging governments of developing countries to slow down their population growth rates. Limiting fertility is seen as the best way to slow down population growth in any population, although it is a complex process. As argued by Coale (1973, cited in Cleland, 1985, p.249), there are three 'preconditions for fertility decline': 1) fertility must be within 'the calculus of conscious choice'; 2) effective techniques of fertility control must be known and available; and 3) reduced fertility must be advantageous. In other words, couples must be "ready, willing, and able”. Each of these components has implications for population policy, therefore a national policy for limiting fertility should address all three preconditions simultaneously.

Many governments include demographic objectives to reduce population growth and to lower fertility as a part of their overall development goals. One of the most popular population policies to limit fertility is to control birth rates through family planning programmes. These programmes remain the principal instrument of current population 
polices of many developing countries (Seltzer, 2002). Simmons (1986, cited in Tsui, 2002, p.187) defines family planning programmes as "organized efforts to assure that couples who want to limit their family size and space their children have access to contraceptive information and services and are encouraged to use them as needed”. A similar concept was adopted by the ICPD document, which declares that " ...the aim of family planning programmes must be to enable couples and individuals to decide freely and responsibly the number and spacing of their children and to have the information to do so and to ensure informed choices and make available a full range of safe and effective methods” (UN, 1994).

In 1965, only 21 countries in the world supported family planning programmes to reduce fertility and lower their rates of population growth. The number increased to 149 in 1976 and to 163 in 1986. By 1998, 192 countries, virtually every nation in the world with 99 percent of the world's population, had some form of family planning programme (Seltzer, 2002; United Nations, 1989). Government-supported family planning programmes have often evolved from the efforts of private organisations seeing a need for such services. In Egypt and Indonesia, for example, the family planning services were first initiated in the 1950s by private groups who provided maternal and child health and birth control services in urban areas. Indonesia’s official family planning programme came into operation in 1970 (Weeks, 1999; State Ministry for Population/NFPCB, 1995).

Seltzer (2002, p.10) proposes three primary rationales for legitimating family planning programmes:

1) Demographic rationale

Based on concerns over the macro level consequences of rapid population growth and high fertility for living standards and human welfare, economic productivity, natural resources, and the environment.

2) Health rationale

Based on concerns about the health consequences of high fertility for mothers and children. A high number of pregnancies, births to older and younger women, closely spaced births, and abortion are believed to contribute to high rates of infant, child, and maternal mortality. 


\section{3) Human rights rationale}

Based on the belief that individuals and couples have a fundamental right to control reproductive decisions, including family size and timing of births.

Concern with the demographic rationale was predominant until the late 1980s. Following the 1994 ICPD, the demographic rationale was gradually replaced by the health and human rights rationales (Demeny, 2003; Seltzer, 2002).

The demographic justification for a family planning programme, according to its proponents, is that the programmes slow population growth by reducing unwanted fertility caused by unmet need ${ }^{2}$ for family planning. Therefore, family planning programmes are designed to provide contraceptive services to reduce the unmet need which is assumed to occur because of lack of access to such services. However, scholars have debated the extent to which family planning programmes have facilitated the fertility decline (Bongaarts, 1997; Casterline \& Sinding, 2000; Demeny, 2003).

Its advocates contend that family planning programmes slow population growth by reducing the unwanted fertility caused by women's lack of access to contraceptives. Some studies have concluded that in most developing countries family planning programmes do have a significant impact on fertility, although it may vary between countries (e.g. Lapham \& Mauldin, 1984). On the other hand, some economists, most notably Pritchett (1994), have proclaimed that such programmes are ineffective. Using the same survey data as used by its proponents, he demonstrates that "it is fertility desires and not contraceptive access that matter” in achieving low fertility (p.39 ). He argues that fertility rates fall in developing countries primarily because socio-economic development reduces the demand for large families, thereby lowering wanted fertility. Further he emphasises the fact that unwanted birth rates have not declined in these countries, thus proving that family planning programmes have little effect on overall fertility. In response to Pritchett's contention, Bongaarts (1997) maintains that family planning programmes reduce unmet need not only

\footnotetext{
${ }^{2}$ Unmet need refers to women and couples who do not want another birth within the next two years, or ever, but are not using a method of contraception (Casterline \& Sinding, 2000)
} 
by providing contraceptives, but also by diminishing social obstacles to contraceptive use by providing information that increases the acceptance of family planning practices. He estimates that family planning programmes were responsible for 43 percent of the average fertility decline in the developing world between the early 1960s and the late 1980s (Bongaarts, 1997).

Concerns regarding reproductive health came to light following the 1994 ICPD. Women's health and welfare were promoted at the conference by women's health advocates and feminists. This led to a new framework for population policy and programmes, where the emphasis was shifted from the impact of population growth and high fertility on overall development to the welfare and rights of individuals, particularly women's right to reproductive autonomy and empowerment to enable women to secure this right (Seltzer, 2002). The ICPD Programme of Action of the 1994 ICPD defines reproductive health as “.... state of complete physical, mental and social well-being and not merely the absence of disease or infirmity, in all matters relating to the reproductive system and to its functions and processes” (UN, 1994). The conference endorsed a broader context of reproductive health instead of the narrow approach of family planning. A consensus set the goal of universal access to reproductive health information and services by 2015 (Seltzer, 2002).

The concept of reproductive health entails the right of men and women to be informed and to have access to safe, effective, affordable and acceptable methods of family planning of their choice. The Programme of Action of the 1994 ICPD states that "Reproductive rights rest on the recognition of the basic right of all couples and individuals to decide freely and responsibly the number, spacing and timing of their children and to have information and means to do so, and the right to attain the highest standard of sexual and reproductive health. They also include the right of all to make decisions concerning reproduction free of discrimination, coercion, and violence.” (UN, 1994).

\subsubsection{Family planning programmes and fertility decline}


As the significant role of family planning programmes has become clear in population policies, debate has continued over the impact of these programmes on fertility decline (see above). This necessitates an analysis of fertility trends in different countries over different time periods to identify the contributing factors to fertility decline.

In most developing countries, the transition from high to low fertility is still underway. Most of Europe and North America had completed their fertility transitions in the period 1870-1930; for the rest of Europe it has occurred in the first half of the twentieth century. In the newly industrialized countries of Asia (Japan, Taiwan and South Korea), the transition started after the 1950s (McNicoll, 1992; Hirschman, 1994).

The foundation of fertility transition theories is the classic 'demographic transition theory' as described by Thompson (1930) and Notestein $(1945,1953)$. This theory emphasises socio-economic changes, particularly in the form of modernization, as the cause of fertility transitions. The socio-economic changes, initially producing a decline in mortality, alter the economic calculus of childbearing in such a way that a large number of children is perceived as disadvantageous. Thus, socio-economic development motivates parents to have fewer children (Caldwell, 1982; Cleland, 1985; Freedman, 1979; Hirschman, 2001; Mason, 1997a; Teitelbaum, 1975; Watkins, 1987).

Thompson (1929, in Teitelbaum, 1975) has proposed that each population passes through three broad demographic transition stages:

1) Pre-industrial stage, with high birth rates, high but fluctuating death rates, and very low but fluctuating rates of natural increase;

2) Transitional stage, with continuing high birth rates, but declining death rates and consequently high rates of natural increase;

3) Industrialized-urbanized stage, with low birth and death rates and near zero rates of natural increase.

Using historical studies in nineteenth century Europe and the twentieth century developing countries, some scholars showed that there was an apparent contradiction in the 
idea that development and modernization bring about fertility declines (Coale, 1973; Hirschman, 1994; van de Walle \& Knodel, 1980; Watkins, 1987). Similarly, Mason (1997) notes that several countries in Asia and Latin America that are currently undergoing the fertility transition are agrarian and "underdeveloped”. Nonetheless, despite the criticism, there is no consensus on an alternative theory to replace the demographic transition theory (Hirschman, 1994).

The most popular theory in explaining fertility transitions is the 'economic theory' of fertility, which was first developed by Leibenstein in 1957 (Robinson \& Harbison, 1980). This theory depicts fertility decline as a rational accommodation to changes in economic circumstances. Currently there are two major economic approaches and several variants in the study of fertility change:

a) The neoclassical microeconomic theory of fertility Becker (1960) and Schultz (1973) propose to replace demographic transition theory which emphasises macro-level structural changes with a "new home economics" approach which focuses on the micro-level (Hirschman, 1994; Robinson \& Harbinson, 1980; Watkins, 1987). This theory focuses on utility function and argues that a couple's fertility choices are determined by: 1) the relative costs of children versus other material goods; 2) the couple's income level; and 3) their preferences for children versus competing forms of consumption (Mason, 1997a, p.444).

b) The "supply-demand framework"

This framework, developed by Easterlin $(1975,1978)$, suggests that the level of fertility in a society is determined by the choices made by individual couples within their cultural context (Bulatao \& Lee, 1983; Easterlin, 1978). This framework proposes three determinants of fertility: 1 ) the supply of children, i.e. the number of children a couple would have in the absence of deliberate fertility limitation; 2) the demand for children, i.e. the number of surviving children a couple would like to have; 3) the costs of fertility 
regulation, which include the psychological, social, time, and monetary costs associated with the use of contraception. This framework argues that couples attempt to maintain a balance between the supply of children and the demand for children. If the supply begins to exceed the demand, couples may start using some method of fertility regulation. The perceived costs of the fertility regulation will affect a couple’s decision in selecting methods of fertility control (Bulatao \& Lee, 1983).

Both the demographic transition theory and the economic theories of fertility share common assumptions about the determination of fertility, as noted by Watkins (1987, p.647-8):

a. Births are the outcome of a 'rational' decision-making process by individuals or couples.

b. In both pre-transition and post-transitional societies, the process of utility maximization determines the demand of children.

c. Mortality declines and economic development are the most important sources of change.

However, studies of fertility transitions in nineteenth century Europe and twentieth century developing countries suggest that economic development is not always a precondition for fertility decline (Cleland, 1985; Waktins, 1987). Hence there has been a notion that values, attitudes, and other psychological orientations may explain fertility trends or variations between populations. This new interpretation of fertility linking with cultural variables is known as the 'ideational theory’ (Cleland, 1985; Lesthaeghe, 1983).

The cultural hypothesis is that groups differ in fertility behaviour because of cultural values. Some populations may have higher levels of fertility than other groups with equivalent socio-economic characteristics because their culture places a higher value on children or proscribes certain methods of fertility control (Hirschman, 1994; Lesthaeghe \& Surkyn, 1988). Another cultural interpretation of the findings suggests that ideas about family size limitation and methods of fertility control may diffuse more quickly within a culturally homogenous population (Cleland, 1985; Freedman, 1979; Hirschman, 1994; Retherford \& Palmore, 1983; Watkins, 1987). This interpretation also applies to explanations of resistance to adoption of new ideas. The above studies also show that 
linguistic, ethnic, and religious boundaries often pose formidable barriers to diffusion (Retherford \& Palmore, 1983).

The ideational theory attributes fertility declines to the diffusion of innovations in birth control technologies and social norms. The central concept of this diffusion of innovation theory is the spread of knowledge about fertility control, the perceived advantages, and the perceived availability of effective means (Freedman, 1979; Cleland, 1985; Cleland \& Wilson, 1987; Watkins, 1987). Opinion leaders and social networks, as well as government policies and programmes play important roles in disseminating the innovation (Cleland, 1985; Retherford \& Palmore, 1983; Rogers, 1995; Rosero-Bixby \& Casterline, 1994; Watkins, 1987).

This thesis focuses on the ideational theory, which gives a wider understanding of how people assign meaning to various aspects of fertility and how decisions are made. However, this will not be exclusive, since it can be argued that the above approaches could have a joint effect on fertility decline. For example, the adoption of fertility control behaviour is facilitated by development, especially in communication technology, transportation networks and infrastructures (Freedman, 1979; Caldwell, 1982; Cleland, 1985).

\subsubsection{The role of international donors}

International donors and funding organisations have played very significant roles in promoting population control and family planning programmes in developing countries (e.g. Hartmann, 1987; Seltzer, 2002; Sinding and Hemmer, 1975; Warwick, 1982). With specific reference to several developing countries, Warwick (1982) concludes that of all the spheres of national development, population has been the most donor driven. He further explains that donors were involved since the initial stage of defining the 'population problem'; the strategies for dealing with the problem; organisational structure and tasks of population agencies, including the promotion of specific family planning methods or the use of targets; the level of commitment from top to bottom; and the criteria for judging programmatic success or failure. 
Financial and administrative limitations within developing countries necessitated the involvement of foreign assistance in population control and family planning programmes (Demeny, 2003). Donor support for international population control and family planning programmes has been provided through three channels: 1) direct bilateral assistance from the governments of developed countries to the governments of developing countries; 2) multilateral assistance from United Nations organisations, primarily the United Nations Population Fund (UNFPA); 3) NGOs and private foundations, including the International Planned Parenthood Federation (IPPF) as well as national and local NGOs in both developing and donor countries (Demeny, 2003; Seltzer, 2002).

For a number of years, developing countries have relied on international donor assistance in developing their population and family planning programmes. However, by the early 1990s the balance has shifted so that around 75 percent of all family planning funds now come from developing country governments. In 1998, governments and national NGOs in developing countries spent roughly $\$ 7.4$ billion, while international donors provided $\$ 2.2$ billion. The majority of these funds came from a few large countries such as China, India, Indonesia, Iran and Mexico (Seltzer, 2002).

Following the 1994 ICPD, the international donor community embraced the broader context of reproductive health in its population assistance programmes. Organisations like the UNFPA and the World Bank incorporate reproductive health goals in their main mission of slowing population growth (Seltzer, 2002).

\subsection{Women, development and family planning}

Feminist scholars contend that development, represented by modernization and capitalism, often increases the disadvantages suffered by women. The development process is believed to increase many existing forms of women's subordination and to introduce new forms of exploitation and oppression (Momsen, 1991; Wieringa, 1994). Modernization of agriculture, for example, has often diminished women’s control over land and excluded 
them from access to new technology (Afshar, 1991; Momsen, 1991). They also claim that the UN Decade for the Advancement of Women (1975-1985) has failed to improve women's position and access to resources (Sen and Grown, 1987).

Wieringa (1994) maintains that the above conditions were the result from women's gender interests were ignored when planning development interventions related to women. Therefore, Momsen (1991) asserts that development programmes, particularly in the Third World, should be aimed at helping women to cope with the declining status, heavier work burdens and growing impoverishment. Others emphasise the need for sexual discrimination to be challenged, particularly in the division of labour, to improve women's ability to control their lives (e.g. Young, 1993).

Feminist and development activists have demanded that development planners and policymakers should ensure that women participate in and benefit from development programmes (e.g. Tinker, 1990). They have urged that development theory should be reformulated to centre on women's experiences and gender relations (Moser, 1993; Mosse, 1993). Three main theories concerning women and development have emerged: Women in Development (WID); Women and Development (WAD); and Gender and Development (GAD).

The concept of 'women in development' was promulgated in the early 1970s and has been described as a liberal feminist approach that aims at women gaining equal status with men (Kabeer, 1994; Mosse, 1993; Rathgeber, 1990; Young, 1993). WID’s concerns with women's exclusion from the development process have led to a goal to integrate and mainstream women into the development process (Rathgeber, 1990).

Critics of WID claim that WID policies remain within the modernization paradigm, despite the recognition that modernization is not a 'panacea to everyone's ill' (Chowdry, 1995; Parpart, 1993; Tinker, 1990). As in modernization theory, WID sees development as economic growth that only occurs in formally productive activities (Parpart, 1993). Postmodern feminists claim that WID theorists and practitioners tend to represent women in the 
Third World as backward, vulnerable, and in need of help from the First World (Chowdry, 1995; Marchand \& Parpart, 1995). Rowlands (1997) asserts that the WID approach sees women as simply recipients of welfare projects and ignores their roles except as housewives and mothers. In addition, Rathgeber (1990) argues that in WID programmes gender relations between men and women were ignored, hence a development strategy based on WID would not be effective to bring about significant changes.

Unlike WID, the WAD approach argues that women have always been part of the development process and that it was their link with modernization that had impoverished them. The WAD perspective was drawn from dependency theory and neo-Marxist approaches to underdevelopment (Mosse, 1993; Rathgeber, 1990).

Sen and Grown (1987) maintain that development policies have to be oriented toward meeting people's basic needs. Further, they argue that short-term 'ameliorative approaches' to improve women's employment opportunities are ineffective unless they are combined with long-term strategies to re-establish women's control over economic decisions. However, critics have seen the work of Sen and Grown (1987) as universalising the Western sexual division of labour, and they failed to provide a genuine alternative to mainstream development (Hirshman, 1995). Rathgeber (1990) points out that WAD, like WID, tends to group women together without much notice given to race, class, or ethnicity. WAD neglects social relations of gender within classes and how these have impacted on women’s lives. In addition, Kabeer (1994) argues that, influenced by Marxism, WAD gives insufficient attention to reproduction.

The GAD perspective has drawn on socialist feminist and Marxist analyses of social change and feminist analyses of patriarchy (Rathgeber, 1990; Young, 1993). Rathgeber (1990) points out that the GAD approach tries to link the production and reproduction roles of women taking into account all aspects of women's lives.

In the GAD approach, gender relations have become the main analytical point. GAD theorists reject the sexual division of labour and argue that the allocation of tasks must be changed (Chowdry, 1995; Rathgeber, 1990). Further, they see women as agents of change 
rather than as passive recipients of development projects (Rathgeber, 1990). Kabeer (1994) and Visvanathan et al. (1997) maintain that GAD has also opened new strategies for feminist intervention to respond to the needs of poor women. However, Rathgeber (1990) points out that GAD recommendations face difficulties in implementation since they depend on significant change in social, economic, and political structures. Wieringa (1998) also contends that GAD discussions have become so 'economistic' and 'reductionist', they have lost their political and critical potential to improve women's conditions. By the end of the twentieth century all the above approaches had been amalgamated into what is usually called the GAD approach (Young, 2002).

Women have always been placed at the centre of attention in population and family planning programmes. Since the Bucharest population conference in 1974, family planning programmes have taken the broader perspective of improving women's health and literacy (Weeks, 1999). The importance of reproductive health also became central during the 1994 ICPD in Cairo, articulated by feminists and members of the international women's movement (McIntosh and Finkle, 1995). This issue, and women’s empowerment override the demographic rationale for population policy. Feminists assert that once women become more empowered and development advances, women will voluntarily opt to have fewer children, and thus population growth will slow (McIntosh and Finkle, 1995).

Nevertheless, feminist activists contend that concern for women has focussed solely on their reproductive role. Multilateral agencies and national governments treat women in an instrumental manner with respect to population programmes. Departing from the assumption that population growth is a hindrance to economic development, women were identified as primarily responsible for limiting fertility and became the primary targets for family planning programmes (Buvinic et al., 1983; Moser, 1993; Sen and Grown, 1987; Smyth, 1991; Young, 1993).

Sen and Grown (1987) maintain that control over reproduction is a basic need and a basic right for all women. They urged that women's rights should be taken into account in policy formulation. Smyth (1991) also asserts that women’s rights to control their fertility 
should be the necessary aim for all family planning programmes. However, national population policies are too often determined by international perspectives which are more concerned with population control. In many developing countries, family planning programmes are seen as a strategy of population control rather than birth control (Smyth, 1991).

The international policy on family planning was supported by the development of contraceptive technologies in the early 1960s. In the beginning, these contraceptives were assumed to enable women to control their own fertility. Their inclusion in the governments' family planning programmes, however, created a debate as to whether contraceptive use does guarantee women's control over their fertility. Many feminists have criticised the use of modern contraceptives as a means of population control rather than birth control (e.g. Hartmann, 1987). Mies and Shiva (1993) contend that contraceptive technologies perpetuate the patriarchy where women have always been the object of male subjects and have been made passive. The motherhood process is rationalized, objectified, planned and controlled by medical experts. Many women also do not have access to information which enables them to make free and informed choices about contraceptive methods (Smyth, 1991).

Nevertheless, Chapman (1996) maintains that what are seen as universal women's rights to control their own fertility by some feminists are based strongly on Western experience. Using the case of Indonesia, she argues that this perspective should be weighed up against the needs and priorities of each country.

\subsection{Gender relations within Indonesian households}

Indonesia consists of more than 350 ethnic groups, where each group has its own culture and tradition (Koentjaraningrat, 1971). In this section, I will focus on the Sundanese communities, the ethnic group which form the majority of the West Java population. However, since people on the northern coast of West Java are influenced by the Javanese, 
and due to limited studies on gender relations among the Sundanese, some discussion will draw on studies in Javanese communities.

\subsubsection{Gender roles and relations}

Traditionally, in Sundanese families, mothers are placed in a more important position than fathers. Both the special character and the position of Sundanese women are also reflected in Sundanese legends, such as Lutung Kasarung, where the female character is placed in the highest position (Garna, 1984; Rosidi, 1984). However, Sundanese couples also follow the principles of Islamic marriage where the husband is bound to support his wife and children. Therefore, in Sundanese communities men are regarded as the head of the family, and they are responsible for the family income. Meanwhile, women are responsible for running the household and taking care of the children. This division of roles of wife and husband in the family is also depicted in cultural proverbs, such as 'Indung nu ngandung bapa nu ngayuga' (mother gives birth and father provides). Nevertheless, among Sundanese villagers, it is common for husbands and wives to work together either in agriculture or in small-scale business activities (Garna, 1984; Suhamihardja, 1984a; Vreede-de Stuers, 1960).

Another character of Islamic marriage is that it does not impose any jointly owned property between husband and wife. The married woman retains complete freedom in managing her own possessions, which means that she may acquire or dispose of them without the approval of her husband (Vreede-de Stuers, 1960). However, such positive aspects are rarely highlighted compared with those that place a lower value on women.

\subsubsection{The process of internalisation of gender roles and relations}

The process of internalisation of gender roles and relations begins in early childhood. In Sundanese and Javanese societies, where the nuclear family is the basis for household formation, the parents play important roles in such a process. This process lasts until the children are married and form families of their own. Until a child is able to walk, the 
mother is the most important person in her/his life. Up to this period, the father has not been an important part of the child's world, although he may have taken turn at carrying the child once in a while. The main role of the mother is to give love and protection, while the father is usually a model for imitation (Garna, 1984; Geertz, 1961, Koentjaraningrat, 1985).

A child will receive training in politeness, respect for parents and elders, relationships with other family members and relatives, and religious practices. Respect for authority and for people with 'higher social status' usually is also emphasised. As soon as a child shows a degree of independence and responsibility, she or he is given the task of watching over a younger sibling (Garna, 1984; Geertz, 1961). In her description of socialization in early childhood, Geertz (1961) does not differentiate between girls and boys.

The changes which occur in adolescents' social relationships are connected with reaching sexual maturity, although sex is rarely discussed openly. A girl enters adolescence with her first menstruation, which is occurs without special note. Girls have a very short adolescence; by the age of fourteen they will be married and by the age of fifteen may already have a child. However, they generally remain more dependent on their mothers and fathers throughout their life than their brothers. Their mothers will usually assist during births or other crises. A boy's first step toward maturity is circumcision. The age of circumcision varies across societies, ranging from 8 to 14 years old. During late adolescence, boys may leave home to work outside the village or to attend Islamic boarding school (Geertz, 1961; Koentjaraningrat, 1985).

As boys reach adolescence, they may start to earn money by occasional work around the village. Boys who stay on in school are dependent on the parents longer. Girls rarely work except to help the mother with domestic duties (Geertz, 1961). Today, girls stay longer in school. Strict attention is paid to prevent pre-marital sexual relations and pregnancies because they are condemned as amoral and they make later marriage difficult. Segregation of the sexes is still practised in many areas of life, especially in rural areas (Berninghausen \& Kerstan, 1992). When adolescents grow into adults, they are expected to be equipped with the norms and values which will enable them to operate successfully in the adult 
world. However, due to early marriage, young couples usually remain dependent on the parents for some time (Koentjaraningrat, 1985).

Javanese parents tend to teach their children a pessimistic view about life, where hardships and misfortune are constantly present. Early in their lives, the children are taught always to feel concern over the hardships of life, and to be in a continuous state of 'eling' and 'prehatin' or forever feeling concern (Koentjaraningrat, 1985).

\subsubsection{Marriage and divorce}

Women in West Java usually marry quite young. The 2003 data revealed that West Java has the lowest median age at first marriage among women age 25-49, i.e. 17.8 years while the national figure is 19.2 years (CBS et al., 2003). In some cases, marriage is still likely to be arranged soon after the girl's first menstruation. Sons have more control over their own fate than daughters; parents usually wait until their son feels he is ready for marriage and comes to them for help (Vreede-de Stuers, 1960). Today, young people may make their own decisions, although parental consent is still needed. For the Sundanese, religious orientation and practice is the main consideration for the selection of a spouse. Women are expected to be virgin at their first marriage. A bride's virginity at her first marriage is highly valued and it can be grounds for divorce if she has lost her virginity (Mustapa, 2002; Budiarto \& Purwantini, 1988). Men are expected to already have a job or income when they get married (Budiarto \& Purwantini, 1987; Harsojo, 1971).

A wedding ceremony is carried out as a combination of religious and adat fashion. After signing the marriage contract, the groom will pronounce the talek, which formulates a condition that protects the woman's position. By means of this talek, the husband declares that his wife will be freed if he fails to keep the terms pronounced at the time of the marriage. This talek does not come into force until after the wife has notified the judge that she wants a separation (Budiarto \& Purwantini, 1988; Sastroamidjojo, 1928 cited in Vreede-de Stuers, 1960, p.35). 
Divorce rates among Sundanese were quite high despite the notion that it should be avoided whenever possible (Budiarto \& Purwantini, 1988; Peacock, 1973; Suhamiharja, 1984). One of the major reasons for divorce is childlessness. The Sundanese perception of marriage, as with the Javanese, is influenced by Islamic principles which stipulate that the task of a good Muslim is to marry and to have many children (Adioetomo, 1995). Children are also associated with love, happiness, and can strengthen the marital bond. Other reasons for divorce include economic hardships, disharmony, or the refusal of a woman to become engaged in a polygamous marriage (Budiarto \& Purwantini, 1988). The authors also note that divorces are prevalent in the first marriage of couples at very young ages (1519 years), which are mostly arranged marriages. The common reasons are because they were still very young or they did not like the spouse. However, after around one or two years both men and women will usually remarry.

\subsubsection{Gender relations and reproductive decision-making}

Studies about reproductive decision-making processes among the Sundanese are few. A study in North Sumatra and West Java (Adioetomo and Eggleston, 1998) reveals that although some couples emphasise compromise in household decision-making, the husbands usually have the last word. This study relates the decision-making process, especially in West Java, with Islamic teaching where women should obey and respect their husbands.

Studies in Javanese societies have demonstrated that household decisions are either made together by the wife and the husband or dominated by the wife (Koentjaraningrat, 1985; Geertz, 1961). Nevertheless, another study has revealed that the dominant role of Javanese women in terms of decision-making falls within the framework of the interests of their husbands (Berninghausen \& Kerstan, 1992). Women seldom make independent decisions with regard to children; husband and wife generally make a joint decision on planning the number of children. Both of them take responsibility for child rearing, but the day-to-day upbringing of the children is usually the sole responsibility of the wife. 
Several studies in Javanese communities have shown that since the 1980s the increase in age at first marriage and the girls' education levels have had important implications for gender and power relations within the household. Women have attained greater power in decision-making and parental involvements have decreased (Singarimbun, 1991).

\subsection{Summary}

The key points that have emerged from the above literature review include the relationships between population growth and development, factors influencing fertility behaviour, and women's empowerment. They provide a framework for analysing the population and family planning policies in Indonesia as they relate to women's empowerment and decision-making, which will be discussed in Chapters 5 and 6.

Concerns for the consequences of population growth on economic development have led to the emergence of two main contrasting views: rapid population growth is a burden for development or development is the primary means to reduce fertility. This thesis addresses both of these with the view to assessing development as the motivating factor that encourages women's empowerment in order to reduce fertility and improve family welfare in Indonesia.

Population control has become part of development strategies in many developing countries, with reducing population growth as one of the major basic assumptions behind the conceptual framework of development planning. These policies have been based on the ideas emerging from a series of United Nations population conferences since the 1970s that adopted Malthusian and modernization views. These views, which emphasise the adverse effects of high population growth on economic development, have led international population agencies and donors to persuade developing countries, such as Indonesia, to adopt population control policies through family planning. In Indonesia, the family 
planning concept has been set within the context of increasing family prosperity through reducing family size (see Chapter 6).

Studies in several developing countries, including Indonesia, have also stressed the role of government family planning programmes in influencing fertility behaviour, (e.g. Bongaarts, 1997; Gertler and Molyneaux, 1994; Lapham and Mauldin, 1984; Warwick, 1986). They suggest that the programmes have influenced couples' fertility behaviour through disseminating information on fertility regulation, both through the media and from provider to client; legitimating birth control practices that lead to social acceptance of fertility control; and increasing accessibility to birth control services. This thesis will add an analysis of social and cultural settings to understand how these factors operate and influence fertility behaviour.

In order to explain a couple's fertility behaviour, this thesis focuses on the ideational theory of fertility transitions. The argument of this theory is that fertility decline is embedded in the process of the adoption of a new behaviour that limits fertility, facilitated by the spread of knowledge about family limitation and the perceived availability of the means for fertility control. Opinion leaders and social networks, as well as government programmes play important roles in disseminating the innovation. However, socioeconomic conditions will also be included in the analysis since studies suggest the consequences of modernization and structural changes influence fertility behaviour by affecting the economic value of children, family structure, material aspirations and acceptance of birth control (Freedman, 1979; Caldwell, 1982; Cleland, 1985).

The implementation of family planning programmes as part of a government's population control policies, which have targeted women's responsibility for fertility control, has generated criticisms. These criticisms, mainly from women's health advocates and feminists, have led to the adoption of a new framework for population policy and programmes across the international community. Policies now emphasise the rights of individuals, particularly women, to reproductive autonomy and empowerment. Given that the concepts of women's autonomy and women's empowerment are multi-dimensional and 
may differ across cultures and communities, this study analyses how gender and family structure within the social system influence women's empowerment and fertility decisionmaking. Since these processes operate at many levels, this study focuses the analysis on the community and household levels. This information is important in understanding reproductive behaviour so that the design of population policies will result in greater gender equity, that is, a more equal balance of power and well being between women and men.

\section{Chapter 4 \\ Participatory Development and Empowerment}

\subsection{Introduction}

As discussed in Chapter 3, the concepts of development entail empowerment and the promotion of community participation in decision-making processes. This chapter provides a framework for analysing the general concept of community participation and examine it in detail as it is employed by the Indonesian family planning programme. The relationship between participatory development and women’s empowerment and decision-making will also be examined. The first section explores the general concepts and principles of participation in development. This is followed by a discussion of the concept of participation as a means toward empowerment, including constraints on participation. Scholars (e.g. Arnstein, 1969; Nelson \& Wright, 1995; White, 2000) argue that the ultimate goal of participatory approaches is the empowerment of the community. The concept of women's participation and empowerment is discussed in the following section leading towards an understanding of the importance of this concept in family planning decisionmaking. Its applications in an Indonesian context are explored in Chapters 5 and 6.

The fourth section reviews participatory development approaches, which emphasise the involvement of a community in decision-making and in the planning stage of development programmes. This is followed by a discussion on fertility decision-making as it relates to empowerment in family planning. Some major fertility decision-making theories are summarized, which include models and levels of fertility decisions. Particular attention will 
be given to the value of children as it is regarded as one of the major reasons underlying fertility behaviour.

The next section focuses on the role of change agents as a basis for analysing the role of PPKBD as a community organisation established by the Indonesian family planning programme at village level. Finally, implications of the above concepts in explaining family planning decision-making at various levels are summarized.

\subsection{Concepts and principles of participatory development}

The failure of many development projects generated critiques from NGOs and development practitioners who called for a new approach. Involvement of the community in the decision-making process of development programmes has been strongly emphasised.

From the late 1970s, major UN agencies, such as FAO, ILO, WHO, UNESCO, and UNRISD, began to embrace the idea of participation by communities and individuals, that is, a bottom-up approach. However, development practitioners maintain that the planning process by international donor agencies or national governments has remained a 'topdown' process. The latter process is characterised by the 'blueprint' approach, that is, the imposition of a pre-determined development plan based to a large extent on Western experiences (Hall, 1988, Korten, 1980). In this construction of people as objects of development programmes, their participation in projects often has meant contributions in the form of labour, cash or kind (Nelson \& Wright, 1995).

From the 1970s, many development agencies and practitioners started to revise their own concepts and models of participation to fit this view. A range of interpretations of participation in development includes:

...participation includes people's involvement in decision-making processes, in implementing programmes, their sharing in the benefits of development programmes, 
and their involvement in efforts to evaluate such programmes. (Cohen \& Uphoff, 1977, cited in Clayton et al., 1997)

...the organised efforts to increase control over resources and regulative institutions in given social situations on the part of groups and movements of those hitherto excluded from such control. (UNRISD, 1979, cited in Stiefel \& Wolfe, 1994, p.5)

...[participation is] a process through which stakeholders influence and share control over development initiatives and the decisions and resources which affect them. (The World Bank, 1996, p.3)

The above definitions reflect the complex nature of the process of participation, hence it is impossible to establish a universally accepted definition and shows the various positions with regard to control.

In the 1990s, 'participation’ regained its popularity as a response to the failures of many top-down style development programmes and projects. This approach called for a paradigm shift to participatory development (Chambers, 1995; Nelson and Wright, 1995). It also contained new ideas about gender equity and good government (Nelson and Wright, 1995).

As Nelson and Wright (1995) and Clayton et al. (1997) observe, during this time much of the discussion regarding participation revolved around the concept of 'stakeholders' and the influence they could have on the outcomes of development programmes and projects. This concept was introduced by the World Bank, who stress that stakeholders need to control development initiatives (The World Bank, 1994, cited in Nelson and Wright, 1995, p.5).

White (2000) asserts that participation can take multiple forms and serve many different interests. Cornwall (2001) clarifies this by claiming that it is crucial to distinguish the shape 
of participation, i.e. who participates, how, at what stages, and in what. In her 'ladder of participation', Arnstein (1969) distinguishes the level of involvement of the community in decision-making processes, from being 'manipulated' to being able to have control in decision-making process. Another typology introduced by White (2000) contrasts the meaning of participation from 'nominal' where the involvement of the local people is only for 'legitimation' the programme to 'transformative' that leads to the empowerment of the community.

Table 4.1:

Typology of Participation

\begin{tabular}{|c|c|c|c|}
\hline Form & Top-Down & Bottom-Up & Function \\
\hline Nominal & Legitimation & Inclusion & Display \\
Instrumental & Efficiency & Cost & Means \\
Representative & Sustainability & Leverage & Voice \\
Transformative & Empowerment & Empowerment & Means/End \\
\hline
\end{tabular}

Source: White, 2000, p.144

Participatory development is not a structured 'blue-print' development. According to Clayton et al. (1997), it is an approach with a set of principles that frame the concept of participation. The authors stress women's empowerment and local autonomy as the important principles. Participatory development should ensure that women's voices be heard so they can take part in decision-making process. Local people should also be encouraged to make decisions and to take actions as opposed to merely responding passively to outside initiatives (Clayton et al., 1997).

It is clear that participation is not merely an input to a project but it is a process that should be inherent through all phases of a project cycle. This process evolves through a series of stages, which may vary according to the nature and purpose of the project, and also to the local circumstances. Clayton et al. (1997) suggest that participation in a particular community should be developed over a period of time if it is to be effective. The 
authors identify several stages of people’s participation in development projects, from ‘passive participation’ to ‘ownership’ of the projects which is achieved through empowerment. These represent stages of an increased complexity in the process of a bottom-up approach.

\subsection{Participation as empowerment}

The concepts of participation entail elements of empowerment, such as sharing of power and resources and opening up opportunities ‘from below’ (Oakley \& Marsden, 1984). Therefore, achieving power is perceived as a fundamental prerequisite for rural people to be fully participating in development. Likewise, Chambers $(1995,1997)$ maintains that participation is an empowering process that enables local people to be part of the research process aimed at designing development programmes in their areas. These concepts associate participation with power in terms of access to, and control of, the resources necessary to the development process.

In order to achieve genuine participation through empowerment, Chambers (1995) stresses the need for changes in bureaucratic procedures and cultures. This include decentralisation and enabling local people to do appraisal and analysis of their conditions. Nevertheless, he recognizes that in practice the top-down reality has changed little over time. The powerful are threatened with a loss of power, since participation as an empowering process implies relinquishing power and control to the people. Therefore, he argues that reversing power relations is the key and also the weak link in achieving participation. He also asserts that the power relations in society have been dichotomised as ‘North’ versus ‘South’ or 'upper’ versus ‘lower’ (Chambers, 1995, p.34). Participation which empowers requires a changing role for dominant uppers: from planning, transferring technology, and supervising, to facilitating and supporting local endeavours. They must 'hand over the stick' to the local people (p.34).

However, Rowlands (1992, cited in Nelson \& Wright, 1995, p.11) warns that since empowerment entails the hand over of power, this new power can be used to perpetuate and 
disguise continued top-down approaches. For empowerment to be effective, the author emphasises that:

Empowerment is more than participation in decision-making, it must also include the processes that lead people to perceive themselves as able and entitled to make decisions. (Rowlands, 1997, p.14)

\subsubsection{Constraints on participation}

Failure of many development programmes to generate popular participation indicates that there are many obstacles to achieving participation. Oakley and Marsden (1984, p.30) classify the obstacles into three major groups:

1) Operational constraints

Emphasised by those who see participation only as a 'means' of achieving project

objectives. Factors such as over-centralised planning, poor delivery of services, lack of local coordination, and inappropriate technology are seen as major obstacles.

2) Cultural constraints

Traditional values, described as 'resistance to change', were previously perceived as obstacles to development. More recent analyses associate the degrees of participation with access to development, and have introduced such concepts as marginalisation, dependence and oppression in explaining the reasons of low-level participation.

3) Structural constraints

Perceived as fundamental to achieving participation, since both operational and cultural obstacles are bound up with the structural support or opposition they receive. Social, economic and political structures at local, national, and international levels determine the climate in which participation can take place.

Each of the obstacles reflects the particular concept of participation being employed, but in practice these three sets of ideas are closely linked. The structural obstacles are identified as the main barrier to participatory development. Many development scholars argue that it is almost impossible to achieve a high level of community participation in the 
decision-making process without a significant change in social, economic, and political structures. Such a structural reform, however, is not easy to undertake (Clayton et al. , 1997; Hall, 1988; Oakley \& Marsden, 1984).

\subsection{Women's empowerment}

The concept of women's empowerment was introduced in 1985 by a network of feminist scholars and women's groups, Development Alternatives with Women for a New Era (DAWN), as the “empowerment approach”. This approach became the central argument of Gita Sen and Caren Grown’s seminal book “Development, Crises, and Alternative Visions” (1987). They contend that development programmes often increase the disadvantages suffered by women. The aim of the approach is to empower women through greater selfreliance (see also Momsen, 1991; Moser 1993, Wieringa 1994). It seeks ways to empower women not in the sense of reversing the existing power hierarchies, but rather in empowering women to make their own choices and to control their own lives. Since then, a number of different definitions and viewpoints of women's empowerment have emerged. A range of concepts of women's empowerment includes:

The objective is to promote gender equality in all spheres of life, including family and community life, and to encourage and enable men to take responsibility for their sexual and reproductive behaviour and their social and family roles. (Paragraph 4.25, ICPD 1994)

The goals of women's empowerment are to challenge patriarchal ideology (male domination and women's subordination); to transform the structures and institutions that reinforce and perpetuate gender discrimination and social inequality... and to enable poor women to gain access to, and control of, both material and informational resources. (Batliwala, 1994, p.130)

Scholars argue that empowerment includes many dimensions and facets and is contextspecific, so it is probably impossible to establish a universally accepted definition of 
women’s empowerment (e.g. Dixon-Mueller, 1998; Mason, 1997b; Sen and Batliwala, 2000).

Another key feature of an empowerment process is that it implies a change in power relations, although it is not necessarily a zero-sum game. It may mean that women share power and control over decision-making and resources within households or communities (Mason, 1997b; Sen and Batliwala, 2000). Sen and Batliwala (2000) explain that power relations which influence women's lives operate at four levels: the household/family; the community/village; the market; and the state. Meanwhile, Parpart (2000) suggests three levels: local, national, and global. These levels are interconnected, which means women's subordinate status at one level being reinforced by power relations at other levels as well. Sen and Batliwala (2000) also point out that power relations take different forms and have different implications for women's reproductive health at different stages in women's lives.

In its chapter on 'Gender Equality, Equity and the Empowerment of Women', the 1994 ICPD Programme of Action declares that the empowerment of women is an end in it itself and not a means to an end (UN, 1994). Women's empowerment is also both a process and an outcome (Dixon-Mueller, 1998; Kishor, 2000; Parpart, 2000). As a process, empowerment covers not only extrinsic control over resources and over ideology, but also intrinsic capability: greater self-confidence and ability to overcome external barriers to accessing resources or changing traditional ideology (Moser, 1993; Rowlands, 1997; Sen and Batliwala, 2000). Hence, a development programme that changes women's control over resources must also build their confidence in themselves if that control is to be retained (Sen and Batliwala, 2000). Sen and Batliwala also argue that participation can lead to women's empowerment only if it genuinely involves women in formulating strategies and policies, making decisions about programmes, and monitoring and evaluating them.

Studies have linked the concept of women's empowerment to demographic change, particularly with regard to fertility and child mortality. The 1994 ICPD Programme of Action states that improving the status of women also enhances their decision-making in 
reproduction. However, Mason (1997b) and Sen and Batliwala (2000) assert that the relationship between women's empowerment and reproductive behaviour is very complex.

Sen and Batliwala (2000) maintain that the empowerment of women is, among other things, about enabling them to know, access, and assert their reproductive and sexual rights. It is the absence or denial of these rights that deprives them of the autonomy, decision-making power, and control over resources that are essential to achieving the highest standards of sexual and reproductive health. Chatterjee (1988, cited in Sen \& Batliwala, 2000, p.24), suggests five gates or barriers that stand between women and their access to health services: need, perception of need, permission, ability, and availability. For women in many societies, at least three of these gates are directly and indirectly controlled by the family, i.e. perception of need, permission, and ability. One of the gates, i.e. availability, is controlled by the state and the market.

The multi-dimensional aspects of women's empowerment also raise concerns about its measurement. Since empowerment is seen as both a process and an outcome, it is often difficult to measure and leads to the use of proxies, such as education level and women's participation in the labour force. Women's education is frequently cited as inversely affecting fertility through a number of mechanisms, for example, it can increase the age of marriage, child survival, and contraception use. These mechanisms operate partly through greater autonomy or power of educated women (Cochrane, 1983; Mason, 1997b).

Nevertheless, Mason (1997b) warns that using such proxies for studying the relationship between gender systems and fertility can sometimes provide a misleading picture, as is evidenced by studies in highly patriarchal societies in Bangladesh and Turkey. It is suggested, therefore, that an analysis of the correlation between women's empowerment and fertility that uses proxies for empowerment should be taken cautiously since it tends to be oversimplified.

\subsection{Approaches to participatory development}


With regard to the purposes and approaches of participation in development, there has been much discussion as to whether it is a means used to achieve development or an end in itself. Each category implies the possibility of very different power relationships between members of a community as well as between them and the government institutions (Nelson \& Wright, 1995). Oakley and Marsden (1984) argue that participation should be an end in itself. Participation, in their view, is the unavoidable consequence of the process of empowering and liberation. Nevertheless, the notion of participation as a means to achieving development has dominated development practice (Oakley \& Marsden, 1984; Nelson \& Wright, 1995).

Community participation has been recommended as an important programme strategy at various conferences on population and family planning. However, in a family planning programme that is guided by demographic goals to reduce fertility, community participation is usually seen as a means to achieve the programme's goals (Askew \& Khan, 1990). The UNFPA also adopts this idea of participation as a means to an end. In its desk review of community participation in family planning, the authors clearly stated that "It is imperative to clarify to all concerned parties that $\mathrm{CP}$ [community participation] is not an end in itself but a strategy for achieving identified objectives...” (UNFPA, 1995, p.7). This point of view is also reflected in the organisation's definition of community participation as:

...the process by which the efforts of potential beneficiaries of development programmes are mobilised and harnessed with those of Government and nonGovernmental authorities to improve the economic, social and cultural conditions of communities; to facilitate integration of these communities into national programmes; and to enhance community level contribution to national development programmes (UNFPA, 1995, p.2).

This idea of participation has led many donor agencies to persuade its recipient countries to maintain a centralised and hierarchical control over planning to ensure that their interests 
and goals are being met (Askew \& Khan, 1990). Within this perspective, participation is characterised by preparing rural people to collaborate with government programmes and by establishing formal organisations to mediate between rural people and government programmes. Although this strategy might be successful in achieving the programme’s objectives, it has not resulted in meaningful participation of the rural people (Oakley \& Marsden, 1984).

Efforts to turn the participation rhetoric into reality have led development practitioners and researchers to continuously develop approaches for participatory development. Blackburn and Holland (1998) identified at least twenty-nine approaches which have been developed since the 1970s, such as Rapid Rural Appraisal (RRA), Participatory Rural Appraisal (PRA), and objectives-oriented project planning (ZOPP). These approaches emerged as a response to the growing recognition of the value of local knowledge and the inability of traditional survey methods to capture the qualitative dimensions of peoples' lives (Clayton et al., 1997).

However, the above approaches are not without limitations. Rowlands (2003) warns that participatory approaches may not be effective if applied without sufficient knowledge of local conditions or by unskilled facilitators. The author also maintains that learning processes, for both individuals and organisations, should be embedded in the approaches if they are to be able to bring about changes. With regard to women's empowerment, Clayton et al. (1997) suggest that these approaches are not inherently sensitive to gender issues.

\subsubsection{Participatory Rural Appraisal (PRA)}

Participatory Rural Appraisal (PRA) is one of the best-known methods of development delivery. The idea of PRA has evolved and spread very fast, mainly among the Third World countries. By the late 1990s it is believed to have been practised in 100 countries. The use of PRA has been transferred from NGO experiences in the 1980s to mainstream development practice and policy in 1990s. Large international donor agencies, particularly 
the UN and the World Bank, have also encouraged the use of PRA in their sponsored programmes and projects (Blackburn and Holland, 1998).

PRA is described as "a family of approaches and methods to enable rural people to share, enhance, and analyse their knowledge of life and conditions, to plan, act, monitor and evaluate" (Chambers, 1997, p.102). It has evolved from several sources and traditions, including Rapid Rural Appraisal (RRA). The main techniques used in PRA are the same as in RRA but with more emphasis on local participation in planning. Unlike RRA where outsiders obtain information and take it away, PRA facilitates local people to be the observers, mappers, analysts, planners, and actors. Hence, PRA is seen as empowering local people to do their own analysis and to make their own decisions (Chambers, 1997; Clayton et al., 1997).

Based on field experiences, Chambers (1997, p.104) explains that PRA has three foundations or pillars:

1) The behaviour and attitudes of outsiders, who facilitate, not dominate;

2) The methods, which shift normal practices;

3) Partnership and the sharing of information and experience between insiders and outsiders, and between organisations through feedback of analysis and reports.

With respect to gender issues, Crawley (1998) maintains that PRA processes are unlikely to be equally accessible to all sections of a community, especially to women. She points out that PRA is concerned only with power relations between insiders and outsiders, or between the North and the South, but ignores gender as a critical aspect of power relations. However, Chambers (1998) notes that 'women' as a focus of attention often distracts attention from gender relations between women and men.

\subsection{Fertility decision-making: empowerment in family planning}


The reproductive rights as stated following the implementation of the 1994 ICPD stipulate that all couples and individuals should be able to decide the number, spacing and timing of their children and to have the information and means to do so. They also include the right of all to make decisions concerning reproduction free of discrimination, coercion, and violence. This implies that ability to make fertility decisions requires empowerment in the forms of access to family planning information and services.

The following section summarizes the models and levels of fertility decisions which provide a framework for discussions of the empowerment process on making family planning decisions .

\subsubsection{Models of fertility decision}

Fertility decisions are explained through various disciplines, such as sociology, economy, psychology and anthropology. However, each discipline has its own version of the model and tends to focus on different aspects (Burch, 1980). Some of the key differences include:

a. The consequences included or emphasised

Economists tend to focus on utilities or price and income constraints, psychologists concentrate on psychological value of children, while sociologists place emphasis on social relationships and social norms.

b. Styles and rules of decision making

Each discipline has its own rule, but these variations can be reduced to a form of maximization. Maximization of utility assumes that an actor seeks the best possible result. The alternative rule to maximization is satisficing, i.e. the actor seeks a result that is good enough to meet his/her some expectations, even though it is not the best obtainable.

c. Individual versus group actors

Economists tend to view fertility decisions as made by couples who try to maximize their utility and the couple's decisions are the focus of analysis. Psychologists, on the 
other hand, emphasise interpersonal processes within the larger decision making unit (couple or household).

The above description suggests that fertility decision-making is a complex process. Many demographers have emphasised the concept of rationality in fertility decisions. However, Caldwell (1982) contends that rationality is derived from industrial and urban viewpoints, and that its criteria are laden with Western values. Therefore, Hull (1983) suggests that the focus is not on absolute rationality, but on different types of rationality that take account of informational, political, temporal, and perceptual constraints. Another view is offered by Demeny (1970, cited in Hull, 1983, p.384), who maintains that rationality in fertility decisions should be interpreted as "simply behaviour that represents a best accommodation of individual desires to the impositions of the environment”. An example of the influence of social environment to couple's fertility decisions was given by Retherford and Palmore (1983). They highlight research which shows that although mass media facilitate awareness and basic information about contraception, the adoption itself is more likely to be encouraged or discouraged by opinion leaders 'closer to home' who share many of the same characteristics as the couples (Retherford \& Palmore, 1983). According to them, this is the key to the success of the 'community-based distribution system'.

Findings of the fertility studies both in Europe (European Fertility Project, 1972) and contemporary developing countries (World Fertility Survey, 1974-1984) suggest that fertility regulation is a behavioural innovation. Changes in fertility preferences are tied to ideational change, not change in ideas to do with children and their benefits and costs, but in ideas concerning acceptability and means of reproductive control (Cleland, 1985; McNicoll, 1992). Based on the European Fertility Project, Coale (1973, cited in Cleland, p.249) argues that there are three preconditions for fertility control:

1) fertility must be within 'the calculus of conscious choice'

2) effective techniques of fertility control must be known and available

3) reduced fertility must be advantageous. 
The author also argues that fertility will decline only if the three preconditions exist. In other words, couples must be “ready, willing, and able” (Coale, 1973, cited in Cleland, p.249).

In analysing a couple's fertility intention, scholars suggest examining it throughout their 'fertility career', i.e. the period when a couple can have children. Personal and familial changes take place during this period might influence the couple's fertility decisions (Bulatao \& Fawcett, 1983). These authors argue that in most cases, couples make a decision early in the marriage and refine it in response to changing circumstances over the course of their fertility career. The major factors that might influence a couples' fertility intention are: age and childbearing experience, socio-economic characteristics, and values and disvalues attached to children (Bulatao \& Fawcett, 1983, p.4).

\subsubsection{Value of Children}

Another approach to study fertility decision-making is based on the perceptions of the value of children. The common emphasis of the value of children is as a determinant of fertility trends and decisions, with satisfactions and costs as the major influencing factors (Arnold et al., 1975). From a cross-sectional study in both developing and developed countries, Arnold et al. draw the positive and negative values attached to children, which cover psychological, economic, social and demographic aspects. The positive values are emotional benefits, economic benefits and security, self-enrichment and development, identification with children, family cohesiveness and continuity. On the other hand, the negative values include emotional costs, economic costs, restrictions or opportunity costs, physical demands, and family costs. There are also values pertaining to large-family and small-family values. The large-family values are sibling relationships, sex preferences, and child survival, while the small-family values cover maternal health and societal costs.

Fawcett (1983) points out that numerous studies in developing and developed countries have confirmed the correlation between measures of perceived satisfaction and costs of children with various measures related to family size and the practice of birth control. 
Further, he notes that the most comprehensive framework which explains the linkages between the value of children with fertility is a 'theory of the transition in the value of children'. This theory identifies five factors which bring about changes in perceptions of the value of children, all related to socio-economic development and modernization: vanishing economic roles for children, the rising aspirations of parents, the emergence of the conjugal family, the weakening of cultural props for high fertility, and reductions in mortality (p.439). The author also explains that various surveys strongly support the explanations connected with vanishing economic roles for children, and mixed support for those connected with rising aspirations and the emergence of the conjugal family (Fawcett, 1983).

Several studies in Indonesia (Darroch et al., 1983; Saefullah, 1976; White, 1975) showed that in Indonesian societies children are an important element of the structure of the production and maintenance of the family’s material well being. Darroch et al. (1983) explain that it is particularly true in Javanese and Sundanese nuclear families, and call this the 'instrumental benefits' of children. Educational levels and residency (rural or urban) influence the degree of expectation for these benefits and wives usually placed more importance on these benefits than did husbands.

\subsubsection{Levels of decision-making}

\subsubsection{Community level}

McNicoll (1975) maintains that a village-specific population and development programme can create social control to achieve fertility reduction. Equity in the distribution of goods and services, and improvement in the standard of living are believed to reduce fertility (Freedman, 1979). In addition to economic and social development, governmentsponsored programmes can also facilitate rapid diffusion of family planning at village level (Retherford \& Palmore, 1983). Such political influences can sometimes overcome a lack of social integration in other areas, such as ethnicity, language, and religion. Further, Retherford and Palmore (1983) also explain that social integration can facilitate or hinder 
the adoption of family planning. This may occur, for example, because of rumours about the side effects of contraception.

\subsubsection{Household level}

Hull (1983) argues that the nature of the decision process is related to the couple's interactions within the social setting. Similarly, Hollerbach (1983) contends that a couple’s decision-making process is influenced by the larger social context of relationships, where perceptions, evaluations, norms and attitudes towards fertility choices are formed and shaped through social interaction. From this perspective, fertility decisions may not be limited to couples or individual families, rather they are influenced by other sources, such as the older generation, other relatives, or extra familial sources, such as neighbours, peers, community leaders, professionals, and state authorities (Hollerbach, 1983; Hull, 1983; Watkins, 1987).

Hull (1983) notes three ways in which such sources influence decisions: by social consensus transmitted through socialization; by shared value judgments on the propriety of fertility-related behaviour and the imposition of sanctions; and by advice and counsel from extra familial resources

Government institutions can also influence couples’ fertility decision. The government family planning programmes may not only make modern contraceptives available, but also actively encourage the acceptability of new reproductive behaviour. The legitimacy or encouragement offered by government institutions can affect the social climate within which individual contraceptive decisions are made (Watkins, 1987).

\subsection{The roles of change agent}

As suggested by the diffusion of innovation theory (see Chapter 3), external agents such as government fieldworkers and opinion leaders play important roles in disseminating 
innovations such as fertility control to the community. In his theory of 'Diffusion of Innovations', Rogers (1995, p.335) uses the term 'change agent', which is defined as “an individual who influences clients' innovation-decisions in a direction deemed desirable by a change agency”. One of the main roles of a change agent is to facilitate the flow of innovations from a change agency to the clients. In this context, the communication relationship between the agent and the client is important for the dissemination to be effective. Change agents should be able to bridge the gap between the two differing worlds: the change agency and the clients. Therefore, he describes the change agent as a figure "with one foot in each two worlds" (p.336).

According to Rogers (1995), the roles of change agents in the process of introducing an innovation to the clients include: to develop a need for a change, to establish an information-exchange relationship, to diagnose problems, and to stabilise adoption and prevent discontinuance. This framework will be used to assist in the analysis of the role of the village facilitators in the Indonesian family planning programme.

As for women's empowerment, Sen and Batliwala (2000) underline the essential role of change agents in facilitating the intrinsic process of women's empowerment (see Chapter 3). Their role is crucial in societies where traditionally women have had little control over resources or voice in decision-making in the household or the community, and when their exposure to new ideas is limited.

Rogers $(1973,1995)$ further distinguishes change agents as 'professional change agents', 'paraprofessional aides' and 'quasiprofessional aides'. According to this classification, the paid government fieldworkers and the PPKBD (volunteers) in the Indonesian family planning programme can be categorized as paraprofessional aides and quasiprofessional aides respectively. The main characteristics of these aides are their lower cost compared to professional change agents. However, they are socially closer to the clients, and thus have higher social acceptability or 'safety credibility'. This is considered to be a more important attribute than technical expertise, as they are perceived to be trustworthy by the clients (Rogers, 1995). The PPKBD, which has a similar socio- 
economic status to the clients, can reach the poorer clients which the fieldworkers cannot reach as effectively. The important role of PPKBD as a change agent was confirmed by a study aimed at investigating the effects of the government family planning programme on fertility in Indonesia (Molyneaux and Gertler, 1999). The study suggests the significant role of the community-based distribution systems (including PPKBD) in lowering fertility levels.

Retherford and Palmore (1983) and Rogers (1973) also emphasise the critical function of opinion leaders in family planning programmes. They maintain that family planning campaigns are more likely to be successful if change agents identify and mobilize opinion leaders. 'Opinion leadership' is defined by Rogers (1995, p.354) as “the degree to which an individual can informally influence other individuals' attitudes or overt behaviour in a desired way with relative frequency.”

\subsection{Summary and implications}

The concepts of participatory development challenge the top-down approach and propose a bottom-up participation in development programmes, which stresses the community's involvement from the planning stage. The above discussion has also highlighted the strong influence of international perspectives on family planning in developing countries. At a national level, this influence interacts with the domestic/ internal points of view.

In summary, the implications of the concepts of participatory development on the formulation and adoption of population and family planning policies at the international, national and community levels are as follows:

\subsubsection{International level}

Between the 1950s and the early 1990s, international population policy was driven by Western concern with population growth rates in developing countries. Embracing the neo- 
Malthusian perspective, the international population movement in the late 1940s was aimed at controlling Third World population growth through family planning using clinic-based methods of contraception. The movement became firmly institutionalised in international governmental agencies, especially those of the United Nations (e.g. UNFPA, FAO, WHO) and in Western governments' foreign aid policies by the mid 1960s. Most of the governments of developing countries were attracted to neo-Malthusian policy because lower rates of population growth would facilitate economic development (Luke and Watkins, 2002). By the early 1990s, most developing countries had adopted population programmes to reduce fertility with the assistance of international organisations and Western government agencies. These developments contributed to fertility declines almost everywhere (Bongaarts and Watkins, 1996).

Using diffusion theory, Retherford and Palmore (1983) explain that not only information, but influence and resources flow from a network of international agencies to national governments through diffusion networks. This theory also applies to the diffusion of international population policies derived from international conferences.

The United Nations had organized three international population conferences, i.e. the 1974 World Population Conference in Bucharest; the 1984 International Conference on Population in Mexico City; and the 1994 International Conference on Population and Development in Cairo. The 1974 and 1984 conferences were built on the basic premise of the neo-Malthusian ideas, that is, population growth is a potential hindrance to a country's ability to develop economically, and that a development plan needs to include a strategy for limiting population growth (Weeks, 1999). The 1994 ICPD in Cairo, however, attempted to change the focus. Strongly influenced by the agenda of Western feminists, the Cairo Programme of Action was concerned more with promoting gender equity and reproductive health than with population growth (Luke and Watkins, 2002).

\subsubsection{National level}


International population policies and systems play important roles in fertility transition in many countries. Structural modernization and the transmission of Western ideas affect the economic value of children, family structure, material aspirations, and acceptance of the principle of birth control (Caldwell, 1982; Cleland, 1985; Watkins, 1987). International conferences have generated support for population policies and family planning programmes; international experts have facilitated transfers of technology and publicized studies on the effectiveness of family planning programmes (Watkins, 1987). This implies that changes in perception and aspiration towards fertility control in a particular country may not come from the society itself, but from interdependence with the worldwide political, economic and communication systems.

\subsubsection{Community level}

It is argued that development and population programmes could be more effective in a homogenous economic-demographic society (McNicoll, 1975). Studies in developing countries have also shown that rapid diffusion of birth control and rapid fertility decline occurred in relatively small geographic areas, in populations with a high degree of cultural homogeneity in such areas as language, ethnicity, and religion (Retherford \& Palmore, 1983). Therefore, programmes should be tailored to the circumstances of each community rather than applied everywhere in the same way.

Two development impacts could contribute to lower fertility in a community level: 1) equity in the distribution of goods and services, and 2) improvement in the standard of living (Freedman, 1979). Nevertheless, Freedman argues that neither case could work unless local communities were effectively linked to larger systems of resources and information interchange.

Thus, it can be said that a family planning programme is an amalgamation of international and national agenda with the local context. The programme was previously aimed at fertility reduction, but is now focusing on women's reproductive health and 
empowerment and community participation. The Indonesian population policy and family planning programme will be discussed in Chapters 5 and 6. 


\section{Chapter 5}

\section{Population and Family Planning as Part of Development Strategy in Indonesia}

\subsection{Introduction}

Population control has been a key issue in the development in Indonesia since the late 1960s. In 2000, with a population of 206.3 million Indonesia ranked as the world's fourth most populous country (BPS, 2003). In addition to its large population size, until the 1970s the Indonesian population was characterised by rapid growth, uneven distribution and a high dependency ratio. Such conditions were perceived by the Indonesian government as a hindrance to social and economic development efforts, and have led to the adoption of population control programmes (State Ministry for Population/NFPCB, 1995). Population has become one of the major basic assumptions of development planning since Independence in 1945, however, the integration of population control policies into development planning began after the 'New Order' government took power in 1966 (Hugo et al., 1987).

This chapter presents an overview of the population and family planning policy as part of the national development plan in Indonesia. First, a summary of the situation of the Indonesian population over the past few decades will be presented. The second section discusses the development strategy adopted by the Indonesian government. Thirdly, the processes of the population and family planning policies formulation are examined. Finally, this chapter reviews the Indonesian population and family planning policies over time. 


\subsection{The Indonesian population dynamics}

\subsubsection{Population size and growth}

The Indonesian population has been characterized as one of the most populous countries in the world. A census conducted in 1930 by the Dutch colonial government enumerated the population as 60.7 million, of which 41.7 million (68.7\%) lived in Java (Nitisastro, 1970). The first census after independence, conducted in 1961, recorded a total of 97.02 million, making Indonesia the fifth most populous country after the People's Republic of China, the USSR, India, and the USA. It is estimated that the population of Indonesia exceeded the 100 million mark in 1963 (Nitisastro, 1970; Hugo et al., 1987). Since then, population censuses carried out every ten years have revealed an ever-increasing figure. In 2000 the Indonesian population had doubled from 97.02 million in 1961 to around 206.3 million, and the country is now the fourth most populous country in the world (BPS, 2003).

Figure 5.1:

Population of Indonesia, 1961-2000

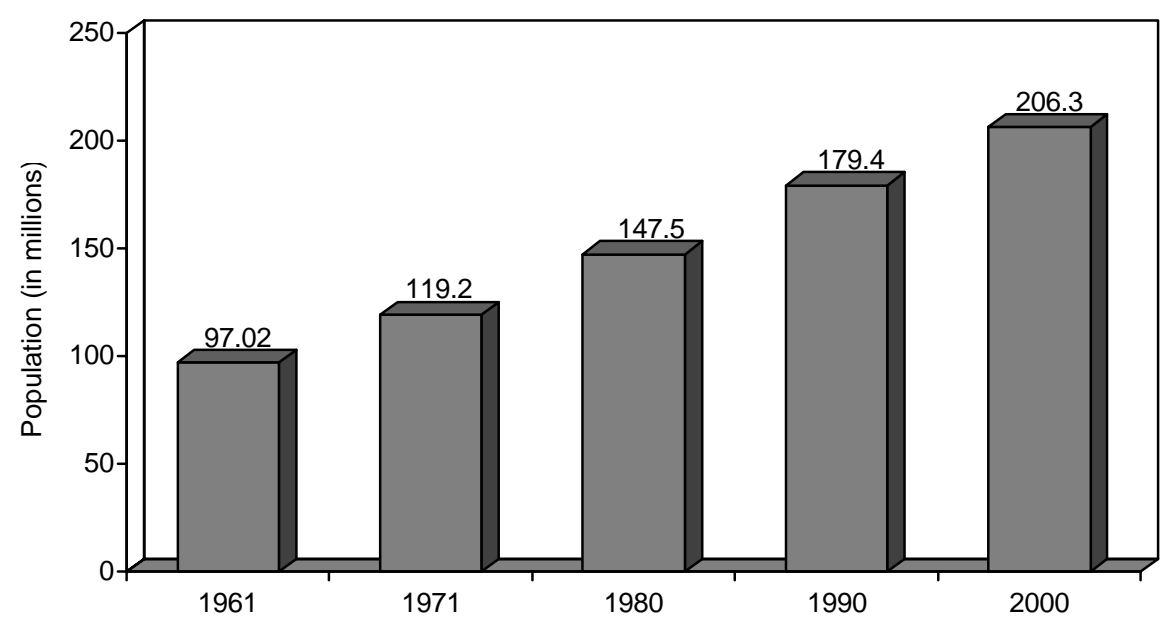

Sources: Nitisastro, 1970; BPS, 2003.

The population growth rate rose from 2.1 percent between 1961-1971 to 2.31 percent in the period of 1971-1980, but slowed down to 1.98 percent in the period of 1980-1990 and 
to 1.49 percent by the period of 1990-2000 (BPS, 2003). The principal determinants of population growth are crude birth and death rates, which are determined by fertility and mortality levels and age structure (Caldwell, 1997). During the 1960s, the Crude Birth Rate (CBR) and Crude Death Rate (CDR) was 43 and 20 per thousand population respectively, which was the highest among the ASEAN member countries at that time, i.e. Malaysia, Singapore, Philippines and Thailand (Nitisastro, 1970; World Development Report, 1993). The maternal and infant mortality rates were also thought to be the highest in the region, although it is difficult to obtain exact figures.

It is difficult to determine the levels and trends of fertility in Indonesia prior to 1960s due to the lack of data. Recent population trends, however, demonstrate a rapid decline in fertility and mortality levels. Following the introduction of the government's family planning programme in 1970, the fertility rates have declined significantly. From 5.6 births per woman between 1967 to 1970, they declined to 2.78 births per woman for the 19951997 periods and to 2.6 births per woman for the 1997-2003 periods (CBS et al., 1998, 2003). The decline in fertility has occurred at all ages, with the largest proportional decline among the 15-19 age group, from 155 births per 1,000 women in the late 1960s to 62 births per 1,000 women in the mid 1990s. The peak of the age-specific fertility rates also shifted from the 20-24 year age group in the late 1980s to the 25-29 in the late 1990s (CBS et al., 1998).

At the end of the first five-year development plan (1969/70 to 1974/75), the family planning programme set a demographic goal, which was a 50 percent reduction of the 1970 fertility rate by the year 2000 (Suyono et al., 1978). The target was revised to be achieved by 1995, but the 1994 Indonesian Demographic and Health Survey (IDHS) showed this target had already been achieved during the 1991-1994 period (CBS et al., 1995). Studies showed that the decline in the total fertility rate was due to increased age at marriage and first birth and also because of extensive use of contraception (e.g. Gertler \& Molyneaux, 1994; Hugo et al., 1987; Hull, 1987).

Figure 5.2: 


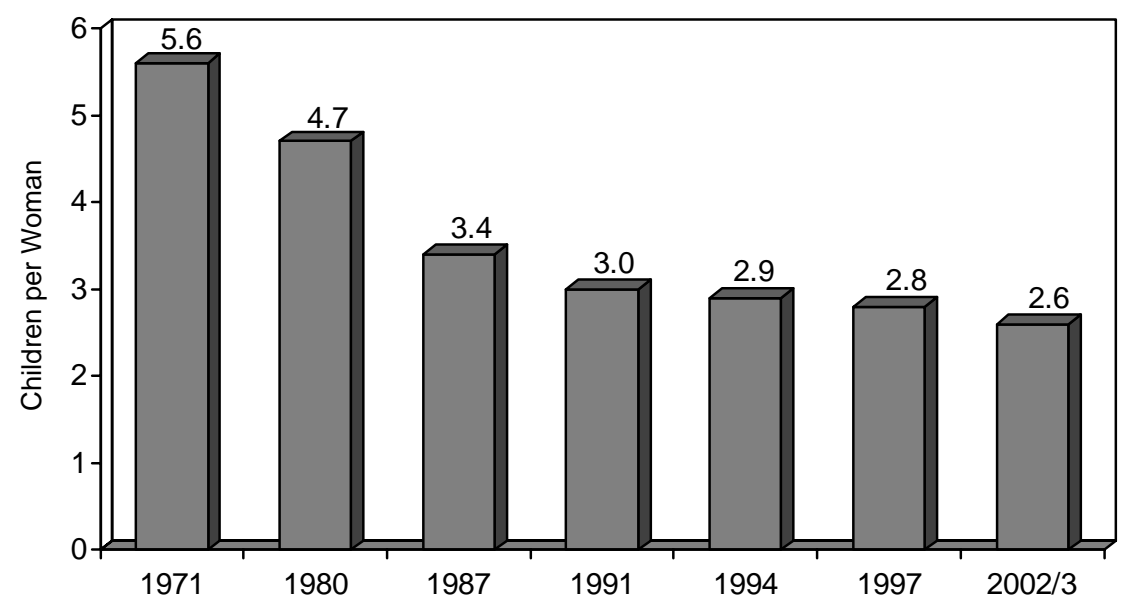

Sources: CBS et al. 1998, 2002/3.

The decline in fertility varied among regions in Indonesia. Surveys undertaken between the periods of 1984 to 1997 have shown that the women in Java-Bali region have lower fertility rates than those in other parts of the country. Differences in fertility rates also occur between rural and urban areas. Over time, rural women had more children than their urban counterparts, in the mid 1990s the discrepancy was 0.6 children (CBS et al., 1998).

The mortality levels have declined more rapidly than the fertility levels. A declining trend in mortality rates has been apparent since the 1960s. Population censuses show that the crude death rate has declined from 19.1 deaths per 1,000 population in 1971 to an estimated of 7.6 deaths in 1999 (State Ministry for Population, 1999). The main causes of death for the under 44 age group, aside from injuries and accidents, were tuberculosis and cardiovascular diseases. Cardiovascular diseases and tuberculosis were also the main causes of death among older adults, 45 and over (Iskandar, 1997).

Even though infant and maternal mortality rates have declined considerably, they are still higher than those of many Asian countries (Iskandar, 1997; Jones, 1999). From a level of 142 infant deaths per 1,000 live births for the period of 1967-1971, the infant mortality rate has fallen to 35 per 1,000 live births in the period of 1998-2002 (Nitisastro, 
1970; CBS et al., 2003). The principal causes of infant mortality are perinatal diseases (such as low birth weight and birth injuries), acute respiratory infection (pneumonia), and diarrhoea (Iskandar, 1997). Although it is difficult to get the actual level of maternal mortality because of inadequate records, the 2002/3 Demographic and Health Survey estimated the rate as 307 per 100,000 live births for the period 1998-2002 (CBS et al., 2003). According to Iskandar (1997), the cause of maternal death is often due to deprived socio-economic conditions, such as of poverty, low education levels, early marriage, lack of access to health services, and poor nutrition.

Mortality rates vary considerably among regions, with provinces in Java-Bali region having the lowest rates over time (CBS et al., 1998). Notable differences also occur between urban and rural areas for deaths in all ages throughout the regions. The decline in infant mortality is faster in rural areas because of intensive mother and child health programmes, thus narrowing the gap between the two areas (CBS et al., 1998).

The decline in mortality rates that preceded the decline in fertility rates resulted in an increasing proportion of the younger age groups in the Indonesian population. The proportion of population under 15 years old, although declining from 41 percent in 1971 to 30.4 percent in 2000, is still very high (World Bank, 1990; BPS, 2003). At the same time, the proportion of those aged 15-60 years reached 62.1 percent in 2000 (BKKBN, 2004). The young age structure means that there is a built-in momentum for population growth, which is likely to make the Indonesian population continue to increase for another halfcentury (Caldwell, 1997).

As this current young population ages, it will put pressure on education and other delivery system as well as the labour market. Nevertheless, the positive side is that the large group of working-age people will be supporting fewer older and younger dependants, and thus it is expected to increase social investment and spur economic growth. This opportunity is known as the 'demographic bonus' or 'demographic window'. However, the window opens only once and closes as another dependent group, the older people, increases (Merrick, 2002; UNFPA, 2004). Indonesia will experience this demographic bonus within 
10 years, between 2015-2025, provided that a fertility rate of 2.1 is achieved by 2015 (BKKBN, 2004). To be able to take advantage of the demographic bonus, however, appropriate socio-economic policies are needed, especially in improving human resources quality and labour markets for both women and men (Bloom \& Canning, 2001; Merrick, 2002; UNFPA, 2004).

Figure 5.3:

Indonesian Population Pyramid, 2000

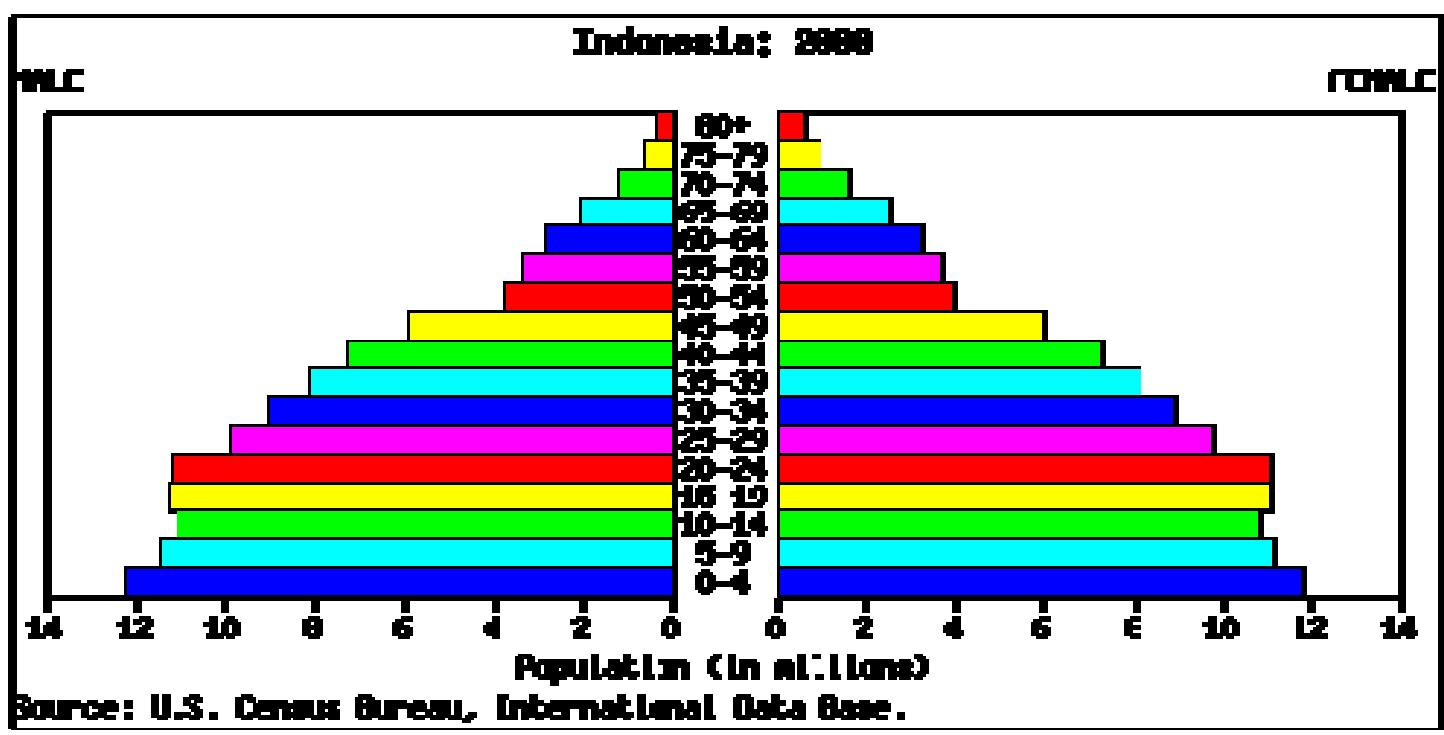

As death rates drop and life expectancy has increased, the percentage of the population aged 65 years and older has increased from 3.77 percent in 1990 to 4.54 percent in 2000 (BPS, 2003). This proportion is still relatively small but is growing rapidly. As in other developing countries, government welfare programmes for the elderly in Indonesia are modest. Therefore, maintaining economic and social security for the elderly has been primarily the responsibility of individuals and their families.

\subsubsection{Population distribution and migration}

In addition to its large size, the Indonesian population has been characterised by an uneven distribution among its islands and provinces. The heavy concentration of 
population on Java has distinguished that island from the other islands over many years. In 1961, 65 percent of the population lived in Java, which covers only 7 percent of the country's land area, but by 2000 this proportion had declined to 59.2 percent. With a population density of 946 persons per square kilometre, far above the national figure of 109, Java has become one of the most densely populated islands in the world. Meanwhile, the population density of other islands ranges from 26 to 88 persons per square kilometre (Nitisastro, 1970; BPS, 2003).

Within Java, the population has been concentrated on the western part of the island due to the rapid growth of Jakarta and West Java. Jakarta is a major focus of migration from all provinces. In the 1980s, West Java's population growth rate was 2.8 percent, far above the national average of 1.98 percent, and more than twice the rate of other Java provinces. This high growth rate has been due to both a higher fertility rate and more in-migration, particularly to the areas surrounding the capital city of Jakarta (Hugo, 1997).

In an effort to reduce the population pressure in Java, the Dutch government started a resettlement programme in the early 1900s. The Indonesian government has continued the programme under its transmigration policy (Hardjono, 1977; Higgins, 1957). During the First Long Term Development Plan, starting in 1969, the overriding objectives of the transmigration programme were to distribute the benefits of development more evenly across the entire population and to maintain national stability. People from the densely inhabited islands of Java, Madura and Bali have been encouraged to move to the empty areas of other islands. However, it has long been recognized that the impacts of transmigration on Java's population have been relatively small and population maldistribution still persists. Therefore, the transmigration programme has concentrated more on regional development rather than demographic redistribution (Hardjono, 1977; Higgins, 1957; Hugo, 1997; Departemen Tenaga Kerja dan Transmigrasi, 2002).

As in other developing countries, urbanization is overtaking the agricultural sector, and its level is continuously increasing. The proportion of the population living in urban areas increased from 22.3 percent in 1980 to 30.9 percent in 1990. By 2000, 42 percent of the 
total population or 86.6 million people were living in urban areas (BPS, 2003). This is higher than that of many developing countries in Asia with an average of 37.2 percent in 2000 (Hugo, 2003). The capital city of Jakarta has become the main destination, and also several cities in West Java that surround Jakarta. Many of these cities' residents work in Jakarta and commute everyday to their workplaces. This contributes to the high population growth rate of West Java, well above the rate of other provinces in Java and the national average (BKKBN and BPS West Java, 2002; Hugo, 1997).

\subsection{Development strategy}

Development plans have addressed some concerns of population growth but initially these were dominated by concerns for economic growth. Shortly after Independence in 1945, the newly established Indonesian government received assistance from the United Nations to develop its national development plan. Higgins' view of development was superseded by a comprehensive five-year development plan formulated for the period of 1956-1961 with the main objective of rebuilding the country's economy. In achieving this objective, the Indonesian government placed a strong emphasis on its own resources rather than on foreign loans and grants (Higgins, 1957). However, after an accelerated capital deterioration and budget deficit in 1958, the government began to seek foreign assistance both from Western and Communist countries (Commission on International Development, 1969). Poor economic and social welfare conditions led to an attempted coup by the communist party in 1965, and this was followed by a shift of power from Soekarno to Soeharto in 1966.

The new government, known as the New Order, formulated its First Long-Term Development Plan in 1969 which constituted a series of five-year development plans called Repelita I (1969/70 to 1974/75) to Repelita V (1989/90 to 1994/95). The ideology behind the development plans should be in accordance with the Constitution of 1945 and the Pancasila (state ideology), both of which are activated under the Broad Outlines of State Policy $(G B H N)$. The State Policy specifies the principles and priorities underlying each five-year development plan. The First Long-Term Development Plan stressed economic 
growth, equity and stability. Rostow's concept of economic 'take-off', as discussed in Chapter 3, has become the driver for economic development since Repelita IV. Repelita V was supposed to prepare the way for this take-off which was to take place in Repelita VI (1994/5 to 1999/2000). President Soeharto stressed that a rapid decline in fertility is a basic precondition for such a take-off to occur (Hugo et al., 1987).

During Repelita I, the priority was the restoration of the economy, mainly by increasing production and income. Increasing food production, particularly rice as the main staple food, and infrastructure rehabilitation were the main foci. Rice production was intensified through the introduction of high yielding varieties, chemical fertilizers and pesticides, and modern farming techniques known as the green revolution (Mears \& Moeljono, 1981). Foreign investment was also encouraged, especially in the manufacturing and mining sectors, which in turn also promoted the construction sector. The new economic policy, supported by the oil boom in the 1970s, was able to bring about changes to the Indonesian economy. However, the fall of oil prices in the mid 1980s slowed down economic growth (Hill, 1992). The following Repelita emphasised employment and distributional equity as well as economic growth (Booth \& McCawley, 1981). Under the New Order government, foreign aid has played a vital role in economic development and institutions such as the World Bank, the International Monetary Fund (IMF), the United Nations Development Programme (UNDP) and the United States Agency for International Development (USAID) were very influential (Hugo et al., 1987).

In line with the concept of modernization, Indonesia's economic structure has gradually shifted from agriculture-based to industry-based. The contribution of the agricultural sector to GDP has decreased from 32.3 percent in 1971 to 19.4 percent in 1990 . On the other hand, the contribution of industrial sector has increased from 38.1 percent in 1971 to 44.4 percent in 1980 and 40.9 percent in 1990. Similarly, the services sector's contribution has also risen from 29.6 percent in 1971 to 32.3 percent in 1980 and 39.5 percent in 1990 (Tjiptoherijanto \& Hasmi, 1998). 
Changes in economic structure have brought about changes in the size and structure of the Indonesian labour force since the 1960s. In the 1980s it had almost doubled and was better educated, less concentrated in agriculture, and more gender balanced (Hugo et al., 1987). Until 1990, the rates of open unemployment in Indonesia were fairly low, around 1.7 percent in 1980 and 3.2 percent in 1990 . These low figures were caused by the fact that the Indonesian labour force was mostly concentrated in the agricultural sector and enumeration is difficult since Indonesia does not have unemployment benefits. Everybody has been forced to work since the government does not provide social security benefits for the unemployed (Ananta et al., 1997; Oey-Gardiner, 1997).

The education and health sectors benefited from the oil revenues during the oil boom era of the 1970s. In 1973, a special programme for primary schooling was implemented with a Presidential Instruction to achieve universal enrolment by Repelita IV (1984-1989). Every village was to have at least one primary school and tuition fees for public primary schools were abolished gradually from 1977 . The impact of this programme was significant, with primary school enrolment increasing from 60 percent in 1974 to 92.7 percent in 2002 (Bappenas, 2004; Oey-Gardiner, 1997). However, continuation rates beyond primary school are still fairly low, 61.7 percent from primary to lower-secondary school in 2002 (Bappenas, 2004)

With a rapidly expanding education system, gender ratios (females/100 males) among students were also increasing. The gender ratio at the primary level rose from 86 percent in the mid 1970s to 100.1 percent in 2002. At lower-secondary level, the ratio rose from 65 percent to 1002.6 percent for the same period, while at the upper-secondary level it increased more sharply, from around 50 percent in the mid 1970s to 97.1 percent in 2002 (Bappenas, 2004; Oey-Gardiner, 1997). Now, both girls and boys have equal access to education opportunities.

Although urban residents have better access to educational opportunities than rural residents, the enrolment trends have been quite similar. However, enrolment ratios for secondary schools are much higher in urban than rural areas due to differences in 
availability and accessibility (Oey-Gardiner, 1997). Another distinction emerging in the 1990s is the pattern of enrolment between the genders. In rural areas boys left school to join the workforce, while in urban areas it was the girls who were attracted to work in the factories mushrooming around the urban centres (Oey-Gardiner, 1997).

Repelita I stressed public health as a priority, with special attention on the control of diarrhoea, respiratory tract infection, and infectious diseases (Hugo et al., 1987). In successive plans, the role of women, nutrition improvement programmes, and rural outreach through community health centres at sub-district level have received special attention. These efforts have been successful in reducing crude death rates and also in increasing life expectancy at birth. The 1971 census indicates that the life expectancy at birth was 48 years for females and 45 years for males (State Ministry of Population/NFPCB, 1999). These figures have increased ever since, in 2002/3 it has reached 69 years for female and 65 years for male (BKKBN, 2004).

Following the fall of the New Order government in 1998, there have been significant changes in Indonesia's economic and political conditions. The current government under President Megawati decided to terminate the International Monetary Fund (IMF) financial assistance at the end of 2003 (Ray, 2003). Another important political issue is the passage of the new policy on decentralisation/ regional autonomy in 1999 which came into force in January 2001 (Rasyid, 2003). All these changes have had a significant impact on the development process in Indonesia, both at central and local levels.

\subsection{Integration of population issues in development planning}

Since the first five-year development plan under the Soekarno government (1956-1960), population growth had become one of the major basic assumptions made when designing a development plan. The government assumed that with a growth rate of 1.7 percent per year, population pressure constituted a serious problem for Indonesian development (Higgins, 1957). However, President Soekarno was opposed to the idea of birth control which was still morally unacceptable. He preferred a population resettlement programme, moving 
people from Java to the other islands. He agreed to the use of birth control methods only for maternal health concerns. Soekarno also believed that Indonesian natural resources were sufficient to feed a large number of people, and so the large population was considered to be a valuable labour resource for the country (Hugo et al., 1987; Hull et al., 1977). The government also believed that economic development would automatically reduce fertility in the long run (Sumbung et al., 1984; Wignyadisastra, 1986)

The shift of power to the New Order government brought a new perspective to the population control policy. Population control became the main focus of the new government's efforts to improve economic and social welfare. After joining the other Heads of State to sign the Declaration of World Leaders on Population in 1967, President Soeharto set up the government family planning programme as the main agenda of the population control policy. This affirmed President Soeharto’s political commitment to the family planning programme and stressed the demographic goal of reduced population growth as part of a broader strategy of economic development (Hugo et al., 1987;

Population Council, 1967; State Ministry for Population/NFPCB, 1995).

During the 1970s, despite an acknowledgement of the importance of population policy in overall development planning, Hugo et al. (1987) note that the responsibility for population formulation was not clearly defined among the agencies involved, i.e. the National Family Planning Coordinating Board, the National Development Planning Board, and the Departments of Manpower, Transmigration and Health. Consequently, population issues in development planning were based on the particular concerns of each agency and were not addressed from a broader perspective. The situation was clarified in 1983 by the appointment of a State Minister for Population and Environment, with a clear mandate to formulate, manage, and co-ordinate population policies in Indonesia. However, there was no consensus among the agencies involved about the role of population growth and distribution within the development process (Hugo et al., 1987).

A series of changes separating the Ministry for Population from the Ministry for Environment has led to the transformation of the State Ministry for Population into the 
National Population Board. The latter body was disbanded only months after it was formed. Currently, population administration is managed by the Ministry of Home Affairs (Hull and Adioetomo, 2001).

Family planning has been included in development plans since the First Five Year Development Plan, with emphasis on the voluntary nature of family planning and the need to consider religious values. During the second stage, it was integrated with other development programmes, especially the health and education sectors. This was followed by a village level implementation strategy which emphasised the role of the PPKBD as the programme implementer at the grass-roots level. Subsequently, with the enactment of Law Number 10/1992 regarding "Population Development and the Development of the Prosperous Family” (Perkembangan Kependudukan dan Pembangunan Keluarga Sejahtera), community participation and self reliance were clearly stated as the main strategy (State Ministry for Population/NFPCB, 1994; 1995). For the period of 2000-2004, the National Development Plan (Propenas) stipulates that the quality of the Indonesian population is to be achieved through fertility control, reducing mortality rates, and improving the quality of the family planning services (Government of Indonesia, 2000).

\subsection{Population and family planning policies}

As has been explained, the New Order government adopted a policy of population control as part of the efforts to promote economic development as a reaction to international pressures. In 1967, President Soeharto began to set up a national family planning programme with the objective of lowering the rates of population growth and fertility. The government was assisted by a team of foreign experts sponsored by the United Nations, the World Bank and the World Health Organisation in developing this programme (Hull, Hull \& Singarimbun, 1977). The team recommended full government involvement at all administrative levels. This recommendation led to the establishment of the National Family Planning Co-ordinating Board (NFPCB) in 1970. This organisation has full governmental responsibility for coordinating all family planning activities, and its Chairman is appointed by and reports directly to the President. As a coordinating body, 
NFPCB is responsible for incorporating population and family planning issues into overall government policies and for coordinating the implementation of family planning programmes by both governmental and non-governmental agencies. At local level, the implementation of the programme is carried out through the heads of the local governments at all administrative levels (State Ministry for Population/ NFPCB, 1995; Sumbung, et al.; 1984; Suyono et al., 1995).

The family planning program has received strong political and financial commitment from the government. The government's high level of involvement and support for the programme has been cited as the key to the programme's success in reducing fertility rates (Freedman et al., 1981; Molyneaux and Gertler, 1999; Warwick, 1986). With widespread information and the provision of a range of modern contraceptive choice, within six years after its creation the programme was able to recruit 24 percent of married women aged 1544 years in Java-Bali to use contraception. Since the majority of these women resided in rural areas with very low income and education levels, it is considered a significant achievement of the programme (Freedman et al., 1981). This is different from Thailand where those with the poorest standard of living had the lowest rates of contraceptive use (Cleland et al., 1979 cited in Freedman et al., 1981, p.23).

The enactment of Public Law No. 10 in 1992, concerning "Population Development and the Development of the Prosperous Family” and the 1994 International Conference on Population and Development (ICPD) Programme of Action have broadened the concept of family planning. Women's reproductive health and empowerment have become one of the major concerns along with strengthening community participation (BKKBN, 2001a).

A new policy regarding decentralisation, Laws 22 and 25 of 1999, stipulate that government programmes, including the family planning programme, are to be devolved to the district level (Rasyid, 2003). These laws were followed by a Presidential Decree in 2001 which stated that government agencies were allowed to maintain their vertical structure only through to the end of December 2003, after which all their responsibilities for programme implementation had to be decentralised to the district government (Hull \& 
Adioetomo, 2001). This policy poses challenges to the district governments to provide funding and to design new systems of service delivery that are able to sustain the level of contraceptive use. The family planning programme in Indonesia will be further discussed in detail in Chapter 6.

\subsection{Discussion}

Observers of Indonesian population and family planning programmes conclude that Indonesia has been able to lower fertility and mortality levels with a lower level of economic development than that experienced by developed countries during their demographic transition (e.g. Ananta \& Pungut, 1992; Caldwell, 1997; Hugo et al., 1987; Jones, 1999; Mason, 2002). This achievement demonstrates the significant role of the government family planning programme in bringing down fertility rates (e.g. Adioetomo, 1993; Hatmadji, 1990; Freedman, 1995; Warwick, 1986). However, Hugo et al. (1987) and Gertler and Molyneaux (1999) argue that it was a combination of socio-economic changes and family planning efforts that allowed Indonesian couples to increase their contraceptive use. The Indonesian case confirms that an accelerated demographic transition is possible with the implementation of effective policies aimed at reducing birth and death rates. Development in communication technology along with the availability of improved birth control procedures has facilitated the adoption of family planning that has lead to fertility decline.

Changes in population structure due to lower fertility and mortality rates are creating both challenges and opportunities for social and economic development. The high proportion of population aged 15-64 years creates pressures on social services like education and health, while at the same time providing opportunities to stimulate economic development. However, appropriate political and economic policies are needed to strengthen and enhance these opportunities. A further concern is the increasing proportion of the elderly over the next 50 years. Although the family support system is still strong, large elderly populations with relatively low levels of income will place enormous pressure 
on families with decreasing family size. The government has to develop economic and social policies to support the aging society.

In the short term, the decentralized family planning programme faces challenges to find alternative sources of funding and effective service delivery systems. The government's commitment to provide high-quality family planning and reproductive health services as required by the ICPD will need a huge increase in financing. The full implementation of decentralisation on family planning programme will be the subject of a further research. 


\section{Chapter 6}

\section{The Indonesian Family Planning Programme}

\subsection{Introduction}

As documented in Chapter 5, the Indonesian family programme has achieved a remarkable success in reducing fertility through increasing contraceptive use. From merely 2.8 percent in 1971, 60.3 percent of married Indonesian women aged 15-49 years were using contraceptives in 2003. The extensive use of contraceptives has led to a sharp decline in the fertility rate, from 5.6 births per woman in 1970 to 2.6 in 2003 (CBS et al., 2003; State Ministry for Population/NFPCB, 1994). These figures reflect the increasing acceptance of the idea of fertility limitation through family planning by the Indonesian population. Fertility decline and the rise in contraceptive use have been attributed largely to the family planning programme run by the government (Freedman et al., 1981; Gertler \& Molyneaux, 1994; Shiffman, 2002; Warwick, 1986). The Indonesian family planning programme’s success story has been recognised internationally; in 1989 President Soeharto was awarded the United Nations Population Award (State Ministry for Population/NFPCB, 1995).

This chapter will describe the main features of the Indonesian family planning programme. The first two sections review the historical background and the philosophical underpinnings to explain the rationale of the establishment of programme. Then, this chapter examines the stages of the programme development which were reflected through changes in its approaches. Starting in urban areas with a clinic-based approach in 1970, the programme has expanded to reach the rural areas through its community-based approach four years later. Despite some limitations, the latter approach has been a major contributor to the programme's success. This chapter also discusses how these approaches work through describing the programme's structure, policies and strategies, and its activities. The Indonesian family planning programme has been characterized by a strong political commitment from the government and a hierarchical administrative structure from the national down to the village level. The changes in programme structure due to the 
government's new policy on decentralisation, however, cannot be reviewed in this thesis as they commenced in 2004.

\subsection{Historical review}

As discussed in Chapter 5, in the 1960s Indonesian development was faced with population and public health problems. As a part of its maternal and child health programme, the Ministry of Health began to introduce birth control in an effort to reduce maternal and infant mortality rates. However, the intention to include birth control as part of this effort did not receive political support from the government (Suyono et al., 1995; Wignyadisastra, 1986)

Given the country's many islands and geographic expanse, Soekarno, the first President of Indonesia, did not perceive the large population size as a problem. He concentrated his population policy on the transmigration programme to redistribute the population of Java and Bali islands to the sparsely populated islands, particularly Sumatra. In addition, the President assumed that a birth control programme might threaten the country's morality, therefore, birth control was allowed only on the basis of maternal health concerns. At that time, the idea of birth control was rejected not only by religious scholars but also by the majority of the population (Hull, Hull \& Singarimbun, 1977).

In spite of opposition from the government, in the 1950s some women's groups and private doctors, motivated by the activities of the International Planned Parenthood Federation, pioneered the provision of contraceptive services to improve maternal and child health. Birth control services were also provided by Jakarta’s General Hospital from 1953. In 1957, the Indonesian Planned Parenthood Association (IPPA) or the Perkumpulan Keluarga Berencana Indonesia was established in Jakarta (Suyono et al., 1995; State Ministry for Population/ NFPCB, 1995). The IPPA has been a pioneer in arousing women's awareness of the importance of birth control and birth spacing. This institution began to use the term 'keluarga berencana' (family planning) which was considered to be more suitable for the Indonesian people than to birth control which was frequently associated with 
abortion (Adioetomo, 1995). The IPPA then collaborated with the Ministry of Health to provide information and contraceptive services through its clinics since government institutions were not allowed to conduct family planning activities at that time. Several IPPA branches in major cities in Java, Sumatra and Bali were established in the mid 1960s. However, IPPA's activities were still limited due to the enactment of a penal code, i.e. articles 283 and 534 of the criminal law code that banned the spreading of family planning notions. In 1967 this organisation finally obtained legal status (Suyono et al., 1995; State Ministry for Population/ NFPCB,1995). Within the same year, the IPPA organized the first national congress on family planning in Jakarta, which recommended the government to organize a national family planning programme (Sumbung et al., 1984; State Ministry for Population/ NFPCB,1995).

The shift of power to the New Order government in 1966, as discussed in Chapter 5, brought a new perspective to the population control policy. Population problems became the main focus of the government's efforts to improve economic and social welfare. In 1967, President Soeharto began to set up a national family planning programme as the central part of the population control policy. However, the President was cautious of opposition from the predominantly Muslim population. He assigned the Minister for People's Welfare who was also the head of Nahdlatul Ulama, the largest Islamic organisation in Indonesia, to assess the potential of developing the IPPA's family planning activities to become a national programme (State Ministry for Population/ NFPCB,1994; Suyono et al, 1995). In 1968, with a Presidential Instruction, the National Family Planning Institute (LKBN) was established with the responsibility designing and implementing a national family planning programme to encourage the acceptance of birth control to reduce family size. The LKBN was able to incorporate family planning into the government's First Five Year Development Plan started in 1969/1970. In the meantime, IPPA continued its activities in providing family planning information and services through its branches, mainly outside Java (Sumbung et al., 1984; State Ministry for Population/NFPCB,1995).

In order to further expand the programme as recommended by foreign experts (see Chapter 5), in 1970 the LKBN was transformed by a Presidential Decree into the National 
Family Planning Co-ordinating Board (NFPCB). This new organisation has full governmental responsibility for coordinating all family planning activities, and its Chairman is appointed by and reports directly to the President. The NFPCB is responsible for incorporating population and family planning issues into overall government policies. As a coordinating body, the NFPCB's role is to coordinate the implementation of family planning programmes into the activities of existing governmental, non-governmental, and community programmes. At local level, the implementation of the programme is carried out by the heads of the local governments (State Ministry for Population/ NFPCB ,1995; Sumbung, et al.; 1984; Suyono et al, 1995). The government's high level of involvement and support for the family planning programme has been cited as the key to the programme’s success (Hayes et al., 2003; Hull and Hull, 1997).

\subsection{Philosophical underpinnings}

The establishment of the NFPCB in 1970 marked the birth of the government family planning programme, known as 'Program Keluarga Berencana'. The philosophical underpinning of the programme has shifted from birth control to population control. At the commencement, the programme's goals were to reduce and control population growth and to lay the foundation for the acceptance of the 'small, happy and prosperous family norm'. The specific objectives were:

1) to reduce the birth rate;

2) to improve maternal and child welfare;

3) to enhance the people's awareness of population problems;

4) to improve the quality of Indonesian human resources as an asset of development (State Ministry for Population/NFPCB, 1995, p.20-21).

The definition of the 'small-family' norm has continuously changed as a response to people's changing attitudes to family size. Initially, since a large family was still considered desirable, the campaign proposed to limit family size to four, then three, and eventually it became a two-child norm (Suyono et al., 1995). 
The foundation of the Indonesian family planning programme was strengthened by the passage of Public Law No. 10/1992 regarding "Population Development and the Development of Prosperous Families” (Perkembangan Kependudukan dan Pembangunan Keluarga Sejahtera). This law defines family planning as "Efforts to increase community awareness and participation in creating 'small, happy and prosperous families' through: delaying marriage; regulating birth; enhancing family resilience; and improving family welfare”. This law reemphasises the objective of the family planning programme, that is to achieve prosperous families. A prosperous family is defined as "A family built through legitimate marriage, capable of fulfilling its own spiritual and material needs, faithful to One Supreme God, with harmonious, balanced, and appropriate relationships among its members, among families, and with the society and the environment.” Community participation is a clear component of this law. This law also specifies a number of statements concerning the nature of the Indonesian family and family decision-making, as well as principles concerning the rights and responsibilities of couples with respect to contraception (Government of Indonesia, 1992).

The above paradigms reflect that family planning was not viewed merely as a contraceptive delivery service, but a comprehensive programme to reduce family size as a means to achieve the ultimate goal of increased family prosperity.

The NFPCB's mandate was broadened by Law 10/1992, not only coordinating population control but also promoting prosperous families. This law also lays the foundation for the 'Prosperous Family Movement', which is aimed at enhancing families' self-reliance in facing the socio-cultural and environmental changes due to development processes (Suyono, 1995).

The 1994 International Conference on Population and Development (ICPD) in Cairo gave new nuances to the Indonesian family planning programme. The ICPD acknowledged reproductive health as one component of the human rights to health. Reproductive health rights imply that "all couples and individuals have the right to decide freely and responsibly the number, spacing, and timing of their children and to have the information and means to do so, and the right to attain the highest standard of sexual and reproductive 
health" (UN, 1994). Equitable gender relations and education were identified as the most important elements in promoting reproductive health rights (UN, 1994). In view of the ICPD Programme of Action, the Indonesian family planning programme was divided into two components: reproductive health and prosperous families. Improvement in quality of care and information became the main agenda of the reproductive health component, while the prosperous families component emphasised empowering the family through various information and education programmes, as well as income generating programmes (State Ministry for Population/ NFPCB,1995; 1996).

From 2000, in light of the 1994 ICPD Programme of Action, the Indonesian family planning programme took on a new vision and mission statement. Since then, the vision has been “Quality Families by 2015”, while the main mission is to empower and motivate the community to build small and high quality families. The 'quality family' is translated as a family which is "prosperous, healthy, advanced, self-reliant, has an ideal family size, future-oriented, responsible, harmonious, and devoted to God Almighty” (BKKBN, 2001a, p.13). This concept of quality family does not specify a particular number of children, rather it promotes the concept of 'ideal family size' through enhancing the understanding of reproductive health concepts, i.e. bearing children during the ages of 20-30 years and maintaining a healthy pattern of birth spacing (BKKBN, 2001a). Women's reproductive health has become one of the major programmes. The main strategies include improving the quality of family planning services along with increasing men's participation in the programme. Community participation and empowerment, including women’s empowerment, are also parts of the strategies (BKKBN, 2001a). With the new vision and mission, the NFPCB has shifted its policy from a 'population control'-based programme to a 'client-centred’ approach (Hayes et al., 2003).

\subsection{The family planning programme approaches}

The family planning programme approach has undergone some changes since its commencement in 1970. Family planning services were initially provided in urban areas through hospitals and clinics, both private and government owned. Over time, the 
programme expanded its services to reach rural people. In 1974, NFPCB began to develop a village-based contraceptive service to make the service more accessible to rural communities. This community-based service is used by the programme as the basis for its community participation approach. Currently, however, it is still in transition towards full community participation as rural communities are partly supported by the communitybased service and partly still dependent on the sub-district health centre.

\subsubsection{Urban and rural approaches}

At the outset of the program, contraceptive services were offered only in urban areas, in both government and private clinics. Potential acceptors were motivated to come to the clinic to get contraceptive services. During this period, contraceptive users were limited to educated urban residents (Suyono, et al., 1976; Teachman \& Rahardjo, 1979).

In 1974 the NFPCB began to develop a village family planning system in Java and Bali. At this time, pills and to a lesser extent condoms, became the most popular contraceptive methods. These methods require ongoing resupply to sustain contraceptive use. Therefore, the NFPCB decided to take the programme out of the clinic into the village in an effort to:

a. simplify contraceptive re-supply in order to prolong contraceptive use with the pill and the condom;

b. avoid the supposed 'plateauing' that has bedevilled other large national family planning programmes;

c. attract younger, lower parity women into the programme.

(Suyono et al., 1976, p.13).

In order to create awareness and support for the programme, the NFPCB also developed information and education programmes to promote the benefits of family planning to community leaders, religious leaders, and the people in both urban and rural areas (State Ministry for Population/NFPCB, 1995; Suyono et al., 1976). 


\subsubsection{The clinic-based approach}

Up to the end of the First Five Year Development Plan (1973/74), as in other countries, the programme adopted a passive clinic-based approach to contraceptive provision. Various methods of contraception were introduced to communities through government and private clinics, particularly those of the IPPA. The Ministry of Health began to provide contraceptive services in its facilities in 1967, followed by other health clinics belonging to the Armed Forces and other government agencies. This approach resulted in slow growth in contraceptive use (State Ministry for Population/NFPCB, 1994; Suyono, et al., 1976; Teachman \& Rahardjo, 1979).

With the aim of raising the number of contraceptive users, the family planning programme extended its coverage to the villages in Java and Bali in 1974. The NFPCB recruited outreach workers to motivate rural couples to seek family planning services at the clinics. By 1974, family planning services were available in around 2,500 clinics across Java and Bali with around 7,000 fieldworkers. The programme also equipped the subdistrict public health clinics with a 'Mobile Family Planning Team' consisting of a medical doctor, a midwife and family planning fieldworkers to provide contraceptive services to remote villages using jeeps or vans (Suyono, et al., 1976; State Ministry for Population/NFPCB, 1994; Teachman and Rahardjo, 1979).

The fieldworkers were semi-volunteers, with pay based on the incentive system depending on the numbers of acceptors they recruited through home visits. If the potential acceptors agreed to use contraceptives, the fieldworkers had to accompany them to the clinics (BKKBN, 2002a; Hull et al., 1977). Each fieldworker was responsible for 3-4 villages and their main targets were the 'high-risk' groups of women, who were those older than 35 years with more than five children; couples whose last child was less than five years old; and women with closely-spaced children (BKKBN, 1972; Hull et al., 1977). The fieldworkers were initially based at the sub-district health centres, but in 1974 the NFPCB decided to base these fieldworkers in the villages they served (Suyono et al., 1995). To 
facilitate the fieldworkers in carrying out their job, they were equipped with some basic knowledge on community development concepts and practices (BKKBN, 2002a).

\subsubsection{The community-based approach}

The community-based approach was developed based on the following basic concepts:

1) To allow for local variation of implementation with the intention of harmonising the programme with the cultural nuances of the area.

2) To move incrementally and focus first on re-supply of contraceptives with an emphasis on making them more accessible for acceptors.

3) To link the village contraceptive re-supply programme to a 'mother clinic' at subdistrict level. Contraceptive supplies were delivered to the village by the fieldworkers. This kept the village family planning programmes within the clinic's reporting system so that activities could be monitored. It also enabled the clinic to exercise control and supervision over the village family planning programme. The clinic also provided information dealing with side effects and maintained supplies of contraceptives (Suyono et al., 1976, p.13)

Based on these concepts, and after a pilot project in West Java in 1974, the provinces in Java and Bali established contraceptive distribution centres at village level. These centres were perceived as the best method for community-based distribution system. A village's centre was under the supervision of the health clinic in the area and the fieldworker who is in charge of that village. In West Java, the centres were established in the home of one of the acceptors, who was usually also an informal village leader, while in Central and East Java the centres were managed by the village office. The task of these centres was to ensure the availability of contraceptives (pills and condoms) to couples. The person who managed the centre was linked to the sub-district health clinic with the assistance of the fieldworker. These centres were then known as the 'Village Contraceptive Distribution Centres' (VCDC) or family planning service posts (Pos KB) (Suyono et al., 1976; Suyono \& Reese, 1978). 
Despite encouraging local variation, the NFPCB issued guidelines to standardize the centre's structure and functions, and introduced the term "Pembantu Pembina KB Desa" (Village Family Planning Management Assistant) or " $P P K B D$ " as a generic name for this centre (State Ministry for Population/NFPCB, 1994, p.48). However, each province can use its own term and in West Java it is called Pos KB. In this thesis the term PPKBD has been used throughout.

In the community-based concept of the programme, the PPKBD and the other community organisations at village level such as the PKK or the Family Welfare Movement ${ }^{3}$ groups serve as 'agents of development'. Gradually, the government's responsibility for providing family planning services was transferred to these organisations. Their involvement was increased from contraceptive re-supply to "more important tasks like motivating non acceptors to join family planning and counselling for new acceptors” (Suyono, 1991, p.7). The new responsibility was seen as an important step because the local organisations were believed to better understand the problems and needs of the people than the fieldworkers. The programme acknowledged that their role is essential towards the improvement of the service delivery.

However, the programme identified some problems in implementing the communitybased approach, among others:

1) The approach seemed to work best in rural areas where homogeneity is greater, where reliance on traditional authority figures is stronger and where community structures and values are able to generate a greater degree of social conformity.

2) Much of the strength of the Indonesian family planning programme stems from using traditional lines of authority to implement the programme.

3) The existing 'paternalistic' approach of the programme had created dependency among the communities, hence the challenge was to increase the community’s ability to identify and solve their own problems (Sumbung et al., 1981).

3 Family Welfare Movement or PKK: a women's movement aimed at promoting family welfare. This movement is managed by wife of the local government's head at all administrative levels. Since 2001, the new policy allows the village $P K K$ chair to be held by an individual other than the village head's wife. 
With a series of changes in its policies and strategies, the programme has been trying to address these problems. The village family planning system was further developed before it was applied to the other provinces in the Third Five Year Development Plan when began in 1979/1980 (State Ministry for Population/ NFPCB,1995).

Derived from this community-based approach, the family planning programme further developed its policies to incorporate 'community participation' as a core strategy in the programme implementation. As stipulated in the Law 10/1992, community participation has become one of the basic policies of the family planning programme. The policies emphasised the importance of enhancing community participation by encouraging a willingness to adopt the small-family norm and to support the implementation of the programme (State Ministry for Population/ NFPCB,1995). At village level, volunteers play the central role in the programme implementation (Hamijoyo, 1992; 1994).

However, Smyth (1991, p.791) warns that it is important not to confuse 'communitybased' distribution of services with ‘community participation'. The focus of a communitybased approach is financial and structural effectiveness, with the aim to increase the acceptability of the programme (Ross et al., 1986 cited in Smyth, 1991, p.791). On the other hand, Smyth maintains that community participation implies that the community participates in the identification and solution of its own problems, and this leads to empowerment, including women's empowerment. She also underlines that in the Indonesian case, the role of the community is limited as 'implementators' while the decision-making process as a vital part of empowerment remains highly centralised (p.791). With its new vision and mission, the Indonesian family planning programme has tried to answer this challenge through stressing community empowerment as its main mission (BKKBN, 2001a).

Through its community-based approach the programme was able to enhance the acceptance of the idea of fertility limitation. This was indicated by the increasing contraceptive prevalence rates, from around 370,000 users or 2.8 percent of reproductive 
age couples in 1971/72 to 2.5 million acceptors or 12.8 percent in 1974/75 (State Ministry for Population/NFPCB, 1994). The first comprehensive survey on contraceptive use was conducted in 1987, known as the National Indonesia Contraceptive Prevalence Survey (NICPS), and was followed by the Indonesian Demographic Health Survey (IDHS) every three years since 1994.

Figure 6.1:

Trends in Contraceptive Use, 1987 - 2002/3

(Percentage of current users among married women age 15-49)

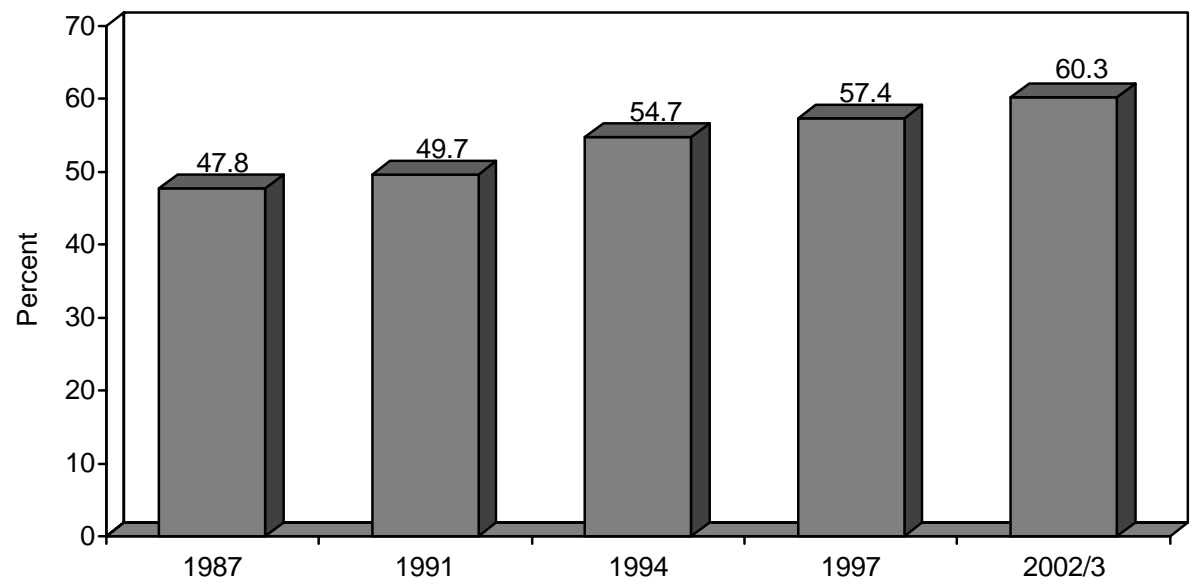

sources: CBS et.al., 1998 \& 2003, based on NICPS (1987) and IDHS (1991-2002/3)

The rate of contraceptive use in rural areas has always been lower than that of the urban areas, except in 1997 where the differences disappeared. Nevertheless, the differences have always been modest (CBS, et al., 1998).

Figure 6.2: 
Trends in Contraceptive Use 1987-2002/3

among Currently Married Women Age 15-49 by Urban-Rural Residence

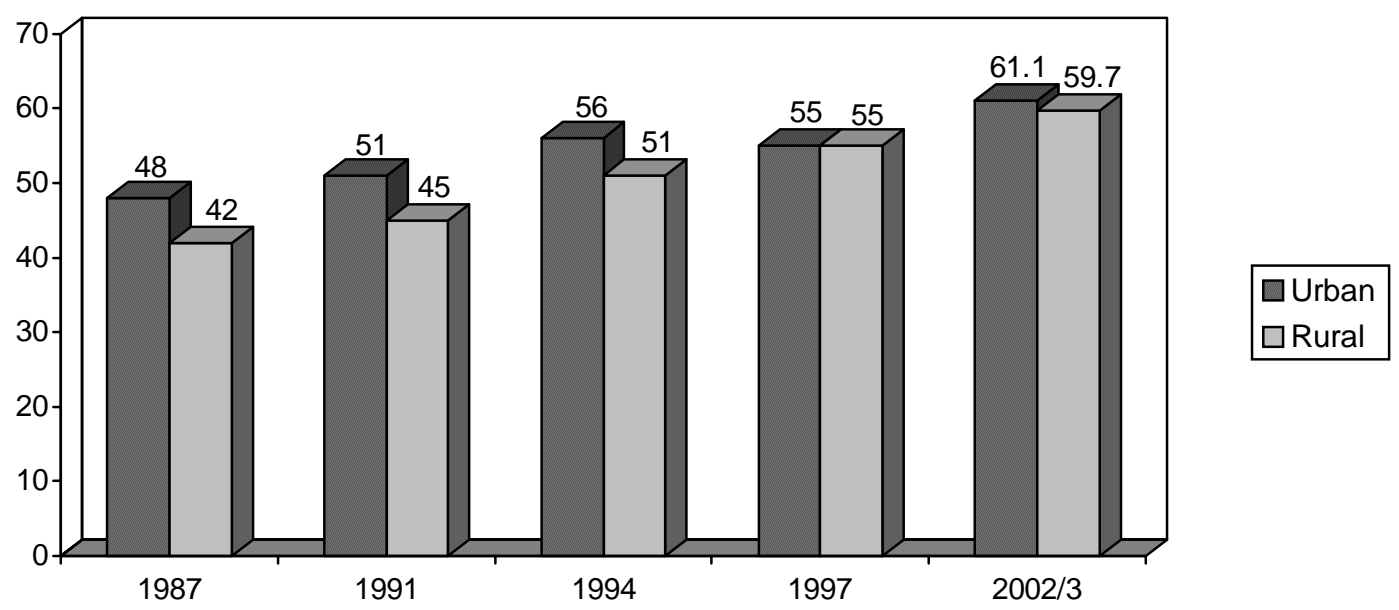

sources: CBS et al., 1998 \& 2003, based on NICPS (1987) and IDHS (1991-2002/3)

\subsection{Policies and structures}

As explained above, the NFPCB's main responsibilities are formulating government policy on family planning and coordinating the implementation of the family planning programme. It coordinates the 'implementing units', which include related government institutions, NGOs and community organisations. At local level, the implementation of the programme is carried out through the heads of the local governments.

\subsubsection{Policies}

From the 1970s, the family planning programme’s policy experienced some essential changes in line with the development of national and international population policy. As an integrated part of national development, the family planning programme has been incorporated with the government's Five Year Development Plan or Repelita since the first plan in 1969. During each Repelita, the family planning programme’s policy has been formulated in accordance with the current Broad Outlines of State Policy (State Ministry for Population/ NFPCB,1995). 
During the First Repelita (1969/70-1973/74), increasing community awareness and collaboration with the Ministry of Health for service provision were the main strategies. At this time, no specific demographic target was set. The family planning services were gradually expanded in line with the availability of funds and resources, started from the heavily populated provinces in Java and Bali islands. An important policy during the Second Repelita was the change in the programme’s approach from clinic-based to community-based as described above. Integration with other development programmes was also initiated during this period (State Ministry for Population/NFPCB ,1995). In the Third and Fourth Repelita, community participation continued to be strengthened. A village level implementation strategy was developed, known as the 'five levels of approaches' (Lima Pola Pembinaan). These approaches emphasised the role of the PPKBD and the family planning groups as the programme implementers at the grass-roots level. A registration system for reproductive age couples, initiated during this period, was carried out by the village volunteers (State Ministry for Population/ NFPCB,1995).

At the Fifth Repelita V, the 'Self-Reliant Family Planning' programme (Keluarga Berencana Mandiri) was launched in 1988 with the aim of promoting self-reliance through limiting the subsidy. Since then, only poor families have received full subsidy for contraceptives. The private sector was encouraged to participate in providing contraceptive services, while better off families share the service costs. Subsequently, with the enactment of Law Number 10/1992 regarding "Population Development and the Development of Prosperous Family”, community participation and self-reliance were clearly stated as the main strategy (State Ministry for Population/NFPCB, 1994; 1995).

At the end of the 1990s, a financial crisis followed by the downfall of President Soeharto and his New Order government brought about major political and social changes to the country. The urge for democratisation and decentralisation became strong. These changes resulted in political uncertainty and diminished funding for government programmes. These changes had an effect on the family planning programme and forced the NFPCB to continuously adjust its policies (BKKBN, 2001a; 2003a). 
For the period of 2000-2004, the national development plan (Propenas, a new form of Repelita) stipulates that the quality of the Indonesian population will be achieved through fertility control, reducing the mortality rates, and improving the quality of the family planning services. Accordingly, the NFPCB set a target for reducing the total fertility rate from 2.78 to 2.4 per woman by the end of 2005. The NFPCB's new policy also includes increasing men’s participation in family planning, developing adolescent reproductive health programmes, and enhancing the role of community institutions in the family planning service. The importance of community participation and self-reliance are further emphasised in achieving the programme’s goals (BKKBN, 2001a; Government of Indonesia, 2000).

In 1999, an important national policy was initiated that led to the decentralisation of government programmes including the family planning programme. Since the new policy, under Law No. 22 of 1999, focusing the regional autonomy on the district rather than provincial government, all government programmes had to be devolved to the district government (Rasyid, 2003). This law was followed by a Presidential Decree No. 103/2001 that lay down the status of non-departmental government institutions, including the NFPCB. Under the decree, these institutions were allowed to maintain their vertical structure until the end of December 2003, after which time all its responsibilities for programme implementation had to be handed over to the local government. In response to the decree, the NFPCB had carried out advocacy to local governments on the importance of the family planning programme and its link to development (BKKBN, 2003a; Hull and Adioetomo, 2001). In line with this decentralisation policy, Law No. 10/1992 is in the process of being amended to comprise regulations for the implementation of population and family planning programmes at all local levels (BKKBN, 2003a).

\subsubsection{Programme structure}

The family planning programme has been hierarchically organized, from the national down to the village level. Its structure grew rapidly in size to accommodate the growing 
activities. By 1980s, the NFPCB had branches in each of the country's 27 provinces and in most of the districts and sub districts (State Ministry for Population/NFPCB, 1995).

With the upcoming devolution of the family planning programme to district governments, there will be a significant change in the programme's structure and implementation. Relationships and working mechanisms between central, provincial and district levels are still being devised (BKKBN, 2003a). Now, each district has the authority to design the programme structure at grass-roots level. This new policy is expected to strengthen the community participation process and increase the involvement of local communities in decision-making process.

In this section, I will focus on the programme structure at grass-roots level prior to the enactment of the Law No. 22/1999, which is expected to be maintained by the local government (BKKBN, 1999a: 2003a). The network of implementers at village level has been credited as one of the keys to the success of the Indonesian family planning programme in increasing contraceptive use (Molyneaux \& Gertler, 1999; Shiffman, 2002). They are responsible not only for implementing the programme, but also for securing local political commitment and support for the programme (BKKBN, 1999a).

Figure 6.3:

The Family Planning Programme Structure (prior to Law No. 22/1999 regarding Local Government ) 


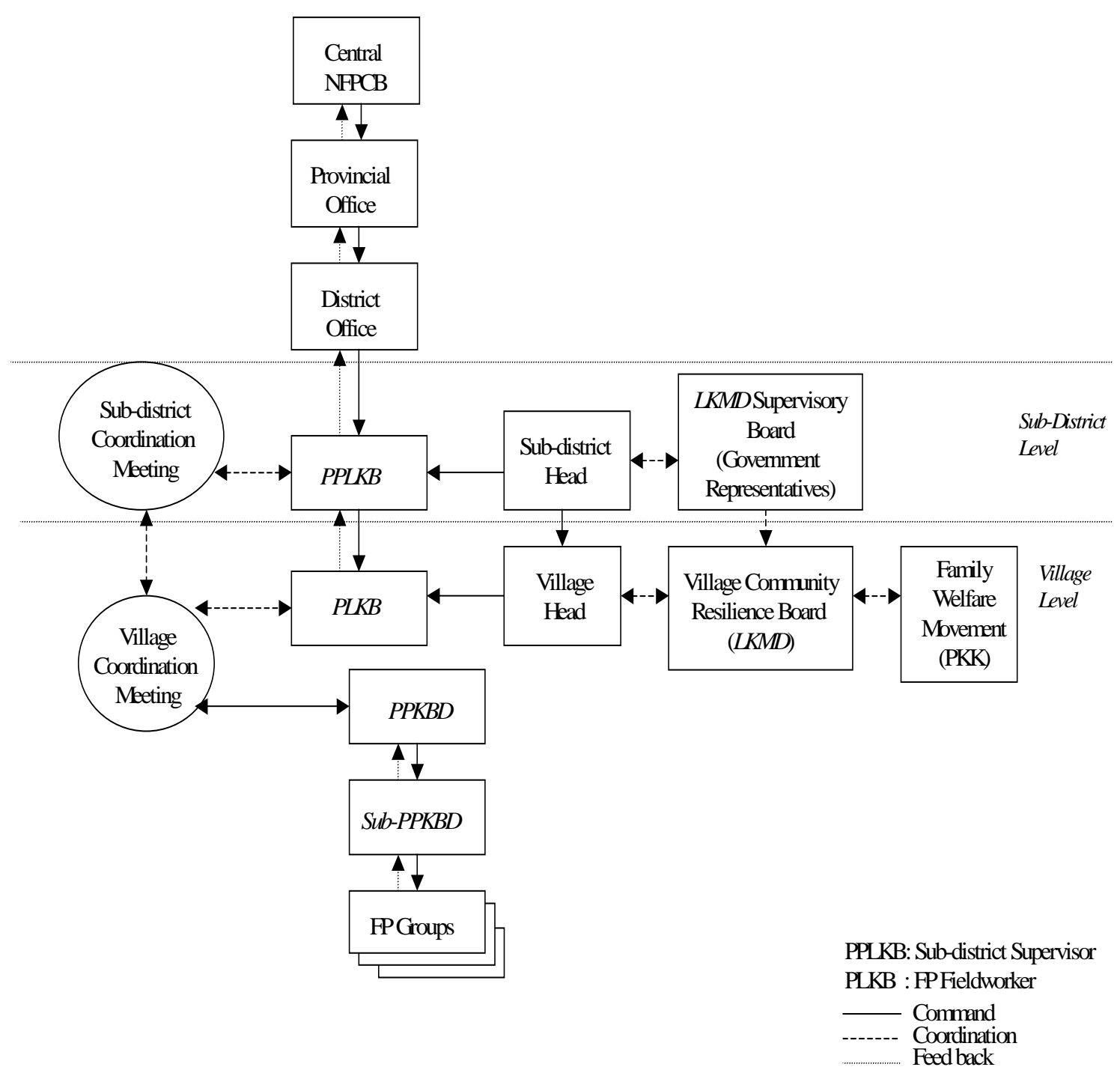

Source: Adapted from BKKBN, 1999a.

\subsubsection{Village level}

Since the family planning programme is a part of the village development programmes, it is implemented within the village administrative system. Therefore, the operational 
mechanism acknowledges the Village Head as the person in charge of the family planning programme at village level and the programme implementation is under the coordination of the Village Community Resilience Board. The task of this board is to assist the village executive government in planning and implementing development programmes and to encourage community participation in the programmes. This board has 10 sections which represent all development sectors including health and family planning (Departemen Dalam Negeri, 2001a).

The village midwife, PPKBD, and the other volunteers (kader ${ }^{4}$ ) carry out the day-today activities and report to the village headman. The volunteers are usually members of the Family Welfare Movement. This system of volunteer workers is a complex system, as they are also involved in some other government programmes, where each programme has its own implementing policies. Other community organisations, such as religious and youth organisations, are also being involved, mainly in sharing information, education and communication activities (BKKBN, 1999a).

\subsection{PPKBD}

As discussed above, PPKBD was established in the mid 1970s as the programme changed its approach from a clinic-based to a community-based delivery system. At that time, its function was merely to distribute pills and condoms to rural people and it is referred to as the Village Contraceptive Distribution Centre. Over time, its function has broadened to become a community organisation with a task of implementing the family planning programme at village level. In the guideline published by the national office, it is stated that “... at village level, the fieldworkers need the community participation to help them implementing the programme, hence it is necessary to establish a community institution...” (BKKBN, 1999b, p.5). Based on this point of view, the PPKBD is defined as “One or several kaders, in a particular organisation, who voluntarily take active participation in implementing/ managing the national family planning programme at village

\footnotetext{
${ }^{4}$ Volunteers working for government programmes at the village are usually known as 'cadres' or kader in Indonesian term.
} 
level” (p.2). This concept is in agreement with Oakley and Marsden's (1984) contention that community organisations established by a government programme like the PPKBD mainly function as a mediator between rural people and the government programme (see Chapter 4).

Since villages in Indonesia usually cover a large area, similar organisations were established at hamlet and neighbourhood levels, known as 'sub-PPKBD' and 'family planning groups' respectively (see Figure 6.3). By 2001, there were 80,563 PPKBDs, 363,280 sub-PPKBDs and 787,145 family planning groups enumerated across the country, mostly classified as 'intermediate' (BKKBN, 2002b).

Previously, the role of PPKBD was limited to the implementation of the programme but since 2001, as part of the decentralisation policy, it has been given a greater role and the responsibility of being the 'manager' (pengelola) of the family planning programme at village level. This organisation is expected to be able to “...serve as a channel to accommodate the aspirations of the community and to manage the family planning programme in the village” (BKKBN, 2001b, p.12). Hence, the function of this organisation has evolved from merely being a contraceptive distributor and an extension of the fieldworkers to becoming the manager of the programme at village level.

In order to fulfil its functions, there are six roles that should be performed by a PPKBD which include:

1) Developing a clear organisational structure, preferably a collective one.

2) Holding regular meetings with the other volunteers, family planning fieldworker, and other related community organisations to discuss and monitor the implementation of the programmes.

3) Conducting information, education, and communication activities as well as counselling to improve the knowledge of the villagers on basic family planning concepts, and to motivate them to use family planning methods. 
4) Conducting routine recording of the programmes' implementation and assisting the fieldworker in the annual family enumeration. These data are for the benefit of the local community as well as the higher hierarchical level.

5) Carrying out family planning programmes and activities

6) Exploring resources to support their activities and to improve their performances (BKKBN, 1999b).

The performance of a PPKBD is assessed on these six roles. An annual assessment of the PPKBDs is conducted by the fieldworkers to a provide database for supervising and developing these organisations. Those who have carried out all the six roles to the fullest degree are classed as 'advanced' (Mandiri), while those who perform the roles with a lower degree are classified as 'intermediate' (Berkembang) and 'basic' (Dasar) for the lowest (BKKBN, 1999b).

These six roles, however, have not been adjusted to include the PPKBD's new role as a 'manager'. These roles emphasise the function of an implementer rather than a manager, therefore they do not necessarily lead the PPKBD to the function as expected by the programme. The new guidelines issued in 2001 (BKKBN, 2001b) still emphasises the implementation of these six roles.

\subsection{Family planning fieldworkers}

The family planning fieldworkers, the paid officials appointed by the district family planning office, form the lowest level of the NFPCB's organisational hierarchy. They report to the family planning fieldworker supervisors at sub-district level (see Figure 6.3). On average, each fieldworker is responsible for 2 or 3 villages (BKKBN, 2002a). In the beginning, the fieldworkers were the main implementer at the grass-roots level, carrying out home visits to motivate the couples to use contraceptives. At that time, they were paid on an incentive basis, depending on the numbers of acceptors they recruited. With the establishment of the PPKBD in the mid 1970s, the fieldworkers handed over some of their tasks to the volunteers, particularly motivation and contraceptives distribution (pills and 
condoms). The fieldworkers' status was then raised to become 'managers' of the programme. In the 1980s, the fieldworkers became government employees.

In line with the programme's new vision and mission formulated in 2000, where community participation was emphasised as the main strategy, the fieldworkers' status became higher and they were expected to act as the programme 'leaders'. The task as 'manager' was relinquished to the PPKBD (BKKBN, 2002a). As leaders, the fieldworkers' main task is to mobilize community participation with the spirit of 'partnership'. To support their new role, the fieldworkers are encouraged to continue to hold monthly coordination meetings as part of the working mechanism at the village level. At these meetings, they can enhance the coordination with the village officials and other government programmes and monitor the family planning programme implementation.

\subsubsection{Sub-district level}

At sub-district level, the paid family planning supervisors manage the activities of the family planning programme, and report to the head of the sub-district . They also supervise the village family planning implementers. For technical matters, they come under the supervision of the district family planning office, while in day-to-day activities, they work closely with the Ministry of Health's clinics/health centres. As at the village level, they coordinate monthly meetings to assess the progress of activities from the planning stage to monitoring and evaluation, working in close association with government institutions and NGOs at this level (BKKBN, 1999a).

\subsection{Planning and decision-making process}

As discussed in Chapter 4, community participation should lead to empowerment which entails the involvement of the community in planning and decision-making processes. In this section, I will review the planning and decision-making approach employed by the Indonesian family planning programme. 
The programme employs a planning system which combines three approaches, i.e. topdown, bottom-up, and horizontal (BKKBN, 2003b; Hamijoyo \& Chauls, 1993b). Based on these approaches, policies and guidelines are established by the national office at central level, and then are translated into detailed objectives, targets, activities, and budgetary guidelines for the lower levels. This extends from provincial to village level. Within the framework of these guidelines, the villages submit proposals to the sub-district, district, and so forth. In addition, the family planning plans at all levels are synchronized with other programmes, particularly health, through coordination meetings.

The following section will discuss the planning system prior to the implementation of the decentralisation policy in January 2004. Since that time, the role of the central level is limited to setting the general guidelines and standards for programme implementation (BKKBN, 2003b).

\subsubsection{Village level}

This level includes villages, hamlets and neighbourhoods to account for smaller groupings of residences to allow greater participation by communities. At village level, the planning focuses on short-term operational planning. This consists of annual, monthly and weekly planning sessions which combine the three approaches mentioned above (Hamijoyo \& Chauls, 1993b).

Annually, upon finishing the family enumeration, family planning groups at neighbourhood level are expected to identify the problems related to family planning and family welfare in their areas and to propose a work plan. Plans from this level are then brought to the hamlet and village meetings. At village level, the PPKBD, assisted by the family planning fieldworker, is supposed to draw up a work plan for the whole village. This plan is discussed at a village coordination meeting chaired by the village headman (see Figure 6.3). This meeting is also used by the fieldworker to ensure that the village plan is in accord with guidelines and targets received from the sub-district (BKKBN, 2002a; Hamijoyo \& Chauls, 1993b). 
Village plans will be combined by the fieldworker to be proposed to the sub-district level. In the following year fieldworkers will receive 'operational guidelines' from the sub-district, containing the activities that should be carried out, targets, and budget allocations for each village. These guidelines are brought back to the village coordination meeting to get the village officials' and community leaders' endorsement and support (BKKBN, 1999a).

Although the planning system involves community organisations in the planning process, within this system planning is still controlled by the programme. Based on White's (2000) typology of participation (see Chapter 4), this approach can be categorised as 'representative participation'. In this case, the function of participation is to allow the local community a voice in the programme and to ensure sustainability of the programme. However, their influence is generally still restricted to the implementation of the programme.

\subsubsection{Sub-district level}

For each sub-district, the family planning supervisor draws together all proposals from the villages and presents them to the sub-district coordination meeting, chaired by the subdistrict head. The sub-district plan is then proposed to the district office. The same processes occur upward, from the district to provincial office. Then, the reverse process takes place, the higher levels distribute the 'approved' plans, guidelines, targets and budget allocations to the lower levels. The targets might be similar to the proposals or modified in line with the targets of the higher levels. Upon receiving the guidelines, the sub-districts elaborate them for all the villages in their respective areas, which contain the activities that should be carried out, the budget allocated to each activity, and the targets to be achieved. Sub-districts can develop their own implementation strategies within the programme framework outlined by the provincial and district offices (BKKBN, 1988; 1999c).

\subsubsection{National, provincial and district levels}


At the national level, the planning process starts with the National Annual Workshop where policies, programmes and targets (qualitative and quantitative) are formulated. Similar workshops are held at provincial and district levels to elaborate the policies and targets from the national level and to set their own targets. Policies and targets derived from these workshops will become the basis for assessing proposals from the lower administrative levels (BKKBN, 2003b; Hamijoyo \& Chauls, 1993b).

From Repelita V, the NFPCB has substituted the target system with 'demand fulfilment', where quantitative targets are determined in response to the community needs (State Ministry for Population/NFPCB, 1999). However, critics point out that estimates of demand are still decided by the programme rather than by the community (Hull \& Hull, 1997). Critics also maintain that although the programme promotes bottom-up planning, the planning system places more emphasis on the top-down approach, since proposals from the lower levels have to match the targets outlined by the national level. Variations and innovations from villages and sub-districts are limited to the implementation strategies for achieving the target (Hull \& Hull, 1997; Shiffman, 2002; Smyth, 1991).

Apparently, the government's policy of controlling population growth as part of the national development plan, as stipulated in Propenas (see Chapter 5 \& Section 6.5.1), drives the NFPCB to maintain its three planning approaches as described above to ensure the achievement of the demographic goals. This is also to meet international donor agencies' requirement of achievements that can be quantifiably evaluated. It is the donors' concern that the utilisation of their funds can be controlled and their interests and goals are being met.

\subsection{Programmes and strategies}

\subsubsection{Programmes and activities}


The 1999 Broad Outlines of State Policy stipulated that 'social welfare' would be achieved by improving the quality of the Indonesian population through fertility control, reducing the mortality rates, and improving the quality of the family planning services. Therefore, in the National Development Plan for 2000-2004, the family planning programme is regarded as a part of the human resources development efforts through improving the quality of the families. The plan proposes several programmes, i.e.:

1) Family planning and reproductive health

2) Adolescent reproductive health

3) Family empowerment

4) Strengthening the family planning institutions and network (Government of Indonesia, 2001)

The NFPCB responded by formulating their programmes at national level to include important issues such as reproductive rights as part of human rights, women's empowerment, gender equity and equality (including increasing men’s participation in family planning), and increasing the accessibility of the poor families to the services offered. Another priority was the preparation process of delegating the authority to implement family planning programmes at the district level by the end of 2003. The NFPCB saw it as a critical point for the sustainability of the programme that some local governments might have different perspectives on the importance of the family planning programme.

\subsubsection{Family planning and reproductive health}

As has been mentioned above, the Indonesian family planning programme has adopted the comprehensive reproductive health approach recommended by the 1994 ICPD.

However, the programme has adapted it to local circumstances and put it in the context of family as part of the objective to increase family prosperity.

The components of these programmes combine conventional family planning and safe motherhood services with Cairo nuances such as promoting reproductive health and rights 
aimed at preventing unwanted pregnancies and reducing maternal morbidity and mortality. Women’s empowerment and increasing men's participation in family planning have been incorporated into the programme's objectives. Increasing the accessibility of poor families through contraceptive subsidies and improving distribution networks have also become major concerns (BKKBN, 2001a; 2003a). . For contraceptive delivery, the programme maintains the 'cafeteria' system which offers an array of contraceptive methods from which the user can choose (Rusmoro et al., 1997).

Efforts for women's empowerment are focused on:

1) Providing information on basic knowledge of family planning and reproductive health concepts, such as types of contraceptives and the possible side effects of each method, service facilities, the best age for childbearing and the healthy interval.

2) Counselling to enable women to make informed choices on contraception and to make decisions regarding childbearing.

3) Increasing service quality and expanding the women's access to a variety of contraceptive methods and back-up medical services for contraceptive side effects (BKKBN, 2001a; 2003a).

Special attention is given to increasing men's participation in family planning which has been very low. In fact, the programme's report showed that there was a decreasing trend of male contraceptive use from 1.93 percent in 2001 to 1.63 percent in 2002 (BKKBN, 2003a). The programme intended to increase their participation to 8 percent by the end of 2004, through activities such as:

a. Tailoring information and counselling specifically to men's needs

b. Providing support from professional medical associations and NGOs

c. Providing services which meet the standard of quality (BKKBN, 2003a).

The programme has also included HIV/AIDS prevention activities through strengthening family resilience, emphasising marital fidelity, premarital abstinence, and family-life education of youth through parents (BKKBN, 2003a). 


\subsubsection{Adolescent reproductive health}

Although the programme has been offered in collaboration with NGOs since the 1980s, adolescent reproductive health formally became a national programme in 2000. Until then, the family planning programme focused its services only on married couples. This program is crucial as research by the Ministry of Health in 1977 showed that teenagers in some urban areas have been engaged in premarital sex from the ages of 12 to 15 years, and 42 percent of teenagers in Jakarta have been sexually active (BKKBN, 2003). Another survey revealed that adolescents generally have inadequate knowledge of reproductive health, including sexually transmitted diseases and HIV/AIDS (Achmad \& Westley, 1999). This survey also suggests that the role of family should not be overlooked as young people in Indonesia usually live with their parents.

The programme for adolescent reproductive health stresses family life education, which is focused on delaying the age of marriage and first birth, and premarital abstinence. The main activities are information sharing and counselling through establishing counselling centres and hotline services. In addition, as part of family resilience promotion, the programme integrates information on adolescent reproductive health with other family planning information for parents (BKKBN, 2003a).

\subsubsection{Family empowerment programmes}

These programme components consist of 'beyond family planning' programmes aimed at enhancing the acceptance of the small-family norm through increasing family welfare, i.e. economic and social well being. Therefore, these programmes were previously grouped as 'integrated programmes'. Later, these programmes became known as the 'prosperous families movement', and then as the 'family empowerment programmes' with the objective of enhancing families’ resilience and prosperity. Currently, the main components of the family empowerment programmes comprise income-generating activities and the improvement of the families’ knowledge and skills in early childhood, youth and elderly care (State Ministry for Population/NFPCB, 1994; 1995; BKKBN, 2003a). 
Since it was first developed in the 1980s, the target population of the income-generating programme has been women. At first, this project gave priority to contraceptive users to attract potential acceptors and to maintain current users. The programme provided revolving credit schemes through the family planning groups. Since 1994, in accordance with the objective of the 'prosperous families movement', the target of this programme has been extended to include women from poor families or families classified as 'preprosperous' and 'prosperous level I'. Taking into account the characteristics of the credit recipients, who mostly have no business experience, the programme is aimed to develop only small-scale businesses, mainly as home industries (State Ministry for Population/NFPCB, 1994; 1995). A collaboration with other Ministries, such as Agriculture and Trade and Industry has been developed to provide technical assistance and training programmes for the women (BKKBN, 2000).

Criticisms of this programme contend that it falls under the 'women in development' (WID) approach. In addition, since the credit schemes were low interest and collateral free, it can be classified under the 'social welfare' approach which will create dependency (Smyth, 1991). The family planning programme has tried to answer these criticisms by developing Kukesra in 1996, a programme where the credit recipients are gradually introduced to the regular credit schemes provided by commercial banks (BKKBN, 2000). However, this programme still faces challenges in assisting the credit recipients in developing their business, particularly in marketing and managing the credit. As both the fieldworkers' and the PPKBDs' capability to manage economic-productive activities is generally limited, this affects the programme’s success.

The other activity of the family empowerment programmes is information and education about best the practices in early childhood, youth and elderly care. As with the incomegenerating projects, these activities are supposed to be managed by the PPKBDs and the other volunteers. Their tasks include organizing group meetings in which the information sharing are carried out. Trained volunteers can oversee the information sharing by themselves or invite government fieldworkers or other knowledgeable individuals to give a 
lecture to group members (BKKBN, 1996; 1999b). Although the PPKBD and some volunteers had received some training, many of them could not carry out the activities without the fieldworker's assistance. It seemed that the subject or topic of this programme is too difficult for them to understand with a short period of training (BKKBN \& FKM-UI, 1999).

\subsubsection{Advocacy, information, education and communication}

The information, education and communication activities have been one of the keys to the success of the family planning programme in introducing and institutionalising the concept of the small family (Warwick, 1986). In accordance with the programme's goal, these activities are mainly aimed at promoting the idea of the small family as a means to achieve a ‘happy and prosperous family’ (State Ministry for Population/NFPCB, 1994).

The strategy for the information, education and communication activities includes integrating family planning messages with other programmes such as health, education, environment, labour, and religious programmes; using specific messages, media, and channels for particular audiences; employing a different approach for each segment of the target population, taking into account differences across regions, including religion and ethnicity (Hamijoyo et al., 1995; State Ministry for Population/NFPCB, 1994).

The programme has been utilizing a variety of media for publicizing information on the basic concepts of family planning, including TV and radio spots and drama. This mass media campaign was strongly supported by the government and the private sector. For example, in 1974 and 1979 the government had released a Rp. 5,- coin with the family planning logo, i.e. a family with two children. The logo has also been printed on a department store shopping bag (State Ministry for Population/NFPCB, 1994; 1995). The aim of this campaign was to increase the people's awareness of the benefits of small family size. Once people accepted the concept of small family, they were expected to seek family planning services as a means to achieve it. The programme has also secured 
religious and community leaders' support in disseminating the information (Hamijoyo et al., 1995; State Ministry for Population/NFPCB, 1994).

To promote the 'small, happy, and prosperous family' norm, the programme's guidelines emphasise the use of specific messages, media, and channels for specific target populations. At grass-root level, the target populations are classified as: 1) the intermediate target, i.e. community/opinion leaders (such as religious leaders and teachers) to be knowledgeable and support the programme; and 2) the ultimate target, i.e. couples and adolescents to accept the family planning concept (Hamijoyo et.al., 1995). At this level, the communication strategy is focused on the person-to-person and group forms of communication.

In order to provide detailed information on the family planning services, the fieldworkers have been provided with audio-visual equipment and supporting materials. The volunteers are also equipped with manuals and supporting materials (Hamijoyo et al., 1995; State Ministry for Population/NFPCB, 1994). However, considering the low education levels of most of the volunteers, continuous training and support to improve their knowledge is needed.

The changing political and social environment after the 1997 financial crisis and the downfall of President Soeharto in 1998 has led the NFPCB to carry out a strong advocacy programme to convince policy makers at national level of the importance of the family planning programme to the overall development efforts. Currently, during the transition to regional autonomy, the advocacy programme is focused on convincing the district governments to continue the family planning programme and preserve its institutions and networks (BKKBN, 2003a).

\subsubsection{Strengthening the family planning institutions and networks}


The NFPCB is renowned for its extensive network of fieldworkers and volunteers which reaches out to the grass-roots level. This network has been credited for the programme's success in increasing contraceptive use (Molyneaux and Gertler, 1999; Shiffman, 2002).

As indicated earlier, the volunteers form the community organisations, i.e. PPKBD at the village level, sub-PPKBD at hamlet level, and family planning groups at neighbourhood level (see Section 6.5.2.1.1). Currently there are around 31,700 fieldworkers and one million community institutions enumerated across the country (State Ministry for Population/NFPCB, 1994; BKKBN, 2002b). These village implementers are the 'spearhead' of the programme implementation. They have also developed a network with fieldworkers from other programmes such as education, co-operative, industry, and agriculture (State Ministry for Population/NFPCB, 1994).

During the decentralisation process, one of the NFPCB's concerns is to convince local governments to maintain this network of village implementers. They are regarded as a valuable asset as they have been trained and are experienced in the family planning programme including its integrated programmes (BKKBN, 2003a). However, this will depend on the local governments' ability to provide the required budget.

\subsubsection{Data and information on population and families}

The Indonesian family planning programme has developed a uniform recording and reporting system for the entire programme's implementing units since 1971 . All clinics offering contraceptive services, both government and non-government owned, used this system to enable programme managers at all levels to monitor and evaluate programme achievement. In keeping with the programme’s development, the recording and reporting system has undergone several revisions to cover all of the programme's activities (BKKBN, 2002c). This section focuses on recording and data collection that volunteers and fieldworkers are expected to carry out in the village, which consists of the activities record and family enumeration. 


\subsection{The activities record}

Each month, programme implementers at grass-roots level are required to record their regular activities. The hamlet volunteers have to have a record of the names of every reproductive age couple in their area (husband's and wife's names), the wife's age, whether or not they are using family planning methods, and the type of contraceptive methods used. This information is reported to the PPKBD during their monthly meetings. The PPKBD then make their own records that include information on contraceptive use, family empowerment programmes and activities such as meetings and information sharing. Currently, PPKBD are not required to make a written report to the fieldworkers, rather the information is shared and discussed during their regular meetings. Through this recording and reporting system, data and information from each village passes upward from the fieldworkers to their supervisors at sub-district level and to the district, provincial and national offices. These offices feedback the reports to the lower levels during the following month (BKKBN, 2001c; 2002c).

\subsection{Family enumeration}

An annual enumeration to record all reproductive age couples and contraceptive users has been conducted since 1985. Initially, this record was developed to assist programme implementers at grass-roots level in assessing their achievement, identifying the potential acceptors, and deciding the target for the following year. Nevertheless, the information is sent to the district, provincial and national offices and serves as a database for formulating policies and targets (BKKBN, 2002c).

The enumeration is conducted at the lowest level of the programme's structure, that is at the neighbourhood level by the family planning groups (see Figure 6.3), other volunteers and community leaders through home visits. Family planning fieldworkers supervise and assist with the data collection. 
Since the enactment of Law No. 10/1992, the record has included social and economic information aiming at providing a database on family welfare for achieving the goal of prosperous family. The enumeration has become known as the 'family enumeration', and also contains demographic data. Currently, the family enumeration is the only system which collects data at the 'micro level' and has also been used by other related institutions (BKKBN, 2002c). Data collected in the family enumeration include:

1) Demographic data: number of households, households heads' sex, marital status, and education level, wife's occupation, number of women of reproductive age (15-49 years old), and number of household members by sex and age (<5, 5-6, 7-15, 16-21, $>60$ years old);

2) Family planning data: number of couples of reproductive age, number of couples using and not using contraception, type of contraceptives used, sources of contraceptives (from government or private service points).

3) Data on family welfare to identify the 'prosperity level' of the family based on basic, social, psychological and developmental needs variables, i.e.: religious practices, ability to purchase foods, clothes and housing, health and family planning practices, education, employment, savings, access to mass media, access to public transport, and interaction within and outside the family. Based on these variables, the families are classified as pre-prosperous, prosperous levels I, II, III with III plus as the highest (see Appendix 3 for the indicators of each level).

4) Individual data: citizen registration number, name, sex, address, date of birth, educational attainment, occupation, and marital status (BKKBN, 2002c).

The above classification of 'prosperity levels', which is based on a range of social and economic variables, is different from common indicators for family welfare which stress only economic aspects measured by income or expenditure.

Based on the enumeration results, the volunteers are supposed to draw a 'family map' at neighbourhood or hamlet level, which gives a picture of contraceptive use and the prosperity level of each family in the area. Specific symbols and colours are used to represent the contraceptive method used and the prosperity level of each family (see Figure 
6.4). The circle symbolises the prosperity level while the rectangle indicates the type of contraceptive method. This map serves as a basis for the volunteers' and fieldworker's work plan (BKKBN, 2002c).

The enumeration process requires the volunteers to visit all the families in their areas, not only the reproductive age couples. The breadth of the information collected also necessitates a certain level of understanding of the matters and skills in collecting such information. A study conducted in Central and East Java revealed that the results of enumeration carried out by the volunteers differ from that of the researchers because of differences in understanding of the indicators (Faturochman et al., 1998).

Figure 6.4:

An example of a family map 


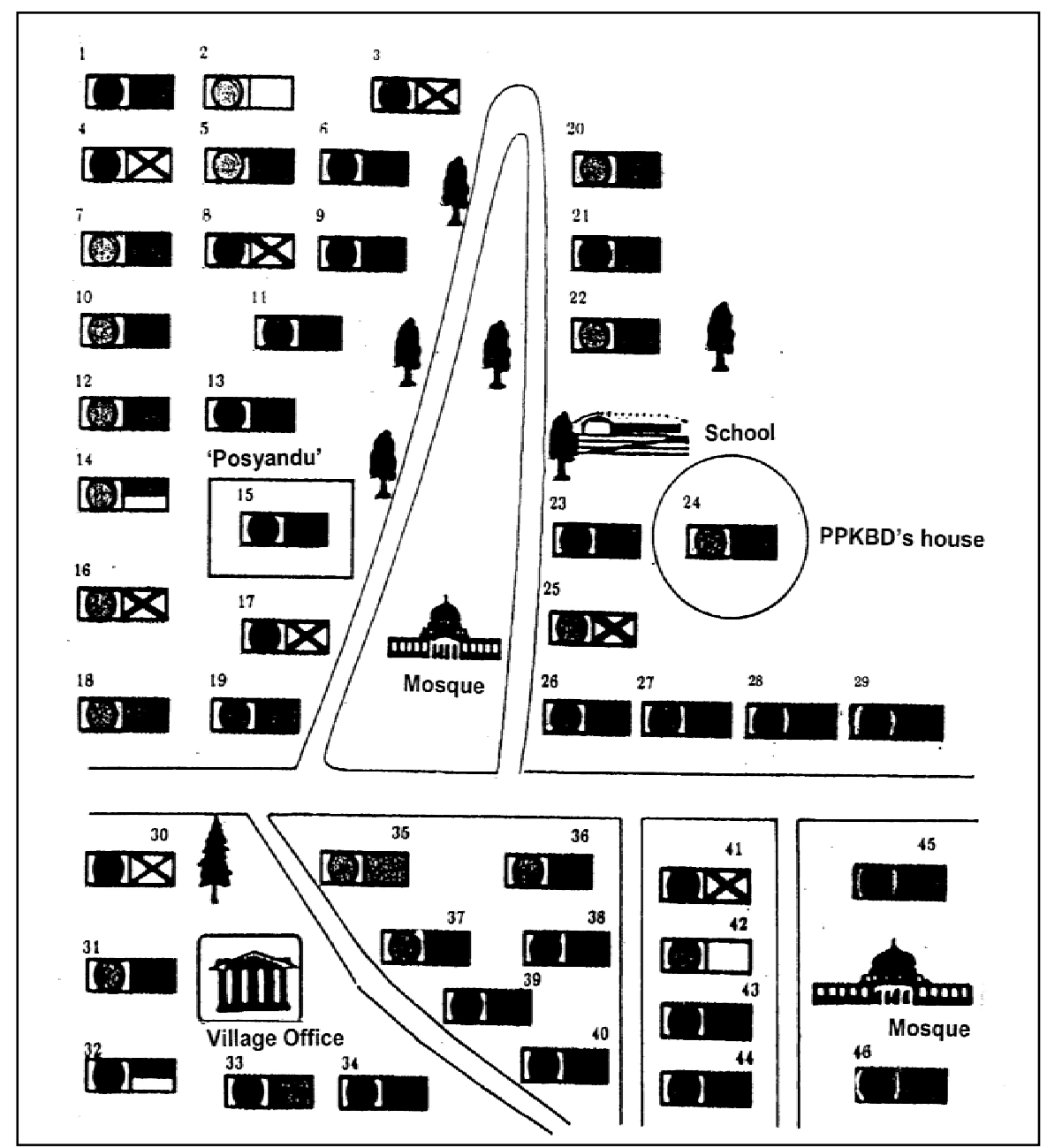

Source: Adapted from BKKBN 2001d, p.105.

In 2001, based on the family enumeration data, the NFPCB national office created a family database for each neighbourhood throughout the country (BKKBN, 2002d). This database includes:

1) Data on the head of the family: family registration number, age, using contraceptives or not, and prosperity level.

2) Data on each family member: personal registration number, name, relationship with the family's head, sex, date of birth, occupation, educational attainment, and marital status.

These databases are sent by the national office to all of the villages. The volunteers' task is to update the database with any changes occurring within the previous year (BKKBN, 
2002d). However, given the large population and the vast geographical areas, some villages have experienced delay in receiving the databases. By March 2003, the villages of my study areas had not received them.

The family databases are also sent as electronic files to the district offices where they can be modified and adjusted to the district's needs. The transition process to decentralisation has required the NFPCB to equip the district offices with the knowledge and technology to manage these databases as part of their management information system. This 'micro level' data can be used by the local governments as a basis for formulating population and family planning policies (BKKBN, 2003a). However, as mentioned in the guidelines (BKKBN, 2002c), at regional level the database should be used with caution as its main purpose is for grass-roots level planning.

As the system is already in place, the NFPCB expects that local government will maintain it to assist the community in developing and implementing family planning and other programmes related to family welfare (BKKBN, 2003). This grass-roots level data will enhance community participation as it will allow the community to assess and evaluate its condition and plan suitable programmes and activities. As discussed in Chapter 4, Chambers (1997) emphasises that one of the principles of participatory development is to allow the community to be the main actor for the planning process. By using approaches like participatory rural appraisal (or PRA, see Chambers, 1997), the community will be able to do a 'self-assessment' through collecting information and analysing it by themselves, and utilize it in developing their own programmes.

\subsubsection{Strategies}

The next section describes some of the programme's salient strategies in achieving its goals, which include securing religious leaders’ support, integration with other development programmes, and promoting 'self-reliant family planning' through partnerships with the private sector. 


\subsubsection{Securing Muslim religious leaders' support}

One of the important keys to the success of the Indonesian family planning programme is the support of the country's predominantly Muslim population, which accounts for 88.2\% of the total population in 2003 (Departemen Agama, 2003; State Ministry for Population/NFPCB, 1998). Realising the important role of Muslim leaders and organisations in the success of the programme, since the beginning the family planning programme has sought their approval and support.

At the commencement of the programme, there were many interpretations of family planning among Muslim leaders based on their schools of thought (mazhab) or individual perceptions. The major tendency was to consider family planning as against Islamic teachings, on the grounds that: 1) the task of a good Muslim was to marry and have many children; 2) the existence of human beings had always been complemented by sufficient resources for their survival, so that people would not have to be worried about hunger; 3) birth control was not for the masses, since it would endanger the institution of marriage and threaten moral values (Adioetomo, 1995, p.115; Yafie, 1982). Over time, with the programme's continuous approach to explain the purpose of family planning and the development of contraceptive technology, the Islamic leaders and scholars began to accept and support the family planning programme (State Ministry for Population/ NFPCB, 1994; 1998).

There are three major Islamic organisations in Indonesia that play an important role in shaping the community’s perceptions and acceptance of family planning, i.e. Muhammadiyah, Nahdlatul Ulama, and Majelis Ulama Indonesia (The Indonesian Council of Islamic Scholars).

Muhammadiyah was established in Yogyakarta in 1912 with the objectives of improving religious and general education and spreading reformed Islamic ideas among Javanese people. Currently, Muhammadiyah has branches across Indonesia with around 30 million members, largely well-educated urban residents. Aside from schools and universities, the 
organisation has also established mother and child clinics, maternity clinics, and hospitals. The female branch of the organisation, called Aisyiyah, has been active in the improvement of education, health, nutrition, and family welfare in general (Koentjaraningrat, 1985; State Ministry for Population/NFPCB, 1998; Zaki \& Danuri, 2001).

Nahdlatul Ulama was founded in 1926 in Surabaya, East Java, by the traditionalist Javanese Muslims as a reaction against the reformist movement of Muhammadiyah. Nahdlatul Ulama members are more tolerant to diverse religious views and practices, including those derived from traditional customs. At present, Nahdlatul Ulama has branches in around 40,000 sub districts across Indonesia with approximately 40 million members, mostly residing in rural areas. The organisation has also established clinics and hospitals. Its two autonomous women's organisations, Muslimat and Fatayat (for female youth), are engaged in education, health, economic and cooperative, and advocacy for women workers' rights and protection (Koentjaraningrat, 1985; PBNU, 2003; State Ministry for Population /NFPCB, 1998).

At the outset, these two organisations opposed the idea of family planning as they believed it was against Islamic teachings. The use of contraception was allowed only in the case of emergency. Muhammadiyah eventually accepted family planning with a condition that the concept of the Indonesian family planning programme is different from the birth control practices in the Western countries. It should be based on moral and religious norms and the main drive is the family and community welfare (Kusnadi, 1973). Similarly, Nahdlatul Ulama accepted family planning on the basis of the welfare of the family. The organisation contends that family planning methods can be accepted only if the mechanism is similar to $a z l$ (withdrawal), that is, preventing the meeting of ovum and sperms (Yafie, 1982).

Majelis Ulama Indonesia (The Indonesian Council of Islamic Scholars) was established in 1975 in Jakarta as an umbrella organisation for numerous Islamic organisations and scholars throughout the country. In 1983, the council sponsored the National Conference of Indonesian Ulama on Population, Health and Development which generated a consensus among ulamas (Islamic scholars) to consider family planning as: 
....an initiative or effort by man to regulate pregnancy in the family, in a way not against religious laws, the laws of the state, and the morality of Pancasila (the state ideology), in order to achieve prosperity for the family in particular, and for the country in general. The teachings of Islam condone the implementation of family planning to support maternal and child care and child education to have a healthy, intelligent and pious child (MUI, 1984 cited in State Ministry for Population/NFPCB in English translation, 1995, p.101)

The conference also stressed the following principles as guidelines for the implementation of the family planning programme:

1) The main purpose is the betterment of the mother's and child's health;

2) Implemented on a voluntary basis, taking into account religious teachings and traditional customs;

3) May involve a contraceptive means voluntarily chosen, not contrary to Islamic teachings, and mutually agreed upon by husband and wife;

4) The use of IUDs is justified provided that their insertion and follow-up check up must be carried out by female doctors or paramedics. In case of emergency, it can be performed by a male doctor in the presence of the woman's husband or another woman;

5) Vasectomy and tubectomy are forbidden except in cases of emergency such as to prevent inherited disease or to save a woman's life;

6) Abortion, including menstrual regulation, is against Islamic teachings. (WAMS, 1983, p.24-25; State Ministry for Population/NFPCB, 1998, p.7)

It is noteworthy that the ulama's interpretation of Qur'an messages of family planning emphasises that it is should be a joint decision between husband and wife. This reflects the concept of gender equality. This view had also been emphasised by Muhammadiyah and Nahdlatul Ulama earlier in the late 1960s (Kusnadi, 1973; Yafie, 1982).

Due to the sensitivity of the issue, the programme did not specify any contraceptive method before obtaining approval from the religious leaders (State Ministry for 
Population/NFPCB, 1994). The decision to accept IUD showed a further step in the religious leaders' support, since in the previous conference of ulamas in 1973 the use of IUDs was still prohibited. Subsequently, with successful experiences of sterilisation reversal processes, Nahdlatul Ulama and Muhammadiyah officially accepted sterilisation as part of the family planning programme in 1989 and 1990 respectively. Then, in a national seminar in 1990 sterilisation was legitimated by the Indonesian ulamas as a part of the Indonesian family planning programme (State Ministry for Population/NFPCB, 1998). The support of Muslim religious leaders in legitimising contraceptive methods to be used in the family planning programme has improved the receptivity of the programme. The acceptance of the small-family norm became widespread after it was included in the ulamas’ speeches in the mid 1980s (Aidid, 1987 cited in Adioetomo, 1995, p.121).

Through collaboration with the Ministry for Religious Affairs, the NFPCB have involved religious leaders in various stages of the programme development. Their role was not limited to legitimising contraceptive use and providing religious guidelines, they also became actively involved in spreading information about family planning. Publications by religious scholars include a book entitled “The Role of Islam in Family Planning” in 1991. This participation has had a significant impact on the programme since religious leaders are generally highly respected by communities. Dissemination of family planning information has been carried out in mosques and beyond. Many Islamic organisations have activities at the village level, such as pesantren (Islamic boarding school) and pengajian (Qu'ran recitation) groups (Adioetomo, 1995; State Ministry for Population/NFPCB, 1994; 1995).

Discussions about family planning mainly emphasise spacing as the objective of the use of contraceptives rather than for limiting fertility which can be regarded as against God's will (Adioetomo, 1995).

\subsubsection{Integration with other development programmes}

With a broad ranging goal, that is to achieve 'small, happy and prosperous families', since the beginning the NFPCB has recognised that integration with other related development programmes was “an absolute necessity” (Sumbung et al., 1984, p.15). Later, 
based on Law Number 10/1992 and the new vision and mission statement in 2000, integration with other programmes has been strengthened as the main strategy (BKKBN, 2001a; Government of Indonesia, 1992).

In 1976/77, a programme entitled 'population education' was introduced into school curricula, from primary up to tertiary levels. However, this was not given as an individual subject, rather it was integrated into the other subjects such as social science, biology, or Indonesian and English languages (as reading material). The topics discussed in the subject were mainly about reproductive health and the link between population and development (State Ministry for Population/NFPCB, 1994).

As one of the family planning programme's objectives was to improve maternal and child welfare, one of the programme's strategies was to integrate family planning with the mother and child health programme. In 1978, at village level, NFPCB brought family planning together with the Ministry of Health’s 'Family Nutrition Improvement Programme'. The main activities were child weighing, nutrition education, provision of oral rehydration solutions for diarrhoea control, provision of vitamin A for children and iron tablets for pregnant and lactating women, and child supplementary feeding. These monthly activities were implemented by village volunteers who were mostly members of the Family Welfare Movement groups and family planning acceptor groups. Family planning fieldworkers and sub-district health centres staff assisted the implementation. The NFPCB and Ministry of Health jointly supported these activities, sharing responsibilities for providing personnel, funds, materials, and training programmes (State Ministry for Population/NFPCB, 1994; Sumbung et al., 1984; Suyono \& Reese, 1978). In 1984, this integrated programme was further developed and became known as Posyandu (Integrated Service Post). The programme’s components were extended to include basic health services, such as immunization and antenatal care, and contraceptive services were provided by visiting paramedics or a midwife. By 1990, almost all of Indonesia's 67,000 villages had established posyandu (State Ministry for Population/NFPCB, 1994; Suyono et al., 1995). The Ministry of Internal Affairs then took a leading role in this programme and in 1990 issued an instruction for the heads of local governments at all administrative levels 
to support the improvement of posyandu's service quality (Departemen Dalam Negeri, 1990). The NFPCB was also involved in the Safe Motherhood Initiatives started in the 1990s by providing information and other supporting materials (State Ministry for Population/NFPCB, 1994, p.45).

In the 1980s, as an effort to develop its income-generating programme, the NFPCB initiated collaboration with the Ministries for Agriculture, Cooperatives, and Trade and Industry to facilitate the development of small-scale business activities carried out by the families (State Ministry for Population/NFPCB, 1994; 1995; 1996).

Since the Fourth Five Year Development Plan, in order to increase the number of contraceptive users, NFPCB has initiated collaboration with other related Ministries and institutions to extend its services to the families in specific settlements such as transmigration areas, slum areas, settlements around the forests, and factory workers (State Ministry for Population/NFPCB, 1994; 1995).

In its 2000 vision and mission statement, integration is mentioned as one of the strategies in achieving the programme’s goal of “Quality Families by 2015”. Integration with other related programmes for family welfare is employed both in the conceptual and implementation spheres, i.e. integration of:

1) the family planning concept with the concepts of reproductive health, reproductive rights, and gender equity and equality;

2) family empowerment activities with family planning services and women empowerment programmes;

3) an adolescent reproductive health programme with the family planning and reproductive health programme;

4) a family planning network and institutions with other related community service institutions;

5) the national family planning programme with other development programmes. (BKKBN, 2001a, p.18). 
Few studies have been carried out to assess the effectiveness of the integrated programmes. Warwick’s study (1986) in 48 villages in West Java, East Java, South Sumatera and South Sulawesi concludes that integration with various development programmes provided public legitimation and hence support for the family planning programme in general. The study showed a statistically significant correlation between the total number of programmes present in a village and current contraceptive use rates for the village. Meanwhile, Wignyadisastra’s study (1986) in similar locations was focused on the management aspect. The researcher suggests that integration with other development programmes has increased the effectiveness of the implementation of family planning programmes.

\subsubsection{Promotion of 'Self-Reliant Family Planning'}

As a response to a reduction in the government budget and diminishing donor support, the NFPCB launched the 'Self-Reliant Family Planning' or KB Mandiri in 1988. This programme encourages families to share the cost of contraceptives through enhancing the involvement of the private sector in family planning services. Through this approach, the long term sustainability of the programme is expected to be secured. The NFPCB had launched a multi media campaign to encourage couples from middle and high-income groups to obtain their contraceptive supplies through the participating clinics which provide the partially subsidised contraceptives under the 'Blue Circle ${ }^{5}$ logo. The lower income group, meanwhile, are still entitled to free or heavily subsidised services (BKKBN, 2003a; Gunawan et al., 1992; Hamijoyo \& Chauls, 1994). Despite fears about the willingness of the population to pay for the services, the Indonesian Demographic and Health Surveys in 1994 and 1997 showed the use of private providers increased from 28 to 42 percent (CBS et al., 1998).

The private sector and NGOs have been playing a broad role in the family planning programme, not limited to the provision of contraceptive services. Some of them are also

\footnotetext{
5 'Blue Circle' is the logo used for the social marketing of the partially subsidised contraceptives provided by private doctors and midwives.
} 
involved in information, education, and communication activities, programmes for families with under-five children and adolescents, and women's empowerment programmes (Gunawan, et al., 1992).

\subsubsection{Funding}

Funds for the family planning programme have been provided by the government, international donors in the forms of grants and loans, and also the private sector and NGOs. Prior to 1970, contraceptive services were provided by private organisations, particularly the IPPA, and the government. From the 1970s, as part of national development plans, the family planning programme began to receive support from international donors and foreign assistance became an important financial source (State Ministry for Population/NFPCB, 1995).

International donors have provided funds in the form of grants through three channels: a) direct bilateral assistance by countries such as the United States, Japan, members of the European Union, and Australia; b) multilateral assistance from the United Nations organisations, primarily UNFPA and UNICEF; and c) NGOs and private foundations. In addition, the programme has also received loans from the World Bank and the Asian Development Bank, of which the government is still paying back. Donors' funds, both grants and loans, complement the government's budget, especially for aspects of the programme's development such as service quality improvement, integration with health and nutrition programmes, and development of information, education and communication activities to support village delivery (State Ministry for Population/ NFPCB, 1995).

In 1970, the government of Indonesia provided the equivalent of US\$1.3 million while foreign donors contributed around US\$3 million. The Indonesian government's contribution has increased in successive years. In 1984, the government provided the equivalent of US\$65 million while foreign agencies supplemented this with US\$25 million. However, it is difficult to know the exact amount of foreign assistance as it is also channelled through the government development budget. The World Bank (1990) estimated 
that foreign contributions for each of the Repelita from I to IV were 59, 48, 29, and 45 percent of the total budget respectively. By the end of Repelita V (1993/94) the government itself had funded 95 percent of the goods and services (State Ministry for Population/NFPCB, 1994).

Between Repelita III (1979-1984) and IV (1984-1989), while the overall development budget experienced a reduction of 32 percent, the budget for the family planning programme declined only 8 percent. This shows not only the government's high commitment to family planning but also the magnitude of the programme (Hugo et al., 1987, Rahardjo \& Reese, 1972; World Bank, 1990).

Provision of contraceptive supplies and service delivery, including back-up and referral services for contraceptive side effects, has absorbed the majority of the government funds since the 1970s. By the end of the 1980s, contraceptive procurement accounted for 41 percent of the total government budget (State Ministry for Population/ NFPCB, 1994, 1995). In 2002, it constituted 29 percent of total government budget at the national level. At the local level (from province to village level), allocation for service delivery accounted for 70 percent of the total budget (BKKBN, 2002d).

Donors' contributions remained less than 10 percent of the total funds available until the economic crisis in 1997. Concern about families' ability to purchase contraceptives, after the government's subsidy had been cut, has led major donors such as UNFPA, USAID, and some European countries to increase their support for provision of contraceptive supplies (Hull \& Adioetomo, 2001). However, this created conflict between donors and the programme. On one hand, donors insisted that the contraceptives they provided be distributed free for the poor, not only implants and IUDs, but also injectables and pills. On the other hand, the programme contended that it would undermine the existing contraceptive delivery system (Hull \& Adioetomo, 2002).

The challenges faced by the Indonesian family planning programme post-economic crisis included not only ever-greater budgetary constraints to meet the increasing demand 
for contraceptive supply, but also to meet the demand for a better quality service. Following the introduction of the decentralisation policy in 2003, the costs for family planning services at the local level have been designated to be shared with the district governments. However, this will depend largely on local governments' abilities and commitments to support the programme. Until now, there has been no comprehensive study of the costs needed for family planning and reproductive health services.

The Indonesian private sector and NGOs have also been encouraged to participate in the provision of family planning services. As discussed earlier, in 1988 the programme launched 'Self-Reliant Family Planning' which encouraged the private sector and couples from middle and high-income groups to share the costs of contraceptive services.

\subsection{Summary and discussion}

The Indonesian family planning programme has evolved from a private endeavour to become the world's third largest government family planning programme (Caldwell, et al., 2002). The structure, which has been hierarchical, is the key factor to its success. With the new policy on decentralisation, however, this structure will be changed as the district governments have the authority to design their own policies.

In response to international pressures, particularly following the 1994 ICPD, the programme changed its focus from demographic target to goals that stressed reproductive health and women's empowerment. Community empowerment is still the main strategy (BKKBN, 2001a). Currently, the program is still in transition to becoming purely community-based, as the villages are still partly dependent on the sub-district health centres. 
The above changes show the programme's responsiveness to both domestic circumstances and international pressures. However, as noted by some observers (Hull \& Hull, 1997; Hull \& Adioetomo, 2001; Seltzer, 2002), for a large bureaucracy such as the Indonesian family planning programme, changes at national policy level may take a long time before they reach villages and hamlets.

Due to many important political and social changes, leading up to the period of 20002004 the program faced challenges such as:

\section{a) Policy on decentralisation}

The law on regional autonomy enacted in 1999, and the Presidential Decree of 2001 stipulated that the family planning programme be handed over to local governments by the end of 2003. This gave little time for preparation and transition. A critical issue is that the family planning agency is not among the 11 obligatory agencies that should be established by district governments as specified by the laws/regulations. By mid 2003, only $12 \%$ of district governments had set up an institution responsible for population and family planning programmes while the others faced uncertainty (BKKBN, 2003).

b) New government

Another challenge to preserve the family planning programme will be faced by the government that will succeed President Megawati's. A general election to be held in July 2004 will determine the next political policy. Nevertheless, decentralisation is likely to continue.

\section{c) Financing policies}

The financial crisis which began in 1997 aggravated the national budget constraints due to decreases in international assistance for the programme. Many donors had been planning to pull out of Indonesia during the 1990s, but after the crisis they continued their support to provide contraceptive supplies for poor families. Donor funding may not make a significant financial contribution in the future (Caldwell, 2002; Hull \& Adioetomo, 2001; UNFPA, 1999). 
The above circumstances, particularly the policy on decentralisation , has important implications for the future family planning programme in Indonesia:

1) Sustainability of the family planning programme

Based on the laws/regulations on regional autonomy, the district government has full authority to decide policies regarding population and family planning practices. The authority of the central government is limited to formulate policies concerning norms, standards (including the type of services to be provided and quality of care) and procedures, to ensure the continuity of the programme. Meanwhile, provincial governments are expected to facilitate the transition process (BKKBN, 2003). With the new system, district governments are expected to take initiatives in developing family planning programmes as a part of development goals that include population policies and strategies. The transition process to decentralisation and full operation by local governments may take years before the new roles and functions run properly.

2) Community empowerment and participation Since the span of the working structure will be reduced, the programme is expected to be more responsive to local needs. The existing bottom-up planning mechanism has to be strengthened to give more opportunities to the community to participate fully in all aspects of family planning. The recording and reporting system, including family enumeration, could serve as an important tool in the process of planning and feed back between district governments and the community at the grass-roots level.

However, concerns over accuracy of the data have to be resolved. Since the data collection system for each village relies on volunteers, who are expected to do home visits, it must match the volunteers' levels of education and capacity to do the enumeration. The annual task of completing the complex forms consisting of several pages of paper is in the process of being simplified. The NFPCB is eliminating the complicated forms and replacing them with a computer processed database at district level. Nevertheless, it should be noted that the computerised system of data processing 
should not distance the community from this data. As part of participatory rural appraisal, Chambers (1995) emphasises that all data and information from a village should belong to the community and they should be able to utilise them for their own betterment.

3) Role of PPKBD and volunteers in the village.

In line with the decentralisation policy, the NFPCB expects the PPKBD to be able to play a greater role in managing and implementing the programme at village level. Hence, the capacity of PPKBD and the volunteers needs to be improved if they are to take an active role in decision-making and the planning process at village level in the future. Empowerment has begun, but needs to be continuously monitored if its effectiveness is to be increased.

4) Service quality

With the new focus in line with that of the 1994 ICPD, the programme has included improvement of the quality of care to improve the quality of service delivery including back up service for side effects (BKKBN, 2001a). However, the implementation of these new programmes depends largely on the resources of local governments.

5) Funding

Future funding for family planning programmes may experience problems as donor funds will be significantly reduced. Furthermore, district governments may have different development priorities and varying abilities to finance their programmes. Development budgets from central government will take the form of block grants, which district governments have full authority to manage (Government of Indonesia, 1999). It is expected that all district governments will maintain the provision of family planning services, with subsidies for the poor and affordable prices for the rest of the population. The importance of the volunteers must not be overlooked. 


\section{Chapter 7}

\section{Decision-making at Community Level: \\ Two Villages in West Java}

\subsection{Introduction}

This chapter discusses the findings of the study which was conducted in two villages of West Java province, Indonesia. The focus of the discussion is to understand the process of reproductive decision-making at the household and community levels. For a better understanding of the process, this chapter begins with background information on the study areas. In order to provide a framework for the discussion, the first section presents a detailed account of the socio-cultural characteristics of the Sundanese, the ethnic group which constitute the majority of the West Java population. As discussed in Chapter 4, reproductive decision-making is influenced by socio-economic and cultural contexts. The second section discusses the implementation of the family planning programme at the village level by highlighting how the programme operates in the field and the role of the village facilitators, i.e. a family planning fieldworker, a midwife and the village family planning organisation. The decision-making process at the community level will be described by looking at the role of the village family planning organisation within the programme. The next section presents a discussion on decision-making processes at household and community levels.

\subsection{Background characteristics of the study areas}

\subsubsection{West Java province}

The province of West Java is located on the western part of Java Island. It is one of the six provinces on the island, the others being Banten, The Capital Territory of Jakarta, Central Java, The Special Territory of Yogyakarta, and East Java. Banten was previously a part of West Java, it became a separate province in 2000. The land area of West Java is 34,770 square kilometres, or 1.83 percent of Indonesia's total land area, and is very 
mountainous. The high central area, the Priangan highlands, forms the core territory where the capital city of Bandung is situated. West Java province consists of 16 districts, 6 municipalities, 447 sub-districts, and 5,836 villages (Bappeda Jabar, 2001).

West Java is Indonesia's biggest province in terms of population with 35.7 million people in 2000, then approximately 17.36 percent of Indonesia's total population. Its annual growth rate in the period of 1990-2000 was 2.03\%, higher than the national figure of $1.49 \%$. With a population density of 1,033 people per square kilometre, West Java was ranked second in terms of population density after Jakarta (BPS, 2003).

Generally, districts in the central and northern parts of West Java are more densely inhabited than the southern part. Unlike the other parts of the country, the 2000 census showed that in West Java the proportion of urban population is slightly higher than the rural, i.e. 50.31 and 49.69 percent respectively (BKKBN \& BPS Jabar, 2002). This is due to the presence of the heavily populated cities of Bekasi, Tangerang, and Bogor which are adjacent to the country's capital city of Jakarta. Many of these cities' residents work in Jakarta and commute everyday to their workplaces.

Due to its large population, West Java was among the first five provinces to implement the government family planning programme in the 1970s, along with the other provinces in Java and Bali islands (State Ministry for Population/NFPCB, 1995). However, the achievement in this province has been behind the other provinces. In 2002/3, 59 percent of reproductive age couples were participating in the programme, while the national figure was 60.3 percent (CBS et al., 2003). The total fertility rate of 2.8 births per woman in 2002/3, although on the decline, was also above the national rate of 2.6 (CBS et al., 2003). According to Hatmadji (1990, p. 195), the low contraceptive prevalence rate in West Java was due to unfavourable socio-economic characteristics of the region, such as a high infant mortality and low female labour force participation, rather than programme inefficiency. 


\subsubsection{The Sundanese}

West Java is the homeland of the Sundanese, the second largest ethnic and linguistic group in Indonesia after the Javanese who occupy the central and eastern parts of Java island (Garna, 1984; Suryadinata et al., 2003). The cultures of these two ethnic groups are related, although there are also some distinctions (Peacock, 1973). The 2000 population census revealed that the Sundanese constituted 17.46 percent of the total Indonesian population. This figure includes the population of Banten province which is predominantly Sundanese (Suryadinata et al., 2003). Despite its large population, the Sundanese have been relatively little described compared with the Javanese.

Harsojo (1971) defines the Sundanese as people who have been using Sundanese language and its dialects as their mother tongue over generations, and who originally come from and reside in West Java region. However, there are some Sundanese speaking communities outside West Java, as in some districts of Central Java and Lampung. Hence, Rosidi (1984) and Adiwisastra (1996) assert that the Sundanese are those who use Sundanese language as their mother tongue, support the Sundanese culture, and reside primarily in West Java.

The written Sundanese history can be traced back to the $5^{\text {th }}$ century from the old scripts of the first Hindu kingdom in West Java, Tarumanagara (Ekadjati, 1984). After the fall of Tarumanagara in the $7^{\text {th }}$ century, several small kingdoms appeared around the region, such as Kuningan, Galuh, and Sunda. These small kingdoms were then merged into the Sunda kingdom, which covered most of West Java and some parts of Central Java. The area of the Sunda kingdom was called Tatar Sunda or Pasundan which means the land of the Sundanese. Most of Tatar Sunda areas became West Java province (Ekadjati, 1984).

Historically, the Sundanese have been influenced by other indigenous and foreign ethnic groups, primarily the Javanese and the Indians who first came to Java in the first century. According to Ekadjati (1984) and Rosidi (1984), the occupation of Mataram kingdom from

Central Java in the $15^{\text {th }}$ century brought Javanese influences to the political system, culture, 
language and rice farming system of the Sundanese. Meanwhile, the Indian traders introduced Hindu to the animistic indigenous inhabitants. However, as Rosidi (1984) notes, there is no evidence that the Hindu caste system was adopted by the Sundanese societies. Chinese immigrants who came since the Tarumanagara era have also left their influences on the Sundanese culture (Garna, 1984).

\subsubsection{Language}

Sundanese language is spoken throughout the province of West Java along with the Indonesian national language. In rural areas, Sundanese is the primary medium for everyday communication, while in urban areas it is used mainly among families and friends (Harsojo, 1971). Sundanese language comprises several dialects, with Banten, Priangan and Cirebon the main dialects. Each dialect has its own vocabulary, structure and accent. The dialect of the central Priangan highlands is considered to be more pure and halus (refined) than the others, while those of Banten and Cirebon are heavily influenced by Javanese. The ancient dialect (Sunda Kuno) is still being used by the Baduy people who live in an enclave in Banten (Rosidi, 1984; Harsojo, 1971).

Basically, Sundanese language has two speech levels, basa kasar ('rough language') and basa lemes ('refined language'), but some forms of kasar pisan (very coarse), sedang (regular), and halus pisan (highly refined) are also used (Muller-Gotama, 2001, p.3; Rosidi, 1984, p.139). Speech levels symbolise differences in status, rank and seniority, hence should be used correctly. Any mistakes can be perceived as disrespectful and the user is considered to be uneducated. These difficulties sometimes make people afraid to use this language with a person she or he should respect (Rosidi, 1984). According to Rosidi, these speech levels were introduced by the Javanese in the $15^{\text {th }}$ century during the occupation of the Mataram kingdom to show respect to the aristocrats. The original Sundanese language, like that of the Baduy, does not have speech levels.

The people in the two villages of my study areas, situated on different parts of West Java, use different dialects. The village in Sumedang, which is located in the Priangan 
highlands, uses the pure and halus (refined) dialect while the village in Subang uses the Cirebon dialect.

\subsubsection{Religion}

Currently, 97.6 percent of the West Java population are Muslims, the rest are Christian, Buddhist and Hindu (Departemen Agama, 2003). Although the available data is for the West Java population which is not entirely Sundanese, the majority of the Sundanese are considered devout Muslims and adhere more strongly to Islam than the Javanese (Peacock, 1973; Suhamihardja, 1984b). There is also an indigenous religion, that of the Baduy people, known as Sunda Wiwitan or the earliest Sundanese (Suhamihardja, 1984b). The Baduy people, who preserve pre-Islamic culture and religion, are often considered as the model of the ‘true’ Sundanese culture (Garna, 1984).

Hindu was introduced by the Indian traders. Hindu kingdoms are believed to have been established in West Java since the first century, although the available evidence starts with Tarumanagara kingdom in the $5^{\text {th }}$ century. According to Ekadjati (1984), during that time only the royal families and aristocrats observed Hindu while the majority of the people were still animistic.

The advent of Islam in West Java began when Arab, Persian and Indian Islamic traders came in the $14^{\text {th }}$ century. Muslim influence first emerged in the harbour areas of Cirebon and Banten in the $15^{\text {th }}$ century. Islam became the major religion of these port towns, replacing Hindu. Demak, the first Islamic kingdom in Central Java, played an important role in spreading Islam through its alignment with the sultanates of Cirebon and Banten. From the coastal areas, Islam penetrated the core Priangan highlands. By the end of the $16^{\text {th }}$ century, almost all regions of West Java were under the power of Islamic leaders and the populace had become Muslim (Ekadjati, 1984).

As Harsojo (1971) notes, religious and adat (customary) laws govern all aspects of Sundanese lives. Sometimes it is difficult to distinguish the two sets of laws since both play important roles in forming the Sundanese values and attitudes. Both religious and adat 
elements are reflected in the life-cycle ceremonies of an individual, beginning while the person is still in the womb and continuing until a thousand days after his/her death.

\subsubsection{Social relations}

According to Garna (1984) and Peacock (1973), there are no large corporate kin groups, clans or lineages among the Sundanese, so the nuclear family is the basic unit. They also maintain that the Sundanese adopt a bilineal system, which according to Vreede-de Stuers (1960) means the children belong to both the husband's and wife's families. In addition, sons and daughters inherit the family properties through both sides, the father and the mother. The bilineal system implies that couples are closely bound to the husband's and wife's extended families. Although the nuclear family is the basic unit for most decisions, other members of the extended families may have influence in all matters that concern a couple.

Most Sundanese couples generally try to set up their own households soon after they marry. Therefore, most of the households consist of one nuclear family, although sometimes other relatives are present such as younger brother or sister of the couple or the children of relatives. However, since many villagers marry at an early age, a young couple usually resides in the house of one of the parents, generally the wife's, until they are considered to able to manage their own household. As in Javanese societies, newly wed Sundanese couples usually set up the new household in the neighbourhood of at least one of the parents, but there is no formulated rule of residence after marriage. Couples from better off families are usually provided with a house by their parents. Despite living separately in a home of their own, the couple is closely bound to the families of both the husband and the wife. Relatives from both sides will also help out should a couple get into difficulties (Budiarto \& Purwatini, 1988; Garna, 1984; Geertz, 1961; Harsojo, 1971; Koentjaraningrat, 1985; Suhamihardja, 1984a; Vreede-de Stuers, 1960). This implies that their families are influential in all matters including fertility decision-making 
Among the Sundanese, as in other communities, when a person gets married it means that he/she becomes a member of the spouse's family. Hence, couples are also responsible for parents and siblings of their spouses. It is common for married couples to support the education of their younger siblings, who often stay with them (Suhamihardja, 1984a).

Outside the nuclear family, the kindred consists of extended families and relatives who still maintain close relationships. According to Harsojo (1971), membership of this kin group are usually involved in important ceremonies like circumcisions and weddings. When an individual needs assistance, he/she will also go to this kin group, including those members who reside outside the village. As in other ethnic groups, among Sundanese a marriage unites not only the bride and the groom but also the two families. Therefore, a marriage may form a new kin group (Garna, 1984). At a wider circle, there are also ancestor-oriented kin groups which include up to seven generations (Harsojo, 1971).

Apart from the kindred, social relations with neighbours are also considered as important, especially in rural areas. Like the Javanese, the Sundanese also possess a philosophy of silih asah, silih asih, silih asuh which means members of a society should share knowledge and experience, love, and care for each other (Koentjaraningrat, 1985; Suhamihardja, 1984a, p.212). The Sundanese also practice various systems of mutual aid called gotong-royong (Garna, 1984, p.52; Koentjaraningrat, 1967, p.261). According to Koentjaraningrat (1967, p.394) the term gotong-royong, which is very popular in Indonesia today, also means "rendering aid to the community for the common benefit". Gotongroyong may be applied to a wide variety of work arrangements, such as in agricultural works and house building. It may also include aid in the form of goods and money as well as services (Garna, 1984; Palmer, 1967). However, as Garna (1984) notes, nowadays there has been a tendency to replace the gotong-royong system in agricultural works with a wage system due to the increasing number of landless labourers.

\subsubsection{Occupation}

Most Sundanese, particularly in rural areas, engage in agriculture. Rice farming and fishing, along with trading, have been the main occupations. Since the area is very 
mountainous, traditionally the rice farming was in dry rice fields but nowadays it is mostly in irrigated fields (Adimihardja, 1984). Irrigated paddy fields are mostly situated in the plains of north coastal areas. However, landholdings of the Sundanese villagers are small, around 0.2-0.3 hectares (Garna, 1984; Palmer, 1973). For fishing, most of the fishermen still use traditional fishing gear and the market is still limited to the local market. Fresh water fish are cultivated in fishponds or in lakes and rivers using karamba (a kind of cage made from bamboo). Sundanese prefer fresh water fish to sea fish, except for salted or dried fish (Garna, 1984).

In urban areas, the occupations are more varied. According to Adimihardja (1984, p.171), the Sundanese communities in cities resemble H. Geertz's $(1967)^{6}$ classification of Indonesian urban communities, i.e. the urban elite, which usually consists of big traders and businessmen, bureaucrats and highly educated people; the urban middle class, composed of middle level civil servants and school teachers; and the urban proletariat consisting of petty traders, pedicab drivers, house servants, and other unskilled labourers.

\subsubsection{Marriage}

As documented in Section 3.5.3, women in West Java marry younger than women from other provinces. Although the median age of the first marriage in this province has been increasing from 15.7 years in 1973 to 17.5 in 1997 (for women 40-44 years old at the time of the survey), it was below the national average of 18.1 years (CBS et al., 2003; Kasto, 1982 cited in Singarimbun, 1991, p.37). It is the parents' concern to have their daughters get married at a young age, around 13 to 15 years, to avoid stigmatisation as old maids. There is even a proverb 'kawin ayeuna, isuk pepegatan' or married now and divorce tomorrow, which reflects the Sundanese attitude in this matter (Suhamiharja, 1984a, p.216). It is not surprising that divorce rates among Sundanese were quite high (Peacock, 1973; Suhamiharja, 1984a).

\footnotetext{
${ }^{6}$ In 'Indonesian Cultures and Communities’ in R. McVey, Indonesia. New Haven: Yale University.
} 
Marriages used to be arranged by relatives of the bride and groom. They selected the future spouse and decided the date of the wedding (Suhamihardja, 1984a; Budiarto \& Purwatini, 1987). Religious orientation and adherence is an important consideration in selecting a spouse (Harsojo, 1971). Some time before the wedding, the relatives of the boy ask the girl's parents for her. If accepted, both parents will arrange the time of the wedding and the money and goods the boy's parents should contribute. The wedding ceremony is carried out in a combination of religious and adat fashion. As in other Muslim societies in other regions, a gift of money or goods (mahar) is given to the bride by the groom (Harsojo, 1971; Palmer, 1967; Peacock, 1973). Although currently the young may make their own choice, parental consent is still needed (Budiarto \& Purwatini, 1987).

\subsubsection{Sexual division of labour}

In Sundanese communities, as in many parts of Indonesia, men are regarded as the head of the family. They are responsible for family income while women run the household and take care of the children. However, if additional help or income is needed, wives also work outside the house. In rural areas, it is common for husbands and wives to work together both in agriculture or in small-scale business activities. In the rice farming system, there are tasks which are traditionally performed by women, like weeding, harvesting, and pounding (Ekadjati, 1995; Suhamihardja, 1984a).

The traditional role for wives and husbands emphasises the women's place is in the domestic sphere, as reflected in the proverb ‘awewe mah tempatna di dapur' or women's place is in the kitchen (Ekadjati, 1995, p.203). Hence, in rural areas women were seldom involved in public affairs such as village meetings. Within the last four or five decades this situation has been changed. Today women have equal opportunities to participate in all spheres of life. Some villages are even headed by a female Lurah (village head) (Ekadjati, 1995).

\subsubsection{Value of children}


The Indonesian Value of Children (VOC) Study in 1975 revealed that the Sundanese placed considerable emphasis on the psychological or emotional aspects of childbearing, such as companionship, happiness, and improved relations between spouses. This was different from the Javanese who stressed the material benefits of children, such as financial aid, assistance in household chores, and support in old age. The Javanese also placed more emphasis on economic costs than did the Sundanese. The study also showed that in both cultural groups material advantages were more likely to be mentioned by wives, rural residents, and those with less education. Conversely, psychological benefits were emphasised more by husbands, urban dwellers, and those with higher educational attainment (Darroch et.al., 1981).

The VOC survey also showed that the Sundanese did not indicate strong sex preferences and drew few distinction between sons and daughters in relation to desired characteristics. However, other studies have shown that couples in rural areas desire both sons and daughters. Sons are considered to be the backbone of the family and provide economic support, while daughters are regarded as care providers for the parents (Adiwisastra, 1996; Budiarto \& Purwatini, 1987). As for the qualities desired in children, the VOC survey revealed that strong moral qualities, especially religious habits, are the most important traits (Darroch et al., 1981).

As with the findings of the VOC survey, studies about the positive and negative values of children among Sundanese which include economic, social and psychological satisfaction and costs associated with having children, revealed that rural residents attach more positive values to children. Couples in rural areas also placed more emphasis on economic benefits than in urban areas. On the other hand, couples in urban areas focused more on the negative values and stressed psychological benefits from children (Adiwisastra, 1996; Saefullah, 1976).

\subsubsection{Village A, Sumedang}


Village A, one of 269 villages in the district of Sumedang, lies around 64 kilometres northeast of West Java's capital city of Bandung. The distance to Sumedang district centre is 20 kilometres, and to the sub-district centre is 3.5 kilometres. The village is situated at the foot of Mount Tampomas (650 m above sea level). In 2002, the village population was 3,015 people (1,453 males and 1,562 females), who formed 1,039 families with about 2.9 members each.

The total land area is 317.6 hectares, of which 64 percent is used as dry fields for fruits and vegetables, 17 percent for rice fields and the rest for houses and courtyards. Most of the houses are located around the village centre, linked to each other by concrete paths, and along the village main road. The houses are mostly made of bricks with tile roofs, only a few made of wood or plaited bamboo. The village office, main mosque, clinic, shops and schools are located along the paved main road. The village has one kindergarten, two state elementary schools, and one state Islamic junior high school.

The village is linked with the sub-district and district centre by good paved roads. Most of the villagers use public transportation, such as ojek (motorcycle taxi) or angkot (small vans, with approximately 12 seats), to go to the sub-district centre and district centre. A frequent bus service connects Sumedang with Bandung.

The family planning programme has been implemented here since the late 1970s. According to the family planning fieldworker's report, by the end of 2002, 92.6 percent of reproductive age women were using contraception. This figure was the highest in the subdistrict and well above the sub-district average of 81 percent. Injectables were the most popular contraceptive method, chosen by 67.1 percent of the users, followed by pills (10.9\%), implant (8\%), IUD (7.1\%), and female sterilisation (6.7\%). Only one man decided to be sterilised. Around 78 percent of the users obtained their contraceptives, mainly injectables and pills, from private sources. The others draw on the government facilities, i.e. the village clinic or the sub-district health centre. 
The socio-economic conditions of the residents are relatively high, as indicated by the family enumeration results (see Appendix 3 for the indicators). The 2002 data showed only one family was classified as 'pre-prosperous', while the majority were classed as prosperous levels II and III. About 58 percent of the population over 19 years old have primary education, and more than 40 percent are high school graduates. Only a few older residents have no schooling or only some primary education. Electricity and ownership of radio and TV sets are common, and nowadays refrigerators, gas stoves and VCD players are also becoming popular. A number of shops serve the village for there is no village market.

The main sources of livelihood are farming rice, fruits (bananas, salak/snake-skin fruits, rambutans, mangoes, papayas, durians), and mlinjo, as well as raising livestock (chickens, goats and ducks). The rice fields and the fruit farms are located on the outskirts of the village. Most of the farmers own a piece of land, an average of 0.1 to 0.5 hectares, and only a small number work as labourers. Mlinjo (Gnetum gnemon) is a kind of nut usually eaten with its leaves as vegetables. Mlinjo nuts can also be made into crackers, called emping, through roasting and pounding them into thin round pieces. Making emping is the main industry in this village. The process of making emping involves many kinds of work, from picking, drying, peeling to roasting, and pounding. The rich families in the village are usually involved in this business, either as owners of mlinjo trees or as wholesalers of mlinjo and emping. The other families are paid to do one of the jobs mentioned above. Some others are petty traders and carpenters, and a small number work as teachers and civil servants. Some young people work outside the village as factory workers (mainly males) or in Saudi Arabia (mainly females), but no accurate data on their numbers are available.

The village is divided into three dusun or hamlets. Each hamlet consists of two Rukun Warga or community groups, and each community group comprises 4 to 6 Rukun Tetangga or neighbourhood groups. In total there are 6 community groups and 27 neighbourhood groups. Generally, village administrative structure is similar throughout West Java, differing only in the names of the officials. In some districts, including Sumedang, the village head is called a Kuwu. A Kuwu is elected for an eight years term. In 
this village, the Kuwu is assisted by a secretary (with two staff); a Kulisi, responsible for security affairs; an Ulu-ulu, responsible for agriculture affairs; a Lebe, responsible for social welfare affairs; and three Kokolot (head of hamlet). All the officials are appointed by the Kuwu, except for the Kokolot who are selected by the villagers. Unlike the other villages in the sub-district, this village does not have tanah bengkok, a piece of land which can be used to provide income for village officials, usually as a rice field. Therefore, the Kuwu and his officials are paid using local taxes.

The Kuwu is accountable to the community through the Village Representative Board. The village's development budget and action plans have to be endorsed by the board before implementation. In 2002, aside from the government allocation and local taxes, approximately 50 percent the village's budget came from the community in the form of gotong royong (mutual self-help) or swadaya masyarakat (community self-reliance) for building community facilities such as mosques, water pipelines, schools, and also road maintenance.

According to the family planning fieldworker, the community leaders are highly respected by the people. However, the Kuwu said it is difficult now to find people who want to fill the jobs as village officials since it is more like a vocation than a job. The incentives are too small compared to the work burden. Islamic religious leaders are also highly respected by the people who are predominantly Muslims. One of the volunteers mentioned they usually ask the leaders’ blessing before undertaking any activities. She also said the religious leaders are supportive of the family planning programme, and sometimes help to communicate the programme activities through their congregation. There are two big mosques, more than twenty small mosques (musholla), six madrasah, and two pesantren (Islamic boarding schools) in the village.

\subsubsection{Village B, Subang}

The district of Subang is located 50 kilometres north of the capital city of Bandung, and covers three areas: mountainous (20\%), hilly (35\%), and plain including coastal area 
(45\%). Village B, one of 251 villages in Subang, is situated on the northern coastal area of West Java. The distance to Subang district centre is 54 kilometres, and 4 kilometres to the sub-district centre. The total land area of the village is 1,449 hectares, bordered to the north by the Java Sea. Approximately 50 percent of the area is used for fishponds, 38 percent for rice fields, the rest is for houses and courtyards.

The village is linked with the sub-district centre by a rough road, with ojek (motorcycle taxi) as the only public transportation available. One of the villagers mentioned that a couple of years ago some angkot (small vans) were ready to operate in the area but were objected by the ojek owners. The distance and difficult transportation means to Subang district centre makes the villagers prefer to go to the adjacent district of Karawang for shopping and also for seeking medical services (private doctors).

Most of the houses are built along the main village road which is parallel to the coastline. The houses alongside the road mainly belong to the rich families, while the second and third rows are mostly those of the poor (shacks with earth floors). The village office, schools, mosques, clinic, shops, and a fish auction centre are located along the main road.

The village population in 2002 was 6,056 people (2,999 males and 3,057 females) which formed 1,949 families, with about 3.1 members each. The family planning programme started at the end of 1970s, almost at the same time as in village A. The family planning fieldworker report shows that by the end of 2002, 69.5 percent of the reproductive age couples were participating in the programme, which was slightly lower than the sub-district average of 71 percent. Injectables and pills were the most commonly used contraceptive methods, 39.4 percent and 28.4 percent respectively, followed by IUD (22.1\%), and male sterilisation (9.1\%). A small percentage of women used implants or had been sterilised (about $0.5 \%$ each). Around half of the users obtained their contraceptives from private sources and the other half used the government facilities, i.e. the village clinic or subdistrict health centre. 
Residents of this village are less affluent than that of the village A, as shown by the 2002 family enumeration. More than 50 percent of the families were classified as preprosperous and about 33 percent as prosperous level I. Only about 10 percent were classed as prosperous levels II and III. The education level is also low. High school graduates comprise not more than 20 percent of population above 19 years old. About 70 percent only have primary education, and the rest have only some schooling and some are illiterate. The Village Secretary said that the low education level contributed to the village being classified among the least developed villages in the district. There is one Islamic kindergarten and three elementary schools in the village.

The main sources of income are fishing and rice farming. Milkfish and prawn are cultivated in ponds along the coastline, some on the area owned by a state company responsible for managing forests including mangroves (PT. Perhutani). The villagers are charged an annual fee for concessions to use the land. The rice fields are located around the settlement. Among those who engage in rice farming and fishing, only half own the lands or the ponds (with sizes between 0.1 to 1 hectare), the other half work as labourers. Some of the labourers work at the rice fields owned by a state company which produces rice seeds (PT. Sang Hyang Seri). Driving an ojek (motorcycle taxi) seems to be an attractive job, it is very easy to find groups of ojek waiting for passengers along the main road. Some motorcycle owners do this job between their routine works in the rice fields or fishponds. Women, both single and married, often work temporarily in Saudi Arabia, but village officials do not have the exact number.

There are 4 hamlets and 17 neighbourhood groups in this village. The village administrative structure is similar to village $A$, except that the village head is called a Lurah. A Lurah is also elected for an eight years term. The Lurah in this village is assisted by a secretary; three personnel in charge for administrative, economic and development, and social welfare affairs; several staff, and four head of dusun (hamlets). As in village A, village officials in this village are also paid using the local taxes due to the absence of tanah bengkok. 
The Lurah is also accountable to the community through the Village Representative Board. Every year the Lurah presents the village's development budget and plan to the board in the Village Development Meeting. In 2001, local taxes were the most important income source for the village (75.5\%), followed by swadaya masyarakat (community selfreliance) and gotong royong (mutual self-help) which contributed 18.5 percent of the income, whereas the government allocation comprised only 6 percent of the total income.

There is no obvious leadership in the village. The chairperson of the village family planning organisation said that nowadays village officials are no longer respected by the people. She also mentioned that the previous Lurah was toppled because of financial mismanagement during his term. According to the Village Secretary, every time a Lurah is replaced, usually all of the village officials will also resign and the new Lurah will bring in his own men. Similarly, the family planning fieldworker explained that if a Lurah or a head of hamlet is replaced, the volunteer workers will also resign. Luckily, the current chairperson of the village family planning organisation could resume her job despite the change of village officials.

The majority of the population in this village is also Muslim. However, unlike in village A, religious leaders do not play an important role in family life. The village's mosques are often empty except for Friday prayers.

Table 7.1:

Percentage of current users by contraceptive method in Village A and B, 2002

\begin{tabular}{|l|c|c|}
\hline \multicolumn{1}{|c|}{ Contraceptive method } & Village A & Village B \\
\hline Injectables & 67.1 & 39.4 \\
Pills & 10.9 & 28.4 \\
IUD & 8 & 22.1 \\
\hline
\end{tabular}




\begin{tabular}{|l|c|c|}
\hline Implants & 7.1 & 0.5 \\
Female sterilisation & 6.7 & 0.5 \\
Male sterilisation & 0.2 & 9.1 \\
Total & 92.6 & 69.5 \\
\hline
\end{tabular}

Sources: R/I/KS/02

\subsection{Implementation of the family planning programme at the village level}

The family planning fieldworkers in both villages mentioned that the implementation of the family planning programme complies with the ‘operational mechanism’ published by the family planning national office (BKKBN, 1988). This operational mechanism standardizes the systems and procedures of the family planning programme at all administrative levels. At village level, since the family planning programme is a part of the village development programmes, it is implemented within the village administrative system. Therefore, the operational mechanism acknowledges the village headman as the person in charge of the family planning programme at village level and the programme implementation is under the coordination of the Village Community Resilience Board. The village midwife, the village family planning organisation and the other volunteers carry out the day-to-day activities and report to the village headman. The family planning fieldworker, the paid official appointed by the district family planning office, acts as the supervisor and coordinator of the overall programme at village level. He/she reports to the sub-district family planning supervisor.

I will discuss the implementation of the family planning programme in the two villages by describing the village administrative structure and highlighting the role of the village family planning organisations in these villages. I will illustrate how the volunteers of these organisations perceive and perform their tasks and carry out the programme's activities as documented in Chapter 6. To maintain confidentiality, I use pseudonyms for the chairpersons of these organisations, i.e. Mrs. Ani for village A and Mrs. Budi for village B.

\subsubsection{Village administrative structure}


A village is the lowest administrative unit in the Indonesian government structure. There are two types of villages in Indonesia, the urban village called kelurahan and the rural village called desa. The headman of the kelurahan is a civil servant appointed by the district head and paid by the government, while the headman of the desa is elected by the village community. Village headmen in rural areas and their officials, particularly in Java, are usually rewarded with a piece of communal office land: tanah bengkok (Tjondronegoro, 1984, p.27). When the village does not have communal land, as in my study areas, the village headman and his officials are paid using local taxes. The main source of these taxes is the landowners. The administrative hierarchy above desa consists of kecamatan (subdistrict), kabupaten (district), and propinsi (province).

According to Koentjaraningrat (1967), the leadership pattern in West, Central and East Java is a single leadership administration, where a single leader is elected by the village community and is usually supervised by a council of elders. Religious leaders usually become members of this council. In West Java, the village headmen are generally assisted by four or five village officials, while in Central and East Java up to ten or fifteen. Each official is in charge of a specific task, such as agriculture, security, social welfare or religious affairs.

The previous law on village administration, Law no. 5 of 1979, set a standardized pattern throughout Indonesia and did not recognize traditional governance structures. In many areas, nevertheless, the traditional systems still persist and have become an integrated system within the standardized structure. Thus while on the one hand villages are uniformly administered from above, the social mechanism of internal activities has remained governed by the local customs (Tjondronegoro, 1984). This leads to many variations in village administrative systems and hence standardized or uniform regulations from above may not work.

The new law on local governance, Law No. 22 of 1999, allows village governments to be based on their origin and the local customs. In an effort to promote democracy, this law introduced a new village board, i.e. the Village Representative Board (BPD) to replace the 
Village Consultative Assembly (LMD) (Government of Indonesia, 1999) The

establishment of this village board has strengthened the separation of powers at the village level: the village board on the one hand, and the village executive government on the other. The function of this new board is as the village's 'parliament' and members of this board are elected by the village community. The board has the authority to draft village regulations and the annual village budget, and to monitor the village executive government. The village headman is accountable to the villagers through this board, and it can even propose to the district government to withdraw a village headman before the term ends. A village headman's office term is extended by this new law, from 8 years to a maximum of 10 years. The district government can decide the best period based on local custom.

Another village institution which was created by the previous law is the Village Community Resilience Board (LKMD). This village board is preserved by the new law, but now local governments can adjust its form and structure to suit their needs (Departemen Dalam Negeri, 2001a). The task of this board is to assist the village executive government in planning and implementing development programmes and to encourage community participation in the programmes. Based on the previous law, this village board has a standardized structure with the village headman as the chairperson. Members of the board are appointed by the village headman and consist of community leaders and chairpersons of community organisations, including women and youth organisations. To be able to perform its function, this board has 10 sections which represent all development sectors including health and family planning. Now, members of this board are elected by the village community. The Law No. 22/1999 also gives the villages the right to reject development projects if they are not accompanied by appropriate funds, facilities and personnel.

The administration system of the two villages of my study areas is as described above: a combination of government and traditional administration. In village $\mathrm{A}$, the village headman is called Kuwu, while in village B he is called Lurah. In both villages the village headman is assisted by six officials, who are all males, plus several staff, who are paid using local taxes. The officials are appointed by the village headman and consist of a village secretary and officers in charge of finance, general affairs, agriculture, social and 
welfare, economic and development, and security affairs. The role of the village headmen in these villages is primarily as a coordinator who decides on the broad policy outlines, while the day-to-day administrative work is carried out by the village secretary. The secretary deals with all the paperwork and makes decisions in the absence of the village headman. Hence, the secretarial duties require a moderate level of administrative expertise.

In village $\mathrm{A}$, the secretary and one of the staff, both high school graduates, have to complete all the paperwork including proposals for development projects. The secretary said sometimes the burdens are too much but they cannot expect the other officials, who are mostly old people with only primary education, to do such complicated tasks. Therefore, he points out that now is the time for 'regeneration' and he expects the next village headman will appoint younger and more educated village officials. However, as stated by the current village headman, it is difficult to attract young people to fill the jobs because of the low payment. Since the village does not have tanah bengkok or office land (see above), the officials' income depends on the local taxes. Unfortunately, the village headman lamented that they have never been able to collect 100 percent of the taxes. Therefore, as he puts it, being a village official is a dedication to the country and can be regarded as heroic.

A similar condition was found in village B. The village secretary, who has had a longer period of office than the village headman, points out that most of the village officials are incapable of performing their tasks appropriately despite their relatively high education level (mostly high school graduates). So, he has to do most of the paperwork. Therefore, he suggests the district and sub-district governments should provide training programmes for the village officials. With the absence of communal land (tanah bengkok), this village also has to rely on local taxes for its officials' payment. As with village A, the village secretary also stated that working as a village official is a dedication since the community’s willingness to pay tax is still low. He also mentions that the low rate of tax payment affects the implementation of the village development programmes.

A Village Representative Board has been established in both villages since 2000, and has performed some of its functions. In village A, the chairperson of the board is a retired 
staff member of the Ministry of Education sub-district office, while in village B the board is chaired by a former hamlet headman. Village headmen in the two villages present their accountability reports to the board at the annual Village Development Meeting (Musyawarah Pembangunan Desa) ${ }^{7}$. The objective of this meeting, which is attended by all village institutions, is to discuss the village development programmes and budget for the following fiscal year. For 2003, village A was planning to hold the meeting in January but was still waiting for the budget forms to arrive from the sub-district office. The budget allocation system requires the villages to fill certain forms and submit them to the subdistrict office. Village B was scheduling the meeting in March, but had not conducted it by the time I finished my fieldwork there at the end of March.

\section{Hamlet}

In Indonesia, hamlets are known by various names, such as dusun, dukuh, or kampung. In these villages, the hamlets are called dusun, hence the hamlet headmen are officially called kepala dusun. Aside from the official name, they are also referred to in local terms, i.e. kokolot in village A and wakil in village B. A hamlet headman serves as the village headman's assistant for a particular area and is elected by the community in that area. His main duty is to relay information or instructions from the village officials to the villagers under his auspices. There is no formal limit to the hamlet head's term of office. In these two villages, almost all of the hamlet headmen have only primary education, except one in village A who is a high school graduate and has a double job as a village staff member. As with the village officials, a hamlet headman is a low paid job and hence needs dedication.

\subsubsection{Village family planning organisations (PPKBD)}

As discussed in Chapter 6, in the beginning the function of the village family planning organisations was merely as contraceptive distributors and they were referred to as the Village Contraceptive Distribution Centres. At that time, they served as the extension of the

\footnotetext{
${ }^{7}$ Musyawarah Pembangunan Desa is a part of the regional development planning process, a similar forum is held at each administrative level, from sub-district to provincial level. The objective mainly is to draw the
} 
fieldworkers. Over time, their function has broadened to become community organisations with the task of managing and implementing the family planning programme at village level. These centres later became known as the PPKBD. A PPKBD is expected to be able to mediate the needs of the community and to incorporate bottom-up aspirations and topdown policies (BKKBN, 2001b).

In order to facilitate the PPKBD in performing their role, the guidelines from the central office lay out six tasks that should be carried out, which include : 1) organisational development (to form a 'collective’ structure); 2) regular meetings with the other kaders, family planning fieldworker, and other parties; 3) information, education, communication and counselling; 4) services provision (contraceptive services, referral, and family empowerment activities); 5) recording and reporting; and 6) self-reliance efforts (BKKBN, 1999b). However, in each village the PPKBD operates differently.

\section{Village A}

Mrs. Ani, 43 years old, started to work as a volunteer for the family planning programme in 1982. However, she could not remember when was she officially became the chairperson of the village family planning organisation. She said there was a letter of appointment (Surat Keputusan) from the village headman, but she could not find it anymore. According to her, at first the family planning fieldworker asked her to help promoting the programme since she had been using contraceptives since 1979. She said:

In 1982 I was asked by the family planning fieldworker and the village officials to become a volunteer for the family planning programme and a kader for posyandu. I told them that I'm uneducated, I have only a primary education, and poor so how can I become a kader? They said that it is not important, the most important thing is my willingness to work. The fieldworker also said that she would teach me. So, on 16 October 1982 I started to work as a 
kader. I conducted posyandu, weighing under-five children and distributing contraceptive pills to their mothers. I told them to come to my house every time they need the pills. At that time they did not have to pay for the pills, they could get as many as they want. I got the pills from the fieldworker. That's how I started to work as a family planning volunteer. It was hard in the beginning, but I enjoyed my work and I always wanted to improve my knowledge. (Mrs. Ani).

Since then she has double tasks, as the posyandu coordinator and as the volunteer for the family planning programme. Since 16 October 1982 until now, the posyandu opens on the $16^{\text {th }}$ of every month. Mrs. Ani said she learned to do the jobs little by little, trained and supervised by the family planning fieldworker, the midwife and other government workers from the sub-district. For example, in the beginning she did the home visits together with the family planning fieldworker, but gradually she was trusted to do it herself. She also had received various training in family planning (e.g. counselling, early childhood care, and income generating activities), in health (e.g. baby care, basic medications, and medicinal herbs), and also in making emping (from the Ministry of Industry).

Upon being asked the reason why she wanted to work as a volunteer, Mrs. Ani said:

I wanted to help the implementation of development programmes in my village. Our village needs those programmes. I wanted the family planning and health programmes to be developed. That was my motivation. I like to watch the villages with successful family planning and health programmes presented on TV, and I wanted my village to be like that. (Mrs. Ani).

When asked further whether she was aware that as a volunteer she would not get any payment, she said the family planning fieldworker had told her that it was an unpaid job and she did not mind. She stated:

I knew from the beginning that this is volunteer work and I will not get paid. The family planning fieldworker said I will only get transportation fees for meetings at the sub-district 
office and I said it doesn't matter. My family, the village officials and all kaders have always been supporting my activities, that encouraged me even though I don't get any payment. As a family planning volunteer I have the opportunities to participate in many activities outside the village. I often take part in competitions held by sub-district or district offices, and I have won many prizes. Besides, the villagers often give me presents to show their gratitude after I accompanied them to the sub-district clinic or district hospital for getting contraceptive services. We have good relationships now, we are like family. So, I feel lucky to become a family planning volunteer. (Mrs. Ani).

With regard to the structure of her organisation, Mrs. Ani maintains that it has a 'collective' structure as outlined in the guidelines, comprising herself as the chairperson, a secretary, a treasurer and a volunteer for each of the six hamlets. This organisation is separated from the village administrative structure but is still under the coordination of the village headman.

Figure 7.1.

Organisational Structure of

Village Family Planning Organisation (PPKBD) in Village A

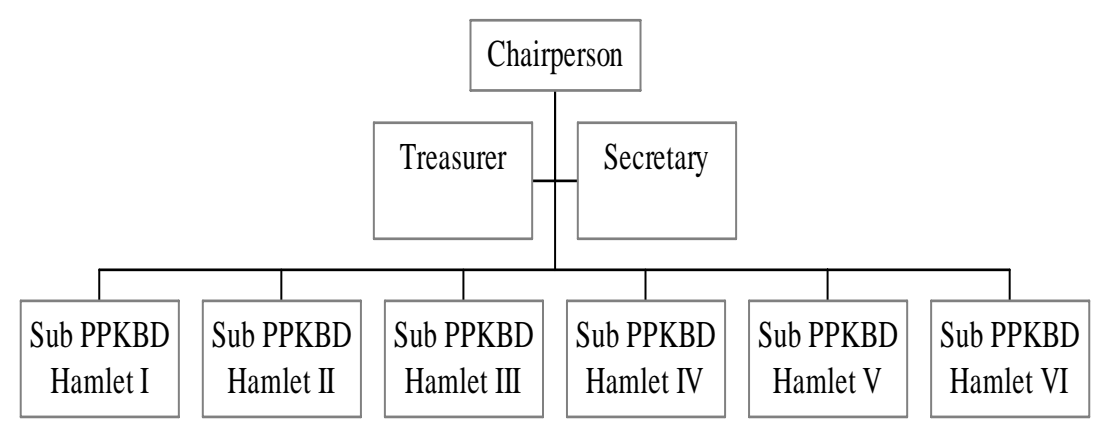

The secretary and the treasurer have double jobs as volunteers for their hamlet (Sub PPKBD). However, Mrs. Ani admitted that they do not stick to the structure in their daily activities. She handles the secretary's and treasurer's tasks for there is not much to be done. 
She explained that they do not have operational funds to be managed by the treasurer and she prefers to do all the paperwork herself, especially the recording and reporting. She pointed out that it is important for her to know all the details of the programme in her village so she can answer anytime she is asked by the family planning fieldworker, village officials or other officers from sub-district and district levels. Besides, Mrs. Ani said it is better for the secretary and the treasurer to concentrate on their work in the hamlets. It is already hard for them since they are also responsible for the posyandu activities and some other programmes, so she does not want to give them additional burdens.

Regarding the organisational structure, the fieldworker in village A explained :

The key factor is the person, not the structure. Mrs. Ani has been working for 20 years, and she always shows a high commitment to the programme. We have a collective structure, with a secretary and a treasurer, but they do not perform their function. Even though the activities are managed by only one person, the programmes run well. So, it is the person who determines the success of the programme, not the structure. (PLKB, A).

The hamlet volunteers are selected by Mrs. Ani together with the fieldworker and the village head's wife from the existing volunteers in each hamlet. Mrs. Ani chose the ones that have worked the longest period because they are considered to be the most knowledgeable about their hamlet. All the hamlet volunteers are middle-aged women and some already have grandchildren. Mrs. Ani pointed out she has to be careful in working with them, particularly with those who are older than her. Using the same approach as the fieldworker, Mrs. Ani said she has to show her respect to them and cannot give instructions or criticize them when they make mistakes. Mrs. Ani seems to be successful in her approach since all the hamlet volunteers have shown similar enthusiasm and commitment to the programme as she does.

The multiple roles among volunteer workers are common. As revealed by a study of kaders (Judd, 1987) and village family planning organisations (Arsyad et al., 1996; BKKBN \& FKM-UI, 1999), most of the volunteers work as kader for several programmes 
simultaneously. In the case of Mrs. Ani, beside being the chairperson of the village family planning organisation and the posyandu coordinator, she is also in charge of distributing the government subsidised rice for poor families every month and for processing certificates for poor families to get free medical services at the sub-district clinic or district hospital. She is also active in PKK (see Chapter 6), assisting the village head's wife, as the chairperson of $P K K$ at village level, in carrying out the day-to-day activities including attending meetings at sub-district or district level. Mrs. Ani is also the only woman in the village to become the chairperson of the neighbourhood association, a position which is traditionally held by a man. She is also the chairperson of the Qur'an learning group in her neighbourhood. Mrs. Ani said she has so many jobs that it is difficult to mention them one by one. When asked whether these multiple functions affect her work for the family planning programme, Mrs. Ani said:

These activities have become my routine job every month, except for $P K K$ meeting which depends on the village head's wife. I don't have much problem in carrying out these activities, but making the records is time consuming. (Mrs. Ani).

Mrs. Ani's husband is the village official in charge of social and welfare affairs. According to the fieldworker, this might be one factor that has allowed Mrs. Ani to stay for a long time in her job. Mrs. Ani’s husband understands and supports her work, and they often work hand in hand in providing the services to the community. Mrs. Ani also said her husband and children often help her with the chores at home if she is busy with her work, although it is not common for an Indonesian man to do household chores. However, she mentioned that she always does her best with her duties at home so that her husband will not have reasons to complain. She also tells the kaders to pay attention to these matters. The activities at the village, such as posyandu, usually starts after 9 a.m. to give the kaders an opportunity to do their household chores and finish at lunch time. Mrs. Ani and the other kaders also do the home visits during this time or in the afternoon and they seldom have activities in the evening except for pengajian (Qur'an learning). 
Mrs. Ani has also been selected to be the coordinator of the village family planning organisations at her sub-district. As a coordinator, her tasks include disseminating information from sub-district and district family planning offices to her colleagues from the other villages and representing the sub-district for meetings and other activities at district level. She said she enjoys her work very much. She pointed out that positive responses from the people encouraged her to always improve her work. It seems all her hard work is paying off. Her village is often chosen as a model for family planning and health programmes. Mrs. Ani said she is proud when her village is praised at sub-district or district meetings, this motivates her to improve her performance. In 2001, her village was selected as the training site for family planning district officials from all over West Java.

According to the family planning fieldworker, Mrs. Ani is now regarded as one of the community leaders. She is respected by the village officials and all villagers, not only the kaders. The fieldworker mentioned that some villagers had even asked Mrs. Ani to run as the candidate for the next village headman election which was due on August 2003, seven months after my fieldwork.

\section{Village B}

Mrs. Budi started to work as a kader in 1992 when she had just finished her junior high school. She is now 28 years old. The village officials asked her to become a kader for posyandu after she participated in a Qur'an reading competition. In 1993, the family planning fieldworker asked her to become a volunteer worker for the family planning programme replacing the volunteer at that time who was a male. According to the fieldworker, it was better to have a female volunteer since most of the family planning users were women. Mrs. Budi commented:

I told the family planning fieldworker that I don't think I can do it, but she said she would teach me and I can learn step by step while working. I eventually accepted the offer because I need to work, I could not continue my study after finishing my junior high school. I thought it was a good opportunity because I did not have the courage to work outside the village, let 
alone to go to Saudi Arabia as some of my neighbours did. Perhaps this is my world, so here I am. I have been working for the family planning programme for ten years, there were good times and bad times, but I had more bad times I guess. (Mrs. Budi).

Upon being asked about the structure of her organisation, Mrs. Budi herself was not sure about it, she said:

I don't remember the structure, we can see it at the village office, but as far as can I recall there is no secretary and treasurer. It's only myself as the chairperson and the hamlet workers. I don't think we need a secretary, what will I do if we have a secretary? What I need most are additional volunteers who can work for a long period. It's difficult to find people who want to work as kader. It's hard for me now to work with only a few kader, especially during family enumeration. (Mrs. Budi).

The fieldworker confirmed that the existing structure was the 'single person' type. He mentioned that such a structure is more suitable for their current condition, considering the difficulty finding volunteers and the load of the administrative work.

Figure 7.2.

Organisational Structure of

Village Family Planning Organisation (PPKBD) in Village B

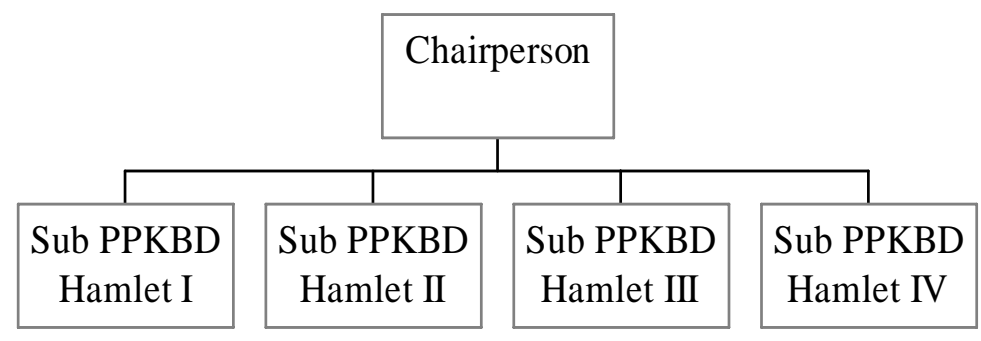

Unlike Mrs. Ani who is a pure volunteer worker, Mrs. Budi is also a village staff member, under the official in charge of social and welfare affairs. She is the only female staff member. Therefore, her organisation is also considered a part of the village bureaucracy. Mrs. Budi said she is needed by the village to help the village head's wife to 
run the $P K K$ programme, which is coordinated by the officer for social and welfare affairs. Regarding this position, the sub-district family planning supervisor said:

It is the village policy since they need somebody to help the village head's wife to implement the $P K K$ programme. Mrs. Budi is considered to be capable of doing the job, so she has double tasks, implementing family planning and $P K K$ programmes as the partner of the village head's wife. Some other villages have the same policy. The family planning district office gives the villages a freedom to decide the structure that suits their need. (PPLKB, B).

The fieldworker said that Mrs. Budi needs more kaders to help her. At the moment, they already have a volunteer for each hamlet but some are quite new and they have not been able to do the required duties properly. As in village $\mathrm{A}$, the hamlet volunteers are selected by Mrs. Budi. However, she mentioned that she does not have many choices. With regard to the difficulty in recruiting kaders, the fieldworker stated:

It's not easy to recruit volunteers. Some people are capable but they are reluctant, others are willing but their education levels are too low. The most important thing for me is willingness since this is volunteer work. Usually those who want to work are relatives of the hamlet headmen. In the beginning, we only give them easy tasks. Mrs. Budi helps me to teach them. We have to be very patient. Sometimes Mrs. Budi and I visit their houses to encourage them. I think our attention and appreciation of their work are important for them. (PLKB, B).

Mrs. Budi and the fieldworker mentioned many of the women they approached declined to work as a kader and the most stated reasons are 'shy', 'feel inadequate', and 'don't have time'. In addition, Mrs. Budi and the fieldworker also have problems in persuading the kaders to stay in the job and the turn-over is high which is due to a variety of factors including marriage, having small children, or moving away from the village. The other factor is the kaders' association with the village headman or hamlet headmen. Since it is difficult to find people who are willing to do the job, the village leaders often ask their own relatives to become kaders. However, if these leaders are no longer in office, because their term ends or they resign, the kaders leave. 
Regarding her routine tasks as the chairperson of the village family planning organisation, Mrs. Budi said:

I have to come to the village office everyday, I always come unless my daughter is ill. I often have to go to the sub-district family planning office. The transportation fee is provided by the family planning office or by the village. We have monthly meetings with all the organisations from the other villages. In the meeting, the sub-district supervisor informs us about the programme for the following month. After the meeting, I pass on the important information to the kaders. I do not hold a regular meeting with the kaders, we meet only for urgent matters, like preparing the family enumeration. The sub-district supervisor often calls me if there is going to be a free sterilisation service at the district hospital, I have to look for the prospective acceptors through home visits. The fieldworker and I usually do the home visits together, but if I am busy the fieldworker goes alone. I also have to attend the posyandu every month. That's all my tasks. We don't have the income generation project anymore. As the coordinator of the village family planning organisations, I sometimes go to the district office to represent our subdistrict. (Mrs. Budi).

Apparently, her position as a village staff member affects the way Mrs. Budi performs her tasks in the family planning programme. She mentioned that she does her work only during office hours and she does not want to work on weekends unless instructed by the family planning fieldworker or the sub-district supervisor. The village midwife complained that Mrs. Budi never shows up if they open the posyandu on Saturday, despite the fact that she is the posyandu coordinator. Mrs. Budi explained that on weekends she has to do the household chores. She said she wanted to do well both at work and at home.

As with Mrs. Ani, Mrs. Budi has been the coordinator for village family planning organisations in her sub-district since 2001. She said the sub-district supervisor asked her to become the coordinator because she had been in the job longer than her colleagues from the other villages. As a coordinator, she often represents her sub-district in district activities. She said she is happy every time she has the chance to go to the district. She also had received various training programmes, e.g. posyandu, early childhood care, and “Participative Plan for Village Community Development” (by the Ministry of Internal 
Affairs). The sub-district supervisor also often asks Mrs. Budi to help her accompany the villagers going to the district hospital for sterilisation.

Mrs. Budi said what motivates her to stay in her job is the support from her parents and siblings. Her family support her choice because according to them this job is the best for her. She is divorced now, and she and her daughter now live at her parents' house. According to her, she and her husband were divorced because her ex husband went back to his hometown in another district since he could not find a permanent job in her village. She said even with many skills he possessed including carpentry and making handicrafts, it was hard to find a job and they could not start their own business because they did not have the capital. Mrs. Budi did not want to go with him because she did not want to leave her parents. As a single mother, Mrs. Budi is now the income earner for herself and her daughter. Therefore, she often expressed her concern regarding the payment from the village. She stated:

I knew that basically this is volunteer work, but as a village staff I'm entitled to payment from the village. The problem is we have to collect the money from the taxpayers ourselves, so we don't automatically get as much as it has been allocated for us. It depends on how much we could get from the taxpayers. As a woman I cannot be as aggressive as the other male staff, so I usually get only around half of it. Luckily, I still get income from the pills sales otherwise I'll quit. (Mrs. Budi).

It can be seen that Mrs. Ani and Mrs. Budi have different characteristics. They have different perceptions about the job. Mrs. Ani truly sees it as volunteer work and a commitment to help the community, while Mrs. Budi perceives it as a main source of livelihood. This distinction was reflected in the way they carried out their tasks.

As discussed above, village family planning organisations are expected to have a collective structure as laid out in the guidelines published by the national office (BKKBN, 1999b; 2001). Although previous studies conclude that village family planning organisations with a collective structure show better performance (Arsyad et al, 1996; 
Rijadi, 1988), there is little information on how these organisations operate. The case of village A shows that despite the collective structure, the activities of the organisation are managed by a single person, i.e. the chairperson.

\subsubsection{Family planning activities}

As mentioned above, the family planning programme started in the two villages almost at the same time, that is in the late 1970s. During this period, as the programme's policy was shifted from the clinical approach to the community-based approach, West Java began to establish village contraceptive distribution centres. These centres later became the village family planning organisations.

Within a particular village, good coordination between the family planning fieldworker and the village family planning organisation are crucial for programme implementation. In both of the study areas, the family planning fieldworkers maintain that they act as pembina (give guidance) and avoid an employer-employee relationship with the personnel of the village family planning organisations. When referring to the chairperson of the village family planning organisation, the family planning fieldworker at village B stated that:

I always treat Mrs. Budi as a colleague, not as somebody with a lower position. I don’t give instructions to her, but we work together. It's for the sustainability of the programme. For example, if we have to visit all the hamlets for data collection, I usually ask her to work at hamlets close to her house because she doesn't have a motorcycle, and I take the rest. (PLKB, B).

A similar perspective was suggested by the sub-district family planning supervisor in Sumedang who said that the most important principle in working with volunteers is to avoid giving instructions or orders. In addition, he stressed that the fieldworker should be able to work together with the volunteers and they should learn the village norms and values to avoid any misunderstandings. This circumstance is illustrated by the family planning fieldworker at village A as follows: 
In fact, it is me who learns from Mrs. Ani and the other volunteers here, especially on how to deal with the villagers. They even monitor and evaluate my work. They often give suggestions on how to do the activities and they always help me with information regarding the characteristics of the people here. Before I started my duty here, my supervisor told me to be careful in working with Mrs. Ani since she is highly respected by the villagers and the volunteers. The volunteers are very 'loyal' to her. They even say they are going to resign if Mrs. Ani resigns, they don't want to work with somebody else (PLKB, A).

As described in the guidelines (see Chapter 6), the family planning programme at the village level comprises four groups of activities: 1) Family planning and reproductive health services, which include contraceptive delivery services, referral for side-effects of contraceptive use, general information and individual counselling; 2) 'Prosperous family'/family empowerment programmes, which include income generation, information/education about best practices of early childhood, youth and elderly care, and also to raise support for the needy; 3) Information, education and communication of basic family planning principles; and 4) Recording and reporting of the programme achievements and family enumeration.

The family planning fieldworkers in both villages mention that ideally every village should carry out all of the above activities. However, these two villages focus more on contraceptive and reproductive health services, along with information, education and communication (no. 3) and recording and reporting (no. 4). The family empowerment programmes (no. 2) seem to be less developed constrained by a lack of training and technical support.

\subsubsection{Family planning and reproductive health services}

As documented in Chapter 6, the programme adopts a 'cafeteria' system for contraceptive delivery which offers a range of contraceptive methods from which the user can choose. Poor families are entitled to free contraceptives, particularly IUDs, implants and sterilisation. The programme also requires its facilitators to conduct counselling which 
allows the prospective user to make an informed choice. In both villages, the fieldworkers and the volunteers claimed they had provided counselling. Mrs. Ani, who had received training on inter-personal communication and counselling, stated:

Unlike in the past where the contraceptive methods were determined by the fieldworkers without explaining the side effects, now we explain all the good and bad sides of each method and let the user choose. I like this approach better, because it prepares the user for any unpleasant side effects and I will not be blamed should they experience these side effects. (Mrs. Ani).

In village $\mathrm{B}$, Mrs. Budi also stated that nowadays family planning users can choose any method they wish to use. She said:

In the past we can tell them to use a certain contraceptive method, but now we cannot do it anymore. The family planning fieldworker has told me to avoid any pressure and let them to choose. Besides, the villagers also said they have the right to decide what is the best method for them. (Mrs. Budi).

The most popular methods in these two villages are injectables and pills. This is similar to the other parts of Indonesia as shown by the 2002/3 Demographic and Health Survey (CBS et al., 2003). According to the village midwife, many women in village A are reluctant to use IUDs because of the insertion process. Even if the insertion is performed by female health personnel, the women still feel uncomfortable. Sterilisation and implants are starting to gaining popularity in village A, where Mrs. Ani said some women are even willing to pay by themselves. They said it is better to pay for these long-term methods than for the monthly injectables or pills. Mrs. Ani also said she has accompanied 27 women for sterilisation service at the district hospital. Some of them are poor women (from 'preprosperous' or 'prosperous level I' families) who are entitled to free sterilisation service and the others are the better off who pay for themselves. They usually go by a chartered van. The transportation costs for the poor women are subsidised by the family planning office or the village office, while the better off pay for themselves. Like the other parts of Indonesia, in these villages condoms are not popular as a family planning method. This is 
due to the notion that family planning is women's business and also to the image of the condom as a prevention for sexually transmitted diseases. The focus group discussions with male adolescents confirmed this perception. In village $\mathrm{B}$, upon being asked about their intention to use family planning methods after they get married, some of them said, "We do not have to use condoms with our wives...”

In village B, Mrs. Budi explains that rumours of its side effects makes the IUD unpopular. The rumour has it that there were women who got sick and died of excessive bleeding after being forced to use IUDs in the late 1980s. According to Mrs. Budi, many of the women who are currently using IUDs obtained the method during the 1990s, when they did not have many other choices but to use it. Sterilisation and implants are also not popular: the women are afraid to use them. Mrs. Budi said that once she was supposed to accompany a woman to the district hospital for sterilisation, but the woman changed her mind at the last minute because she was afraid. The village midwife also explained that the opportunity to get free services for implants and sterilisation was used not only by the poor but anybody who was interested.

Except for pills which can be obtained from the family planning volunteers, the other methods are provided by health professionals at the village clinic, sub-district health centre, or district hospital. The village family planning organisations in the two study areas provide pills, obtained from the family planning fieldworkers or bought from drugstores. However, the villagers can no longer get the pills free as in the past, they have to buy them. The district family planning offices allow village family planning organisations to sell the pills to support their activities for there are no operational funds provided by the programme. As an effort to enhance their self-reliance, village family planning organisations are also allowed to become the 'sales agents' for commercial contraceptives in collaboration with local drugstores (BKKBN, 1999b; 2001). Mrs. Ani said she sells the pills for Rp. 3,500 to Rp. 5,000 (US\$ 0.50 to 0.65 ) per package for one month’s supply depending on the brand, and gets Rp. 1,000 (US\$ 0.15) from each package. The profits are used for transportation costs, meetings or purchasing office supplies. Mrs. Budi also obtained the pills from the family planning fieldworker or drugstores. Every month she 
receives 30 to 50 monthly packages from the fieldworker, which she sells for Rp. 2,500 (US\$ 0.30) per package. Mrs. Budi said the price is determined by the district office who controls the price of pills provided by the programme. In this district, profits from pills sales are mainly intended as incentives for the volunteers. To avoid the notion that a village family planning organisation is selling pills from the government programme, they use the term 'returning the transportation cost'.

The village midwife plays a central role in delivering contraceptive and reproductive health services at the village level. She provides her services at the village maternity clinic. The deployment of the midwives and the establishment of the clinic in every village is a joint effort of the Ministry of Health, the NFPCB and the Ministry of Internal Affairs aimed mainly at reducing the maternal mortality rate. Within the clinic, the midwife provides maternal and child health care and contraceptive services including referral for side effects under the supervision of the sub-district health centre. Under this programme, traditional birth attendants have also been trained for safe delivery practices and provided with a delivery kit. They are now working in partnership with the village midwife. This programme has become one of the factors that contribute to the reduction of infant and maternal mortality rates. The midwives in the study areas have worked together with traditional birth attendants and with this collaboration they have been able to encourage village women, who previously preferred to give birth at home assisted by the traditional birth attendant, to go to the clinic for prenatal care and delivery.

In village $\mathrm{A}$, the family planning fieldworker, who is also the village midwife (she is one of the family planning fieldworkers trained as midwife with scholarships provided by the NFPCB in the 1990s), mentioned that there was no coordination problem between family planning and health programmes. As a midwife, she is automatically the staff of the subdistrict health centre. She maintained she does not have a problem in working with the other clinic staff and she has the same authority as the other midwives. According to her, the other family planning fieldworkers also have good relationships with the health centre staff. In village B, Mrs. Budi said the teamwork with the village midwife works pretty well although the midwife claimed that Mrs. Budi is too busy with her family enumeration. The 
midwife wished Mrs. Budi would pay more attention to other tasks, such as completing the posyandu register (register for pregnant women and under-five children). She also said Mrs. Budi often fails to give attention to post-partum women to remind them to use contraceptive methods after 40 days.

Family planning services are also provided through posyandu (see Chapter 6). In these villages, posyandu activities are regularly conducted every month. In village A the posyandu opens on the same date every month, on the $16^{\text {th }}$, at the village hall. This fixed date is well memorized by the villagers, so the volunteers do not have to remind them to come. The village midwife is always present, as well as Mrs. Ani and the other volunteers. In village $\mathrm{B}$, because of the large area of the village, the posyandu opens at each hamlet. Every month a team consisting of the village midwife or a nurse (the midwife's husband), Mrs. Budi and some volunteers moves from one hamlet to another using motorcycles. Sometimes the family planning fieldworker joins this team. There is no fixed schedule for the posyandu, it depends on the availability of the midwife or the nurse who does the immunization. So, every month the hamlet headmen have to inform the villagers a day before the posyandu team come to their hamlet. The hamlet headman and head of the neighbourhood groups in each hamlet always help the team in carrying out the activities. It's interesting to see these men involved in posyandu since it is commonly regarded as women's activity and usually carried out and attended by women only, as in village A. In both villages, the posyandu provide family planning and health services, i.e. weighing of under-five children; immunization for children and pregnant women; distribution of vitamin A for children and iron tablets for pregnant women; prenatal care; and information sharing regarding nutrition, health and family planning. However, since the establishment of the village clinic, most of the contraceptive services have been provided by the clinic.

\subsubsection{Information, education and communication}

At village level, these activities are focused on the person-to-person and group forms of communication. This strategy is more effective than using mass media since in rural areas 
most people do not read newspapers or magazines and they listen to the radio or watch TV mainly for entertainment.

In village A, Mrs. Ani mentioned that she carries out information sharing not only in posyandu, but also during any other opportunities, including in the class for Qur'an learning (pengajian). She also does it through home visits or even when she meets her target person on the street or while shopping at the village shops. Mrs. Ani said it is impossible to encourage a woman to use a long-term contraceptive method at just one meeting, it has to be repeated several times. Mrs. Ani said she prefers to hold the conversations in an informal way, it is more effective since the women are more relaxed and they do not feel pressured or forced. The village midwife confirmed Mrs. Ani’s statement and said many of the women who come to the clinic to get long-term contraceptive methods are 'the products' of Mrs. Ani’s repeated home visits. Mrs. Ani also asked the religious leaders to help by conveying positive messages. Since the people in village A are known as devout Muslims, Mrs. Ani said the role of the religious leaders is very important in encouraging the acceptance of family planning and in convincing the people that family planning methods, except abortion, are allowed by their religion. According to Mrs. Ani, the religious leaders are very supportive of the programme.

Since most of the families in the village have only two children and the awareness of using family planning methods is already high, Mrs. Ani mentioned that now the messages are no longer focused on 'two children are enough' as in the past. Now, the information is focused on the reproductive health concept (e.g. to bear children between the age of 20 to 30 years old) and the use of long-term contraceptive methods, along with the campaign to draw on the clinic/midwife services for prenatal care and delivery. According to her:

Nowadays most families wish to limit the number of their children to two. People often say that they do not want to have many children who are just hanging around on the street because they cannot send them to school, it's useless. The people here also learn about family planning from TV. Sometimes people come to me asking for the contraceptive methods they saw on TV. In the past, it was the [family planning] programme who needed the acceptors, but now the 
acceptors need the programme, the contraceptive services. With all the information, nowadays even village people are knowledgeable about family planning. (Mrs. Ani).

For newly wed couples, Mrs. Ani said she often shares the information through their mothers. Early marriages are still practiced by some people in this village, where a marriage is arranged soon after a girl finishes her elementary school. However, these young couples tend to delay the first pregnancy by using family planning methods. Mrs. Ani said it is common for mothers to come to buy pills from her for their newly wed daughters who are still shy of seeking family planning services. Therefore, she gives the family planning information through the mothers.

In village B, Mrs. Budi mentioned that information sharing is mostly carried out during posyandu, and sometimes during the Qur'an learning class or when she meets the women around the village. Since injectables and pills are the most popular methods, there are cases where women get pregnant because they cannot afford to pay for the products regularly. Therefore, Mrs. Budi said she promotes long-term methods to maintain the interval between births, i.e. a minimum of 3 to 5 years as stated in the guidelines. She also encourages women with more than four children to be sterilised or to use implants, which are free of charge for poor families. She gives the information about contraceptive side effects together with the midwife during posyandu.

However, Mrs. Budi lamented that it is often difficult to carry out the information sharing during posyandu since the women tend to go home as soon as their children have been weighed or immunized. Besides, due to lack of volunteers, Mrs. Budi is often too busy filling the register and does not have time to talk to the women. Mrs. Budi also complained about the community responses. She said she once gave a group lecture about the advantages of family planning and various contraceptive methods using the 'IEC kit' provided by the fieldworker (after training from the fieldworker to do it), but only a few women showed up. She said villagers do not value the information if it is given by her or the other volunteers because she is just one of them and has a similar education level with them. Therefore, she suggested it is better to have government personnel or fieldworkers to 
come to the village to provide the information. According to her, even the village officials are not 'heard' by the villagers, because they are no longer respected as in the past. She said if the village headman mentioned about family planning in a speech, the villagers would say “We already know about it, you don’t have to tell us anymore, just don’t force us”.

Unfortunately, according to Mrs. Ani and Mrs. Budi, men are not interested in the information and do not participate or discuss the matter. However, this might be due to the programme’s focus on women. Mrs. Ani and Mrs. Budi revealed that family planning information sharing and activities are carried out mainly in posyandu where men rarely attend. Many male informants stated they were not familiar with the family planning workers' activities in the village and they seldom had contact with these workers.

\subsubsection{Family empowerment programmes}

These programmes consist of income generation activities and information/ education about the best practices in early childhood, youth and elderly care.

Within the income generation projects, the tasks of village family planning organisations are to identify the women eligible for credit (from families classified as 'preprosperous' and 'prosperous level I'), to form groups with around 20 women as members, and to help them to obtain the credit schemes and developing their businesses.

In village $\mathrm{A}$, the family planning fieldworker has formed two groups who have used the credit to make emping, banana chips, and rice crackers. However, difficulties in marketing and managing the credit hampered these women from further developing their businesses. Members of the groups mostly discontinued their businesses once they had paid back their credit. Mrs. Ani said only emping making is still running, with the volunteers often helping in promoting the products to the staff of government offices at the district centre. In village $\mathrm{B}$, the fieldworker has also formed two groups with fish paste making as their business. For the same reasons as in village A, these groups were not able to continue their businesses. 
Some members could not even pay back their credit because they did not make enough money. When asked about her role in the project, Mrs. Budi said she did not know much about it, as it was the fieldworker who managed the project.

The other activities of the family empowerment programmes are information and education about the best practices in early childhood, youth and elderly care. Families, usually represented by the wives, are grouped for each activity, i.e. those who have underfive children, teenagers, and elderly parents. The tasks of the village family planning organisations are to form the groups and to help the volunteers in implementing the activities, i.e. organising group meetings in which the information sharing is carried out. Volunteers can lead the information sharing by themselves or invite government fieldworkers or other knowledgeable individuals to give a lecture to group members. Although the programme for early childhood care has been introduced since the 1980s and the chairpersons of village family planning organisations and some volunteers had received some training, they said they could not carry out group meetings without the fieldworker's assistance. They point out that the topics of this programme are too difficult for them to understand with a short period of training. In village A, Mrs. Ani said the schedules of these activities depend on the availability of the fieldworker, while in village B all of these activities are no longer held. Mrs. Budi stated she has been told to maintain these activities but she said it's difficult to gather the women aside for posyandu.

The family planning fieldworkers in both villages agree that organising these activities is quite difficult for the volunteers. Continuous supervision and assistance is needed for the programme to run. The fieldworker in village B also mentioned that the problem of high turnover rates of volunteers adds to the difficulties. With limited resources, it is impossible to have frequent training programmes for the new volunteers. He pointed out that one of the reasons for the high turn over rate is the volunteers' association with the village or hamlet headman. The fieldworker said:

We previously had two groups for early childhood care in two hamlets, but after the hamlet headmen were replaced the groups became inactive since the volunteers were the previous 
headmen's relatives. That's the problem here, any changes in the village power could affect the programme implementation since most of the volunteers are the village or hamlet headman's relatives. (PLKB, B).

According to the guidelines, the groups for income generating activities and for family education are established as a 'vehicle' to hold the activities of the family empowerment programmes. Hence, these groups are parts of the village family planning organisations, and their activities are supposed to be coordinated and supervised by the organisations. However, in the two study areas these groups were formed by the family planning fieldworkers. Their establishment is a part of the fieldworkers' plan and the village family planning organisations' tasks are only to help carrying out the groups' activities. This fact is in agreement with the findings of the study by the NFPCB and the University of Indonesia (BKKBN \& FKM-UI, 1999), that many of the groups were formed by the family planning fieldworkers and were not based on the village family planning organisations' work plan. Since the groups involved with family planning programmes received direct supervision from fieldworkers, there was no working relationship with the village family planning organisations.

\subsubsection{Activities recording and family enumeration}

In village A, Mrs. Ani said she always tries to have accurate and up-to-date records and family lists as a basis for the programme’s activities. Besides, according to her, the village's achievements cannot be assessed without proper and accurate records. The information is gathered not only from the volunteers but from the villagers as well, such as information on births. She also conducts home visits, especially to the poor families, to get first hand information regarding their problems and to see what she can do to help them. She said:

I want to see with my own eyes...the factual information...so I know the target for services like free sterilisation, free medical services, and subsidised rice, and I can propose that to the village headman or the family planning fieldworker. (Mrs. Ani). 
Mrs. Ani holds a monthly meeting with the hamlet volunteers to verify and prepare the records and update the family list. In addition, she uses every occasion she meets the volunteers to update her record. The volunteers always inform her of any changes that take place in their area, e.g. changes in household numbers (moves out, moves in, divorces, newly wed couples), contraceptive users (cessations, method changes), births and deaths. Because of their close relationships with the community, the volunteers are usually aware of these changes. Mrs. Ani is also present when the village midwife opens the clinic three times a week so she can update her records, such as those who change contraceptive methods from pills to injectables, without delay. The fieldworker said Mrs. Ani's records are always accurate and reliable, and Mrs. Ani seems to know each household in the village. She knew when one of the volunteers mistakenly wrote the number of the households in her hamlet and asked why one household was missing. Mrs. Ani explained it is important to have up-to-date record as a basis for their activities. For example, with this record she can make plans for her home visits. Women who have just given birth are among her targets for home visits to remind them to bring the baby to posyandu for immunization and to use contraceptives after 40 days. She also keeps a record of every implants user, so she and the volunteers can notify them when their implants have expired and tell them to go to the village clinic to have the implants removed. According to Mrs. Ani the village officials always use her records for their planning purposes, such as for distributing subsidised rice for the poor families (families classed as pre-prosperous and prosperous level I).

In village B, Mrs. Budi explained that she had not kept records since December 2002 because she was too busy with collecting data for the family enumeration. Due to lack of personnel, she had to help the hamlet volunteers in collecting data from house to house. She said:

I know I have to do the recording regularly, but I was too busy with the family enumeration since we only have a few volunteers. I didn’t have time to do it. Basically, collecting data from 
house to house is not my duty, it's the hamlet volunteers' duty, my responsibility is only to compile the data, but I had go with them to the hamlets. (Mrs. Budi).

The limited number and high turn over of volunteers also hampers her in updating the family list frequently. Most of the hamlet volunteers are newly recruited and have been working for less than a year. They have not been able to keep regular records properly. Hence, Mrs. Budi could only revise her family list once a year during the family enumeration. Besides, Mrs. Budi said it is difficult to keep track of the changes in contraceptive use since many of the users obtain their contraceptive methods from outside sources. They buy the pills from drugstores or get the injectables or IUDs from midwives outside the village. Mrs. Budi could only have information on those who obtained the pills from her and the injectables or IUD from the village midwife. Therefore, some of the information in her family list was out of date or inaccurate. For example, one woman was registered as 40 years old and using an IUD, but when I visited her it turned out that she was 50 years old, did not use any contraceptive method, and had never used IUD.

The volunteers in both villages no longer draw the 'family map’ (see Chapter 6). According to Mrs. Ani, the dynamic of the data makes it difficult to make an up-to-date family map. Meanwhile, Mrs. Budi mentioned that the high turn over of kaders hampers her in teaching them to keep monthly records and to draw a family map.

\subsubsection{Planning and decision-making process for the family planning programme at village level}

As discussed in Chapter 6, the planning system used by the family planning programme consists of top-down, bottom-up, and horizontal approaches. At village level, the type of planning focuses on short-term operational planning, consisting of annual, monthly and weekly planning which mix the three approaches.

\subsubsection{Annual plan}


Every year, the family planning fieldworker submit a proposal to the sub-district supervisor. This proposal is supposed to be based on the village plan drawn in the village coordination meeting. However, it is usually made by the fieldworker based on the data collected by the volunteers combined with the target determined by the sub-district. The family planning worker at village B explained:

We, the family planning fieldworkers from each village, calculate our own targets and submit our proposals to the sub-district level. I calculate the target for contraceptive use together with Mrs. Budi based on her family list. Newly wed women who are still very young are encouraged to postpone the first birth using pills. Women with two children are targeted for IUDs, while those who have more than four children are targeted for sterilisation. Women who still want another child but want to postpone it usually prefer pills and injectables. From the list we can also identify who can afford to pay and those who can't afford to pay are entitled to free services. Apart from recruiting new users, I also have targets for other activities, such as encouraging pregnant women to go to the village clinic for delivery, where they can also get post-partum contraceptive services. I also want to increase the number of volunteers in each hamlet. The sub-district makes its plan based on our proposals. (PLKB, B).

At the sub-district level, the family planning supervisor combines the proposals from the villages to become its proposal to the district office. The same process occurs upward, from the district to the provincial office. Then, the reverse process takes place, the higher levels distribute guidelines and targets for the current fiscal year to the lower levels. The district office distributes programme and budget guidelines to the sub-districts which subsequently breakdown the guidelines for the villages in their respective areas. The guidelines contain the activities that should be carried out, the budget allocated to each activity, and the targets to be achieved. The sub-district family planning supervisor in Sumedang mentioned that he has the authority to decide their implementation strategies so long it is within the framework determined by the district office. Likewise, his counterpart in Subang stated:

We can make adjustments to the targets to a certain extent. For example, we can adjust the target for new acceptors or the target for a particular type of contraceptive if we feel it is not feasible. (PPLKB, B). 
Upon receiving programme and budget guidelines from the sub-district office, the family planning fieldworkers formulate their work plans and bring them to the village meeting. They present the plans to the village officials to get approval and support. The fieldworker in village B explained that during the annual Village Development Meeting he also presents his work plan to get budget support from the village. He stated:

I submit my proposal to the village administration during the Village Development Meeting. I try to get funds to support our programme, usually for family enumeration, referral for contraceptive side effects and posyandu. Before the economic crisis, the budget allocated for family planning could reach 3 million rupiah. After the economic crisis, and by coincidence the village was also experiencing a crisis where the village headman was brought down, the situation changed, we cannot get that much anymore. (PLKB, B).

\subsubsection{Monthly and weekly planning}

The family planning fieldworkers breakdown the annual plans into short-term planning, i.e. monthly and weekly plans. The family planning fieldworker at village A stated:

At sub-district level, we [fieldworkers and the sub-district supervisor] have a monthly meeting where we evaluate the programme achievements and discuss our plans for that month. Results of this meeting are brought to the sub-district coordination meeting held by Camat (sub-district head) and attended by all government institutions and all village headmen. In this meeting, we present our plans for that month to get Camat's and village headmen's endorsement. This meeting is then followed by a meeting at village level, chaired by the village headman and attended by village officials, chairman of Village Representative Board, hamlet headmen, members of $P K K$, village family planning organisation, all volunteers, myself as the fieldworker and village midwife, and the traditional birth attendant. In this meeting, we first evaluate the previous month results, problems encountered, and then we discuss our plans for that month. (PLKB, A). 
Fieldworkers in both villages mentioned that they made some adjustments to the planning process. For example, ideally every month they should hold a special meeting with the village officials for family planning discussion, but since the village has weekly meetings (minggon), they use these meetings instead. Meetings on the first week of the month are used for discussing the monthly plan, and the subsequent meetings are used to discuss the weekly plans.

After the village meeting, the fieldworkers in both villages usually hold a follow-up meeting with village family planning organisations to elaborate the plan with detailed activities. The fieldworker in village A revealed:

After the village meeting, I discuss the detailed steps of the activities with Mrs. Ani and the other volunteers. We discuss the plan together, I begin with the broad plan and then Mrs. Ani and the volunteers give their inputs. For example, Mrs. Ani and the volunteers offered to do the home visits because the villagers might feel uncomfortable if being approached by a government personnel. The volunteers also said it is better to do the home visits in an informal way, chatting while cooking or making emping. (PLKB, A).

From the above statements, it can be noted that the fieldworkers play a dominant role in the planning process. The involvement of the village family planning organisations is still limited to provide data for calculating the target or information for implementing the programme. Upon being asked about her role and involvement in the planning process, Mrs. Ani explained:

It's the fieldworker who made the proposal and calculated the target. She made it together with her supervisor. I just received from them. My task is to provide data for calculating the target, such as the number of women from poor families who need the free sterilisation, as for implants it depends on the allocation from the district office. I only make plans for my routine activities, but they are not written. (Mrs. Ani).

A similar answer was given by Mrs. Budi, as she stated, "I just wait for instructions from the fieldworker...”. 


\subsection{Family planning decision-making at household level}

This section discusses the family planning decision-making at household level by presenting the results of in-depth interviews with married women of reproductive age (1549 years old), married men, and couples in the two villages. Some results of the focus group discussions with the adolescents are also presented to complement the discussion.

As discussed in Chapter 4, in family planning, empowerment implies that individuals and couples should be able to make decisions concerning the number, spacing, and timing of their children. This process is facilitated through access to information as well as to safe, effective, affordable and acceptable methods of family planning. In addition, a couple's reproductive decisions are influenced by their perceptions, evaluations, norms and attitudes towards fertility choices which are formed and shaped through social interaction within the village setting. In this line of thinking, fertility decisions may not be limited to individual families, rather they are influenced by other sources, such as relatives, neighbours, community leaders, professionals, and state authorities.

In line with the above framework, I will discuss the family planning decision-making processes by describing the informants' access to information and contraceptive services; the local knowledge; and the preferences that shape their decisions. I will also discuss key factors that influence the informants' capability to control their fertility.

\subsubsection{Access to information}

As has been mentioned, the family planning programme started in both villages in the late 1970s. Since then, the programme has been employing intensive information, education and communication programmes. These activities, combined with the deployment of a midwife, play an important role in enhancing people's knowledge and attitudes in family planning. 
Almost all married women of reproductive age in village $\mathrm{A}$, and more than half in village B, were currently reported to be using contraception either to space or to stop childbearing. The most popular methods in both villages are pills and injectables. Many women have used both methods, alternating between the two. Other longer term methods such as IUD and implants are not popular because of fears of their side effects. Among the women who were not using contraceptives, the most common reasons are wanting more children, being pregnant, or having trouble getting pregnant despite not using contraceptives. It was difficult to find women who had never used any contraceptive methods.

The small-family norm has also become widely accepted in these villages. Most informants stated that young couples in their villages usually have only two or three children, fewer than the older couples. Some of the informants who already had two or more children said they do not want another child, while those who only had one child said they would like to have one or two more.

In both villages, many informants mentioned the programme facilitators at village level, particularly the chairperson of the village family planning organisation and the other volunteers as the primary sources of family planning information. They know some of the volunteers by names, particularly Mrs. Ani and Mrs. Budi, and some others only as kaders. However, when asked about their knowledge of the village family planning organisation or Pos KB (West Java's term for PPKBD) they usually said they have never heard of it. Indeed, Mrs. Ani and Mrs. Budi explained they seldom mention the organisation to the villagers. Mrs. Budi said they might think she was proud if she mentioned that she is the chairperson of the organisation.

Mrs. TJ (40 years) of village A said she knew about family planning from a kader who encouraged her to use contraception after she gave birth to her first child. She said:

Unlike today, we were not told to postpone the first pregnancy so I gave birth to my first child when I was 16. After I gave birth, the kader told me about contraceptives which I didn't know before. She asked me to choose between pills and IUD, I chose pills because I was afraid to use 
IUD. I used pills for ten years, then Mrs. Ani suggested that I use implants, and I said okay because I was bored taking pills everyday, and sometimes I forgot. I wanted to wait until my first child was big enough before having the second child. After I gave birth to my second child, Mrs. Ani asked me what contraceptive I would like to use and I said I wanted to be sterilised. She was surprised and asked whether I was sure I didn’t want another child, I said yes, I'm sure. I was accompanied by Mrs. Ani and one kader to the district hospital when there was a free sterilisation service. My husband left the decision to me, because I was the one who take care of the children so it's up to me.

At the outset of the programme, village officials were more involved in influencing the village people to participate in family planning. Older informants in village B remembered that in the past the village headman and his officials were very active in persuading the villagers to use family planning methods. Mr. KS (41) recalled:

I knew about family planning from the mass campaigns by the village headman and the health centre's staff in the 1980s. There were also many family planning pictures posted around the village. At that time, TV was still rare here and I did not have one.

Mrs. SC (38), also of village B, remembered that she has been approached by the village headman and his officials to use an IUD. She said:

It was in 1983, my third child was two years old and I was using injectables, but I was told to use IUD by the village headman. I suffered bleeding afterward and when I consulted a midwife, she removed the IUD and recommended me to continue to use injectables. In 1989, when my fourth child was two months old, the village headman accompanied by the hamlet headman, the neighbourhood association chairman, and the village security officer came to my house. They said there was a 'KB Safari' at the village office and I had to go there. I asked what is 'KB Safari' and they told me it was a free contraceptive service and I can choose any method I wish to use. So, I went there and I chose injectables. The following day the hamlet headman came again, he did not believe me when I told him I already got injectables and urged me to go the village office again to get an IUD. I got angry, I came to the village office and told them that I already got injectables so why should I change it into IUD. I was not afraid, because I knew I was right. 
Mr. KC (43), who is the chairman of a neighbourhood association in village B revealed a similar experience. He and his wife were persuaded to use contraception by the village officials. He stated:

It was not my wife or I who made the decision to use family planning method, but it was the village regulation. I live in the government's hands, so I had to obey it. I told my wife to use IUD as requested by the village officials. However, despite using IUD, my wife still got pregnant, so I gave up. When the village headman and the family planning fieldworker offered me to have a free sterilisation, I agreed. After the operation I had some problems since I had to work hard everyday in the paddy field, I got sick. Luckily, the midwife gave me a card which I can use to get free medical services at the sub-district clinic.

Nonetheless, couples in both villages said they now can choose any methods they wish to use. As Mrs. Ani and Mrs. Budi stated, now the government workers do not propound any particular method. Mrs. WK (32) of village B said:

Now I was offered to choose any method I'd like to use. I often met Mrs. Budi at posyandu, she always reminded me to use contraceptives and she said there are many methods available, pills, injectables, IUD, or implants. I chose injectables.

The above statements demonstrate the strong influence of the government's programme on couples' decisions to adopt family planning. The informants' responses also highlight the change in the government's approach, from strong persuasion to use a particular method to giving the couples freedom to chose their preferred methods.

In addition to the programme facilitators, family members, especially mothers, also appear to be an important source of family planning information. Some informants explained they first knew about family planning from their mothers. Mr. IS (34) of village A said: 
I first knew about family planning from my mother. When I was still in elementary school I saw my mother took some pills and I asked her what they are for, she told me that they are birth control pills for birth spacing.

Mrs. IU (27) of village B also knew about family planning from her mother. She said:

Before I got married I have heard about family planning from my mother. My mother said at that time only a few people used family planning methods. She had to use it because my father was a civil servant. According to her it was to prevent her to have too many children.

Some informants mentioned that their mothers' role was not limited to information sharing, but also in influencing them to use family planning methods. In village A, some of the women said they had been using contraceptives as soon as they got married because their mothers told them to do so. Since they got married early, at around 15 years old, their mother told them to use pills to delay the first birth until they were 'ready' to have a child. Although the national average age of first marriage (for women 20-49 years old) has reached 19.5 years old (CBS et al., 2003), some people in this village still practice early marriage. Nevertheless, since family planning information has become widely spread, women aged 30 years old or over were aware of the reproductive health practices and therefore advised their daughters to defer the first birth by using contraceptives. Mrs. CA (28) of village A who got married at 15 years old explained:

When I got married my mother told me to use pills to postpone the pregnancy. According to her pills is the most suitable method for women who haven't given birth since the other methods will make our womb dry. Almost all of my neighbours were using contraceptives, so I decided to use it as well. I used pills for around 3 years.

A similar experience was shared by Mrs. IU (32), also of village A, she said:

My mother and older sister told me to use contraceptives after I gave birth to my first child to delay the next pregnancy. It's common here for women to use contraceptives soon after they give birth. 
After the first birth, however, most of the women said their mothers were not involved anymore and it was up to them to decide when to have the next child or the type of contraceptives used. Another interesting example of family influence is the case of Mr. ED (36) of village A who has two children. He said:

My grandmother has told me not to have too many children so they can be kaperhatoskeun, kasakolahkeun sareng kapiara (parents can give proper attention, education, and care), that is why my wife and I decided to use contraception.

Neighbours also play an important role in influencing the use of contraceptives. Mrs. NR (31) of village B said she was advised by her neighbours to use contraceptives:

When I just got married my neighbours advised me to use pills to delay the pregnancy. Since I often felt nauseous when using pills, after I gave birth my neighbours suggested to try injectables. They said there are two kinds of injectables, the cheap and the expensive. So I use injectables now, the cheap one, and I never have any problem anymore. My neighbours prefer to use injectables than pills, because they are cheaper.

The deployment of a midwife at their village provides opportunities for women to seek information from a professional in addition to the advice from family members or neighbours. Mrs. AKT (24) and Mrs. SI (25) of village A said they also consulted the midwife to ask whether pills were suitable for them, since their mothers told them to use this method.

The tradition to pass on family planning information from parents to children was also practised by some of the informants. In village A, Mrs. EU (45) who already had a grandchild said she has told both her daughter and son to only have two children. Another younger woman, Mrs. AS (30) mentioned, "I will surely tell my children to have only two children and to use family planning methods”.

In village B, Mrs. WK (32) explained she bought pills for her newly wed daughter, because according to her: 
My daughter is still ignorant, so I buy the pills for her. I'm afraid she might get pregnant if I don't give her the pills. She is still too young, she is 13 now, and I thought it would be better to wait until she is 19 or 20 to have a child. I know she is too young to get married, but her prospective husband has been asking to marry her since she was 12, and I feel bad to say no. Besides, it would ease our burden because we are poor.

Another example was given by Mr. OY (33) also of village B who grew up in Bandung, the capital city of West Java. He said he knew about family planning from TV and from his experiences as an active member of 'Karang Taruna' (a government sponsored youth organisation). Through the group's activities he said he often saw how families with 5 or 6 children, especially the lower class families, could not give proper care to their children. Therefore, he determined that he had to carefully plan his future family and he would tell his children to do the same. He said:

I hope my children will also plan their future family carefully, according to their socioeconomic condition. From the mass media we can see examples of unplanned families, like neglected or street children. I use that as examples for my children, especially the eldest, she is 10 years now, her brother is 2 years old. When we saw these street children on TV, I told her it's because their parents have too many children and could not afford to give proper care for them. I hope she would understand.

As has been mentioned, in Sundanese societies, although couples generally try to set up their own households soon after they marry, they maintain close ties with their parents. This might explain the high involvement of parents, particularly mothers, in reproductive decisions. These cases, however, were different with Hatmadji's study in other districts of West Java (1990, p.199), where the strong influence of older generations tended to result in greater resistance to contraceptive use.

\subsubsection{Local knowledge}

\subsubsection{Local sharing}


Most of the informants in the two villages mentioned 'spacing' (menjarangkan) when asked about their intention to use family planning methods, including those who said they did not want another child. Upon being asked about their opinion of family planning they answered, “...it’s good because births can be regulated, so children are not too closely spaced”. This might be due to religious leaders’ messages which usually emphasise spacing as the objective of family planning rather than for limiting fertility, which can be regarded as 'against God's will'. This perception is the key to family planning acceptance among religious communities such as the people of village A. This way of thinking is reflected in the answer of Mrs. MS (39) of village A, who has been sterilised, when asked about her opinion of family planning:

According to me, family planning is not against God's will because our intention is only to keep interval between births, so our children are not too closely spaced. If that's our intention, I think it's not forbidden (haram).

The other plausible explanation is that because the couples do not have any plan for how many children they would like to have, they use contraceptives to space the childbirths and then stop when they feel they are too old to have another child. This point of view is reflected in the answer of Mr. TA (33) of village B who currently has two children upon being asked how many children he would like to have:

I probably want another child after my second child is big enough, five or six years from now. Now we have to keep the interval. Probably another child before I reach 38 years old, it would be too old to have a child after 38 .

The informants were aware of the family planning programme's recommendation of an interval from 3 to 5 years, but they preferred to have a longer period. Those who wanted another child said that they would like to wait until the last child was 'big enough', some even said until the last child finished elementary school which meant more than 10 years. This is much longer than the national average of 4.5 years in 2002/3 (CBS et al., 2003). The most common reasons for the long interval are: the mother will not be too busy, 
parents can give proper attention to the children, and the elder child can help looking after the younger sibling. As an example, Mr. IS (34) of village A said:

Ideally, the interval is 3 or 4 years, but I think it would be better to wait until my daughter finishes her elementary school. She is now 8 years old, when she is older she can help her mother doing the household chores and she can also help to take care of the baby.

Similarly, Mrs. YK (24) of village B said:

We will wait until my daughter is in junior high school before having another child, so she can help me taking care of her younger brother or sister.

\subsubsection{Gender relations}

As documented in Chapter 3, in Sundanese culture men are regarded as the head of the family. Men are responsible for family income, while women run the household and take care of the children. This traditional role between wives and husbands was evident in the two villages. However, some men stated they were also involved in household chores when their wives were busy. Meanwhile, some women work outside the house to help augment family income, either as paid workers in emping industries (in village A) or as food vendors. Most of female informants mentioned their husbands often help to look after the children and only occasionally do the washing or cooking. The husbands seemed to prefer to help looking after the children rather than doing the household chores. It was common to see men carrying small children in both villages.

The role of husbands as the head of the family makes them the dominant decisionmaker. When asked who made decisions for important family matters, most informants said that the husband usually have the last word but after a discussion process with the wife. The importance of dialogue or discussion is stressed by most of the informants, as stated by Mr. KS (41) of village B: 
Without discussions, everything will not work. I cannot force my opinion to my wife, everything should be discussed.

Upon being asked whether they have plans for how many children they would like to have and who made the decisions, some informants mentioned it was a joint decision between husband and wife, while most of them said it's the wife's decision. Mrs. TJ (40) of village A who has two children explained:

I was the one who made the plan and I had never discussed it my husband. I wanted to have only two children because I wouldn't be too busy and they will not feel lonely.

Likewise, Mrs. YK (24) of village B stated:

We have a plan to have only two children. Actually I was the one who decided to have only two children, my husband said it's up to me because it's my responsibility to take care of the children.

Mr. TA (33) of village B gave a similar answer that it was his wife who made the decision, he revealed:

Actually I wanted to have 4 or 5 children, but my wife said two is enough for the time being. Well, it's up to her...

The other informants, however, said they had never made any plans regarding their family size. Mrs. TAM (31) of village B said:

No, we don't have any plan, we just let everything flow. My husband never mentions how many children he wants to have, it's up to me. We never discuss it. I never mention to my husband that I wanted to have two children, I only said that I want another child because now we only have one child, but I'll wait until my son is in elementary school. 
Although men tend to leave the decisions regarding family planning to their wives, most of the women said they consulted their husbands before making any decisions.

The husbands generally approve their wives intention to use contraceptives, but some men raise concerns regarding some particular methods, because of its side effects or other concerns. Mrs. IU (32) of village A said:

I kept on getting pregnant despite of using pills, but my husband does not allow me to use an IUD. He does not want my private parts to be seen by other people, including the midwife.

There were some cases where women used contraception without consulting their husbands as described by Mrs. MS (39) of village A:

I was the one who decided to use contraception without asking my husband because it is us, women, who bear the responsibility of taking care of our kids and not our husbands. They leave early in the morning, they don't know the hassle we go through everyday. I used pills then, but I hid them so my husband did not know. Eventually I told him that I have been using birth control pills and he said it was okay.

Another illustration is given by Mrs. NR (31) of village B, she said:

I decided to use pills right after I got married for the second time because of the experience of my first marriage: I gave birth in the first year of our marriage, but then my husband divorced and left me. My current husband wanted to have a child as soon as we got married, but I used pills. He was angry but I did not care, I hid the pills. Now I use injectables. I want to be sterilised but my husband does not agree, he still wants to have a daughter because our two children are boys. I said no way...

The above statements demonstrate that in these two villages women play a major role in the family planning decision-making process. However, since family planning is considered as women's business, it seems it is also women's responsibility to use contraceptives. Therefore, although women are dominant in reproductive decision-making, 
it does not necessarily mean they can make their husbands share the responsibility for using family planning methods.

Two male informants who have been sterilised, Mr. OY (54) of village A and Mr. KC (43) of village B, said they decided to be sterilised because they had no choice; their wives still got pregnant despite using contraceptives. Not every man is willing to be sterilised, however, as Mr. DW (35) of village B revealed:

\footnotetext{
Now my wife uses injectables even though she is not recommended to use them due to her high blood pressure. She has to take some medicines for 2 or 3 days to lower her blood pressure before getting every injection. She wanted to be sterilised but I don't agree, I'm afraid of the side effects, like her mother who suffered excessive bleeding after the operation. I feel sorry for my wife, she has asked me to be sterilised, but...I don't know...it's the last resort. My neighbours said some men also suffered bleeding until one year after the operation, that's a long time! Also, we cannot carry heavy stuff up until 3 months. I don’t think I’m ready for sterilisation...
}

The focus group discussions with male adolescents in the two villages supported that family planning is perceived as women's responsibility. The participants were not familiar with the idea that men should also participate in the family planning programme. In village A they mentioned that "family planning methods are only for women, not for men" and they are going to leave family planning matters to their future wives. Similarly, in village B they commented, "Men participate in family planning? Men cannot use family planning methods, they are for women.” Interestingly, the female adolescents in the two villages were aware that men can participate in family planning by being sterilised. This is consistent with a youth survey in the three provinces of Java and Lampung (Achmad \& Westley, 1999) which revealed that in general young women were better informed about contraceptive methods than were men.

\subsubsection{Value of children}


Another factor influencing fertility decisions is the value of children to the couples. As discussed in Chapter 4, perceived satisfaction and costs of children will influence the couples' decisions regarding family size and practice of birth control. In these two villages children are no longer perceived as 'additional hands' in the field although most of the informants are engaged in agriculture. In line with the parents' rising aspirations to provide adequate lifestyles for their children, most of the children, boys and girls, are now going to school at least until junior high school (until about 16 years old). Therefore, most informants said they usually ask the children, especially boys, to help them in the field only during holidays or school breaks. During focus group discussions, the young men explained that they help their parents in the field only during holidays. The young women said they just help their parents around the house, not in the field. Mrs. EY (42) of village A said she had never asked her daughters to help her in the field because, "they are already busy with their school assignments..."

Nevertheless, children are still regarded as an insurance for parents' old age security. Although most informants said they do not want to be a burden to their children in their old age, they expected the children to take care of them especially when they get sick. Upon being asked about her expectations of her children, Mrs. TAM (31) of village B who is originally from Sumedang answered:

Our children are our insurance for the future. We, Sundanese, perceive children as precious possessions. Other possessions can be used up, but children cannot, they are our old age insurance.

However, some couples have to compromise the desire to have many children as old age insurance as Mr. ED (36) of village A, who has two children, explained:

Since the beginning we had a plan to only have two children, because it will be hard for poor people like us to have many children. The government's recommendation is also two children. It will be nice, though, to have 3 children, so when the elder children marry and leave the house there will be another child who stay with us and take care of us when we get sick. 
Moral qualities are also important characteristics desired by the parents. All of the informants said they want their children to be religious. According to Mr. KC (43) of village $B$ :

...it's a shame if we do not have children. My purpose in this world is not to accumulate gold or jewels, but to take care of my family and my children, so my children become religious and they will take care of me when I get old. Thank God, I was given four children, that are enough, I don't want to have many children. Four is enough to carry my body when I die.

Mrs. ME (42) of village A who has two children of 28 and 23 years old clearly stated soleh (pious) as the most important characteristic she wanted her children to have, and her husband added:

We did not want to have many children but we could not take care of them, we did not want them to be troublesome kids who just hanging around on the streets. Thank God my children are now taking good care of us, their attention to us is remarkable. Had I known my children would be like this, I might want to have more than two.

The informants' statements reflect that couples take into account the costs and benefits of children in making decisions regarding family size, but in a different way to that of the traditional theory of supply and demand of children. Couples in these villages do not expect the children to contribute to family income in the short term, but later in the future as their old age insurance. With decreasing family size, elderly parents will place huge pressures on their children and this necessitates the development of government policies to help these families in supporting their ageing parents.

\subsubsection{Preferences}

\subsubsection{Number of children}

It seems the small-family norm has been adopted in these two villages. Most informants stated that young couples in their villages have fewer children than do older couples. 
Nevertheless, the general definition of 'small' seems to be slightly different between the two villages. In village A, 2 or 3 children are sufficient, while in Village B 3 or 4 children suffice.

Parents’ aspiration to provide better education and economic pressure are the most stated reasons for limiting the number of children. Couples wanted their children to have a higher level of education than themselves because education is seen as a precondition to access better jobs and to have a better future. However, the informants said they could not afford to send too many children to high school because of the high cost. Hence they limit the number of children. Mrs. CA (27) of village A, who currently has one child, illustrated this attitude when asked how many children she would want to have and why:

We want to have only two children to ensure that we can provide a better education for them. It would not be too hard for two children. We want them to go at least to high school so they can have good jobs like other people, unlike their father who has a very low income.

Because of their low income, the informants stated that their economic condition would not allow them to have many children. They also contended that the cultural proverb 'more children, more economic fortune' (banyak anak, banyak rejeki) which is widely known in many Indonesian cultures, is no longer valid in practice. An example was given by Mrs. IU (32) of village A who has 4 children. She said she wanted to have only 2 or 3 children, but she got pregnant while using pills and now she has 4 children. Since her husband's income was not enough to make ends meet, in 1998 she decided to go to Saudi Arabia to work as a baby sitter for two years. When asked about her opinion of the proverb 'more children, more economic fortune' she said:

That's not true, that's a lie! We cannot have the same way of thinking as our parents. It's hard to have four children today. Our income has never been enough, and now we have to divide everything we have to more people than before. 
Some couples in village B, however, have different attitudes regarding family size. Mr. TA (33), who currently has two children, has a different opinion about the above proverb:

I know that people generally disagree with that proverb, but I think it is correct in a way. I agree that when children are small they mean hard work for us, but after they grow up they can bring 'fortune' to us. If we cannot work anymore, our children can support us, and if we have many children they can share the burden among them. If we only have two children, it might be hard for them to support us, we become a burden for them. So, I would like to have 3 or 4 children.

The other consideration for deciding family size, which can explain why some people look 'deviant', is their past experience. Some of the informants in village B mentioned that some of their siblings died when they were babies, which left them with only a few siblings or they even became an only child. Mrs. WK (32) of village B, who is pregnant with the sixth child, said:

When I was still single I already had a plan to have many children, 4 or 5, because I'm the only child. I don't have brothers and sisters, I was lonely. Mrs. Budi has often told me to have only two children, but two is not enough, I wanted to have 4 or 5. My husband also wanted to have 4 children.

Adoption is the alternative for childless couples and for helping other family members. Mr. NJ (38) of village B said that his sister died one year after he got married, so he and his wife decided to adopt his sister's seven months old baby. At the time, Mr. NJ was still childless. Currently, he has two daughters. Another case is revealed by Mr. IS (33) of village A. Before his wife gave birth to their twin daughters, his mother in law offered to adopt one of the babies to lighten the couple's economic burden. So, after the twins were born, one baby was taken to his mother in law's house which is nearby. Until now, one of the girls lives with her grandparents.

\subsubsection{Sex preferences}


Most informants who said they only wanted to have two children stated that it did not matter whether these were boys or girls. However, when asked further whether they were going to 'try again' to get the other sex, some of them, especially in village B said, "yes...probably". Meanwhile, some informants explicitly said that they wanted to have one of each sex, as stated by Mr. DW (35) of village B:

When our second child was born, my wife wanted to stop having children. She said taking care of two children is tiring enough, particularly when they are ill. I persuaded her to have another child, hoping it will be a boy, because I wanted to have a son, but it turned out to be a girl again, so I gave up. I do not want another child.

Mr. IS (34) of village A said he wishes to have a son, he explained:

My wife and I have a plan to have another child after our daughter finishes her elementary school. I wish it will be a boy so I can have a friend to go to the field, but if it is a girl again it's okay. I don’t want to have too many children.

The desires to have one of each sex are in agreement with other studies which suggest that Sundanese couples, particularly in rural areas, generally want to have both sons and daughters (Adiwisastra, 1996; Budiarto \& Purwatini, 1987; Romdiati, 1988). However, in these cases, the couples need to balance the desire for another child and their ideal family size.

\subsubsection{Age of childbearing}

As mentioned above, 15 or 16 years old is now considered to be 'too young' to have children. After three decades, the programme seems to have been successful not only in introducing the small family norm but also the ideology of bearing children between 20 to 30 years old (see also Adioetomo, 1993). Today, women 30 to 40 years old persuade their newly wed daughters to delay the first child until around 20 years old. The young couples 
are mostly aware of this recommendation. Mrs. YK (24) of village B said that it was the couple's decision to postpone the first birth, she said:

We decided to wait until 3 years before having our first child because I was only 17 when we got married. I was not ready yet to have a child, I was not ready to become a mother.

Accordingly, 30 years old is now considered to be too old to have a child. Mrs. MS (39) and Mrs. TJ (40) of village A and Mrs. SK (34) of village B decided to be sterilised at the age of 29-32 years old because according to them 30 years is too old to have another child. This is because they started childbearing at an early age, between 15 to 16 years old, and they already had the number of children they wanted. In addition, since they already had grandchildren, they said it would be embarrassing to have another child. So, it is too old from a social point of view.

\subsubsection{Capability to control fertility as an important step in women's empowerment}

As has been mentioned, empowerment implies that people should have access to the fertility control means to enable them to decide the number, spacing, and timing of their children. Two important elements that facilitate the empowerment process are: access to information and access to affordable contraceptive services.

The people in the two villages seemed to already have the basic knowledge of family planning concepts, such as the idea of 'two children are enough', best age for childbearing, healthy intervals, and also types of contraceptives available and the service facilities. Nevertheless, local norms affect the people's attitudes. One important example is the perception that childcare and family planning are women’s business and responsibility. This perception was clearly stated by the informants. Their contraceptive preferences reflect that the women bear the responsibility for using family planning methods. Another example, as explained by the fieldworker in village $\mathrm{A}$, is that some women in her village were reluctant to use IUD because of the insertion process which is considered as forbidden by devout Muslims. 
Rumours and inadequate information on a particular contraceptive method, which still prevail in these villages, affect the local preferences. In village B, rumours of side effects and inadequate information on IUD and sterilisation (for male and female) make these methods unpopular. Some poor women choose to pay for the pills or injectables rather than getting free services for IUD or sterilisation. It seems the efforts of the village facilitators, including Mrs. Budi, to cope with the rumours have not been very successful.

Access to contraceptive services undoubtedly is one of the important factors that enables a couple to control their fertility. This means that all couples should have access to their preferred methods of contraception and to a good quality of service, including a back-up service for side effects. With the establishment of the village clinic staffed by a midwife, the informants in both villages said they were happy because they could get a family planning service in their own village. Many of the informants said they previously had to go to the sub-district health centre, which means extra expenses for the transportation, but now they said, “...it’s easy and handy to get contraception, we can just walk to the clinic.” However, for implants insertion they have to go to the sub-district health centre and for sterilisation to the district hospital. For the poor families, the transportation costs are subsidised by the programme or the village.

Unfortunately, poverty obstructs some couples’ access to contraceptive services and hence affects their ability to control fertility. Mrs. WK (32) of village B, who is currently pregnant with her sixth child, said that since she gave birth to her second child she has been using injectables but she did not get them regularly. If she did not have money, she did not go to the clinic to get the contraceptive. She explained:

Actually, I did not want to get pregnant anymore. I missed out one period of injection because I did not have money and now I'm pregnant again. What can I do? My husband told me to keep the baby because it's a sin to have an abortion. I hope this would be the last one, but, I don't know, if I don't have money for the injection I might be 'absent' (bolos) again. The village midwife said we don't have to pay right away if we don't have money, but it’s 
embarrassing to keep on delaying the payment, so I choose not to come if I don't have money. Perhaps in the future I will use implants, but I'm still not sure because I have to work hard and according to my neighbours it's not good to use implants, my arm will be swollen.

Similarly, Mrs. NR also of village B and using injectables said:

Our village midwife allows us to pay later on if we don't have money, but I feel ashamed, so I don’t go to the clinic if I don’t have money.

The above examples show that financial factors play a major role in fertility control. Lack of financial resources makes some women choose to stay away from the clinic and risk getting pregnant. Though the nationwide financial crisis which began in 1997 did not seem to have an impact on the national prevalence of contraceptives use (see Hull \& Adioetomo, 2002), it might have aggravated the poor families’ inability to purchase contraception.

Nevertheless, the efforts of the village facilitators in providing information and accessible contraceptive services have enabled most of the women to make their own decisions regarding the type of contraception they wish to use.

\subsection{Discussion}

Analysis of the village data has revealed an important distinction between decisions made by the couples within the household level and those by personnel at the community level. The distinction between these two levels is important for understanding the success of family planning within these villages. The two villages offer variation on this information.

\subsubsection{Household level}


The findings in the two villages suggest that decisions are made by couples as the household unit in Indonesian culture. The family planning programme has been delivered to those households by targeting the women. In these two villages the men overtly stated that family planning is women's business. Nevertheless, the findings revealed that these decisions were either preceded by discussions with the husbands or made solely by the wives. This dual set of responses was revealed by discussions with both men and women in the villages. The interrelationships between men and women are a major finding for this study.

The major influences on decisions to adopt family planning as a means to limit the number of children are:
a. Motivation to increase family prosperity
b. Access to family planning information and services
c. Desire to conform to village expectations

a. Motivation to increase family prosperity

In both villages, the informants decided to limit their family size mainly out of economic concern. They said their low income and shortage of paid employment would not allow them to have many children, particularly if they wish to see their children educated in high school. Education is a precondition for the children to have a better future, better than that of their parents. For some informants, small family size also makes it easier to ensure that the children are exposed to upholding religious teachings. In both villages, religiosity is an important part of their ideal concept of prosperous family.

In village $\mathrm{A}$, informants decided that having two or three children would be the best means to achieve their goal of a prosperous family. This aspiration made them compromise the desire to have one child of each sex or to have many children as insurance for old age security. For some informants in village B, however, the desire to have both sons and daughters overrode the economic pressures. For them, old age security was also a dominant concern, with some informants wanting to have three or four children. 
b. Access to family planning information and services

The government family planning programme, started in these villages in the late 1970s, has provided access to family planning information and services through its structured framework. In the village, the programme is implemented by government fieldworkers, local volunteers and village officials.

Familiarity with the programme’s campaign of 'two children are enough' and 'prosperous family' has developed over time. Information on basic concepts such as the ideal age of childbearing, healthy intervals and various methods of contraception has also become accepted. Many informants mentioned the village facilitators as the main source of this information, and some others mentioned family members, especially mothers, and neighbours.

Community leaders also play an important role. At the outset of the programme, especially in village $B$, village officials took a more active role in persuading the villagers to use family planning methods. Currently, in both villages their role is more focused on providing endorsement and support for programme implementation. Religious leaders are also influential in village $\mathrm{A}$, but not in village $\mathrm{B}$.

The availability of a wide-range of modern contraceptive methods in the two villages has been facilitated by the establishment of a village clinic staffed by a midwife. Addressing safety concerns and providing local access have proved beneficial. These measures along with subsidised contraceptive services have enabled women from all socio-economic groups to use family planning methods. This is consistent with Freedman and Freedman's (1992) findings that socio-economic differentials in contraceptive use weaken in the presence of strong family planning programmes. However, since the economic crisis in the late 1990s the subsidies have been limited to those labelled 'poor'. 
The information sharing and activities have been targeted primarily at women and carried out mainly through posyandu. Men rarely attend these activities. Women are the primary target because men asserted that family planning is women's business. Although the programme has empowered women to make informed choices on contraception and thus take control of their own fertility, it has not reached their husbands who are only marginal to the programme. Women's decision is thus made within the framework of the interests of their husbands.

\section{c. Desire to conform to village expectations}

Aside from individual motivation to increase family prosperity, couples' decisions regarding family size have also been influenced by external factors such as social norms and values. The small family size norm and the concept of best age of childbearing have been accepted in these villages and these principles are transmitted through social interaction or advice from family members, neighbours, or community leaders. As RoseroBixby and Casterline (1994, p. 438) point out, birth control is “contagious” through information flow or a demonstration effect which influences the adoption of birth control by some individuals. The experiences of family members and neighbours also confirm the benefits and costs of using certain methods of contraception. Furthermore, since family planning has become a subject of discussion in occasions such as posyandu and Qur'an learning groups, women experience a social pressure to comply. People in rural areas usually do not want to behave differently from the others, for fear of being considered as 'deviant'.

Many young women were advised by their mothers or the volunteers to defer the first pregnancy until around 20 years old, since under 20 years is regarded as 'too young' to have a child. Older women, who started childbearing at the age of 15 or 16, decided to stop having children at around 30 years old since it is considered as 'too old' and it would be embarrassing to have another child. 
The informants' intentions to send their children to high school also influences family size for couples are encouraged to send their children to high school despite high cost, and this has contributed to the limitation of the number of children. Children are no longer expected to contribute to family income, but they are expected to take care of the parents in the future. Some informants in village B clearly stated they would live with their children in the future, and some of them said they wanted to have three or four children so that they would have 'choices' where to live.

These attitudes have led most of young couples to have small families. In both villages, informants mentioned that today young couples have fewer children than in previous times. They said their parents' generation usually had at least four children and some informants had more than seven siblings, but nowadays few couples have more than four children.

The couples' needs and aspirations regarding family planning are reflected in the structures of the family planning organisation at the community level.

\subsubsection{Community level}

Community organisation, for the purpose of family planning, has been formalised in terms of workers and their programme, i.e. the PPKBD. The historical background of PPKBD suggests that the establishment of this community organisation was initiated in order to implement the programme at the grass-roots level. This policy can be seen as effective even though community participation in the programme is induced by the central authority, i.e. the government. However, this structure has been criticized by foreign observers as a top-down government intervention (e.g. Hull \& Hull, 1997; Smyth, 1991). Nevertheless, this organisational structure, especially in the example of village A, can be considered as a valuable asset to the programme. With appropriate training and support from the programme, they can be empowered to function as a two-way channel for the community to articulate their needs and interests.

The case studies revealed the following key issues: 
a) The role of village family planning organisations (PPKBD)

As discussed in Chapter 6, the current approach places more emphasis on the role of implementers rather than managers. Although the planning system involves these organisations in the planning process, their role in planning and evaluation processes has not been specifically delineated in the formal guidelines from the central office. The guidelines only mention 'work plan' under role number 2, i.e. as the 'product' of regular meetings with kaders and the fieldworker (BKKBN, 1999b). The organisations in the study areas translated this role into establishing plans for routine activities. Therefore, current tasks, as stated in the guidelines should be adjusted to fit with the organisations' new role as a manager and a channel for articulating the communities' needs and aspirations. As Mrs. Ani and Mrs. Budi stated, they were not the ones who made the programme plans and proposals or who decided the targets. They received them from the fieldworkers.

b) The training process

The sub-district family planning supervisors in Sumedang and Subang explained that the most important criteria for selecting a chairperson for the village family planning organisation is not a candidate's education level but whether or not she is trusted by the community. Currently, many village family planning organisation chairpersons in these areas have only primary education, including Mrs. Ani. Given the low education levels, training of the volunteers is crucial to enable them to carry out the required duties.

However, further research will be needed to design a training programme that suits their education level while also preparing them to take up greater roles and responsibilities. The current training process by means of ‘step by step’ and 'learning by doing', while it may be the most appropriate method for current conditions, restricts the volunteers' vision of the whole picture of their role. An interesting finding of a study by researchers from the NFPCB and the University of Indonesia in West Java, Central Java and Yogyakarta illustrates this problem (BKKBN \& FKM-UI, 1999). This study found that almost all village family planning organisations in the study areas perceived themselves to have achieved the highest classification ('advanced') as outlined by the national 
guidelines. On the other hand, the researchers' assessment using the same guidelines showed less than 10 percent could be classed as 'advanced'. This discrepancy shows that the village workers have different perceptions about their achievements as contrasted with the expectations of the programme. They have a limited understanding of their expected role.

c) The concept of 'volunteer'

Volunteers such as Mrs. Ani and Mrs. Budi were recruited by the village officials using criteria set out in the guidelines. Within this perspective, the term 'volunteer' is defined only as an unpaid worker with no relation to choice or spontaneity. The recruitment process carried out by village officials and the family planning fieldworker invites volunteers to fulfil their duty in delivering government programmes. They are expected to comply with the fieldworkers' directions. As in the case of village $B$, the involvement of village officials in the recruitment process also contributes to the high turnover among the volunteers.

Another concern is the incentives for the volunteers. A study of kaders (Judd, 1987) and another study of village family planning organisations (BKKBN and FKM-UI, 1999) suggest that incentives are among the important factors that affect the volunteers' performance. The incentives may not be only in the form of cash remuneration, but also in the forms of self-satisfaction with tasks accomplished and training opportunities that lead to skill-enhancement. Both Mrs. Ani and Mrs. Budi agreed with these views, both of them were happy with the privileges they received such as opportunities to attend activities at sub-district and district levels. However, as a single mother, Mrs. Budi stressed the importance of the cash incentive. Although as a village staff member she is entitled to payment from the village office, she often complained that the payment is too low compared to the work burden. A study in five Asian countries (Askew \& Khan, 1990) also demonstrated the importance of cash incentives to community volunteers. According to this study, nonmaterial incentives were not considered sufficient to compensate for the time and effort spent participating in a family planning programme. 
d) Gender issues

Women play a vital role in the family planning programme in these villages as they are the main actors, i.e. the midwives and the volunteers. Women are preferred as providers of family planning services since the majority of the users are women. This was the reason for replacing the male volunteer in village B with Mrs. Budi. Women are also expected to do this job since family planning is considered as women's responsibility.

While women are expected to take an active role as volunteer workers, this has to be done within the context of their primary role as 'wife' and 'mother'. They should not neglect their duties to their husband and children. The importance of this primary role is emphasised by Mrs. Ani. To be successful as a kader, Mrs. Ani explained, she should be able to become a role model, not only by using contraceptives herself but also as a good wife and mother. As a wife, she has to look after her husband's needs and she should maintain marital fidelity. As a mother, she has to take care of the children and give them proper religious and moral education. She said, “These are important to gain people’s trust and respect. You cannot be successful as a kader if the people do not trust and respect you". Hence, her performance as a kader is assessed by the villagers not only in terms of her technical skills but also in terms of how she is perceived as a wife and a mother. For this reason, Mrs. Ani claimed it is more difficult to become a kader than a paid fieldworker.

e) 'New professionalism' and decentralisation

As discussed above, the approaches used by the government workers tend to still be topdown. This made the volunteers perceive their role as assisting the fieldworkers and they depend on these workers to direct the execution of their activities. In order to empower them to act as managers of the programme, a paradigm shift is required. The fieldworkers will have to diminish their dominance and involve the volunteers in all stages of the exercise and encourage them to assume greater roles and responsibilities. The 'family map' (see Chapter 6) can be used as an effective tool for the volunteers to learn how to analyse of their situation and to make plans. 
With the new policy on decentralisation, community participation at the grass-roots level will necessarily be strengthened through greater involvement in the planning and evaluation processes. The family planning programme should facilitate this outcome through enhancing the bottom-up planning process and developing a more responsive system which allows the grass-roots level to develop local specific programmes.

The complementary of the community level with the village level has played a major part in enabling the whole family planning programme to be successful. Women have been the key to reducing family size, albeit while maintaining the integrity of their husbands as heads of the households. 


\section{Chapter 8}

\section{Conclusions and Recommendations}

\subsection{Conclusions}

The Indonesian family planning programme was successful in halving the total fertility rates between the 1970s and the 1990s. This was achieved mainly due to strong political and bureaucratic support at all administrative levels, from national down to village levels. Family planning has become an integral part of the village development programme. Through its hierarchical structure, the programme disseminated family planning messages to the families, stressing the 'small, happy and prosperous families' norm as its central concept. The programme has also developed an effective delivery system encouraging couples to use a wide-range of modern contraceptive methods. Many of these activities were integrated with other programmes for family welfare, particularly health and nutrition. This combined approach has increased the receptivity of the programme, with varying degrees of success across the country. This thesis uses ideational and diffusion of innovation theories to analyse the influences on families' decisions regarding family size as revealed in the case studies through a phenomenological approach.

Since its commencement in 1970, the Indonesian family planning programme has focused on creating 'prosperous families' as its ultimate goal, this contrasts with a narrow view of family planning programme as merely a contraceptive service. The concept of prosperous family, which covers health, social, and economic dimensions, has become a 'development ideal' that encourages families to move upward to increase their prosperity. This philosophy is different from that of the Millennium Development Goals, which interprets prosperous families from the standpoint of poverty.

The philosophy of prosperous family has permeated down to the grass-roots level. Although rural people’s perceptions of ‘prosperous family' might be simpler than those proposed by the programme (see Faturochman et al., 1998), the idea has influenced their 
decisions regarding future family size. Smaller families with better-educated children are believed to lead to increased family prosperity.

The case studies in the two villages reveal some key factors about the practice of the Indonesian family planning programme at grass-roots level. These villages dutifully implement the programme but with a different degree of compliance. Village A has an average of two or three children per couple whereas in village B it is three or four. In village B children are still perceived as insurance for parents’ old age security, and many couples desire to have both sons and daughters. These two villages may reflect the diversity of issues confronting villages in other regions. Further research will reveal the complexity of the issues.

Starting in the late 1970s, the programme has used village facilitators to persuade families in the two villages to reduce the size of families. These facilitators include paid government workers, local volunteers and community leaders. Fellow family members, particularly mothers, and neighbours who have experienced the benefits of using family planning methods greatly influence a couple's decisions, as also shown in Rosero-Bixby and Casterline’s study in Costa Rica (1994, p. 435). Using diffusion of innovation theory, these authors argue that birth control is 'contagious' through social interactions. In the two Indonesian villages, this process is facilitated by local volunteers, who act as 'change agents' to encourage the use of modern contraception. As postulated by Retherford and Palmore (1983), adoption of family planning is more likely to be influenced by facilitators who have the same characteristics as the couples. Thus, for these two villages it can be concluded that couples' family planning decision-making has been influenced by external and internal sources alike. The adoption of family planning is promoted by the government's programme but supported at the local level.

The case studies highlight the importance of understanding family planning decisionmaking at grass-roots level. Achievement of a 'prosperous family' is driven by:

\section{a. Socio-economic and cultural factors}


As explained by fertility transition theories, changes in socio-economic factors affect the perceived costs and benefits of children and influence couples' demands for children. The modernization process has reached the villages through modern communication and transportation systems altering the socio-economic characteristics of the local people. Couples' material aspirations for their children and their families have been a major influence on limiting the numbers of children. Desire to increase the family's prosperity has led couples to opt to limit the number of children, as a small family is perceived to be more affordable and advantageous. Due to changes in socioeconomic circumstances, children are no longer expected to contribute to the family income as household labour. Nowadays children, both male and female, are educated at least to high school level with an expectation they will get better jobs as a precondition to better lifestyles in the future. Couples send their children to school despite fact that the costs of education are continually rising and job opportunities for high school graduates are limited. A family can become prosperous, they believe, only through limiting the size.

b. Effective government delivery

Through its strong campaigns, delivered via a hierarchical structure, the government family planning programme has been able to propagate the concept and practice of family limitation. The programme has established a network of fieldworkers and volunteers who provide information and services accessible to rural people. The activities include not only contraceptive and reproductive health services, but also income generating projects and programmes for early childhood, youth, and elderly care. However, as government provides only a limited subsidy, couples now have to pay for contraceptive services. This creates a dilemma for low income families, since the costs of contraceptives compete with other family expenses, such as food or children’s education.

Both socio-economic changes and government delivery are major factors contributing to the reduction of family size. These findings are consistent with Gertler and Molyneaux's 
study (1999), which suggests that such a combination has had a major influence on Indonesian couples adopting family planning.

Generally, decisions relating to contraceptive use and childbearing are made by women, because men regard them as women's business. Contraceptive preferences reflect that women bear the major responsibility in the use of family planning methods. Thus, it can be said that women in these villages were empowered, but only partially. They were not able to make their husbands share the responsibility in the use of family planning methods. The women's role in terms of decision-making still exists within the framework of the interests of their husbands.

Women's empowerment in family planning has emerged from the case studies as a key factor that has enabled village women to make 'informed choice' to control their family size. Analysis has revealed that the process includes:

\section{a. Access to information}

Women are now knowledgeable about family planning through the programme's vigorous information and communication activities. The information conveyed to them includes the best age for childbearing, the healthy intervals, various contraceptive methods and the possible side effects of each method, and the location of back-up facilities. However, since many women have very limited access to mass media, they rely on the village facilitators as the most important source of information. This raises concerns about the level of knowledge of the village facilitators, particularly the volunteers. The information may also be biased by the programme's targeting particular methods of contraceptives as propounded by the paid fieldworkers.

\section{b. Access to contraceptive services}

Since the start, the programme has provided a fairly wide range of modern contraceptive methods. Although previously some observers attributed the success to 
'coercive' methods, nowadays women can choose any method they wish. The establishment of a village clinic staffed by a midwife has increased the women's access to safe contraceptive services. However, they must pay for these services. This change gives women only a limited sense of power as they must find the cash. Shortage of cash hampers some women obtaining their preferred methods on a regular basis. The major source of cash is their husbands. As shown by Adioetomo and Eggleston's study (1998), women in West Java make decisions only for daily expenditures, while decisions for large items are usually made by the husbands. When women have greater access to household cash, then empowerment will become a greater reality.

Women's control of fertility has been a major contributor to the success in reducing fertility and increasing family prosperity. For this success to be maintained, this thesis has revealed several key issues, including the cost of contraceptives, men's informed involvement in decisions about family size, and acknowledgment of volunteers’ contribution to program delivery by payments for their services. The volunteers' capability to increase their own family's prosperity should be ensured if they are expected to work effectively to implement the programmes. Therefore, the programme's strategy that currently relies on unpaid volunteers for programme operation at grass-roots level will need to be reviewed. Decentralisation raises several issues referred to in this thesis which have not yet been addressed.

Figure 8.1:

The process of family planning decision-making 


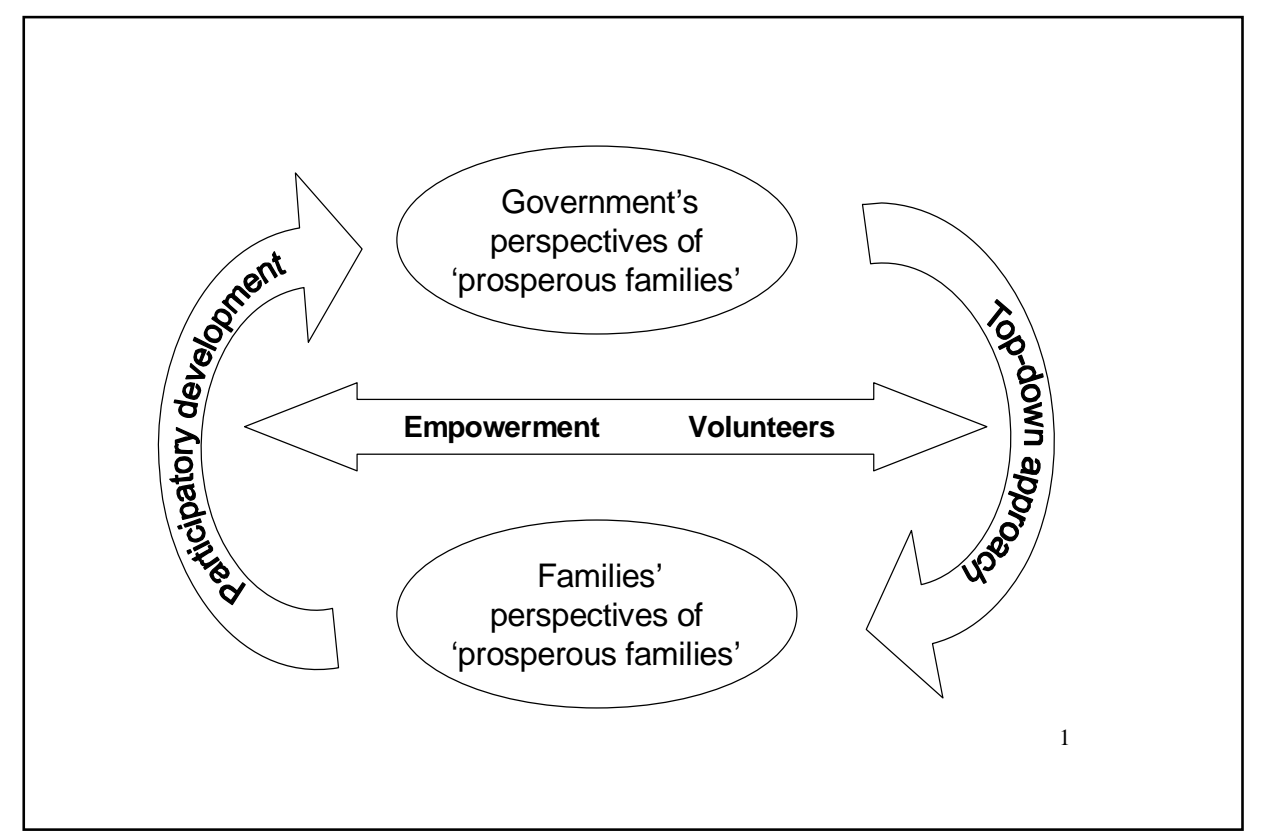

\subsection{Recommendations}

Some issues that should be given greater credence to ensure women's empowerment and community participation in family planning in the future include:

a. Women's empowerment and gender equality

Efforts to empower women and to increase gender equality in family planning should take into account the Indonesian concept of gender roles within the different cultural contexts of each region. Future programmes, however, need not reverse the power relationships between husbands and wives but rather should increase men's awareness and involvement in family planning. Men’s attitudes that perceive childbearing and family planning as women's business will only be changed with information targeted at them specifically. The programme will need to tailor information and services to increase men's acceptance of these new principles.

b. Community participation and the role of volunteers 
In order to generate genuine community participation and strengthen the bottom-up planning process, the programme’s approach to 'community participation' needs to be reconsidered. The monitoring process should include: re-evaluation of the concept of 'volunteer', with recognition of the means of recruitment; the training process; the status of the unpaid volunteers as opposed to the paid fieldworkers; and incentives for more women to participate as volunteers. The programme's strategy that currently relies on unpaid volunteers is inconsistent with to the goal of 'prosperous families'. This affects the volunteers' commitment and motivation to work. As the volunteers are mostly members of the PKK and also work for other programmes, the NFPCB should initiate discussions across government sectors, the $P K K$ and the local governments to resolve these issues. Future research will assess the most effective mechanisms for enhancing community participation.

c. Improving the services

To ensure that both women and men can obtain their preferred methods of contraception on a regular basis, local governments will need to be responsive to their aspirations. Strengthening the bottom-up planning process and feedback from grassroots level will be an important step that will allow local governments to develop specific processes of service delivery while also improving the quality of these services.

d. Information and services for adolescents

Reproductive health services for adolescents, including information and counselling, must be directed at both male and female youth. The services need to be tailored to the needs of the youth. The programme also needs to overcome cultural barriers and many parents’ reluctance to discuss family planning with their children. Accurate information will help adolescents formulate their perceptions of their responsibilities for the future.

e. Areas for further research 
The continued success of family planning in Indonesia will be reliant on service delivery to the grass-roots level. Women will play an increasing role in clarifying the process to younger generations and the question of the volunteers' contribution need to be rethought. Decentralisation as commenced in 2004 throws up many concerns about the future of family planning for Indonesian society. Close monitoring and evaluation through research will be essential. 


\section{References:}

Achmad, S.I. \& Westley, S.B. (1999). Indonesian survey looks at adolescent reproductive health. Asia-Pacific Population and Policy, 51.

Adimihardja, K. (1984). Pertanian: Mata pencaharian hidup masyarakat Sunda (Agriculture: The source of livelihood of the Sundanese). In E.S. Ekadjati (Ed.), Masyarakat Sunda dan Kebudayaannya (The Sundanese Society and Its Culture). (pp. 163-204). Jakarta: Pustaka Jaya.

Adioetomo, S.M. (1993). The Construction of a Small-Family Norm in Java. Unpublished PhD thesis, Australian National University, Canberra.

Adioetomo, S.M. (1995). The role of religion in the construction of the small family norm in Java, Indonesia. Journal of Population, 1(2), pp. 107-130.

Adioetomo, S.M. \& Eggleston, E. (1998). Helping husband, maintaining harmony: Family planning, women's work and women's household autonomy in Indonesia. Journal of Population, 4(2), 7-32.

Adiwisastra, J. (1996). The Impact of Family Planning Implementation on the Change of Value of Children within the Sundangese at Subang Regency. Unpublished Ph.D thesis, Padjadjaran University, Bandung.

Adler, P.A. \& Adler, P. (1998). Observational techniques. In N.K. Denzin \& Y.S. Lincoln (Eds.). Collecting and Interpreting Qualitative Materials. (pp. 79-109). Thousand Oaks: Sage.

Afshar, H. (1991). Women, Development and Survival in the Third World. London: Longman.

Ananta, A. \& Pungut, U.H. (1992). Population change and economic development in Indonesia. ASEAN Economic Bulletin, 9(1), 55-65.

Ananta, A., Anwar, E.N. \& Suzenti, D. (1997). Implications of Indonesia’s future population. In G.W. Jones \& T.H. Hull (Eds.), Indonesia Assessment: Population and Human Resources. (pp. 301-322). Canberra and Singapore: Australian National University and Institute of Southeast Asian Studies.

Appleman, P. (Eds.). (1976). An Essay on the Principle of Population, Thomas Robert Malthus: Text, Background, Contemporary Opinion and Critical Essays. New York: W.W. Norton \& Company Inc.

Arnold, F., Bulatao, R.A., Burikpadi, C, Chung, B.J., Fawcett, J.T., Iritani, T., Lee, S.J., \& Wu, T.S. (1975). The Value of Children: A Cross-national Study. Volume I: Introduction and comparative analysis. East-West Center. 
Arnstein, S.R. (1969). A ladder of citizen participation. Journal of the American Institute of Planners, vol. 35, pp. 216-224.

Arsyad, S.S., Rahmadewi, Siwi, M. \& Suwartiningsih (1996). Pengembangan Kemandirian IMP di Propinsi Jawa Timur dan Sumatera Barat (Village Community Institution Self Reliance in East Java and West Sumatera). Jakarta: BKKBN.

Askew, I., \& Khan, A. R. (1990). Community participation in national family planning programs: some organizational issues. Studies in Family Planning, 21(3), 127-142.

BKKBN (1972). Tata Cara Kerja PLKB. Buku Pedoman I (Manual for Fieldworkers, Book I). Jakarta: BKKBN.

BKKBN (1988). Mekanisme Pengelolaan Program KB Nasional di Tingkat Kecamatan dan Desa (Operational Mechanism of the Family Planning Programme at Sub-district and Village Levels). Jakarta: BKKBN.

BKKBN (1996). Petunjuk Pelaksanaan Pengembangan Bina Keluarga Balita (Manual for Early Childhood Development). Jakarta: BKKBN.

BKKBN (1999a). Mekanisme Operasional Gerakan Keluarga Berencana Nasional di Lini Lapangan dalam Aplikasi dan Pengembangannya (Operational Mechanism of the Family Planning Movement). Jakarta: BKKBN.

BKKBN (1999b). Petunjuk Pelaksanaan Pembentukan dan Pengembangan Institusi Masyarakat Pedesaan dalam Gerakan Keluarga Berencana Nasional (Manual for Developing Village Community Institutions within the National Family Planning Movement). Jakarta.

BKKBN (1999c). Pedoman Tata Cara Kerja Pengawas PLKB dalam Gerakan Keluarga Berencana (Manual for PPLKB within the National Family Planning Programme). Jakarta: BKKBN.

BKKBN (2000). Petunjuk Pelaksanaan Pengembangan Kelompok UPPKS (Manual for UPPKS Groups Development). Jakarta: BKKBN.

BKKBN (2001a). Visi dan Misi Program Keluarga Berencana Nasional (Vision and Mission of the National Family Planning Programme). Jakarta.

BKKBN (2001b). Revitalisasi Peran Institusi Masyarakat Pedesaan Dalam Program KB Nasional (Revitalisation of the Village Community Institutions' Role within the National Family Planning Programme). Jakarta: BKKBN. 
BKKBN (2001c). Petunjuk Teknis Pencatatan dan Pelaporan Pengendalian Lapangan Program Keluarga Berencena (Technical Guidelines for Recording and Reporting of the Family Planning Programme). Jakarta: BKKBN.

BKKBN (2001d). Petunjuk Teknis Pencatatan dan Pelaporan Pendataan Keluarga (Technical Guidelines for Family Enumeration). Jakarta: BKKBN.

BKKBN. (2002a). Pedoman Pembinaan Peran PLKB dalam Program KB Nasional. (Manual for Supervising Fieldworkers within the National Family Planning Programme). Jakarta: BKKBN.

BKKBN. (2002b). Analisa Pendataan Kuantitas dan Kualitas Institusi Masyarakat Pedesaan Tahun 2001 (Quantitative and Qualitative Analysis of the Village Community Institutions, 2001). Jakarta: BKKBN.

BKKBN. (2002c). Menyusuri Liku-liku Pendataan Keluarga: Apa dan Bagaimana? (History of Family Enumeration: What and How). Jakarta: BKKBN.

BKKBN. (2002d). Petunjuk Teknis Pencatatan dan Pelaporan Pemutakhiran Data Keluarga dalam Pelaksanaan Pendataan Keluarga (Technical Guidelines for Recording and Reporting of the Implementation of the Family Enumeration). Jakarta: BKKBN.

BKKBN (2002e). Rencana Anggaran Program KB Nasional Tahun 2002 (Budget Plan for the National Family Planning Programme, 2002). Jakarta

BKKBN. (2003a). Rapat Kerja Nasional Program Keluarga Berencana Nasional Tahun 2003 (National Workshop on the National Family Planning Programme, 2003), Jakarta 27-31 January 2003. Jakarta: BKKBN.

BKKBN. (2003b). Sub Sistem Perencanaan Program KB Nasional (Planning Sub-system for the National Family Planning Programme). Jakarta: BKKBN.

BKKBN. (2004). Profil Kependudukan dan Keluarga Berencana 1994-2004 (Population and Family Planning Profiles 1994-2004). Jakarta: BKKBN

BKKBN \& BPS Propinsi Jawa Barat (2002). Pola dan Kecenderungan Penduduk Jawa Barat (Patterns and Trends of the West Java Population). Bandung.

BKKBN \& FKM-UI. (1999). Kemandirian Institusi Masyarakat Perdesaan di Propinsi Jawa Barat, Jawa Tengah dan D.I. Yogyakarta (Village Community Institutions' Self Reliance in West Java, Central Java and Yogyakarta). Jakarta: BKKBN.

BPS. (2003). Statistics Indonesia. Retrieved December 4, 2003 from http://www.bps.go.id.

Bandarage, A. (1997). Women, Population and Global Crisis: A Political - Economic Analysis. London: Zed Books. 
Bappeda Jabar (2001). Sekilas Jawa Barat (West Java in a Glimpse). Retrieved June 8, 2003 from http://www.jabar.go.id.

Batliwala, S. (1994). The meaning of women's empowerment: new concepts from action. In G. Sen, A. Germain \& L.C. Chen (Eds.), Population Policies Reconsidered: Health, Empowerment, and Rights. (pp. 127-138). Cambridge: Harvard University Press.

Beckman, L.J. (1978). Couples’ decision-making processes regarding fertility. In K.E. Taeuber, L.L. Bumpass \& J.A. Sweet (Eds.), Social Demography. (pp. 57-77). New York: Academic Press.

Bernard, H.R. (2000). Social Research Methods: Qualitative and Quantitative Approaches. Thousand Oaks: Sage Publications.

Bernard, H.R. (2002). Research Methods in Anthropology: Qualitative and Quantitative Approaches . ( $3^{\text {th }}$ ed). Walnut Creek, CA: AltaMira.

Berninghausen, J. \& Kerstan, B. (1992). Forging New Paths: Feminist Social Methodology and Rural Women in Java. (translated by B.A. Reeves). London: Zed Books.

Birdsall, N. (2001). New findings in economics and demography: Implications for policies to reduce poverty. In N. Birdsall et al. (Eds.), Population Matters: Demographic Change, Economic Growth, and Poverty in the Developing World. (pp. 411-417). New York: Oxford University Press.

Birdsall, N \& Sinding, S.W. (2001). How and why population matters: New findings, new issues. In N. Birdsall et al. (Eds.), Population Matters: Demographic Change, Economic Growth, and Poverty in the Developing World. (pp. 3-23). New York: Oxford University Press.

Blackburn, J. \& Holland J. (Eds.). (1998). Who Changes? : Institutionalizing Participation Development. London: Intermediate Technology.

Bloom, D \& Canning, D. (2001). Cumulative causality, economic growth, and the demographic transition. In N. Birdsall et al. (Eds.), Population Matters: Demographic Change, Economic Growth, and Poverty in the Developing World. (pp. 165-197). New York: Oxford University Press.

Blomstrom, M. \& Hettne, B. (1984). Development Theory in Transition. The Dependency Debate and Beyond: Third World Responses. London: Zed Books.

Bongaarts, J. (1978). A framework for analyzing the proximate determinants of fertility, Population and Development Review, 4(1), 105-132.

Bongaarts, J. (1986). The transition in reproductive behaviour in the Third World. Center for Policy Studies Working Paper no. 125, The Population Council, New York. 
Bongaarts, J. (1997). The role of family planning programs in contemporary fertility transitions. In G.W. Jones et.al. (Eds.), The Continuing Demographic Transition. (pp. 423-442). Oxford: Clarendon Press.

Bongaarts, J \& Watkins, S.C. (1996). Social interactions and contemporary fertility transactions. Population and Development Review, 22(4), 639-682.

Booth, A. \& McCawley, P. (1981). The Indonesian economy since the mid sixties. In A. Booth \& P. McCawley (Eds.), The Indonesian Economy during the Soeharto Era. (pp. 1-22). Kuala Lumpur: Oxford University Press.

Boserup, E. (1970). Woman's Role in Economic Development. New York: St. Martin’s Press.

Boserup, E. (1981). Population and Technological Change: A Study of Long-Term Trends. Chicago: The University of Chicago Press.

Budiarto \& Purwatini, I. (1987). Survai Tingkah Laku Fertilitas di Kalangan Masyarakat Pedesaan di Jawa Barat (Fertility Attitudes Survey Among Rural Communities in West Java). Bandung: Padjadjaran University.

Budiarto \& Purwatini, I. (1988). Latar Belakang Sosial Budaya pada Tradisi Perkawinan dan Perceraian di Jawa Barat (Socio-cultural Background of Marriage and Divorce Traditions in West Java). Bandung: Padjadjaran University.

Bulatao, R.A. \& Arnold, F. (1977). Relationships between the value and cost of children and fertility: Cross-cultural evidence. In International Population Conference, Mexico 1977, Vol. I. Liege: International Union for the Scientific Study of Population (IUSSP).

Bulatao, R.A \& Fawcett, J.T. (1983). Influences on Childbearing Intentions Across the Fertility Career: Demographic and Socioeconomic Factors and the Value of Children. Papers of the East-West Population Institute, Number 60-E.

Bulatao, R.A \& Lee, R (Eds.).(1983). Determinants of Fertility in Developing Countries. 2 volumes. New York: Academic Press.

Burch, T. K. (1980). Decision-making theories in demography: An introduction. In T.K. Burch (Ed.), Demographic Behavior: Interdisciplinary Perspectives on Decisionmaking. (pp. 1-22). AAAS Selected Symposium; 45. Boulder: Westview Press.

Burkey, S. (1993). People First: A Guide to Self-Reliant, Participatory Rural Development. London: Zed Books.

Buvinic, M., Lycette, M.A. \& McGreevey, W.P. (Eds.).(1983). Women and Poverty in the Third World. Baltimore: The Johns Hopkins University. 
CBS, NFPCB, MOH, Macro International. 1998. Trends in Demographic, Family Planning, and Health Indicators in Indonesia: 1971-1997. Jakarta.

CBS, NFPCB, MOH, ORC Macro. 2003. Indonesia Demographic and Health Survey 20022003. Jakarta.

Caldwell, J.C. (1982). Theory of Fertility Decline. London: Academic Press.

Caldwell, J.C. (1997). Population and human resources: Indonesia's demographic place in the larger scene. In G.W. Jones \& T.H. Hull (ed.), Indonesia Assessment: Population and Human Resources. (pp. 59-67). Canberra and Singapore: Australian National University and Institute of Southeast Asian Studies.

Caldwell, J.C., Phillips, J.F. \& Barkat-e-Khuda. (2002). The family planning programs in the $21^{\text {st }}$ century. Studies in Family Planning, 33(1), special issue.

Cassen, R. (1994). Population and Development: Old Debates, New Conclusions. New Brunswick: Transaction.

Cassen, R. (1994). Overview: Population and development: Old debates and new conclusions. In R. Cassen. Population and Development: Old Debates, New Conclusions. (pp. 1-26). New Brunswick: Transaction.

Casterline, J.B. \& Sinding, S.W. (2000). Unmet need for family planning in developing countries and implications for population policy. Population and Development Review, 26(4), 691-723.

Chambers, R. (1993). Challenging the Professions: Frontiers for Rural Development. London: Intermediate Technology Publications.

Chambers, R. (1995). Paradigm shifts and the practice of participatory research and development. In N. Nelson and S. Wright (ed.). Power and Participatory Development: Theory and Practice. (pp.30-42). London: Intermediate Technology Publications.

Chambers, R. (1997). Whose Reality Counts? Putting The First Last. London: Intermediate Technology Publications.

Chambers, R. (1998). Foreword. In I. Guijt \& M. K. Shah (Eds.), The Myth of Community: Gender Issues in Participatory Development. (pp. xvii-xx). London: Intermediate Technology Publications.

Chapman, R.J. (1996). The Significance of Family Planning for Women in Indonesia. Working Paper no.99, Centre of Southeast Asian Studies, Monash University, Australia. 
Chowdry, G. (1995). Engendering development? Women in development (WID) in international development regimes. In M.H. Marchand and J.L. Parpart (Eds.), Feminism/Postmodernism/ Development. (pp. 26-41). London: Routledge.

Clayton, A., Oakley, P. \& Pratt, B. (1997). Empowering people: a guide to participation. CSOPP Documents. UNDP. Retrieved November 27, 2003 from http://www.undp.org/csopp/CSO/New Files/docemppeople.html.

Cleland, J. (1985). Marital fertility decline in developing countries: theories and the evidence. In J. Cleland \& J. Hobcraft (Eds.), Reproductive Change in Developing Countries. (pp. 223-252). London: Oxford University Press.

Cleland, J. \& Hobcraft, J. (Eds.).(1985). Reproductive Change in Developing Countries: Insights from The World Fertility Survey. London: Oxford University Press.

Cleland, J. \& Scott, C. (Eds.).(1987). The World Fertility Survey: An Assessment. London: Oxford University Press.

Cleland, J. \& Wilson, C. (1987). Demand theories of the fertility transition: an iconoclastic view. Population Studies, 41(1), 5-30.

Commission on International Development (1969). Partners in Development. New York: Praeger.

Crawley, H. (1998). Living up to the empowerment claim? The potential of PRA. In I. Guijt \& M. K. Shah (Eds.), The Myth of Community: Gender Issues in Participatory Development. (pp.24-34). London: Intermediate Technology Publications.

Creswell, J.W. (1994). Research Design: Qualitative and Quantitative Approaches. Thousand Oaks: Sage.

Creswell, J.W. (1998). Qualitative Inquiry and Research Design: Choosing Among Five Traditions. Thousand Oaks: Sage.

Darroch, R.K., Meyer, P.A. \& Singarimbun, M. (1981). Two are not enough: The value of children to Javanese and Sundanese parents. Papers of the East-West Population Institute, Number 60-D.

Dasgupta, B. (1998). Structural Adjustment, Global Trade and the New Political Economy of Development. London: Zed Books.

Demeny, P. (2003). Population policy: A concise summary. Working Papers, No. 173. Population Council. 
Denzin, N.K. \& Lincoln, Y.S. (1998). Introduction: Entering the field of qualitative research. In N.K. Denzin \& Y.S. Lincoln (Eds.), Collecting and Interpreting Qualitative Materials. (pp. 1-34). Thousand Oaks: Sage.

Departemen Dalam Negeri (1990). Instruksi Menteri Dalam Negeri Nomor 9 Tahun 1990 tentang Peningkatan Pembinaan Mutu Pos Pelayanan Terpadu (Posyandu) (Instruction of the Minister Internal Affairs No. 9 of 1990 concerning the Improvement of Posyandu Quality). Jakarta.

Departemen Dalam Negeri (2001a). Keputusan Presiden Republik Indonesia Nomor 49 Tahun 2001 tentang Penataan Lembaga Ketahanan Masyarakat Desa atau Sebutan Lain (Presidential Decree No, 49 of 2001 concerning the Village Community Resilience Board). Jakarta.

Departemen Dalam Negeri (2001b). Surat Edaran: Pedoman Penyelenggaraan Forum Koordinasi Pembangunan Partisipatif. Jakarta.

Departemen Tenaga Kerja dan Transmigrasi (2002). Kebijakan dan Strategi Pembangunan Kawasan Transmigrasi (Policies and Strategies of the Development of Transmigration Areas) 2002-2003. Jakarta.

Departemen Agama (2003). Data Penduduk Menurut Agama (Population by Religion Data). Retrieved April 20, 2004, from http://www.depag.go.id

Desai, V. \& Potter, R.B. (Eds.).(2002). The Companion to Development Studies. London: Arnold.

Dixon-Mueller, R. (1993). Population Policy and Women's Rights: Transforming Reproductive Choice. Westport, CT: Praeger.

Dixon-Mueller, R. (1998). Female empowerment and demographic processes: Moving beyond Cairo. Policy and Research Paper , No. 13. IUSSP.

Drakakis-Smith, D. (1990). Concepts of development. In D.J. Dwyer (Ed.), Southeast Asian Development: Geographical Perspective. (pp. 48-77). New York: Longman.

Drennan, M. (1998). Reproductive health: New perspectives on men’s participation. Population Reports, Series J, No. 46.

Eade, D. (Ed.).(2003). Development Methods and Approaches: Critical Reflections. Oxford: Oxfam.

Easterlin, R.A. (1975). An economic framework for fertility analysis. Studies in Family Planning, 6: 54-63. 
Easterlin, R.A. (1978). The economics and sociology of fertility: A synthesis. In C. Tilly (Ed.), Historical Studies of Changing Fertility. (pp. 57-134). Princeton: Princeton University Press.

Ehrlich, P.R. (1968). The Population Bomb (Revised). New York: A Sierra Club/Ballantine Book.

Ekadjati, E.S. (1995). Kebudayaan Sunda: Suatu Pendekatan Sejarah (Sundanese Culture: A Historical Approach). Jakarta: Pustaka Jaya.

Escobar, A. (1995). Encountering Development: The Making and Unmaking of the Third World. Princeton: Princeton University Press.

Esteva, G. (1992). Development. In W. Sachs. (Ed.), The Development Dictionary: A Guide to Knowledge as Power. (pp. 6-20). London: Zed Books.

Faturochman, Hull, T.H. \& Dwiyanto, A. (1998). Validity and reliability of family welfare measure: An experiment in Central and East Java. Journal of Population, 4(2), 33-56.

Fawcett, J.T. (1983). Perceptions of the value of children: Satisfactions and costs. In R.A. Bulatao \& R. Lee (Eds), . Determinants of Fertility in Developing Countries. (Vol. 1, pp. 429-457). New York: Academic Press.

Finkle, J.L. \& Crane, B.B. (1975). The politics of Bucharest: Population, development, and the New International Economic Order. Population and Development Review, 1(1), 87114.

Finkle, J.L. \& Crane, B.B. (1985). Ideology and politics at Mexico City: The United States at the 1984 International Conference on Population. Population and Development Review, 11(1), 1-28.

Fontana, A. \& Frey, J.H. (1998). Interviewing: The art of science. In N.K. Denzin \& Y.S. Lincoln (Eds.), Collecting and Interpreting Qualitative Materials. (pp. 47-78). Thousand Oaks: Sage.

Fontana, A. \& Frey, J.H. (2000). The interview: From structured questions to negotiated text. In N. K. Denzin \& Y.S. Lincoln (Eds.), Handbook of Qualitative Research. (pp. 645-661). Thousand Oaks: Sage.

Freedman, R. (1979). Theories of fertility decline: a reappraisal. In P.M. Hauser (ed.). World Population and Development: Challenges and Prospects. (pp. 63-79). Syracuse: Syracuse University Press. 
Freedman, R. \& Freedman, D. (1992). The role of family planning programmes as a fertility determinant. In J.F. Phillips \& J.A. Ross (Eds.), Family Planning Programmes and Fertility. (pp. 10-27). Oxford: Clarendon Press.

Freedman, R., Khoo S.E. \& Supraptilah, B. (1981). Modern contraceptive use in Indonesia: A challenge to conventional wisdom. WFS Scientific Report, no. 20. London: World Fertility Survey.

Garna, J. (1984). Gambaran umum daerah Jawa Barat (General sketch of the West Java area). In E.S. Ekadjati (Ed.), Masyarakat Sunda dan Kebudayaannya (Sundanese Society and Its Culture). ( pp. 9-74). Jakarta: Girimukti Pasaka.

Geertz, H. (1961). Javanese Family: A Study of Kinship and Socialization. New York: Free Press of Glencoe.

Geertz, C. (1973). The Interpretation of Cultures: Selected Essays. New York: Basic Books.

Gertler, P.J. \& Molyneaux, J.W. (1994). How economic development and family planning programs combined to reduce Indonesian fertility. Demography, 31, 33-63.

Government of Indonesia. (1992). Law of The Republic of Indonesia Number 10 of 1992 concerning Population Development and The Development of Happy and Prosperous Families. English translation. Jakarta: State Ministry for Population/NFPCB.

Government of Indonesia. (1999). Undang-Undang Republik Indonesia Nomor 22 Tahun 1999 tentang Pemerintahan Daerah (Law of The Republic of Indonesia Number 22 of 1999 concerning Regional Autonomy). Jakarta.

Government of Indonesia. (2000). Undang-Undang Republik Indonesia Nomor 25 Tahun 2000 tentang Program Pembangunan Nasional (Propenas) Tahun 2000-2004 (Law of The Republic of Indonesia Number 25 of 2000 concerning National Development Programs for the Year 2000-2004). Jakarta.

Gunawan, N., Untoro, R., Wirakartakusumah, M.D., \& Hatmadji, S.H. (1992). The Role of the Private Sector and Nongovernmental organizations in the Provision of Health Care and Family Planning Services in Indonesia. Paper Series No. 9, Demographic Institute. Jakarta.

Hall, A. 1988. Community participation and development policy: A sociological perspective. In A. Hall \& J. Midgley (Eds.), Development Policies: Sociological Perspectives. (pp. 33-46). Manchester: Manchester University Press. 
Hamijoyo, S.S. (1992). Community Participation and the Role of Leaders (The Indonesian Experience). Jakarta: National Family Planning Coordinating Board.

Hamijoyo, S.S. \& Chauls, D. (1993a). Volunteers in The Indonesian Family Planning Program. Jakarta: National Family Planning Coordinating Board.

Hamijoyo, S.S. \& Chauls, D. (1993b). The Purposes and Processes of Planning in The Indonesian Family Planning Program. Jakarta: National Family Planning Coordinating Board.

Hamijoyo, S.S. \& Chauls, D. (1994). The Evolution of Private Sector Involvement in the Indonesian Family Planning Program: Transfer of Responsibility from the Government to the People. Jakarta: National Family Planning Coordinating Board.

Hardin, G. (1968). 'The tragedy of the commons', Science 162:1243-48.

Hardjono, J.M. (1977). Transmigration in Indonesia. Kuala Lumpur: Oxford University Press.

Harsojo. (1971). Kebudayaan Sunda' (Sundanese Culture). In Koentjaraningrat (ed.), Manusia dan Kebudayaan di Indonesia (People and Culture in Indonesia). (pp. 307328). Jakarta: Jambatan.

Hartmann, B. (1987). Reproductive Rights and Wrongs: The Global Politics of Population Control and Contraceptive Choice. New York: Harper \& Row.

Hatmadji, S.H. (1990). The Impact of Family Planning on Fertility in Java. Unpublished PhD thesis, Australian National University, Canberra.

Hauser, P. (Ed.).(1979). World Population and Development: Challenges and Prospects. Syracuse: Syracuse University Press.

Hayes, A., Lewis, G. \& Vogel, R. (2003). The National Family Planning Program in Indonesia: Review of Past Achievements, Future Directions. Briefing Notes, STARH Program.

Hettne, B. (1990). Development Theory and The Three Worlds. Harlow: Longman.

Higgins, B. (1957). Indonesia's Economic Stabilization and Development. New York: Institute of Pacific Relations.

Hill, H. (1992). Manufacturing industry. In A. Booth (Ed.), The Oil Boom and After: Indonesian Economic Policy and Performance in the Soeharto Era. (pp. 204-257). Singapore: Oxford University Press.. 
Hill, H. (1996). The Indonesian Economy Since 1966: Southeast Asia's Emerging Giant. Cambridge: Cambridge University Press.

Hirschman, C. (1994). Why fertility changes. Annual Review of Sociology, 20, 203-233.

Hirshman, M. (1995). Women and development: A critique. In M.H. Marchand \& J.L. Parpart, (Eds), Feminism/Postmodernism/Development. (pp.42-55). London: Routledge.

Hirschman, C. (2001). Comment: Globalization and theories of fertility decline. In R.A. Bulatao \& J.B. Casterline (Eds.), Global Fertility Transition. Supplement to Population and Development Review 27, 116-125.

Hollerbach, P.E. (1983). Fertility decision-making processes: A critical essay. In R.A. Bulatao \& R. Lee (Eds), Determinants of Fertility in Developing Countries. (Vol. 2, pp. 340-380). New York: Academic Press

Huberman, A. M. \& Miles, M.B. (1998). Data management and analysis methods. In N.K. Denzin \& Y.S. Lincoln (Eds.). Collecting and Interpreting Qualitative Materials. (pp. 179-210). Thousand Oaks: Sage.

Hugo, G.J. (1997). Changing patterns and processes of population mobility. In Jones, G.W. and T.H. Hull (ed.). Indonesia Assessment: Population and Human Resources. (pp. 67100). Canberra and Singapore: Australian National University and Institute of Southeast Asian Studies.

Hugo, G.J. (2003). Population mobility in Asia. Development Bulletin, 62, pp. 19-25.

Hugo, G.J., Hull, V.J., Hull, T.H. \& Jones, G.W. (1987). The Demographic Dimension in Indonesian Development. Singapore: Oxford University Press.

Hull, T.H. (1983). Cultural influences on fertility decision styles. In R.A. Bulatao and R. Lee (Eds). Determinants of Fertility in Developing Countries. (Vol. 2, pp. 381-414). New York: Academic Press

Hull, T.H. (1987). Fertility decline in Indonesia: An institutionalist interpretation. International Family Planning Perspectives, 13(3), 90-95.

Hull, T.H., Hull, V.J. \& Singarimbun, M. (1977). Indonesia’s family planning story: Success and challenge. Population Bulletin, 32(6), 4-51.

Hull, T.H. \& Adioetomo, S.M. (2002). Women, family planning and decentralisation: New variations on old themes. In K. Robinson \& S. Bessell (Eds.), Women in Indonesia: Gender, Equity and Development. (pp. 235-249). Singapore: Institute of Southeast Asian Studies. 
Hull, T.H. \& Hull, V.J. (1997). Politics, culture and fertility: Transitions in Indonesia. In G.W. Jones et al. (Eds.), The Continuing Demographic Transition. (pp. 383-421). Oxford: Clarendon Press.

Huntington, S.P. (1996). A universal civilization? Modernization and Westernization. In S. Schech \& J. Haggis (Eds.).(2002), Development: A Cultural Studies Reader. (pp. 1931). Oxford: Blackwell.

Iskandar, M.B. (1997). Health and mortality. In G.W. Jones \& T.H. Hull (Eds.), Indonesia Assessment: Population and Human Resources. (pp. 205-231). Canberra and Singapore: Australian National University and Institute of Southeast Asian Studies.

Jones, G.W., Douglas, R.M., Caldwell, J.C. \& D’souza, R.M. (Eds.).(1997). The Continuing Demographic Transition. Oxford: Clarendon Press.

Jones, G.W. 1999. The population of South-East Asia. Working Papers in Demography, No. 81. Australian National University.

Jones, G. W. \& Hull, T.H. (Eds.).(1997). Indonesia Assessment: Population and Human Resources. Canberra and Singapore: Australian National University and Institute of Southeast Asian Studies.

Judd, M. (1987). Kaders in Indonesia. Jakarta: USAID/Indonesia.

Kabeer, N. (1994). Reversed Realities: Gender Hierarchies in Development Thought. London: Verso

Kelley, A.C. (2001). The population debate in historical perspective: Revisionism revised. In N. Birdsall et al., (Eds.), Population Matters: Demographic Change, Economic Growth, and Poverty in the Developing World. (pp. 24-54). Oxford: Oxford University Press.

Kishor, S. (2000). Empowerment of women in Egypt and links to the survival and health of their infants. In H.B. Presser and G. Sen. Women's Empowerment and Demographic Processes: Moving Beyond Cairo. Oxford: Oxford University Press.

Koentjaraningrat (Ed.).(1967). Villages in Indonesia. Ithaca: Cornell University Press.

Koentjaraningrat (Ed.).(1971). Manusia dan Kebudayaan di Indonesia (People and Culture in Indonesia). Jakarta: Djambatan.

Koentjaraningrat. (1985). Javanese Culture. Singapore: Oxford University Press.

Korten, D.C. (1980). Community organization and rural development: A learning process approach. Public Administration Review, 40, 480-510. 
Kusnadi. (1972). KB dalam pandangan Islam (Family planning in Islamic perceptions), Bina Sejahtera, 1, 44-47.

Lapham, R.J. \& Mauldin, W.P. (1984). Family planning program effort and birth rate decline in developing countries. International Family Planning Perspectives, 10(4), 109-118.

Lapham, R.J. \& Mauldin, W.P. (1985). Contraceptive prevalence: The influence of organized family planning programs. Studies of Family Planning 16 (3), 117-137.

Lesthaeghe, R. (1980). On the social control of human reproduction. Population and Development Review, 6(4), 527-548.

Lesthaeghe, R. (1983). Century of demographic and cultural change in Western Europe: An exploration of underlying dimensions. Population and Development Review, 9(3), 411435.

Lesthaeghe, R. \& Surkyn, J. (1988). Cultural dynamics and economic theories of fertility change. Population and Development Review, 14(1), 1-45.

Lofland, J \& Lofland, L.H. (1995). Analyzing Social Settings: A Guide to Qualitative Observation and Analysis. Belmont, Calif.: Wadsworth

Luke, N. \& Watkins, S.C. (2002). Reactions of developing country elites to international population policy. Population and Development Review 28(4), 707-733.

Marchand, M.H. \& Parpart, J.L. (Eds.).(1995). Feminism/Postmodernism/ Development. London: Routledge.

Mason, K.O. (1997a). Explaining fertility transitions. Demography, 34, 443-454.

Mason, K.O. (1997b). Gender and demographic change: What do we know. In G.W. Jones et al. (Eds.), The Continuing Demographic Transition. (pp. 158-162). Oxford: Clarendon Press.

May, T. (Ed.).(2002). Qualitative Research in Action. London: Sage.

McCawley, P. (1981). The growth of the industrial sector. In A. Booth \& P. McCawley (Eds.), The Indonesian Economy During the Soeharto Era. (pp. 62-101). Kuala Lumpur: Oxford University Press.

McClelland, G. (1983). Family-size desires as measures of demand. In R.A. Bulatao \& R. Lee (eds). 1983. Determinants of Fertility in Developing Countries. Volume 1. New York: Academic Press. 
McIntosh, C.A. \& Finkle, J.L. (1995). 'The Cairo Conference on Population and Development: A new paradigm?’ Population and Development Review, 21(2): 223-260.

McKendrick, J.H. (1999). 'Multi-method research: An introduction to its application in population geography’. Professional Geographer, 51(1): 40-50.

McNicoll, Geoffrey. (1975). 'Community-level population policy: An exploration', Population and Development Review, 1(1): 1-21.

McNicoll, G. (1980). 'Institutional determinants of fertility change', Population and Development Review 6(3): 441-462.

McNicoll, G. (1983). Notes on the local context of demographic changes. Center for Policy Studies Working Paper no. 98, The Population Council, New York.

McNicoll, G. (1992). 'Changing fertility patterns and policies in the Third World', Annual Review of Sociology, 18: 85-108.

Menard, S.W. \& Moen, E.W. (Ed.). 1987. Perspectives on Population: An Introduction to Concepts and Issues. New York and Oxford: Oxford University Press.

Merriam, S.B. (1988). Case Study Research in Education: A Qualitative Approach. San Fransisco: Jossey-Bass.

Merriam, S.B. \& Associates. (2002). Qualitative Research in Practice: Examples for Discussions and Analysis. San Fransisco: Jossey-Bass.

Merrick, T. W. (2002). 'Population and poverty: New views on an old controversy', International Family Planning Perspectives, 28(1): 41-46.

Mies, M. \& Shiva, V. (1993). Ecofeminism. Halifax, N.S.: Fernwood.

Molyneaux, J.W. \& Gertler, P.J. (1999). The Impact of Targeted Family Planning Programs in Indonesia 1986-94. Paper presented at the conference: Economic Aspects of Demographic Transition: The Experience of Asia-Pacific Countries, Taipei, June, 1999.

Momsen, J.H. (1991). Women and Development in the Third World. London: Routledge.

Moser, C.O.N. (1993). Gender Planning and Development: Theory, Practice and Training. London: Routledge.

Mosse, D. (1995). Local institutions and power: the history and practice of community management of tank irrigation systems in south India. In N. Nelson \& S. Wright (Eds.), Power and Participatory Development: Theory and Practice. (pp. 144-156). London: Intermediate Technology Publications. 
Mosse, D. (1998). Process-oriented approaches to development practice and social research. In D. Mosse, J. Farrington \& A. Rew (Eds.), Development as Process: Concepts and Methods for Working with Complexity. (pp. 3-30). London and New York: Routledge.

Mosse, J.C. 1993. Half the World, Half a Chance: An Introduction to Gender and Development. Oxford: Oxfam.

Muller-Gotama, F. (2001). Sundanese. Muenchen: Lincom Europa.

Mustapa, R.H. Hasan. (2002, First edition 1985). Adat Istiadat Sunda (translated by M. Sastrawijaya). Bandung: Alumni.

Nelson \& Wright. Participation and power. In N. Nelson \& S. Wright (Eds.), Power and Participatory Development: Theory and Practice. (pp. 1-18). London: Intermediate Technology Publications.

Nitisastro, W. (1970). Population Trends in Indonesia. Ithaca: Cornell University Press.

Nortman, D. (1975). 'A longitudinal analysis of population policies in developing countries', in Godwin, R.K. (Ed.), Comparative Policy Analysis: The Study of Population Policy Determinants in Developing Countries. (pp. 19-45). Lexington, MA: Lexington Books.

Oakley, P \& Marsden. D. (1984). Approaches to Participation in Rural Development. Geneva: ILO.

Oey-Gardiner, M. (1997). 'Educational developments, achievements and challenges', in, G.W. Jones \& T.H. Hull (Eds.), Indonesia Assessment: Population and Human Resources. (pp. 135-166).Canberra and Singapore: Australian National University and Institute of Southeast Asian Studies.

Ostergaard, L. (ed.). 1992. Gender and Development: A Practical Guide. London: Routledge.

Palmer, A.W. (1967). 'Situradja: A village in highland Priangan', in Koentjaraningrat (Ed.), Villages in Indonesia (pp. 299-325). Ithaca: Cornell University Press.

Parpart, J.L. (2002). 'Gender and empowerment: new thoughts, new approaches', in V. Desai \& R.B. Potter (Eds.), The Companion to Development Studies. (pp. 338-341). London: Arnold.

Patton, M.Q. (1980). Qualitative Evaluation Methods. Beverly Hills, Calif: Sage. 
Peacock, J.L. (1973). Indonesia: An Anthropological Perspective. Pacific Palisades, CA: Goodyear.

Phillips, J.F. \& Ross, J.A. (1992). Family Planning Programmes and Fertility. Oxford: Clarendon.

Presser, H.B. \& Sen, G. (Eds.).(2000). Women's Empowerment and Demographic Processes: Moving Beyond Cairo. Oxford: Oxford University Press.

Preston, P.W. (1996). Development Theory: An Introduction. Oxford: Blackwell.

Pritchett, L.H. (1994). Desired fertility and the impact of population policies. Population and Development Review, 20(1), p. 1-55.

Pullum, T.W. (1983). Correlates of family-size desires. In R.A. Bulatao \& R. Lee (Eds), Determinants of Fertility in Developing Countries. (Vol.1, pp. 344-368). New York: Academic Press.

Rahman, M.A. (1981). 'Reflections', in 'Participation of the rural poor in development', Development ,1: 43-51.

Rasyid, M.R. (2003). Regional autonomy and local politics in Indonesia. In E. Aspinall \& G. Fealy (Eds.), Local Power and Politics in Indonesia: Decentralisation \& Democratisation. (pp. 63-71). Singapore: Institute of Southeast Asian Studies.

Rathgeber, E. M. (1990). WID, WAD, GAD: Trends in research and practice. Journal of Developing Areas, 24, p.489-502.

Ray, D.J. (2003). Survey of recent developments. Bulletin of Indonesian Economic Studies, 39(3), 245-70.

Retherford, R.D. \& Palmore, J.A. (1983). Diffusion processes affecting fertility regulation. In R.A. Bulatao \& R. Lee (Eds.). Determinants of Fertility in Developing Countries. (Vol. 2, pp. 295-339). New York: Academic Press.

Rigg, J. (2001). Southeast Asia: The Human Landscape of Modernization and Development. London: Routledge.

Rijadi, S. (1988). Community-level Effects of Village Contraceptive Distribution Centers on the Institutionalization of the Small Family Norm in Indonesia. Unpublished PhD thesis. The University of Michigan, Ann Arbor.

Robinson, W.C. \& Harbison, S.F. (1980). Toward a unified theory of fertility. In T.K. Burch (Ed.), Demographic Behavior: Interdisciplinary Perspectives on Decisionmaking. (pp. 201-229). AAAS Selected Symposium; 45. Boulder: Westview Press. 
Rogers, E.M. (1973). Communication Strategies for Family Planning. New York: The Free Press.

Rogers, E.M. (1995, first edition 1962). Diffusion of Innovations. New York: The Free Press.

Romdiati, H. (1988). Fertilitas dan Pandangan Orang Tua Mengenai Nilai Anak: Kasus Desa di Kecamatan Buah Dua, Kabupaten Sumedang, Jawa Barat (Fertility and parents perceptions of children: the case of the villages in Buah Dua sub district, Sumedang, West Java). Jakarta: Demographic Institute, University of Indonesia.

Rosero-Bixby, L \& Casterline, J.B. (1994). Interaction diffusion and fertility transition in Costa Rica. Social Forces, 73(2), 435-463.

Rosidi, A. (1984). Ciri-ciri manusia dan kebudayaan Sunda (Characteristics of the Sundanese people and culture). In E.S. Ekadjati (Ed.), Masyarakat Sunda dan Kebudayaannya (Sundanese Society and Its Culture). (pp. 125-161). Jakarta: Girimukti Pasaka.

Rowlands, J. (1997). Questioning Empowerment: Working with Women in Honduras. Oxford: Oxfam.

Rowlands, J. (2003). Beyond the comfort zone: some issues, questions, and challenges in thinking about development approaches and methods. In D. Eade (Ed.), Development Methods and Approaches: Critical Reflections. (pp. 1-20). Oxford: Oxfam.

Rusmoro, D., Ryanto, H. Zaemah, Munfaatin, Vogel, R \& Chauls, D. (1997). Contraceptive Services in the Indonesian Family Planning Program: History, Approaches, Achievements. Jakarta: NFPCB.

Saefullah, A.D. (1979). The Value of Children Among Tea Estate Workers' Families: A Case Study in a Village of West Java, Indonesia. MA in Demography Research Series, the Australian National University, Canberra.

Schutjer, W.A. \& Stokes, C.S. (1984). Rural Development and Human Fertility. New York: Macmillan.

Seccombe, W. (1983). Marxism and demography. New Left Review, 137, pp. 22-47.

Seltzer, J.R. (2002). The Origins and Evolution of Family Planning Programs. Santa Monica, CA: RAND.

Sen, A. (1987). Commodities and Capabilities. Delhi: Oxford University Press.

Sen, A. (1999). Development as Freedom. New York: Anchor Books. 
Sen, G. \& Grown, C. (1987). Development, Crises, and Alternative Visions: Third World Women’s Perspectives. New York: Monthly Review Press.

Sen, G., Germain, A. \& Chen, L.C. (1994). Population Policies Reconsidered: Health, Empowerment, and Rights. Boston: Harvard University Press.

Sen, G \& Batliwala, S.(2000). Empowering women for reproductive rights. In H.B. Presser \& G. Sen (Eds.), Women's Empowerment and Demographic Processes: Moving Beyond Cairo. (pp. 15-36). Oxford: Oxford University Press.

Shiffman, J. (2002). The construction of community participation: village family planning groups and the Indonesian state. Social Science and Medicine, 54(8), pp. 1199-1214.

Shiffman, J. (2004). Political management in the Indonesian family planning program. International Family Planning Perspectives, 30(1), pp. 27-33.

Silverman, David. 1993. ...

Silverman, D. (2000). Doing Qualitative Research: A Practical Handbook. London: Sage.

Simon, J.L. (1981). The Ultimate Resource. Princeton, N.J.: Princeton University Press.

Simon, J.L. (1992). Population and Development in Poor Countries: Selected Essays. Princeton: Princeton University Press.

Singarimbun, M. (1991). Perkawinan pada masyarakat Jawa (Marriages in Javanese communities). Majalah Demografi Indonesia, no. 35, pp. 27-41.

Sinding, S.W. \& Hemmer, C.J. (1975). Population policy development: The application of theory. In R.K. Godwin (Ed.), Comparative Policy Analysis: The Study of Population Policy Determinants in Developing Countries. (pp. 267-282). Lexington, MA: Lexington Books.

Smyth, I. (1991). The Indonesian family planning programme: A success story for women? Development and Change, 22(4), pp. 781-805.

So, A.Y. (1990). Social Change and Development: Modernization, Dependency, and World System Theories. Newbury Park: Sage.

Stake, R.E. (2000). Case studies. In N.K. Denzin \& Y.S. Lincoln (Eds.), Handbook of Qualitative Research. pp. 435-451. Thousand Oaks: Sage.

State Ministry for Population/NFPCB (1992). Law of The Republic of Indonesia Number 10 of 1992 concerning Population Development and The Development of Happy and Prosperous Families. Jakarta. 
State Ministry of Population/NFPCB (1994). Informasi Gerakan KB Nasional Selama Pembangunan Jangka Panjang I (Information on the National Family Planning Movement during the Long Term Development I). Jakarta.

State Ministry of Population/NFPCB (1995). 25 Years Family Planning Movement. Jakarta.

State Ministry of Population/NFPCB (1996). Basic Information: Family Planning Movement and Prosperous Family Development. Jakarta.

State Ministry of Population/NFPCB (1998). Role of Muslim Leaders and Organizations in Indonesian National Family Planning/Reproductive Health Program. Jakarta.

State Ministry of Population/NFPCB (1998). Country Report: ICPD+5. Jakarta.

Stephens, W.N. (1963). The Family in Cross-cultural Perspective. New York: Holt, Rinehart and Winston.

Stewart, D.W., \& Shamdasani, P.N. (1990). Focus Groups: Theory and Practice. Newbury Park, Calif: Sage.

Stiefel, M. \& Wolfe, M. (1994). A Voice for the Excluded: Popular Participation in Development : Utopia or Neccesity? London/Geneva: Zed Books/UNRISD.

Suhamihardja, A.S. (1984a). Organisasi dan struktur sosial masyarakat Sunda (Organization and social structure of Sundanese society). In E.S. Ekadjati (Ed.), Masyarakat Sunda dan Kebudayaannya (Sundanese Society and Its Culture). (pp. 205222). Jakarta: Girimukti Pasaka.

Suhamihardja, A.S. (1984b). Agama, kepercayaan dan sistem pengetahuan (Religion, belief, and knowledge system). In E.S. Ekadjati (Ed.), Masyarakat Sunda dan Kebudayaannya (Sundanese Society and Its Culture). (pp. 277-304). Jakarta: Girimukti Pasaka.

Sumbung, P.P., Pandjaitan, S., Soejatni \& D’Agnes, T. (1984). The integrated service delivery approach in the Indonesian context. Technical Report Series, Monograph no. 43. Jakarta: National Family Planning Coordinating Board.

Sumbung, P.P., Pardoko, H., Rahardjo, P. (1981). The Indonesian population programme: An overview of the organization, its processes and achievements of the population and development planning effort. Technical Report Series, Monograph no. 27. Jakarta: National Family Planning Coordinating Board.

Suryadinata, L., Arifin. E.N. \& Ananta, A. (2003). Indonesia’s Population: Ethnicity and Religion in a Changing Political Landscape. Singapore: Institute of Southeast Asian Studies. 
Suyono, H., Pandi, S.H., Astawa, I.B., Moeljono \& Reese, T.H. (1976). Village family planning the Indonesian model, institutionalising contraceptive practice. Technical Report Series, Monograph no. 13. Jakarta: National Family Planning Coordinating Board.

Suyono, H. 1991. Managing a Community Movement: The Development of the Family's Full Potential Through Family Planning Program in Indonesia. Paper presented at the UNFPA International Seminar on Population, Bonn, 9-11 May 1991.

Suyono, H. 1995. Prosperous Family Development in Indonesia. Jakarta: State Ministry of Population/NFPCB.

Suyono, H \& Reese, T.H. (1978). Integrating village family planning and primary health services: The Indonesian perspectives. Technical Report Series, Monograph no. 19. Jakarta: National Family Planning Coordinating Board.

Suyono, H., Hendrata, L. \& Rohde, J. (1995). The family planning movement in Indonesia. Technical Report Series, Monograph no. 81. Jakarta: National Family Planning Coordinating Board.

Taylor, S.J. \& Bogdan, R. (1998). Introduction to Qualitative Research Methods: A Guidebook and Resource. New York: John Wiley \& Sons.

Teitelbaum, M.S. (1975). Relevance of demographic transition theory for developing countries. Science 188(2): 420-425.

Tinker, I. (ed.). 1990. Persistent Inequalities: Women and World Development. New York: Oxford University Press.

Tjiptoherijanto, P. \& Hasmi, E.N. (1998). Population, environment and development in Indonesia at present and in the near future. Technical Report Series, Monograph no. 92. Jakarta: State Ministry for Population/National Family Planning Coordinating Board.

Tjondronegoro, S.M.P. (1984). Social Organization and Planned Development in Rural Java: A Study of the Organizational Phenomenon in Kecamatan Cibadak, West Java, and Kecamatan Kendal, Central Java. Oxford: Oxford University Press.

Todaro, M.P. (1985). Economic Development in the Third World. New York: Longman.

Tsui, A.O. (2001). Population policies, family planning programs, and fertility: The record. In R.A. Bulatao \& J.B. Casterline (Eds.), Global Fertility Transition, Population and Development Review, a supplement to vol. 27, pp. 184-204.

United Nations Conference on Environment and Development, 3-14 June 1992. Rio de Janeiro, Brazil: Outcomes of the Conference/Agenda 21. 
United Nations, Population Division. (1981). 'Selected factors affecting fertility and fertility preferences in developing countries', Pp. 141-227. World Fertility Survey Conference 1980, Vol. 2. London: World Fertility Survey.

United Nations. (1986). Policy Relevance of Findings of the World Fertility Survey for Developing Countries. New York.

United Nations. (1987). Fertility Behaviour in the Context of Development. Evidence from the World Fertility Survey. Population Studies no. 100. New York.

United Nations. (1994). International Conference on Population and Development (ICPD). 5-13 September 1994, Cairo, Egypt. www.iisd.ca. Accessed on 12 December, 2003.

United Nations. (2002). World Summit on Sustainable Development: Plan of Implementation. Retrieved July 7, 2003 from http://www.johannesburgsummit.org.

United Nations Population Fund. (1995). Desk Review of Community Participation in Family Planning. Evaluation Findings, Issue 6. New York. Retrieved October 17, 2003 from http://www.unfpa.org/monitoring/pdf/n-issue6.pdf

United Nations Population Fund. (1999). Donor Support for Contraceptives and Logistics 1999. New York.

United Nations Population Fund. (2001). Footprints and Milestones: Population and Environmental Change. New York,

United Nations Population Fund. 2003. State of World Population 2002: "People, Poverty and Possibilities". New York.

United Nations Population Fund. 2004. State of World Population 2004: "The Cairo Consensus at Ten: Population, Reproductive Health and the Global Effort to End Poverty". New York.

Van de Walle, E. (1992). Fertility transition, conscious choice and numeracy. Demography, 29(4), p.487-502.

Van de Walle, E \& Knodel, J. (1980). Europe’s fertility transition: new evidence and lessons for today's developing world. Population Bulletin, 34(6).

Vreede-de Stuers, C. (1960). The Indonesian Woman: Struggles and Achievements. The Hague: Mouton.

WFS. (1984). World Fertility Survey: Major Findings and Implications. Oxford: Alden Press. 
Watkins, S.C. (1987). The fertility transition: Europe and third world compared. Sociological Forum, 2(4), p. 645-673.

Warwick, D.P. (1982). Bitter Pills: Population Policies and Their Implementation in Eight Developing Countries. Cambridge: Cambridge University Press.

Warwick, D.P. (1986). The Indonesian family planning program: Government influence and client choice. Population and Development Review, 12, p. 453-90.

Weeks, J.R. (1999). Population: An Introduction to Concepts and Issues, $7^{\text {th }}$ edition. Belmont, CA: Wadsworth.

White, B. (1975). The economic importance of children in a Javanese village. In M. Nag (Ed.), Population and Social Organization (pp. 127-146). The Hague: Mouton.

White, S.A. with Nair, K.S. \& Ascroft, J. (1994) Participatory Communication: Working for Change and Development. Thousand Oaks, Calif.: Sage Publications.

White, S.C. (2000). Depoliticising development: The uses and abuses of participation. In D. Eade (Ed.), Development, NGOs, and Civil Society: A Development in Practice Reader (pp. 142-155). Oxford: Oxfam.

Wieringa, S. (1994). Women's interests and empowerment: Gender planning reconsidered. Development and Change, 25(4).

Wieringa, S. (1998). Rethinking gender planning: A critical discussion of the use of the concept of gender. Working Paper Series, No. 279. Institute of Social Studies.

Wignyadisastra, N.M. (1986). The Problems of Family Planning in Indonesia from the Viewpoint of Historical Development, and Degree of Success in the Program Implementation According to Its Apparatus: A Survey in the Province of East Java, West Java, and South Sumatra. Unpublished PhD thesis, Padjadjaran University, Bandung.

World Association of Muslim Scholars (WAMS). (1983). Resolution of the National Conference of Ulama on Population, Health, and Development. Jakarta, 17-30 October 1983.

World Bank. (1990). Indonesia: Family Planning Perspectives in the 1990s. Country Department V, Asia Regional Office, Report No. 7760-IND. January 30, 1990.

World Bank. (1994). Population and Development: Implications for the World Bank. Washington DC: The World Bank.

World Bank. (1996). The Wold Bank Participation Sourcebook. Washington DC: The World Bank. 
World Commision on Environment and Development (1987). Our Common Future. Oxford and New York: Oxford University Press.

Yafie, A. (1982). Pandangan Islam Terhadap Kependudukan dan Keluarga Berencana (The Perceptions of Islam Toward Family Planning). Jakarta: LKKNU and BKKBN.

Yin, R.K. (1994). Case Study Research: Design and Methods, $2^{\text {nd }}$ edition. Thousand Oaks, London, New Delhi: Sage Publications.

Young, K. (1993). Planning Development with Women. New York: St. Martin’s Press.

Young, K. (2002). WID, GAD and WAD. In V. Desai \& R.B. Potter (Ed.), The Companion to Development Studies (pp. 321-324). London: Arnold.

Zaki, A.M. \& Danuri, M. (2001). The Roles of Muhammadiyah in Indonesia's FP/RH Programme. Paper presented at the Observation Study Tour, The Role of Religious Institutions and Leaders in the FP/RH Program in Indonesia: Current and Historical Perspective. Jakarta: 12-25 September 2001. 
1. Name: (husband and wife)

2. Socio-economic information

2.1. General: (for husband and wife)

Place and date of birth?

How long have lived in this village? (if not originally from this village)

Educational level?

Current occupation?

2.2. Household property:

House ownership?

Amenities?

2.3.Access to media:

Read newspaper? Everyday? What news?

Read magazine? What topic?

Listen to radio? What programme?

Watch TV? What programme?

3. Marriage

Age of first marriage (husband and wife)?

Reason to get married at that age?

Who chose the spouse?

Criteria for choosing spouse?

Husband's occupation when get married?

Period of current marriage?

4. Household structure

How long have lived in this household?

How many families live in this household? Reason? 
If a nuclear family: who decided to set up individual household and when?

Who makes important decisions in the family? Reason?

Any involvement of other people in decision-making? If yes, who and in what way?

Who does the household chores?

Who looks after the small children?

What work do women do? (adult and young women, inside and outside household)

What work do men do? (adult and young men, inside and outside household)

5. Reproductive health

Wife:

Age of first menstruation?

Age of first pregnancy/delivery?

Practising breast-feeding? Reason? If yes, how long?

When (at what age) to expect menopause?

Husband:

Age when wife first got pregnant/gave birth?

Number of children ever born?

Alive? (record age and sex)

Any miscarriages, stillbirths, deaths?

Interval between marriage and first birth?

Reason to defer first pregnancy?

Who made the decision? Any involvement of other people in making the decision? If yes, who and in what way?

Contraceptive used to defer first pregnancy?

Perceived ideal interval between children?

Following/not following that ideal? Reason?

When (at what age) will stop having children?

6. Family planning practices 
Currently using contraceptive?

If yes:

Reason for using contraceptive?

Who made the decision? When (before or after marriage)?

Any involvement of other people in making the decision? If yes, who and in what way?

Ever received information on family planning? If yes, what, when and from whom?

When first used contraceptive? Use continuously? Reason?

Ever changed method? If yes, reason for changing method?

Current contraceptive method? Reason for choosing it?

Place of obtaining the service? Who provided the service? How to get there?

Paid for the service or free? If paid, how much? Considered as expensive or not?

Knowledge of side effects of the current method? Reaction?

Knowledge of other methods?

Plan for contraceptive use in the future? Reason?

If no:

Reason for not using contraceptive?

Perceptions of the family planning programme?

Any intention to use contraceptive in the future? Reason?

7. Desired family size and expectations from children

Have a plan about number of children to have?

If yes, how many and why that number? When was it made (before/after marriage)?

Any changes in the plan? Reason?

If no, what is the reason?

Who made decision about having children? Any discussions between husband and wife?

Any involvement of other people in making the decision? If yes, who and in what way? Perceived ideal family size? Reason?

Following/not following that ideal? Reason?

Efforts to achieve the desired number of children? Any difficulties? 
How many children do couples in this village have (on average)? Any differences between younger and older couples?

Do all your children live in this household? If elsewhere, what is the reason?

Expectations from children? (now and in the future)

Do you think they will have the same number of children as you in the future?

Number of siblings? (husband and wife)

8. Perceptions and expectations of the family planning programme

Perceptions about the family planning programme?

Opinions about family planning services (e.g. accessibility and quality of service)?

Any changes in the programmes/services in this village compared with the past?

Roles of village leaders (formal and informal) in the family planning programme?

Expectations from the programme?

9. Knowledge and perceptions of $P P K B D / P o s ~ K B$

Ever heard of $P P K B D / P o s K B$ ? If yes: from whom and when?

Is there a $P P K B D / P o s ~ K B$ here?

Who are the $P P K B D / P o s K B$ volunteers/kader?

What are their activities?

Any activities they have conducted in the last two months? If yes, what were they?

Ever been contacted/visited by kader of the $P P K B D / P o s K B$ (at least in the last two months)? If yes, what was their purpose?

Ever participated/been involved in the PPKBD/Pos KB activities? Reason?

Ever participated/been involved in other community/village activities? Reason?

Opinion about $P P K B D / P o s ~ K B$ activities/services?

Expectations from them?

\section{Interview Schedule for PPKBD Chairperson}

1. General information: 
Name?

Age?

Educational level?

Marital status?

Number of children?

Practising family planning?

2. Experiences as PPKBD chairperson:

How long have been associated with the family planning programme?

How was the recruitment/appointment as PPKBD chairperson?

What are the tasks of a PPKBD chairperson?

Any difficulties in carrying out the tasks?

Ever undergone training?

If yes, who organised the training? What are the subjects? Opinion about the training? Involvement in other government programmes?

3. Roles and activities of PPKBD

What are the roles of PPKBD?

How do you carry out the roles?

Have autonomy in carrying out the roles?

Have adequate resources for carrying out the roles?

Any difficulties in carrying out the roles?

How are the responses of the community/families? Any changes in their responses? If yes, what is the possible cause?

What were the activities conducted in the last two months?

Cooperation with:

- village midwife?

- family planning fieldworker?

- health centre staff?

- community leaders (formal \& informal)?

- other community organisations/volunteers in the village? 
- fieldworkers of other government programmes?

4. Family planning decision-making and planning

Please explain the planning process of the family planning programme in the village What is your role in the process?

Who are involved in the process? What are their roles?

Who makes the final decisions? 


\section{Focus group discussion with adolescents}

1. Knowledge and perceptions of family planning and reproductive health

Has anybody ever heard about the family planning programme?

What information have you heard?

Where, when \& from whom did you first hear about it?

What do you think about the programme?

Do you think the families here need the programme?

Do you think the families here are aware of family planning practices?

Do you think the younger generation should have knowledge about family planning and reproductive health?

Who do you think should give the information? Do you think parents should be involved?

What is the average family size here? What do you think about it?

What do you think is the ideal family size? Do you think the child's sex would matter and affect the number of children?

When do you think is the best time to get married?

When do you think is the best time to have children/give birth?

What are your expectations of the family planning programme?

Have the programme workers involved you in their activities? If yes: what activities? In what way? What do you think about the activities?

\section{Knowledge of PPKBD}

Have you heard about PPKBD?

Is there a PPKBD here?

What are their activities?

Have you ever been involved in those activities? If yes: what activities? In what way?

What do you think about their activities?

What about with the other community/village activities, have you ever been involved? If yes: what activities?

What do you think about the PPKBD? 
What are your expectations from them?

Appendix 2 
VICTORIA UNIVERSITY OF WELLINGTON

Te Whare Wānanga o te Ūpoko o te Ika a Māui

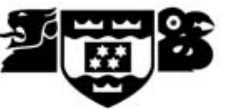

Information Sheet for the 'Family Planning Decision-making at Grass-roots Level: Case Studies in West Java, Indonesia'

Researcher: Rina Herartri, School of Earth Sciences, Victoria University of Wellington.

I am a Ph.D student at the Development Studies Programme at Victoria University of Wellington. As part of this degree I am undertaking a research project leading to a thesis. The research I am undertaking is 'Family Planning Decision-making at Grass-roots Level: Case Studies in West Java, Indonesia'. This research has been designed to comply with the guidelines of the Human Ethics Committee of Victoria University.

In this research I aim to obtain information about the processes of family planning decision-making at household and community levels and the role of PPKBD in the family planning programme in the village. Therefore, I will conduct an interview with you to ask details about your family planning practices and the PPKBD activities. Should you feel the need to withdraw from the project, you may do so without question at any time before the data is analysed.

Information gathered will be put into a written report on an anonymous basis, so that you will not be identified personally. All material collected will be kept confidential. The thesis will be submitted to the School of Earth Sciences and deposited in the University Library. Some parts of the thesis might also be submitted for publication in journals or presented at conferences.

If you have any questions or would like to receive further information about the research, please contact me at 021-7511557 or email me at herartrina@scs.vuw.ac.nz. You can also contact my supervisor, Dr Nancy Pollock, at the School of Earth Sciences at Victoria University, Wellington (Nancy.Pollock@vuw.ac.nz or phone: 64-4-4635281).

Rina Herartri

Note: The information will be read to the participant in Bahasa Indonesia or his/her native language to inform them and seek consent. 


\section{Consent Form}

Title of project: Family Planning Decision-making at Grass-roots Level: Case Studies in West Java, Indonesia

Researcher: Rina Herartri, School of Earth Sciences, Victoria University of Wellington.

I have been given and have understood an explanation of this research project. I understand that I may withdraw myself (or any information I have provided) from this project without having to give reasons or without penalty of any sort.

I agree to take part in this research. I agree to be interviewed for the purposes described in the information sheet. I understand that any information will be kept confidential and that no opinions will be attributed to me in any way that will identify me.

\section{Signature Date}

Note: In case of literacy problem, the consent will be done verbally. 
Prosperous family indicators:

'Pre-prosperous':

Families which are still incapable of meeting their minimum basic needs.

'Prosperous level I':

1. Family members practice their religion

2. Family members eat at least two meals a day

3. Family members have different set of clothes for different occasions

4. Majority of the house floor is not earthen

5. Family members use modern health and family planning facilities/services

'Prosperous level II':

Indicators 1-5 added with:

6. Family members pray/practice religion regularly

7. Family members eat eggs/meat/fish at least once a week

8. Family members get at least one set of new clothes in a year

9. Household density $\geq 8$ square meters per person

10. No family illness during the last three months

11. At least one family member, aged 15 or over, has a permanent job

12. All family members aged $10-60$ are literate

13. All children aged 6-15 attend school

14. Families with two children or more (if not pregnant) practice family planning

'Prosperous level III':

Indicators 1-14 added with:

15. Family members make efforts to improve religious knowledge

16. Families have savings from income

17. All family members eat together at least once a day

18. Family members take part in community activities

19. Family members join a recreational activity together at least once in six months

20. Family members have access to mass media

21. Family members have access to public transport

'Prosperous level III plus':

Indicators 1-21 added with:

22. Family members make contribution/donation to social activities in the community

23. Family members take an active role in community organisations

(BKKBN, 2002c) 
